\title{
Seabed Ripple Morphology and Surficial Sediment Size at the SAX04 Experiments near Fort Walton Beach, Florida, Fall 2004.
}

By Daniel M. Hanes, Li H. Erikson, Jamie M.R. Lescinski, Jodi N. Harney, Carissa L. Carter, Gerry A. Hatcher, Jessica R. Lacy, David M. Rubin

Open-File Report 2007-1232

U.S. Department of the Interior

U.S. Geological Survey 


\section{U.S. Department of the Interior DIRK KEMPTHORNE, Secretary}

\section{U.S. Geological Survey \\ Mark D. Myers, Director}

U.S. Geological Survey, Reston, Virginia 2007

For product and ordering information:

World Wide Web: http://www.usgs.gov/pubprod

Telephone: 1-888-ASK-USGS

For more information on the USGS-the Federal source for science about the Earth, its natural and living resources, natural hazards, and the environment:

World Wide Web: http://www.usgs.gov

Telephone: 1-888-ASK-USGS

Hanes, D.M., Erikson, L..H., Lescinski, J.M.R., Harney, J.N., Carter, C. L. Lacy, J.R., Hatcher, G.A., Rubin D.M., 2007, Seabed Ripple Morphology and Surficial Sediment Size at the SAX04 Experiments near Fort Walton Beach, Florida, Fall, 2004: U.S. Geological Survey Open-File Report 2007-1232, 184 p.

Any use of trade, product, or firm names is for descriptive purposes only and does not imply endorsement by the U.S. Government.

Although this report is in the public domain, permission must be secured from the individual copyright owners to reproduce any copyrighted material contained within this report. 


\section{Contents}

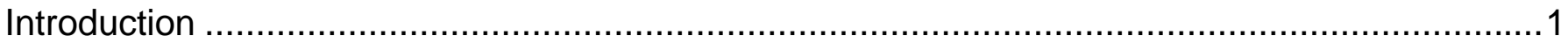

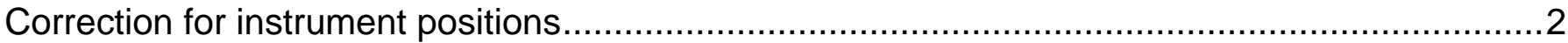

ADP

INX

MTA

Slide projector

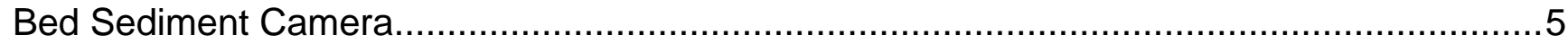

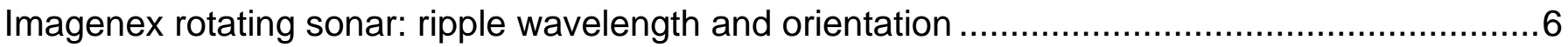

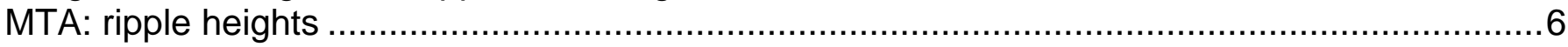

Extracted data

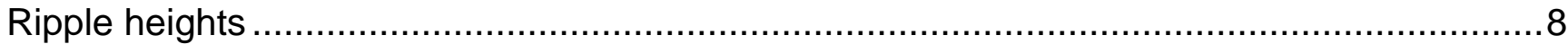

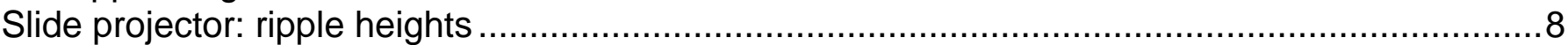

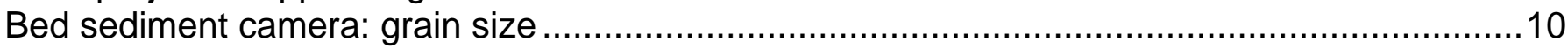

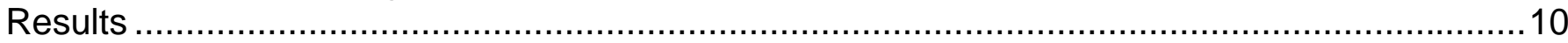

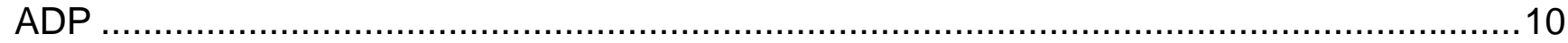

INX

MTA …

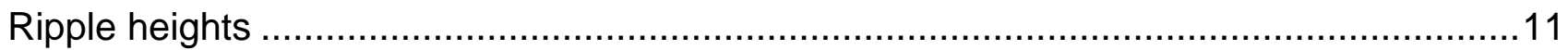

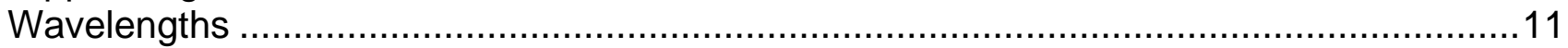

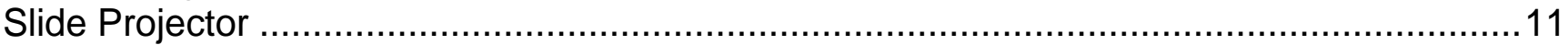

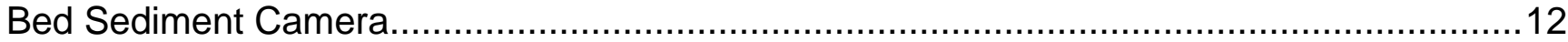

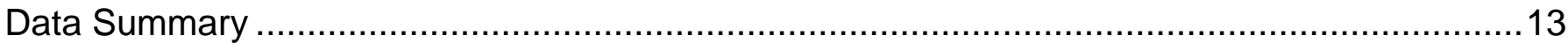

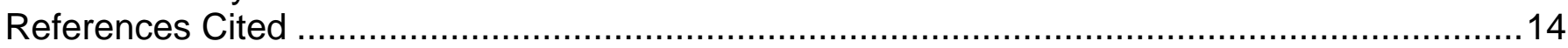

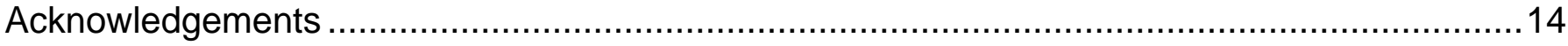

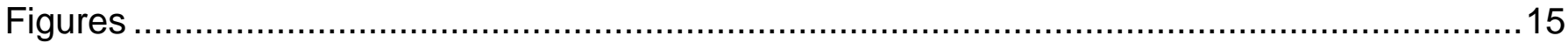

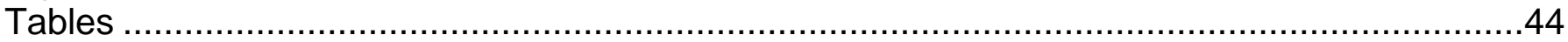

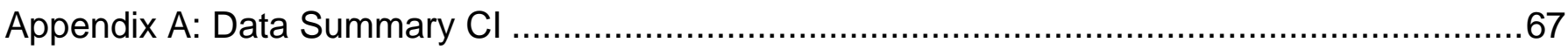

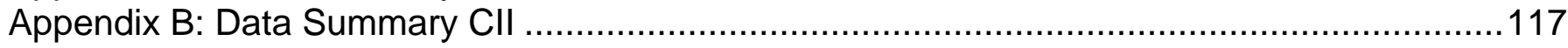




\section{Figures}

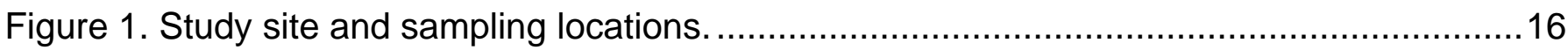

Figure 2. Tripod and instruments employed to measure hydrodynamic and seabed

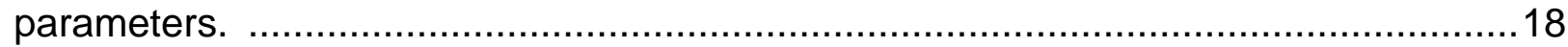

Figure 3. Instrument positions in tripod coordinates including compass bearings ....................19

Figure 4. Conceptual diagram of tripod positions on the seafloor and instrument sampling

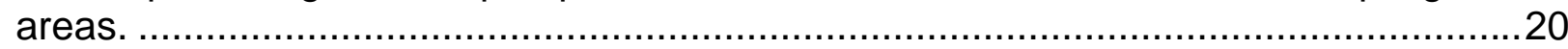

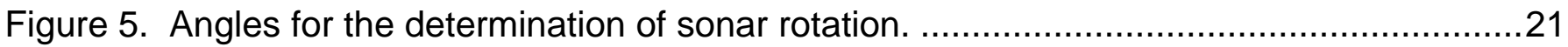

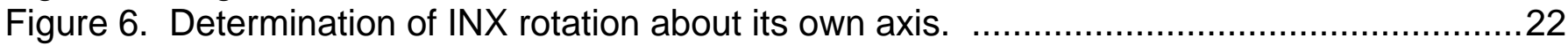

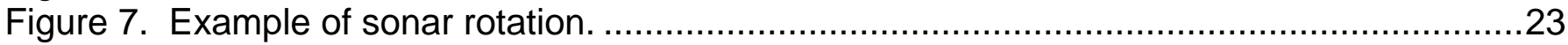

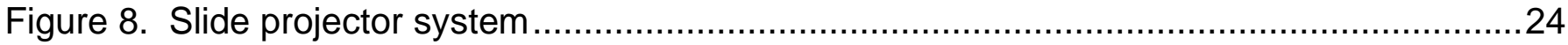

Figure 9. Determination of threshold values for extraction of MTA data................................25

Figure 10. Overview of method employed to obtain MTA ripple heights. .................................26

Figure 11. Histograms of threshold values selected for the MTA data................................27

Figure 12. Method of rotating slices for determining ripple heights from SP data ....................28

Figure 13. Method of parallel slices for determining ripple heights from SP data......................29

Figure 14. Comparison of ripple wavelengths orientations obtained with $4 \mathrm{~m}$ and $10 \mathrm{~m}$

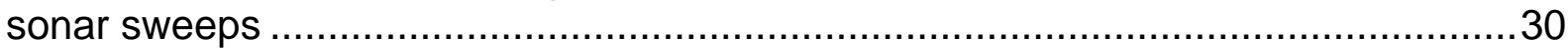

Figure 15. Example of smear and concentricity near the center and edges of $10-\mathrm{m}$ scans ........31

Figure 16.Ripple wavelengths and orientations measured with the INX sonar and sediment

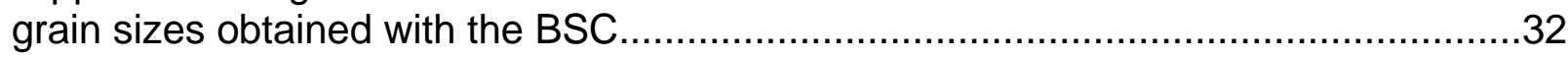

Figure 17. Comparison of wavelengths as measured by the MTA and INX sonar.....................35

Figure 18. Profiles extracted from parallel slices of SP surface data and least-squares fitted sine curves..........................................................................................................

Figure 19. Comparison of ripple heights as measured by the MTA and SP ...........................37

Figure 20. Comparison of median grain sizes obtained with the BSC and grab samples ...........38

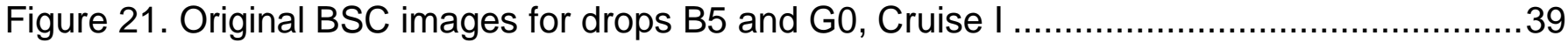

Figure 22. Ripple wavelengths plotted against depth and offshore distance .............................40

Figure 23. Ripple heights as a function of depth, ripple wavelength, and sediment grain size....

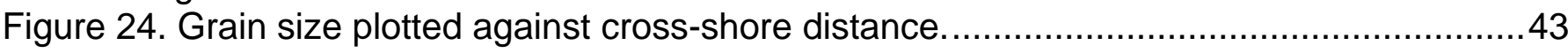

\section{Tables}

Table 1. Mean heading, pitch, and roll measured at each drop ...........................................45

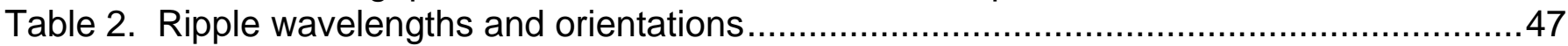

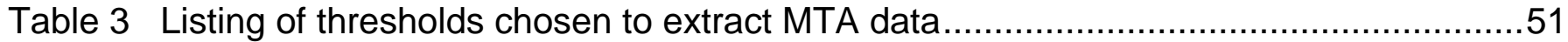

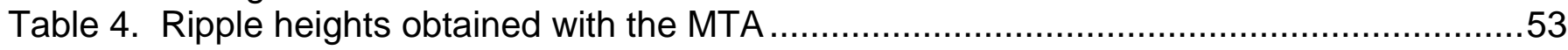

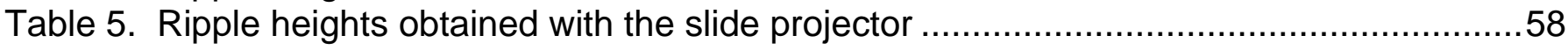

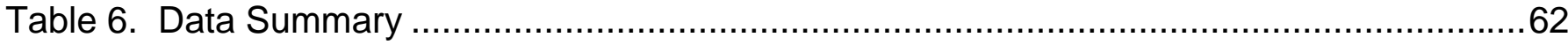




\section{Seabed Ripple Morphology and Surficial Sediment Size at the SAX04 Experiments Near Fort Walton Beach, Florida, Fall 2004.}

By Daniel M. Hanes, Li H. Erikson, Jamie M.R. Lescinski, Jodi N. Harney, Carissa L. Carter, Gerry A. Hatcher, Jessica R. Lacy, David M. Rubin

\section{Introduction}

For readers not interested in the methodologies and data processing, figure 16 (p. 32-34) and table 6 (p. 62-66) provide the processed measurements of ripples and bed sediment size.

Data presented in this report originates from measurements obtained off the Florida coast (fig. 1) as part of the Sediment Acoustics Experiment (SAX04) and Ripples Department Research Initiative (DRI) (Office of Naval Research (ONR), Critical Benthic Environmental Processes and Modeling, Long Range BAA 04-001, Sept. 10, 2003). The aim of this document is to present methods employed to extract data and the resulting measured ripple characteristics (ripple height, wavelength, and orientation) and seabed grain sizes. Application and analysis of the data with respect to hydro- and morphodynamics will be addressed in subsequent reports.

Sediment transport in the coastal region is a complex process involving interactions between flow dynamics, sediments, and bedforms. Sediment type and bed geometry directly influence entrainment of sediments into suspension, and at sites where ripples occur (sand formations on the order of several $\mathrm{cm}$ high and less than two meter long wavelengths), the understanding of ripple dynamics is an essential component in improving sediment transport models. To gain a better understanding and ability to predict sediment transport, a field study was undertaken to investigate morphology, orientation, and dynamics of ripples on the seafloor. The data obtained from the field campaign also supports an on-going effort to study the effects of ripples on low grazing acoustic penetration into sandy marine sediments for the detection of objects, such as mines (Jackson and others, 2002).

Data was collected during two separate cruises in the Florida panhandle following Hurricane Ivan which made landfall near the Florida / Alabama border on Sept. 16, 2004:

Cruise I (CI): September 25-28, 2004; and

Cruise II (CII): November 7-10, 2004.

A tripod (fig. 2) supplied with a combination of acoustical and optical instruments powered and controlled through a single cable using network communication protocols, was designed and built in collaboration with Monterey Bay Aquarium Research Institute (MBARI) to obtain hydrodynamic and seabed measurements. The control system consisted 
of a surface unit that provided 40 volt direct current, an Ethernet link, and two NTSC (national television standards committee) video channels via a custom cable to the subsurface unit. Housed in the subsurface unit are two DC/DC converters, a Lantronix terminal server, 2 video baluns to enable transmission of video signals, and a micro controller to switch power to any of the possible 7 external devices. The external equipment interfaced with the sub-surface equipment through wet pluggable underwater connectors capable of providing either RS232 serial data transfer up to $115 \mathrm{k}$ baud, or live video. Each port provided DC power (12 or 24 volts) with a max draw of approximately 300 Watts total. With the setup, it was possible to access each of the 7 channels

simultaneously or individually as required.

The tripod was deployed from the $R / V$ Pelican at 50 and 63 distinct locations for Cruises I and II, respectively (Fig. 1). Most sites from Cruise I (CI) were also sampled during Cruise II (CII). At each site (drop), the tripod was lowered to the seabed where data related to current, ripples, and sediments were collected. Five instruments were mounted on the tripod:

1. Acoustic Doppler Profiler (ADP ${ }^{\mathrm{TM}}$, three-beam $1500 \mathrm{kHz}$ Sontek),

2. Imagenex rotating sonar (INX, Imagenex Technology Corp., Model 881A),

3. Multiple transducer array (MTA, manufactured by Seatek, Inc.),

4. Slide projector (SP, manufactured at USGS, Menlo Park, CA )

5. Bed sediment camera (BSC, manufactured at USGS, Menlo Park, CA)

The purpose of the ADP was to obtain the orientation (heading, pitch, and roll) of the tripod and remaining instruments, and to measure pressure (depth) and vertical profiles of water velocity. The main function of the INX, a sector-scanning fan-beam sonar, was to estimate ripple wavelengths $(\lambda)$ and orientations $(\theta$, orthogonal to ripple crest and troughs), while the MTA and slide projector were used to measure ripple height $\left(r_{\mathrm{h}}\right)$. Ripple wavelengths may also be measured with the SP and MTA; however, this was not usually possible due to the arbitrary orientation of the instruments with respect to the ripple direction and limited sampling length of these instruments $(90 \mathrm{~cm}$ and $62 \mathrm{~cm}$ maximum length, respectively). Digital images of the seabed were obtained with a BSC fitted with a macro lens for the determination of sediment grain size.

A suite of primarily Matlab-based scripts, previously developed or specifically developed for this project, were employed for the extraction and assimilation of collected data. Methods for extracting and assimilating the data are summarized in the following sections, with concluding estimates of ripple heights, wavelengths, orientations, and sediment grain sizes listed in table 6 .

\section{Correction for instrument positions}

Codes were written to rotate, correct for instrument pitch and roll, and translate data to an earth-based coordinate system (ENU, east-north-up) with a common origin to the tripod center at each individual drop. The z-reference was chosen to be zero at the plane passing 
through the bottom of the weights of the tripod feet, with positive upward. Because the instruments were removed and re-installed onto the tripod between Cruise I and Cruise II, corrections for instrument positions were done separately. For the second cruise, the ADP was rotated $120^{\circ}$ clockwise with respect to the original position, and the rotating sonar was replaced at $26^{\circ}$ counter-clockwise. These corrections are discussed for each instrument in the following sections. Image results from the INX, MTA, slide projector and bed sediment camera are shown in Appendices A and B, for Cruise I and Cruise II, respectively.

\section{ADP}

Instrument positions and orientations, relative to the tripod coordinate and ADP compass coordinate systems, are shown on INX sonar images in Figure 3. The ADP was mounted such that the compass was installed in an upward looking direction with the $y$-axis pointing to the shown bearing $\left(120^{\circ}\right.$ and $0^{\circ}$ counterclockwise from the tripod $\mathrm{x}$-axis, for Cruises I and II respectively).

Time-series of heading, pitch, and roll were assessed for erratic data thought to be associated with electrical interference from lowering and raising the BSC. To remove the affected data, a start and stop time were determined visually and used to limit the time over which heading, pitch and roll were averaged. The variance of remaining time-series heading, pitch and roll was small $\left(<0.04^{\circ}\right)$ in all cases indicating that there was little movement of the tripod once it settled at the bottom and data was collected with the INX, MTA, SP, and BSC. Resulting measurements of heading, pitch, and roll measured at each drop are summarized in table 1.

\section{INX}

The multi-frequency INX rotating sonar was run at an operating frequency of $1 \mathrm{MHz}$ and mounted on the inside of one of the tripod legs where a fan shaped beam (as seen from the side) rotated through a series of small steps. Images of high and low backscatter, representing ripples and shadow zones, respectively, were then generated (Fig. 3).

Rotation and translation of INX images to ENI coordinates (east-north-intensity, referenced to tripod center) was done via a two- as opposed to a three-dimensional algorithm, ignoring the tilt and pitch measured by the ADP. The effects of tilt and pitch could be ignored because the sonar was mounted only $14.5 \mathrm{~cm}(21.02 \mathrm{~cm}$ for the first drop of CI) above the tripod bottom ensuring that the beam footprint displacement was minimal (Fig. 4a). In addition, it is the amplitude of the bottom return that is used to calculate the range, and hence, as long as the bottom is within the fan beam, the correct range is recorded.

The angle of rotation $(\theta)$ was required to orient the sonar images to the ENI coordinates (Fig. 5):

$$
\theta=(\pi-\beta)-(\phi-\delta)
$$

where $\beta$ is the angle between the sonar origin and ADP heading, $\phi$ is the heading measured by the ADP at each drop, and $\delta$ is the magnetic declination $\left(1.75^{\circ}, \mathrm{NGDC}\right)$. Because the instruments were removed after CI and re-installed for CII, the angle between the sonar origin and ADP heading differ for the two cruises but can be found from known positions relative to the tripod coordinate system: 


$$
\beta=\alpha_{1}-\alpha_{2}
$$

where $\alpha_{1}$ is the angle between the INX 0 -axis and tripod $x$-axis ( the rotation of the INX about its own axis) and $\alpha_{2}$ is the angle between the ADP bearing (compass $y$-axis) and tripod $x$-axis. Rotation of the INX about its own axis was determined by geometry and inspection of raw sonar images from both cruises. The INX was positioned at $x=69.53 \mathrm{~cm}$, $y=101.06$ (in tripod coordinates) while the tripod leg to which it was attached was positioned at $x=84.67 \mathrm{~cm}, y=126.42 \mathrm{~cm}$. Defining the 0 -axis to be coincident with the attached tripod leg, the angle between the INX and tripod $x$-axis $(\varphi)$ is, by geometry,

$$
\varphi=\tan ^{-1}\left(\frac{126.42-101.06}{84.67-69.53}\right)=1.03 \mathrm{rads}=59.16^{\circ} .
$$

Inspection of raw sonar images shows that the INX 0 -axis (central axis passing through the shadow produced by the attached leg) was offset by $23^{\circ}$ clockwise and $3^{\circ}$ counter-clockwise for Cruises I and II, respectively (Figure 6), so that the resulting angle $\alpha_{1}$ was thus $59^{\circ}+23^{\circ}=82^{\circ}$ and $59^{\circ}-3^{\circ}=56^{\circ}$, for Cruises I and II respectively.

Mounting of the ADP on the tripod was done such that the heading vector pointed $120^{\circ}$ counter-clockwise from the tripod $x$-axis for $\mathrm{CI}\left(\alpha_{2}=120^{\circ}\right)$ and was aligned with the $x$ axis for CII $\left(\alpha_{2}=0^{\circ}\right)$.

The INX sonar images were rotated by $\theta$ using the heading of the ADP compass $(\phi)$ and Eq. (1), which simplified to

$\theta=143.75^{\circ}-\phi$

for CI, and

$\theta=125.75^{\circ}-\phi$

for CII. An example is shown in Fig. 7 where the red vector shows the ADP compass orientation and the blue line depicts calculated true north. The right panel in Fig. 7 shows the same sonar image rotated so that the north vector points up.

Following rotation, the sonar images were translated, with the aid of geometry and measured coordinates of the INX and tripod centers, so the origin coincided with the tripod center. Rotated and translated sonar images from both cruises are shown in the appendices.

\section{MTA}

The MTA consisted of 32 downward pointed transducers placed $2 \mathrm{~cm}$ apart along a line. The transducers transmitted $5 \mathrm{MHz}$ acoustic signals; a coupled processor logged the return signal which, along with the speed of sound in water, was used to determine the distance of the transducers above the seabed (see Jette and Hanes, 1997 for further description).

Figure $4 \mathrm{~b}$ shows a schematic representation of the tripod and MTA. Assuming that the MTA is mounted parallel to the tripod bottom plane, the red tripod system depicts the situation when the tripod lands on the seafloor such that it is level, while the blue represents 
the tripod system tilted. Because the MTA transducers measure the distance from the transducer to the bed, the tilt of the transducer array with respect to the horizontal must be known if bed relief is to be determined. The tilt of the transducer array was found by first changing the frame of reference to that of the compass coordinate system and then applying a three-dimensional transformation matrix.

The right-most tripod leg in fig. 2a was accidentally bent about halfway through CI when the boat drifted over the tripod. Fortunately, estimates of ripple heights are fairly insensitive to the overall tilt of the transducer array as it is the relative difference between adjacent transducer sampling points that provides an estimate of ripple heights. However, overall bed slope should be viewed with caution.

\section{Slide projector}

The slide-projector system consisted of a user-triggered flash that simultaneously projected light through a "striped" slide and photographed the projected stripes of light on the seabed with a digital camera contained in a separate housing (fig. 2 and 8). The "striped" slide projected 26 evenly spaced bands of light, which after calibration, provided a means to determine $x, y$, and $z$ coordinates relative to an established slide projector coordinate system. Calibration of $x$ and $y$ coordinates was done prior to each cruise by projecting the light stripes onto a $1 \times 1 \mathrm{~cm}$ gridded and submerged metal plate positioned approximately parallel with the tripod bottom. Vertical coordinates were then calculated by taking the cross product of the vector from the center of the slide projector image to the calibration plane with the vector describing the intersection of a given light stripe with the calibration position.

Consider the schematic of the tripod and the slide projector (SP) in figure 4c depicting the situation when the tripod lands flat on the seafloor and is tilted. The projected camera view, or field of view (FOV), and center of image is shown with light dashed lines. If the tripod lands such that it is tilted as shown in an exaggeration with the blue tripod system, the FOV and image center will be at different locations with respect to the tripod center than if the tripod is parallel with the bed. Although the FOV increases in size, the final size of the area analyzed is the same because only that part of the image that contains the numbered lines portrayed by the SP is used in the analysis to determine the relief. The location of the sampled area is not the same however. To compensate, a 3D algorithm, very similar to the one used to rotate and translate MTA transducer locations, but with the vertical measurements obtained with vector products as described above was employed. The algorithm first translates and rotates the data to ADP compass coordinates, rotates it with respect to pitch and roll as measured by the ADP compass to obtain ENU coordinates, and finally translates and references the data to the tripod center. The relief (change in vertical direction) was determined with the projected striped lines, and hence an erroneous bed slope was not introduced to the data from the ADP associated with the bent leg.

\section{Bed Sediment Camera}

The bed sediment camera, a.k.a. the 'poking eyeball' (Rubin, 2004), was mounted in a protective housing about $50 \mathrm{~cm}$ above the tripod bottom. A user-controlled electric motor allowed for the extension or retraction of an aluminum pipe on which a Nikon camera was mounted. When the motor was run in one direction the actuator extended allowing the camera to make contact with the seafloor. After a sediment photo was taken (see Fig. 21 for 
examples), the linear actuator's motor was reversed and the camera was recovered from the bottom and stowed with the linear actuator fully retracted. The camera employed for this study, consisted of a 5-megapixel sensor with a resolution of $5.9 \mu \mathrm{m} / \mathrm{pixel}$.

No rotation or translation was necessary for the BSC data. The camera lens of the BSC protruded from its casing until the lens was at a set distance from the bed, thus not requiring any correction for tilt and roll.

\section{Imagenex rotating sonar: ripple wavelength and orientation}

Prior to rotating the INX images as described in the previous section, full sweeps, defined by consecutive transducer pings with common settings of range, gain, and sampling frequency, were extracted. Anywhere from one to five full sweeps were extracted from each drop. The spatial coverage of the sweeps varied, with the most common radii being $4 \mathrm{~m}, 10$ $\mathrm{m}$, and $20 \mathrm{~m}$. A two-dimensional fast Fourier transform (FFT) was used to decompose the images into sinusoids with varying magnitudes and wave numbers, which were interpreted to estimate ripple wavelengths and orientations.

Regions of the sonar images were selected manually and re-sampled to generate an evenly spaced square image. Sampled areas measured $1.8 \mathrm{~m}$ square for $4 \mathrm{~m}$ sweeps with a re-sampled size of $2^{8}$ pixels, and $2.8 \mathrm{~m}$ square for $10 \mathrm{~m}$ sweeps with a re-sampled size of $2^{10}$ pixels. The relatively small size of the sampled area with respect to the radius of the sweep was chosen to avoid smears near the central part of the sonar image and concentric intensity lines near the outer edges of the images. Four meter sweeps were primarily used for the analysis. Ten meter sweeps were used when wavelengths greater than about $80 \mathrm{~cm}$ were evident. Wavelengths and orientations associated with the Fourier component with the greatest amplitude were identified and are listed in Table 2 for the 4- and 10-m scans. Best quality sonar images are included in Appendices A and B. All wavelengths and orientations were checked manually by digitizing points coincident with ripple crests and calculating wavelengths and orientations. With the exception of one site (G3, CII), there does not appear to be any strongly multi-modal conditions (two or more prominent wavelengths and orientations).

\section{MTA: ripple heights}

Prior to determining ripple heights from the MTA, it was necessary to decide upon the appropriate threshold value to extract the data. Chosen threshold values are presented in the next section followed by estimates of the ripple heights and to some extent, ripple wavelengths.

\section{Extracted data}

A threshold method was used to detect bottom relief with the MTA (Jette and Hanes, 1997). Distances between the bottom and transducer array were obtained by measuring the time it took for acoustic pings (at $5 \mathrm{MHz}$ ), transmitted from the transducers, to travel to the bed and back and dividing these by the speed of sound in water $(1529 \mathrm{~m} / \mathrm{s})$. The timer was stopped when the return signal exceeded a specific threshold. These values were in turn multiplied by a linearly increasing gain factor which effectively set an upper limit to the time for the return signal and assisted in defining a plateau region, where there was little further 
change with time. Due to variations in conditions such as suspended sediments and grain size and shape, the appropriate threshold values are not necessarily consistent from one site to another or even the same at a given site over an extended time. Hence, measurements with several threshold values were reported for each transducer at each site. In all, five return signals (pings) from 10 threshold values, ranging from $50 \mathrm{mV}$ to $500 \mathrm{mV}$ in increments of 50 $\mathrm{mV}$, were reported for each site. Three criteria were used to objectively choose the best threshold for both Cruises:

1. small variance between measurements at a given transducer for a given threshold (suggests repeatability of the measurements);

2. small sum-squared-residual between the median of subsequent thresholds at each transducer (suggests that the plateau region had been reached); and

3. angle of repose between measurements obtained at adjacent transducers was not exceeded.

In determining if the angle of repose was exceeded, without discarding nearly all of the data, it was necessary to introduce an uncertainty factor of 1.3 times the angle of repose (assumed to be $32^{\circ}$ ) in addition to re-sampling and smoothing the data. The data were interpolated to yield a sampling frequency four times greater than the original (decreasing the distance between sample points from $2 \mathrm{~cm}$ to $0.5 \mathrm{~cm}$ ) and treated with an 8-point moving average (eight points on each side of a given data point). The smoothing was thus done over $(2 \times 8) \times 0.5=8 \mathrm{~cm}$ (equivalent to four times the original spatial sampling frequency). Increasing the smoothing from a 4-point to an 8-point moving average only slightly altered the results. However, employing an 8-point smoothing as opposed to a 4-point, allowed data from an additional five sampling sites to be included when otherwise they would have been discarded.

As an example, consider Figure 9a in which the mean of each threshold is shown for drop E0 (CII). The zig-zag effect in the data for all thresholds is clear and calculating the slope between adjacent points results in slopes that exceed the angle of repose in all cases. By smoothing the $150 \mathrm{mV}$ threshold data with a 2-point moving average, the original curve is followed quite closely as can be seen in Fig. 11b. However, there is still too much elevation change which results in slopes in excess of the angle of repose. With a four-point smoothing, the extreme peaks disappear, and the angle of repose is not exceeded.

After data sets where the angle of repose was exceeded were discarded, determining which threshold to use was done by ranking the remaining datasets according to the smallest variance within a given threshold and the smallest sum-square-residual (SSR) between the mean of subsequent threshold data sets. An example of the variance and SSR for drop E0 are plotted in Fig. 11c. The minimum occurs around a threshold of $150 \mathrm{mV}$ to $200 \mathrm{mV}$. However, due to the steep slope seen at the end of the $200 \mathrm{mV}$ dataset in Fig. 11a, this threshold is discarded and the final choice for which dataset to use is that which corresponds to the $150 \mathrm{mV}$ level. If the $200 \mathrm{mV}$ threshold had not been discarded, a median of the two datasets would have been taken and considered to be the best estimate of measured distances between the transducers and bed. An overview of the steps involved for obtaining ripple heights from MTA data is shown in Fig. 10. 
Table 3 lists the threshold values deemed to be most representative at each sampling station, according to the method described above. For drops where two threshold values are listed, the resulting median at each transducer is considered to be the final MTA measurement. Histograms in Fig. 13 show the distribution of selected threshold values for both Cruises.

\section{Ripple heights}

Several methods to obtain the ripple heights from extracted MTA data corrected for transducer locations were considered (fast-Fourier transforms and zero-up or -down crossing models). However, due to the limited sampling length $((32-1) \times 2=62 \mathrm{~cm})$ these approaches did/will not yield very good results. Instead, it was assumed that the bottom bathymetry can be characterized by the dimensions of sinusoidal ripples. An iterative leastsquares approach was applied and used to fit the MTA data to:

$z=A \sin (k x+\varsigma)$

where $z$ is the bed elevation, $A$ is the amplitude and equal to $r_{h} / 2$ (where $r_{h}$ is the ripple height), $k=(2 \pi) / L$, where $L$ is the ripple wavelength, and $\zeta$ is the phase. Curve fitting was done in Matlab using a Marquardt-Levenberg least-squares technique (BruunNielsen, 2005). Prior to fitting sine curves to the data, selected outlier data points were smoothed out by taking the mean of neighboring points applied to the raw data. This was done only for data points for which the angle of repose (again assumed to be $32^{\circ}$ ) was exceeded with adjacent points on both sides. In order to evaluate the influence of the data filtering, sine curves were fit to the raw data in three ways: 1) without neighbor averaging; 2) with neighbor averaging; and 3) with neighbor averaging re-sampled at four times the original sampling rate and smoothed with a 4-point filter. Results are presented in a later section.

\section{Slide projector: ripple heights}

Similar to the MTA data, determination of ripple heights (and wavelengths) from slide projector images using FFTs is not feasible due to the limited sampling area. The slide projector sampling area measured approximately $90 \mathrm{~cm}$ by $45 \mathrm{~cm}$, while the ripple wavelengths were on the order of 30 to $150 \mathrm{~cm}$ as measured by sonar images. In the best cases when the tripod happened to land so that the long edge of the slide projector's sampling area spans a shorter wavelength, two full cycles would be evident in the data, which would still be barely sufficient for an FFT algorithm to detect a cyclical behavior. Instead, ripple heights from the slide projector data were obtained by fitting sine curves, as was done with the MTA data: where the amplitude of the fit sine curve is equivalent to one-half the ripple height. However, because the SP data spans a surface, as opposed to one cross-section, the application of sine-curve fitting was done in a slightly different manner, than for the MTA.

Ripple heights were estimated from the slide projector data by taking slices through three-dimensional surfaces re-gridded to uniform spacing of $1 \mathrm{~cm}$ in both the $x$ - and $y$ - 
directions (original data consisted of irregularly spaced data at about $1 \mathrm{~cm}$ intervals). The slices were oriented ortho-normal to the $x-y$ plane with the orientation determined by one of two approaches, as follows:

In the first approach, vertical slices were taken through the center of the sampling area rotated at increments of $2^{\circ}$, for a total of 90 slices. An example is shown in Fig. 12a but with increments of $60^{\circ}$ for ease of viewing. Two-dimensional data describing the sliced distance in the $x-y$ plane and elevation ( $z$ ) data were then extracted (Fig. 12b) followed by fitting a sine curve using the same algorithm as was done for the MTA data. Histograms of amplitudes obtained from the curve fitting were then generated and inspected for determining the final amplitude/ripple height. The corresponding histogram in Fig. 12c shows the results categorized according to the coefficient of determination $\left(\mathrm{R}^{2}\right)$. The best fits are obtained at the greater ripple heights. Amplitudes are also plotted against the wavelengths inferred from sine curve fitting in Fig. 12d. As the slice rotates, the ripple height or amplitude increases to a maximum coinciding with a perpendicular slice crossing the ripple, and the wavelength increases as the slice lines up with the trough. Using Figs. 12c and $12 \mathrm{~d}$ as an example, the maximum occurs at a wavelength of about $36 \mathrm{~cm}$ which corresponds to a ripple amplitude of $3.7 \mathrm{~cm}$.

The second approach involved taking slices parallel to the ripple orientation as determined by sonar images. Slices were taken at $1 \mathrm{~cm}$ increments extending from the near ends of the surface data. The number of slices of the 3D data set varied since the orientation of the slices with respect to the position on the surface data fluctuated, yielding different lengths between parallel end planes. An example is shown in Fig. 13 where three slices define the center and limits of the sampled area. Ripple heights (amplitudes) were then estimated by fitting sine-curves to the extracted profile data as was done in the previous method. In contrast to the previous method though, amplitudes obtained with the current method all represent the ripple height, assuming uniform heights along a given ripple.

There are pros and cons to both methods. The first method is advantageous in that the ripple orientation does not need to be known beforehand. However, because of the limited sampling area with respect to the wavelength, a single ripple is often missed. Drop F8 is such a case. Referring to Fig. $13 \mathrm{~b}$ it can be seen that there is an overall tilt of the surface and by taking rotated slices through the center, the best fit sine-curve would be obtained with the slice oriented approximately diagonally from the front to back low points. However, in this particular example, it is clear that such a slice is not representative of the true situation. By visual inspection, a $45^{\circ}$ slice with respect to the Easting gives the best slice orientation, with a resulting ripple amplitude of about $4 \mathrm{~cm}$, as opposed to $4.8 \mathrm{~cm}$ using the rotating slices. Of course, the $45^{\circ}$ slice is also an estimate / extrapolation as the bottom of the trough is not actually included in the dataset. The $45^{\circ}$ slice angle coincides with the ripple orientation obtained from the sonar images, thus suggesting that the approach of using orientation from the sonar data to determine the slice orientation is better suited. However, because sonar data were not taken at exactly the same location as the SP (albeit in the same vicinity, within half a meter or so), they do not always coincide and the orientation may not be the same. Due to the limited sampling area and variation of ripple orientation with respect to the sampled area, each data set needs to be evaluated individually as to which method is most appropriate. 


\section{Bed sediment camera: grain size}

An autocorrelation algorithm (Rubin, 2004) was employed to determine the median grain size diameter as measured with the BSC. Spatial autocorrelation was determined by calculating the correlation of the intensity between pixels ( distance between two pixels ). The value of the spatial correlation approaches 1.0 where the offset between the pixels is small relative to the grain size and approaches 0 where the offset approaches the size of the largest grains. Spatial correlations were calculated for a total of 50 offsets yielding a calibration curve specific to the camera used. The calibration curve relates the correlation as a function of distance which was subsequently converted to grain size.

\section{Results}

\section{ADP}

Table 1 lists measured heading, roll, and pitch at each individual drop. All pitch and roll data after drop $\mathrm{C} 1$ of Cruise I are slightly affected by the bent leg.

\section{INX}

Table 2 summarizes wavelengths and ripple orientations obtained with the 2D FFT algorithm. Sonar sweep distances (radii) are listed for each drop in column six. The $20 \mathrm{~m}$ radii images were often smeared, not showing a clear break between ripple crests and troughs, and so only results from sweeps with 4 and 10 meter radii are reported herein. Resulting wavelengths $(\lambda)$ and ripple orientations $(\theta)$ from sonar images of $4 \mathrm{~m}$ and $10 \mathrm{~m}$ radii scans are listed in columns two through five. Ripple orientations are reported as the vector normal to the crests and troughs, with zero pointing east and a positive angle counterclockwise (arithmetic coordinate system). The final value chosen to be the most representative for a given site, was based on visual assessments of image quality, manual checks by digitizing points, and by noting that the 4-m scans often produced better results for the shorter wavelengths.

A comparison between 4-m and 10-m scans at sites where sweeps from both 4 and 10 $\mathrm{m}$ sweeps are available, is shown in Fig. 14 for both cruises combined. Wavelengths are compared in the upper plot. The filled circles in Fig. 14a, are for cases where the measured wavelengths are less than one meter for both sweeps $\left(R^{2}=0.90\right)$ which, based on close inspection of the images, is the most prevalent for the data. Through manual digitization and visual analysis, it is apparent that the FFT frequently over-estimates the wavelengths on the 10 -meter sweeps. This is likely related to the lower resolution of the 10 -meter scans and the anomaly of concentric patterns which tend to increase with distance from the center. At site I5 (CII) Fig. 15, for example, ripples are difficult to discern near the center due to 'smearing'. Further out from the center, the ripples are more easily distinguishable, but become concentric so that an estimate of $\lambda$ is affected by the tendency of the upward turning pixel signal.

Figure $14 \mathrm{~b}$ compares ripple orientations from the 4-m and 10-m scans as obtained with the 2D FFT algorithm. Although there is a strong linear trend, there is quite a bit of scatter $\left(R^{2}=0.61\right)$. Some of the scatter is associated with the concentricity introduced by the $10-\mathrm{m}$ scans, with the remaining scatter due to variability between the sampling regions and 
sensitivity of the 2D FFT. Repeated analysis of the sonar images yields a wavelength rootmean-square error (rms) of $0.10 \mathrm{~m}$ with a maximum of $0.27 \mathrm{~m}$, and an orientation $\mathrm{rms}$ of $8^{\circ}$ with a maximum of $21^{\circ}(N=82)$.

In Fig. 16, ripple wavelengths and orientations are shown on a digital base map with the wavelength corresponding to the length of the shown arrows in the legend. Ripple orientations are statistically within the same range between $51^{\circ}$ and $127^{\circ}$ counter-clockwise from east, for both cruises. The ripple orientations tend to be toward the north-north-west for both cruises for the offshore sites and toward the north-north-west in the inshore region for CII.

\section{MTA}

\section{Ripple heights}

Results of fitting the sine curve described by Eq. (5) to raw data, neighbor smoothed data, and 4-pt smoothed data are summarized in Tables $4 \mathrm{a}$ and $4 \mathrm{~b}$, respectively. Columns two through four list the best fit sinusoidal amplitudes ( $a$, where $2 a=r_{h}$ ), columns five through seven, the best fit wavelengths, and columns eight through ten, the corresponding coefficients of determination for each of the data sets. The coefficient of determination increases substantially with the smoothed data but the amplitude does not vary much. The chosen ripple heights (two times the amplitude) listed in the last column of Table 4, was determined based on the greatest coefficient of determination, with the exception of a few cases where it was estimated manually as indicated with a superscript $m$.

\section{Wavelengths}

Estimates of wavelengths from the MTA data are limited due to the random placement of the transducer array with respect to ripple orientations. Knowledge of the ripple orientation as determined by the sonar images in addition to knowledge of the transducer locations provides sufficient data to correct the wavelengths obtained with the sine curve fitting algorithm to yield a predicted length normal to the ripple crests. Corrected wavelengths measured with the MTA were calculated with $\lambda c_{\text {MTA }}=\lambda_{\text {MTA }} \cos (\alpha)$, where $\lambda c_{\text {MTA }}$ is the corrected MTA wavelength, $\lambda_{\text {MTA }}$ is the uncorrected wavelength obtained by fitting a sine curve to the data, and $\alpha$ the absolute difference between the ripple orientation as determined from the sonar images and MTA array alignment. Wavelengths measured with the sonar are compared to corrected MTA measurements in Fig. 17, for cases when the angle between the transducer array and ripple orientation was less than $30^{\circ}$. The correlation between measured wavelengths using the two instruments is not very good $\left(R^{2}=0.24\right)$, but does exhibit a linear trend with a slope of about 1.3. The poor correlation is likely due to the short transducer array length relative to the true ripple wavelength.

\section{Slide Projector}

The max, mean, and standard deviation of amplitudes obtained by fitting since curves to the SP data are listed in table 5 for cases where $R^{2} \geq 0.6$. The number $(N)$ of extracted profiles for which this criteria was met are also listed for both methods (rotated and parallel slices). 
To aid in visualizing the goodness-of-fit, a few select cases of parallel slices and resulting sine curve fits are shown in Fig. 18. The fitted sine-curves are shown with red filled circles and were generated with the chosen ripple heights listed in the last column of Table 5 and corresponding predicted wavelength and phase (not listed in the table).

Because there is much variation in spatial coverage from one drop to another, there is not one consistent method ( taking rotated slices or slices parallel to ripple orientation ) that is superior to another. Hence, each set of surface data was carefully inspected and the most reasonable result, considering slice location and reasonable representation of ripple fields, was selected. For 14 drops, neither method gave acceptable results, either because the $\mathrm{R}^{2}$ requirement was not met or the predicted sine curves gave highly overestimated amplitudes (this occurred in some cases using the method of rotated slices; the effect is likely related to slices taken at very oblique angles to ripple troughs and with absent crest elevation data, thus suggesting a continued increase of crest heights). For those cases where neither method gave acceptable results, the data was visually inspected for the best representative relief change and manually digitized. The final ripple heights deemed to be the most representative of the surface data, are listed in the last column of Table 5 along with a superscript denoting the selected method.

A comparison of ripple heights measured with the slide projector and MTA is shown in Fig. 19. Although there is a linear trend between the two datasets, there is much scatter as shown in Fig. 19a. The absolute residual between measured ripple heights employing the SP and MTA are plotted against the angle between the MTA and ripple orientation in Fig. 19b. It can be seen that the error (absolute residual) increases as the MTA lines up parallel with the ripple crests. The difference between the two measurement instruments is small (less than $0.5 \mathrm{~cm}$ ) for drops where the MTA was approximately normal to the ripple crests and troughs.

\section{Bed Sediment Camera}

Analysis of the camera images was done by employing an autocorrelation algorithm as described previously, and with two different sets of offsets: 10 to 50 pixels, and 1 to 50 pixels. Using the different offsets for a given image produced some variation of the grain size estimates with a maximum difference of $38 \%$ (and a mean of $9 \%$ ).

In addition to measuring grain sizes with the $\mathrm{BSC}$, a total of 18 grab samples were obtained during the study (eight during CI and ten during CII) and later sieved to 1/2-phi gradation. Grain sizes obtained with the BSC and using the two different offsets are compared in Figure 20 to the grab samples. As was done in previous graphs, filled circles are sized according to a subjective quality rating, with the larger circles representing better data (image) quality. The blue solid straight lines indicate a perfect fit between BSC and grab sample results.

For Cruise I, there is little variation in the grab sample grain-size results. With the exception of drop B4, which was noted to consist of a thick layer of mud, CI grab samples only ranged from $0.41 \mathrm{~mm}$ to $0.48 \mathrm{~mm}$, while the $\mathrm{BSC}$ suggests a range of $0.1 \mathrm{~mm}$ to $1.7 \mathrm{~mm}$ (Drops B5 and G0). Original BSC images are shown for these two drops in Figure 21 and clearly indicate that the BSC results are reasonable representations of the surface sediments. Grab samples were obtained from the upper few $\mathrm{cm}$ of the bed; the combination of the two 
datasets suggests that there is some vertical gradation of sediment sizes, or at least some recent deposition of material that is different from the underlying material.

For Cruise II, there seems to be a slightly greater homogeneity in the upper bed and surface layer as may be inferred from Figure 20b. Note that the filled circles are sized according to a subjective quality rating (on a scale of 1 to 5 , with five being the best) where larger circles denote better quality. Inspection of the figure shows that there is quite good agreement between grab samples and BSC results for cases where the image quality is good. For cases where the quality rating is three or better, the maximum discrepancy between the $\mathrm{BSC}$ and grabs is $0.09 \mathrm{~mm}$.

\section{Data Summary}

Table 6 summarizes measurement results described in the previous sections (ripple wavelength $(\lambda)$, orientation $(\theta)$, and height $\left(r_{\mathrm{h}}\right)$ as well as sediment grain size $\left(D_{50}\right)$ ). Depths $(h)$, as measured by the ADP and corrected for height above the sea bed, are listed in the third column. The fourth and fifth columns list latitude and longitude coordinates as measured by an on-board differential ground positioning system (gps); the 'c-s' and 'a-s' columns denote sites that define a beach profile cross-section and an along-shore section, respectively. Because the SP samples a three-dimensional area as opposed to a single transect with the MTA, available results of the SP are used to represent measured ripple heights at all drops. For CI however, slide projector results are only available for 14 out of the total 49 sampled sites, and as such the ripple height data set for CI was augmented with MTA results, but only for cases when the MTA was at most $50^{\circ}(0.87$ rads $)$ from the ripple orientation (as determined with the INX). The $50^{\circ}$ angle was chosen assuming a wavelength of $40 \mathrm{~cm}$ and transducer array length of $60 \mathrm{~cm}$ yielding a maximum $50^{\circ}$ angle for catching two crests. A subjective and relative quality rating (one through five with five being the best) has been assigned to all data and listed under column headings containing "QR".

Ripple wavelengths are plotted against water depth in Fig. 22a. The wavelengths tend to increase with increasing water depth (and distance from shore) for both cruises. The increase with water depth translates to an increase with distance from shore, as can be inferred in Fig. 22b, and seen for the points along the cross-shore (c-s) direction in Fig. 22c. The shortest wavelengths are on the order of $20 \mathrm{~cm}$ in a depth of about $5 \mathrm{~m}$, and the longest are about $130 \mathrm{~cm}$ in $40 \mathrm{~m}$ to $50 \mathrm{~m}$ of water. Cruise I data were collected just 11 days after hurricane Ivan hit the Florida coast, whereas Cruise II data were collected nearly two months after the hurricane and thus represents a time further along in the recovery period towards background conditions.

Ripple heights are plotted against depth in Fig. 23a. A weak linear trend is again evident, particularly for the second cruise $\left(R^{2}=0.22\right)$. A correlation between ripple heights and wavelengths is also evident for CII $\left(R^{2}=0.38\right)$ in Fig. $23 \mathrm{~b}$, but CI data, obtained shortly after the hurricane, shows no particular trend. Median grain sizes are plotted against ripple heights in Fig. 23c. Again there is a very weak correlation for CII $\left(R^{2}=0.23\right)$.

In Figure 26, grain sizes from CII are plotted against the cross-shore distance. There is an increase in grain size with distance from shore $\left(R^{2}=0.16\right.$ for points shown, but increases to $R^{2}=0.42$ if the points within $1.5 \mathrm{~km}$ from shore are ignored); this trend is less apparent in the CI data and is likely a function of bottom reworking caused by the passing of 
Ivan. The correlation between grain size and depth is not as strong; the difference may be linked to the effect of large scale swales and ridges throughout the region.

\section{References Cited}

Bruun-Nielsen, H., 2005, Danish Technical University (http://www2.immm.dtu.dk, Sept. 2005)

Jackson, D. R., Williams, K.L., Ghorsos, E.I., and Kargl, S.G., 2002, High-frequency

subcritical acoustic pentration into a sandy sediment: IEEE Journal of Oceanic Engineering, V. 27, no. 3, p. 346-361.

Jette, C., and Hanes, D., 1997, High-resolution sea-bed imaging; an acoustic multiple transducer array. Measurement Science Technology, V. 8, p. 787-792.

NGDC (National Geophysical Data Center, NOAA Satellite and Information Service http://www.ngdc.noaa.gov/seg/geomag/jsp/struts/calcDeclnation, Sept. 2005

Rubin, D., 2004, A simple autocorrelation algorithm for determining grain size from digital images of sediment: Journal of Sedimentary Research, V. 74, no. 1, p. 160-165.

Sontek, 2000, ADP Operation Manual - Firmware Version 6.7.

\section{Acknowledgments}

Funding for this study was provided by the U.S. Office of Naval Research coastal geosciences program, and the U.S. Geologic Survey Coastal and Marine Geology Program. This research is a collaborative effort with the University of Florida (Professor Don Slinn), Monterey Bay Aquarium Research Institute (MBARI, Craig Okuda), Woods Hole Oceanographic Institution (WHOI, Peter Traykovski), and the Sediment-Acoustics Experiment (SAX04) led by the University of Washington's Applied Physics Laboratory(Eric Thorsos). Special thanks are also extended to Hank Chezar, Kevin O'Toole, Viktor Adams, Allison Penko, and Sidney Schofield. The cruises were coordinated and shared with Peter Traykovski (WHOI). 
Figures 
(a)

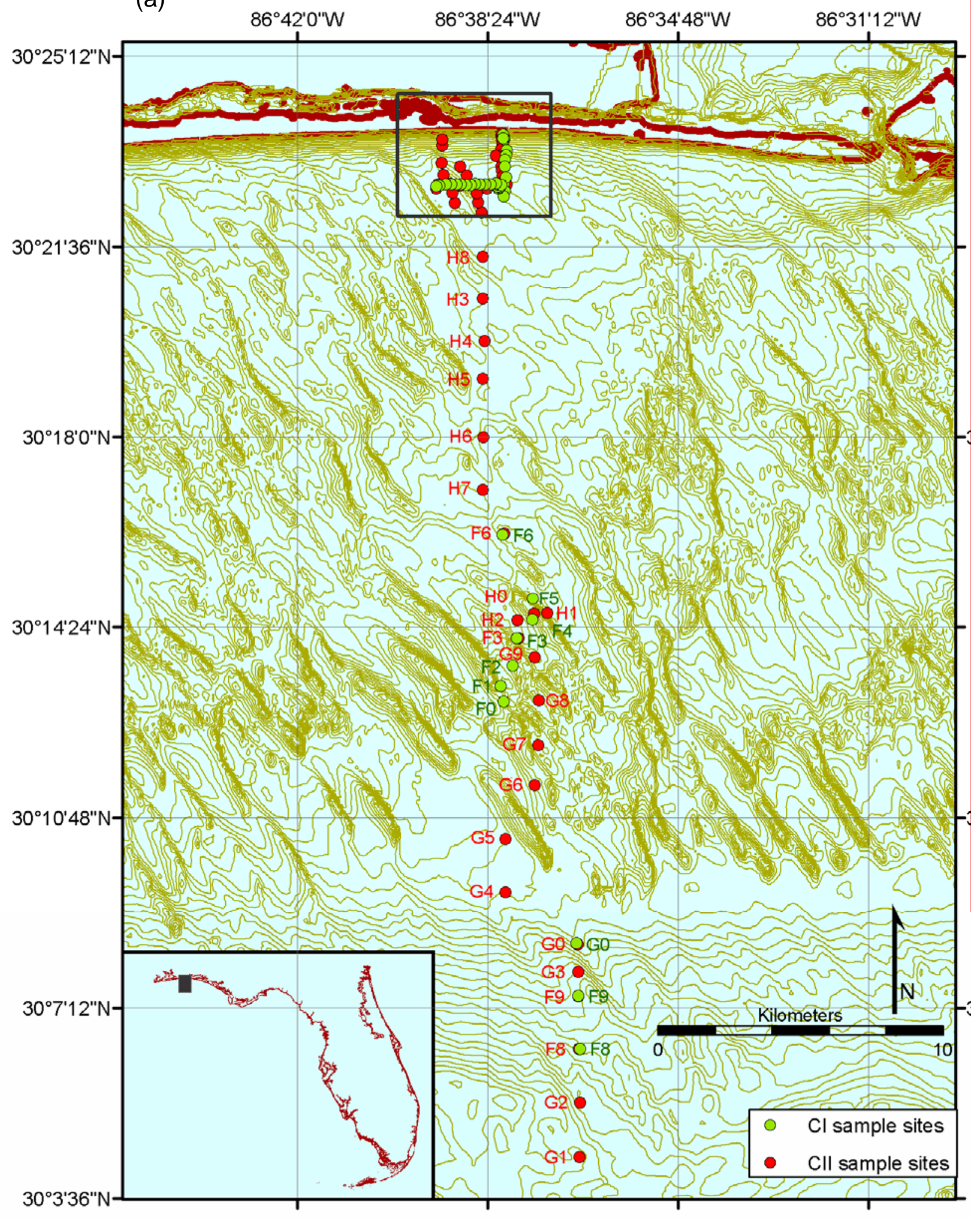

Figure 1a. Study site, sampling locations, and 1 meter depth contours: (a) entire area, (b) inshore sampling locations. 


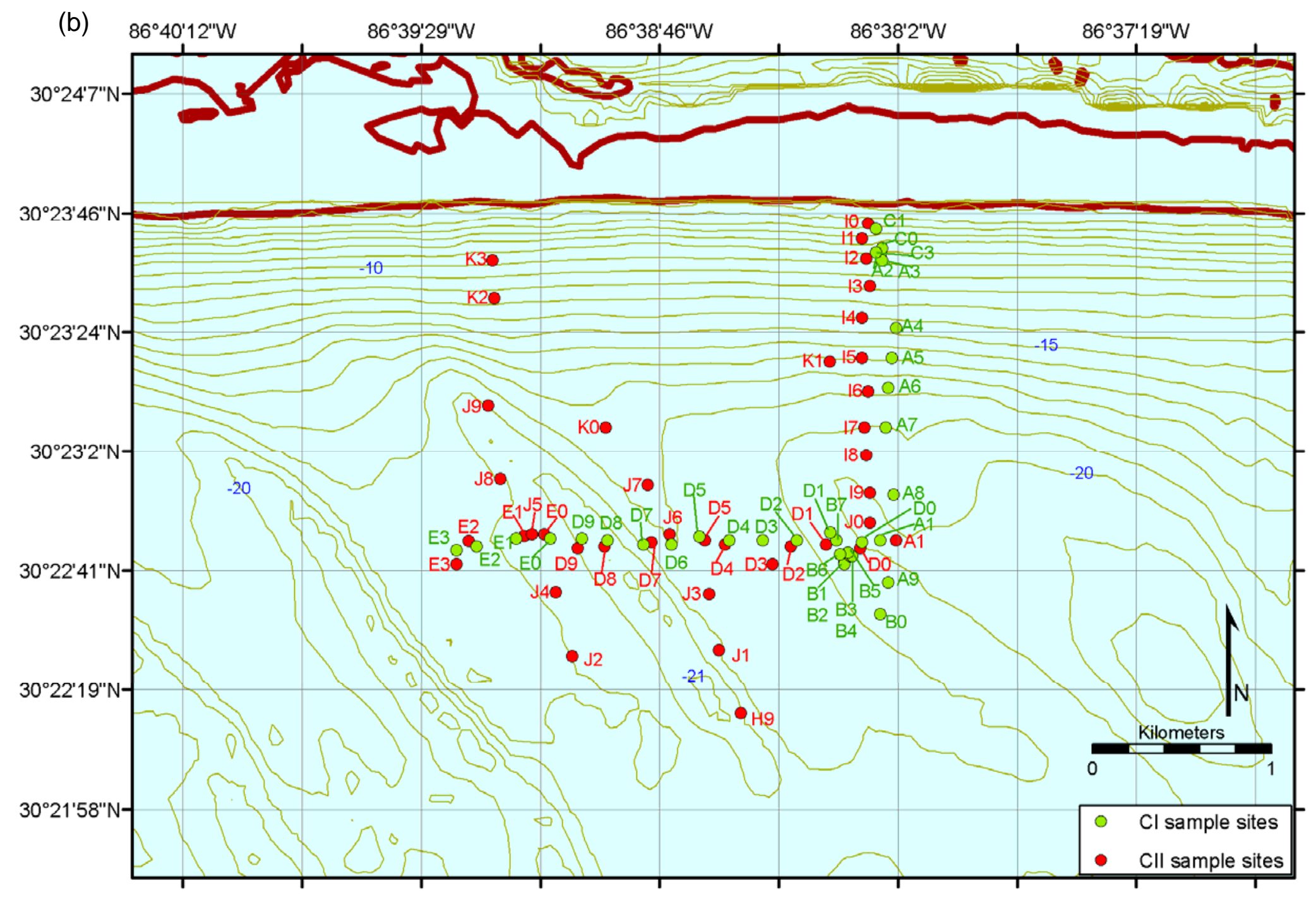

Figure 1. continued. 


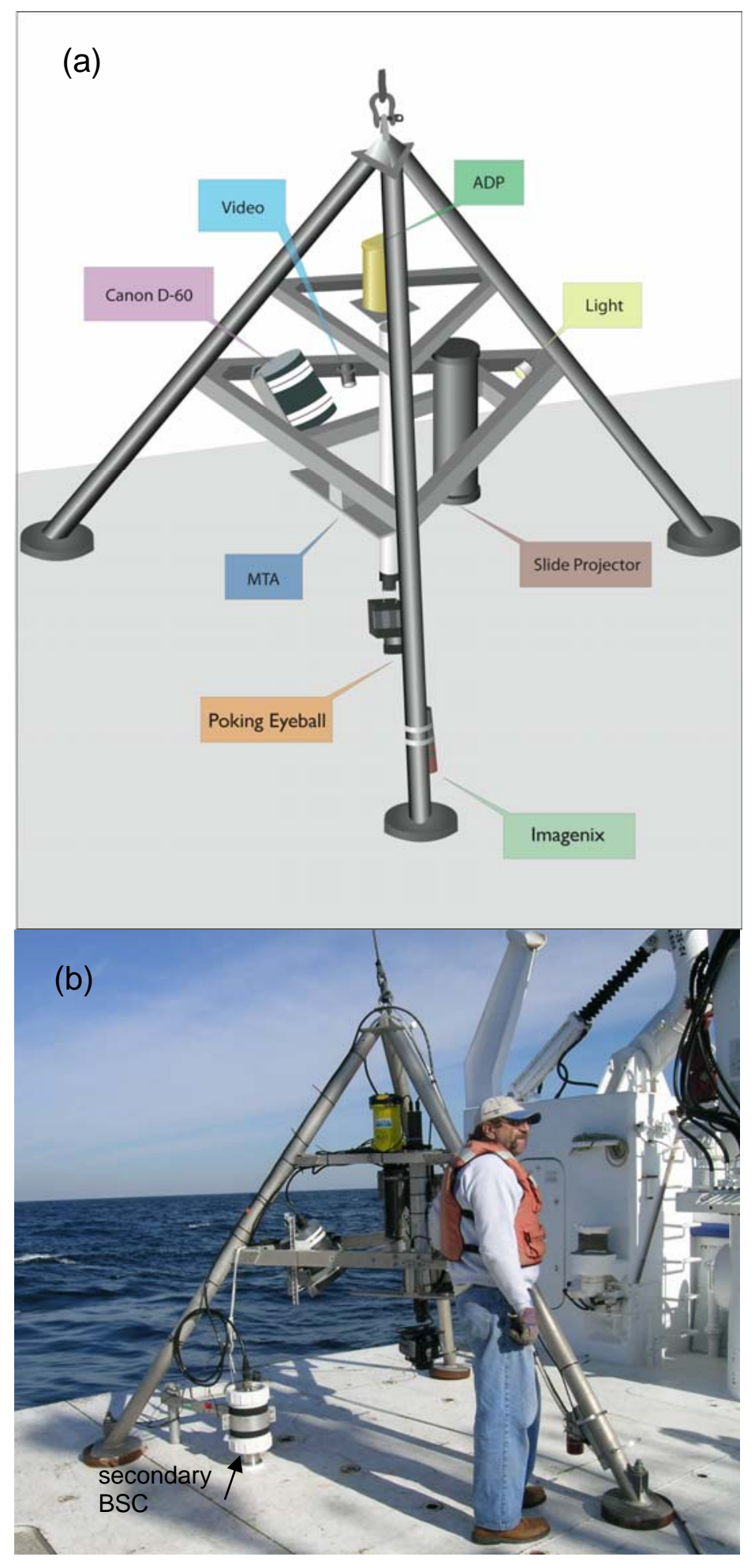

Figure 2. Tripod and instruments employed to measure hydrodynamic and seabed parameters: (a) schematic, (b) photo taken aboard R/V Pelican (with Viktor Adams, University of Florida). 
(a)

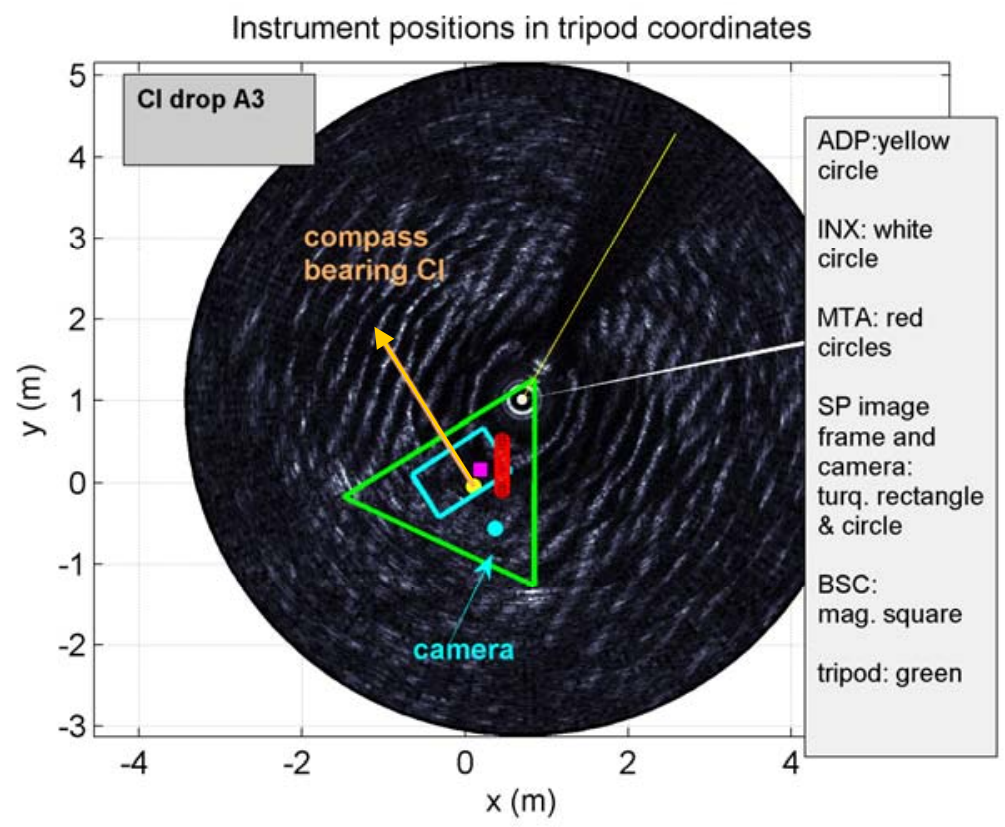

(b)

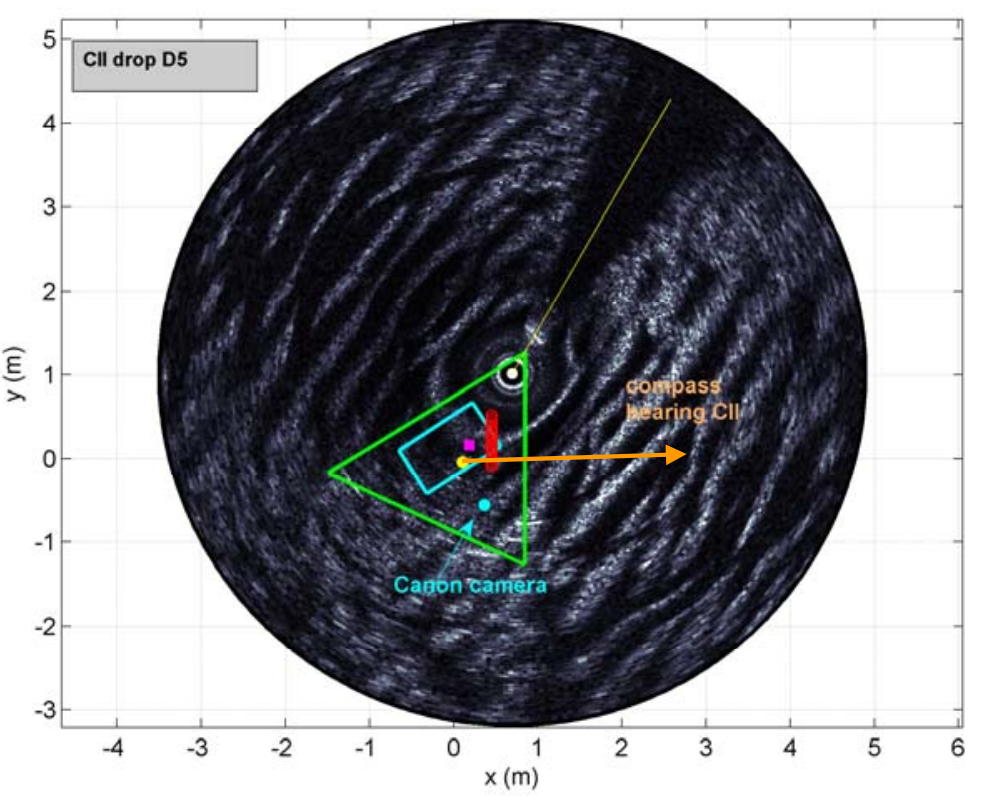

Figure 3. Instrument positions in tripod coordinates including compass bearings for (a) $\mathrm{Cl}$ and (b) Cll. 


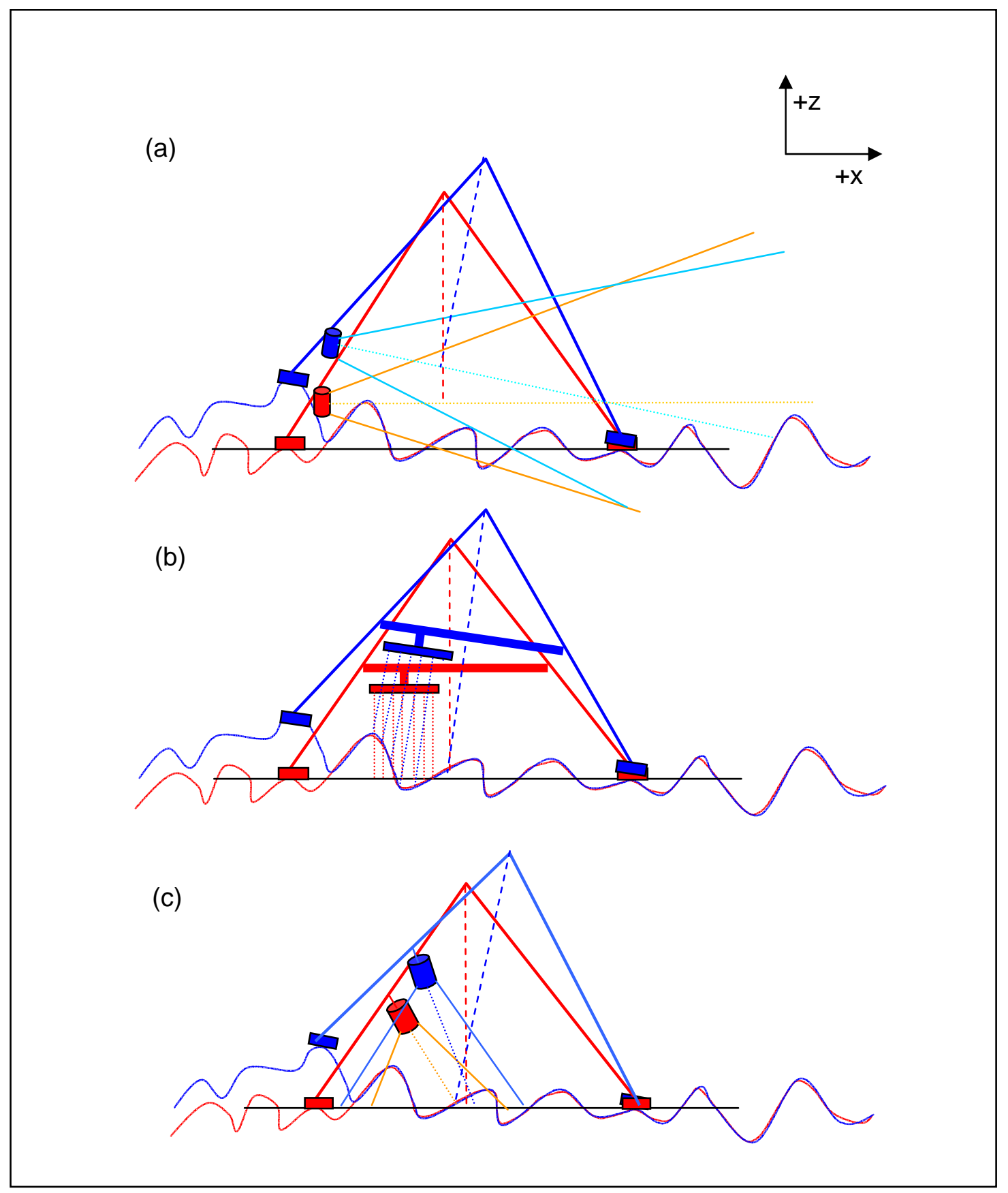

Figure 4. Conceptual diagram of tripod positions on the seafloor and instrument sampling areas: (a) INX sonar, (b) MTA, and (c) slide projector. 


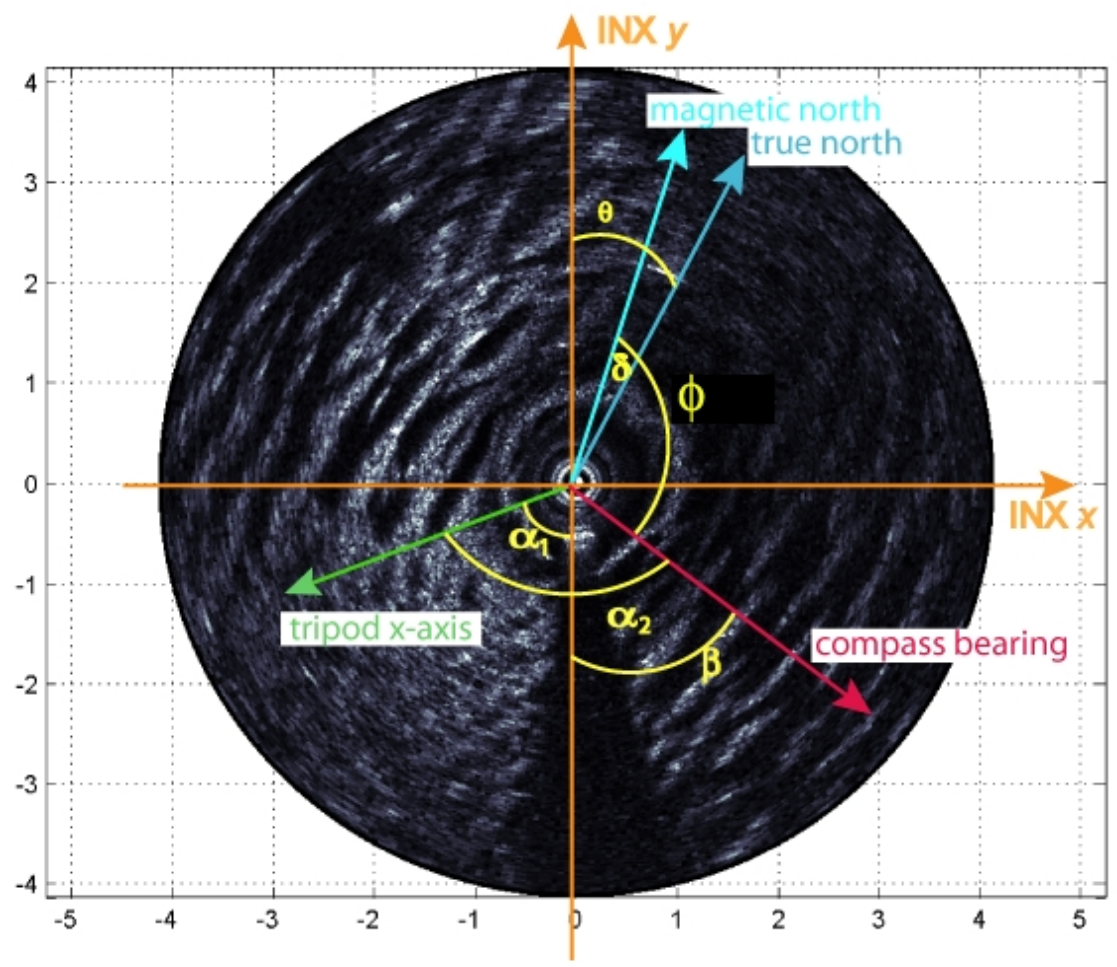

Figure 5. Angles for the determination of sonar rotation. 
Drop A2 Cl

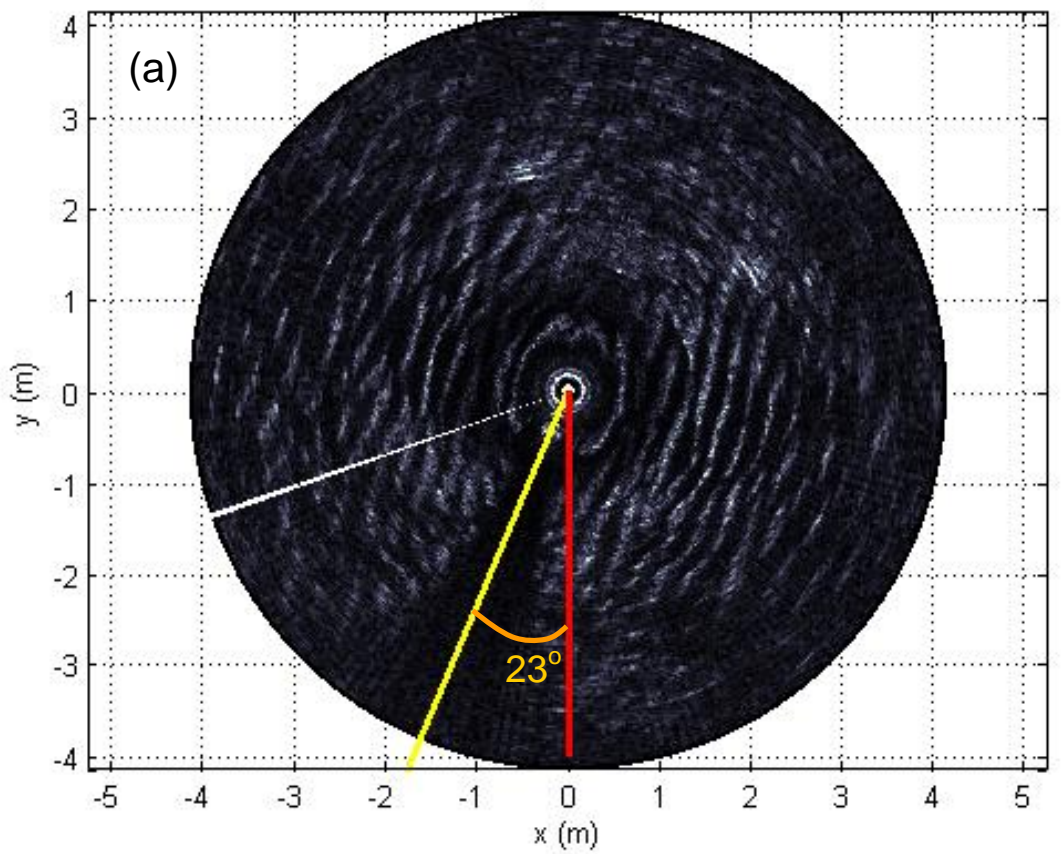

Drop D5 Cll

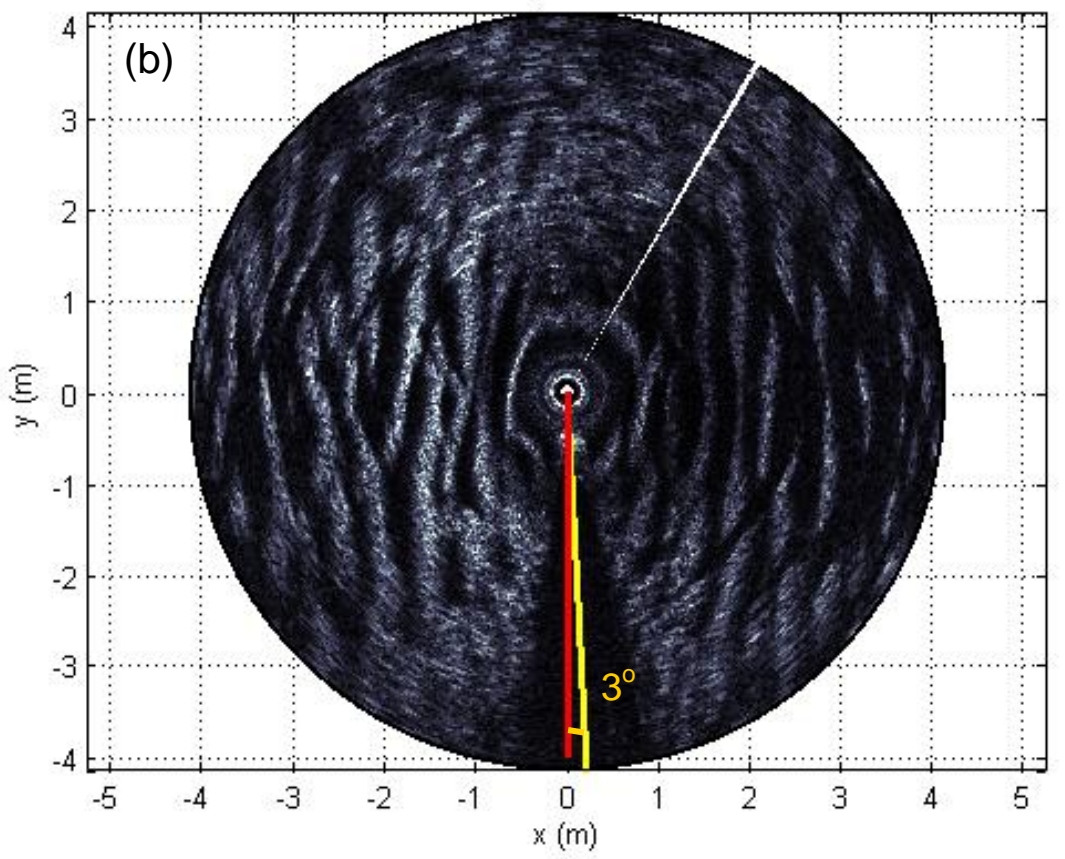

Figure 6. Determination of INX rotation about its own axis for (a) $\mathrm{Cl}$ and (b) CII. 

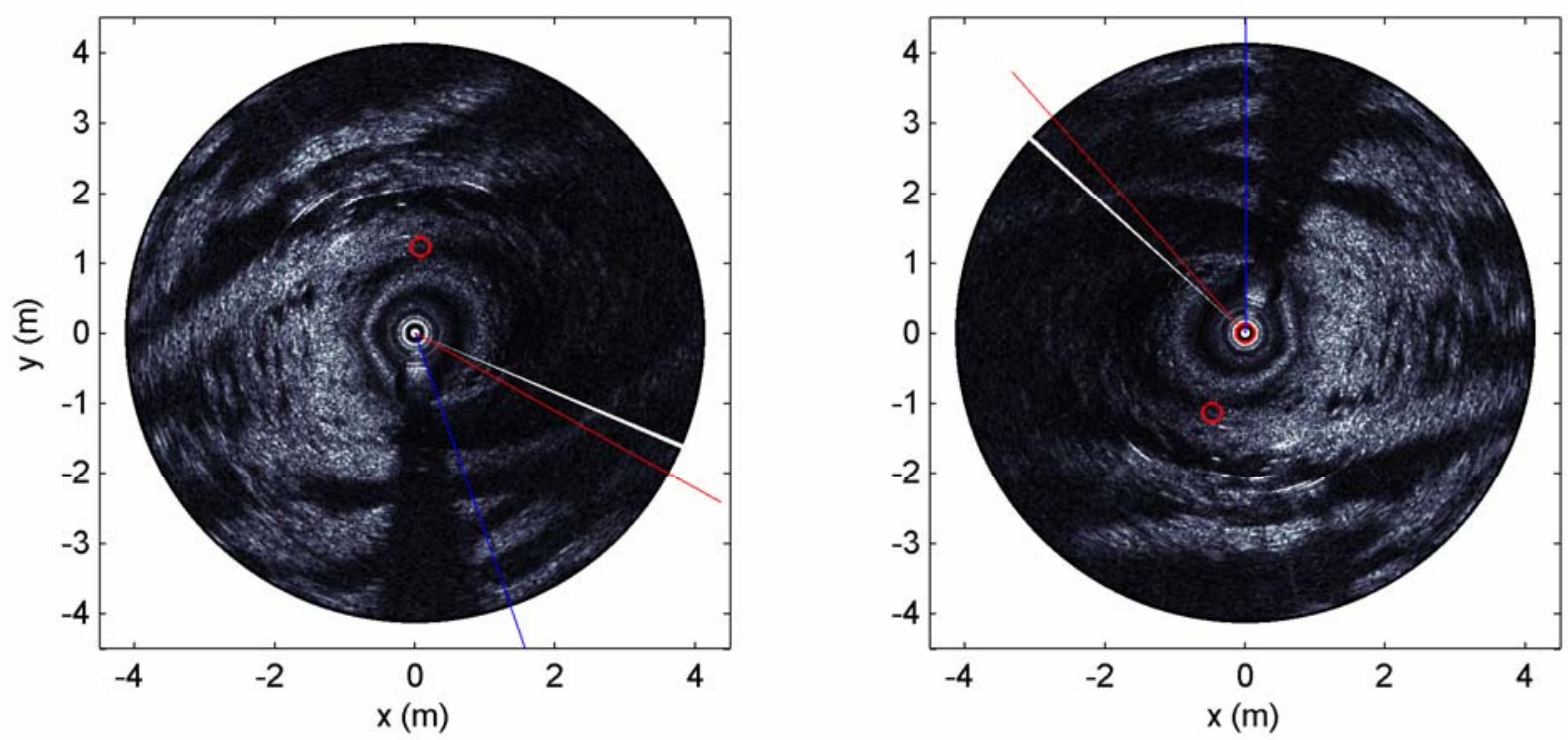

Figure 7. Example of sonar rotation. Left panel shows pre-rotation with the red vector depicting the ADP compass heading vector, and the blue line the true north with a heading reading of $320^{\circ}$. Right panel shows sonar image after rotation with the true north pointing up. Red circle is the tripod center. 


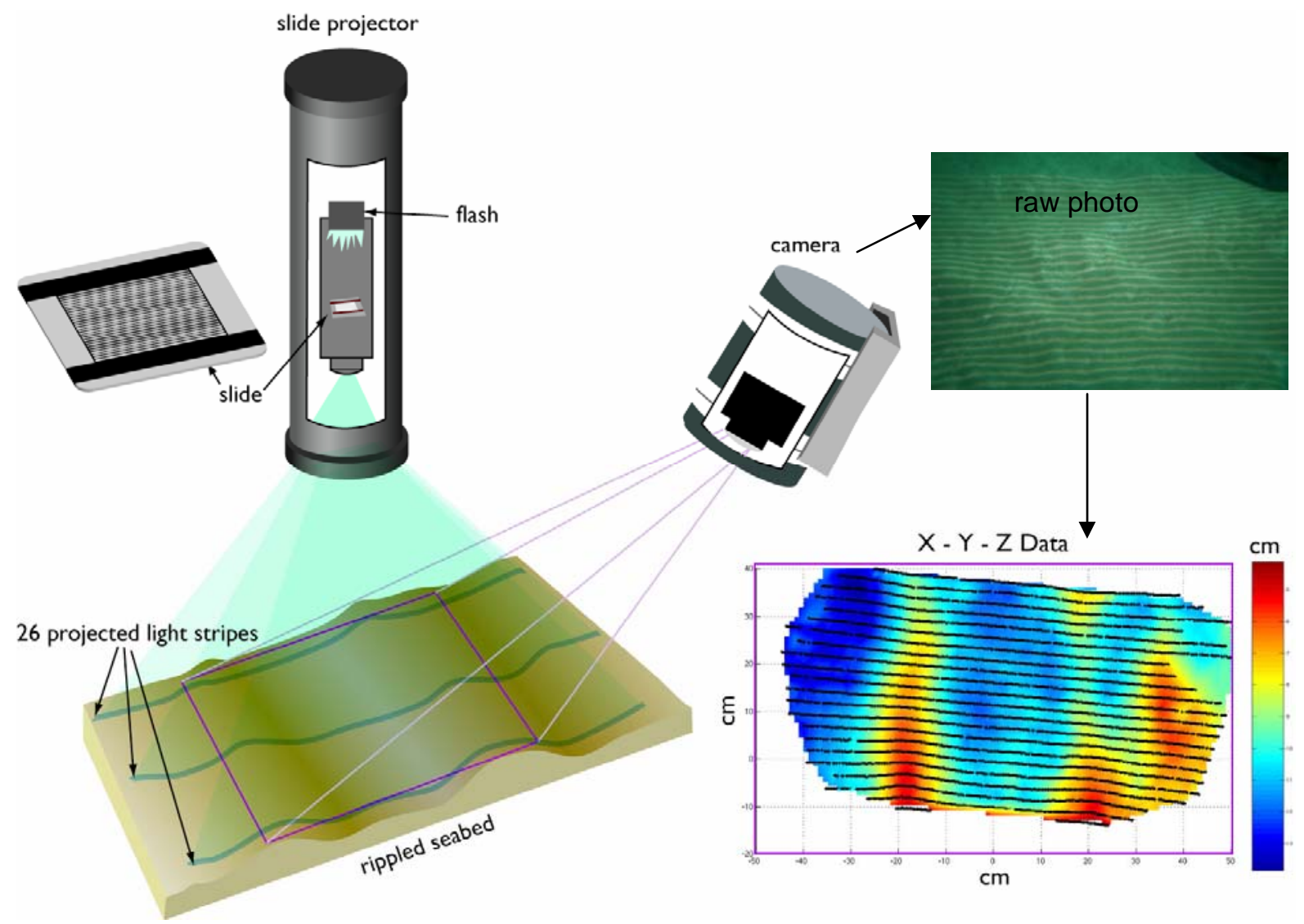

Figure 8. Slide projector system. Figure on the left shows slide projector and camera setup along with conceptual sampling area. Figure on the right shows typical $x, y, z$ data. 
(a) E0

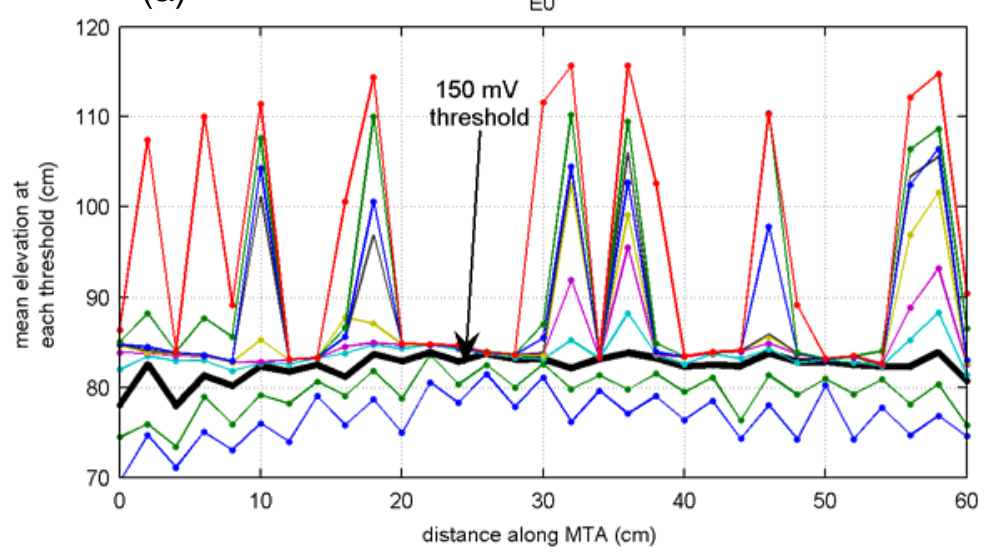

(b)

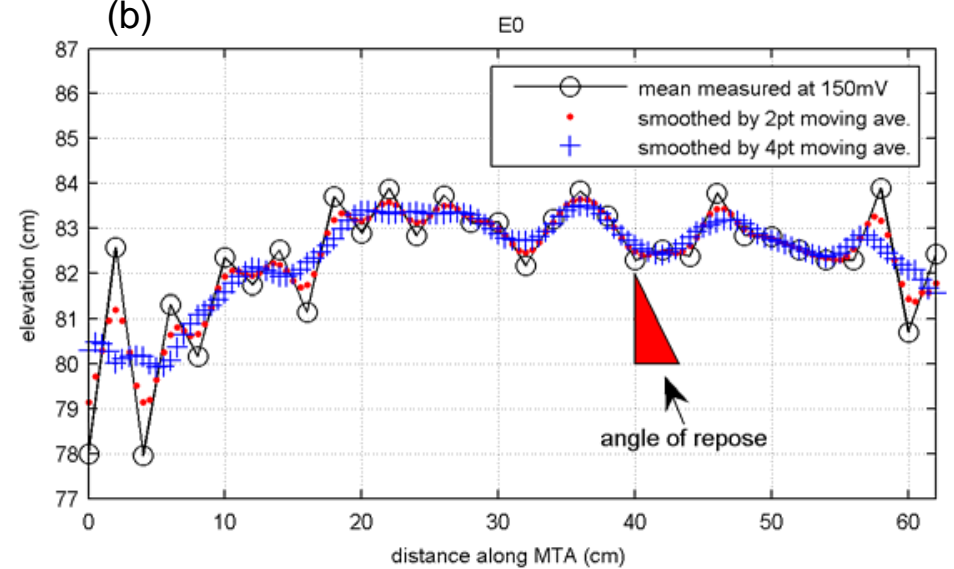

(c)

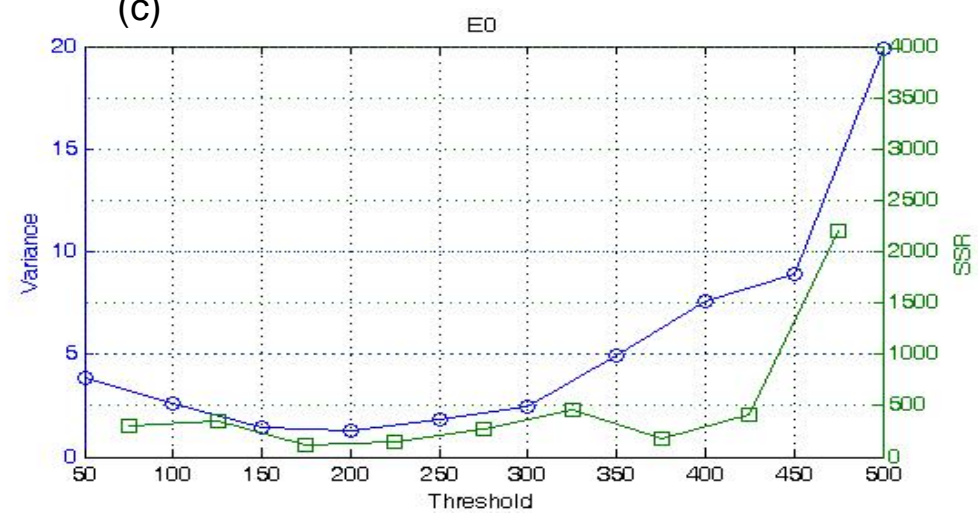

Figure 9. Determination of threshold value to use for extraction of MTA data (drop E0, CII): (a) raw data measured with ten different threshold settings; (b) 2- and 4-point moving averages of measurements obtained at a threshold of $150 \mathrm{mV}$; and (c) the variance (blue) and sumsquared-residuals (green) of repeated measurements at the selected threshold level. 


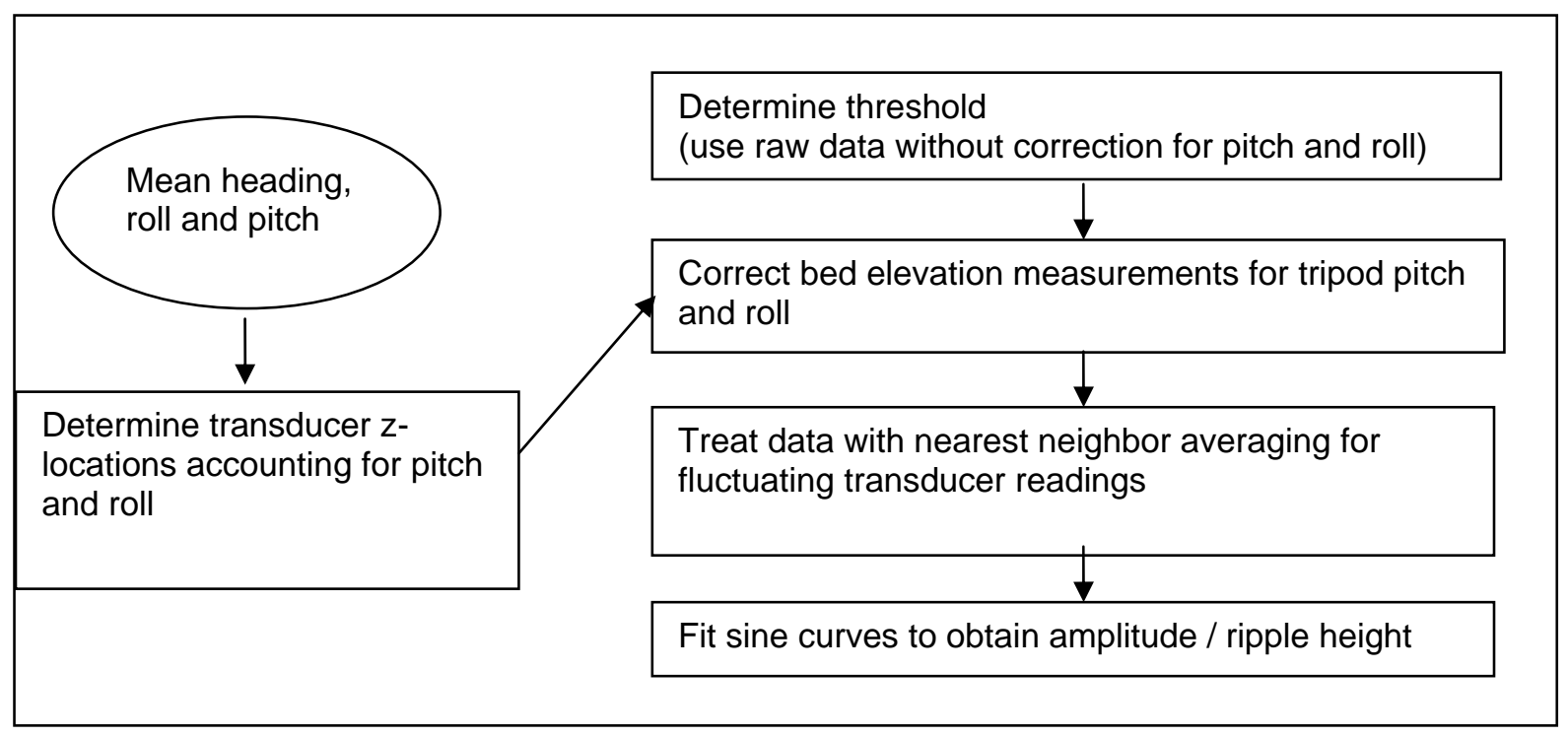

Figure 10. Overview of method employed to obtain MTA ripple heights. 

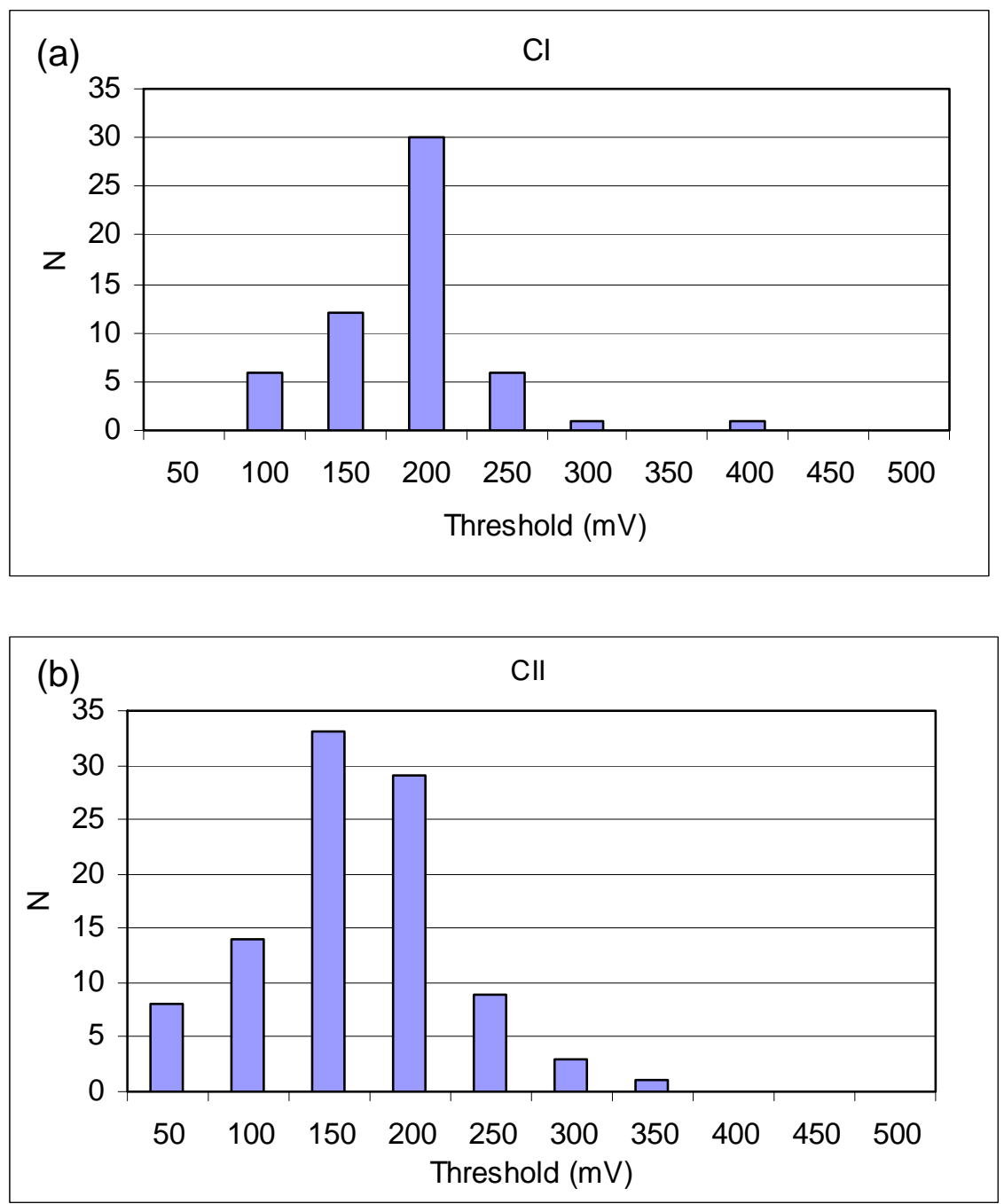

Figure 11. Histograms of threshold values selected for the MTA data, (a) Cruise I and (b) Cruise II. 

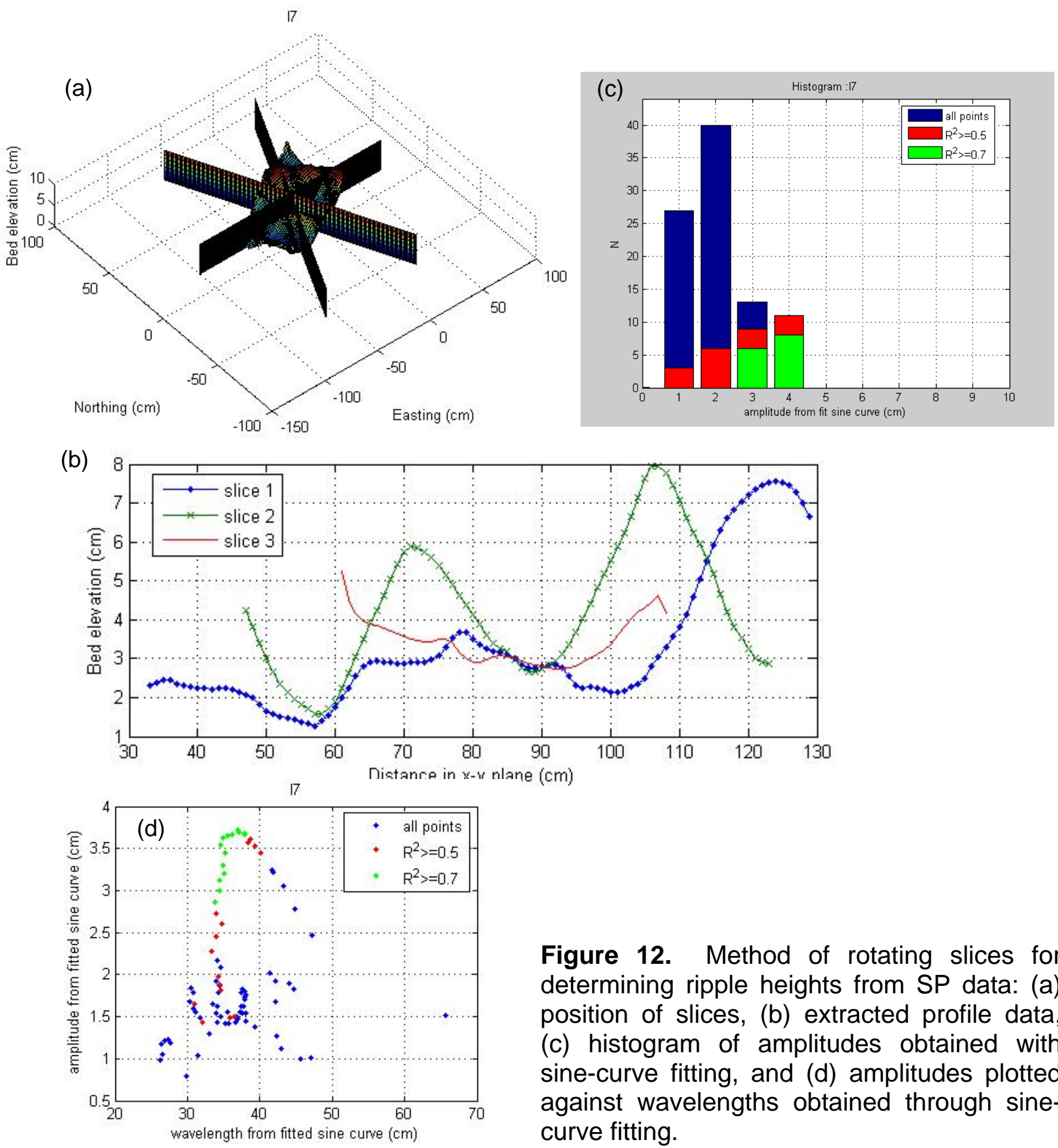

Figure 12. Method of rotating slices for determining ripple heights from SP data: (a) position of slices, (b) extracted profile data, (c) histogram of amplitudes obtained with sine-curve fitting, and (d) amplitudes plotted against wavelengths obtained through sinecurve fitting. 
(a)

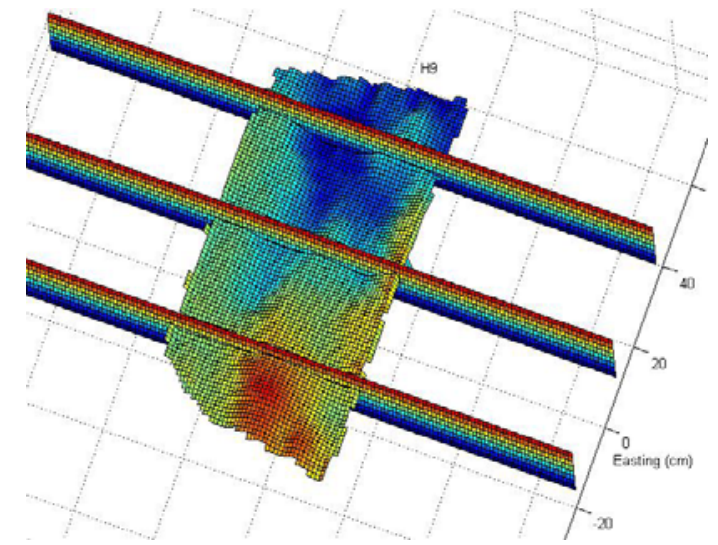

(b)

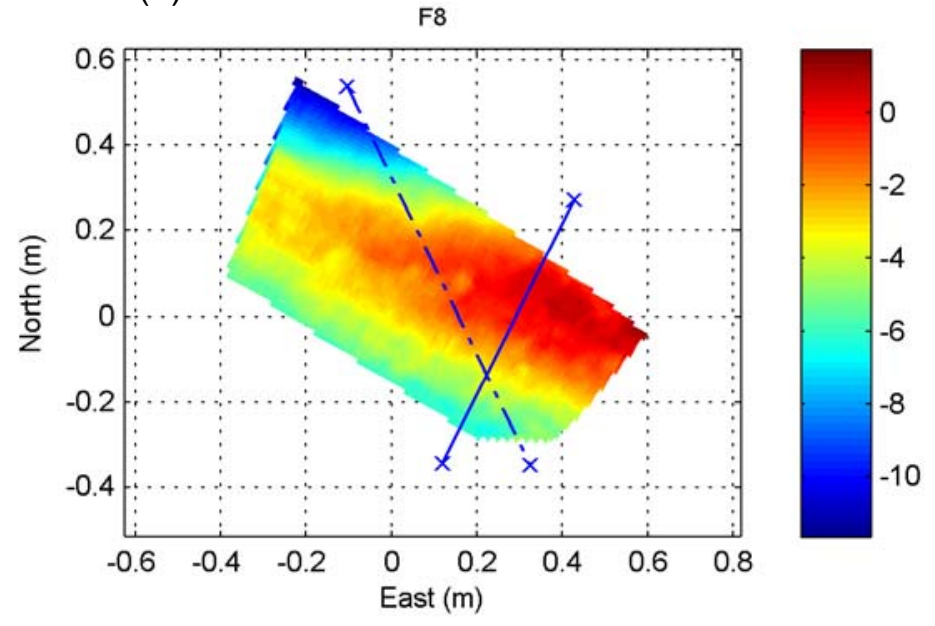

Figure 13. Method of parallel slices for determining ripple heights from SP data. An example of a surface for which the rotating slice approach is not as well suited as the alternative approach of taking slices parallel to an a priori known orientation is shown in (b). In (b), the solid line depicts a slice using the 'parallel slice' method and the dashed line depicts a slice using the method of rotating slices. 
(a)

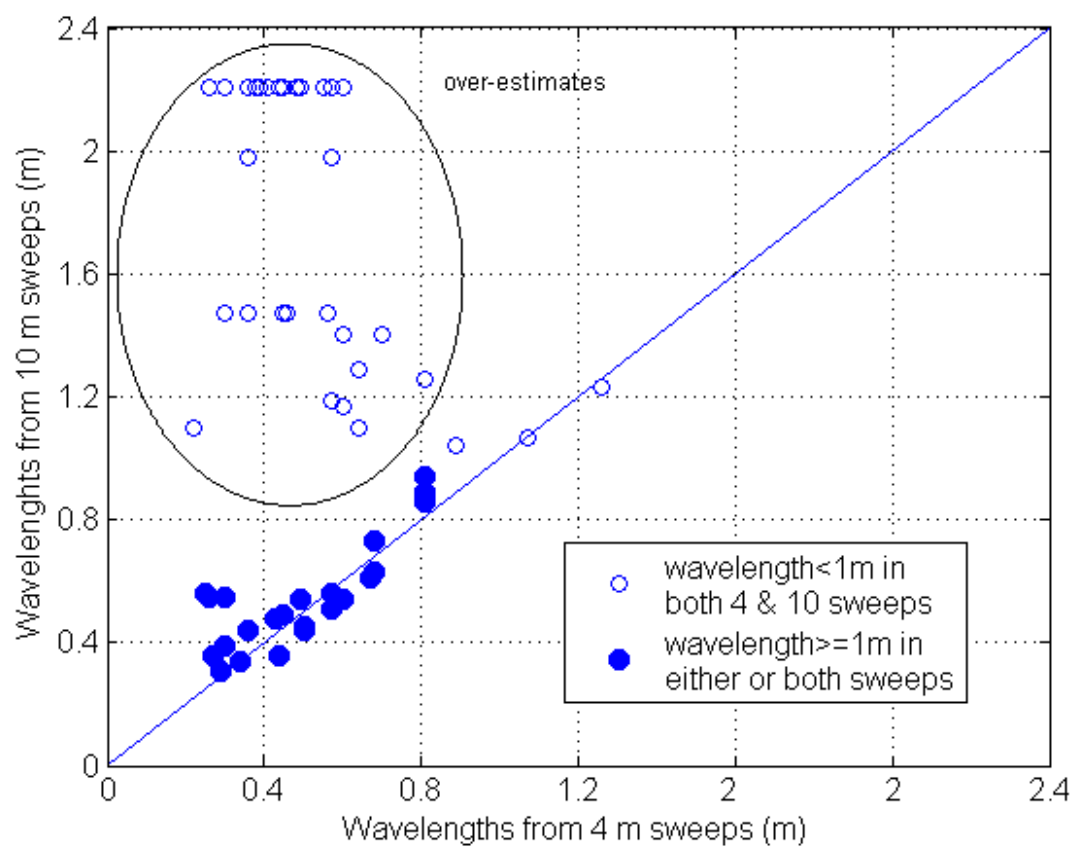

(b)

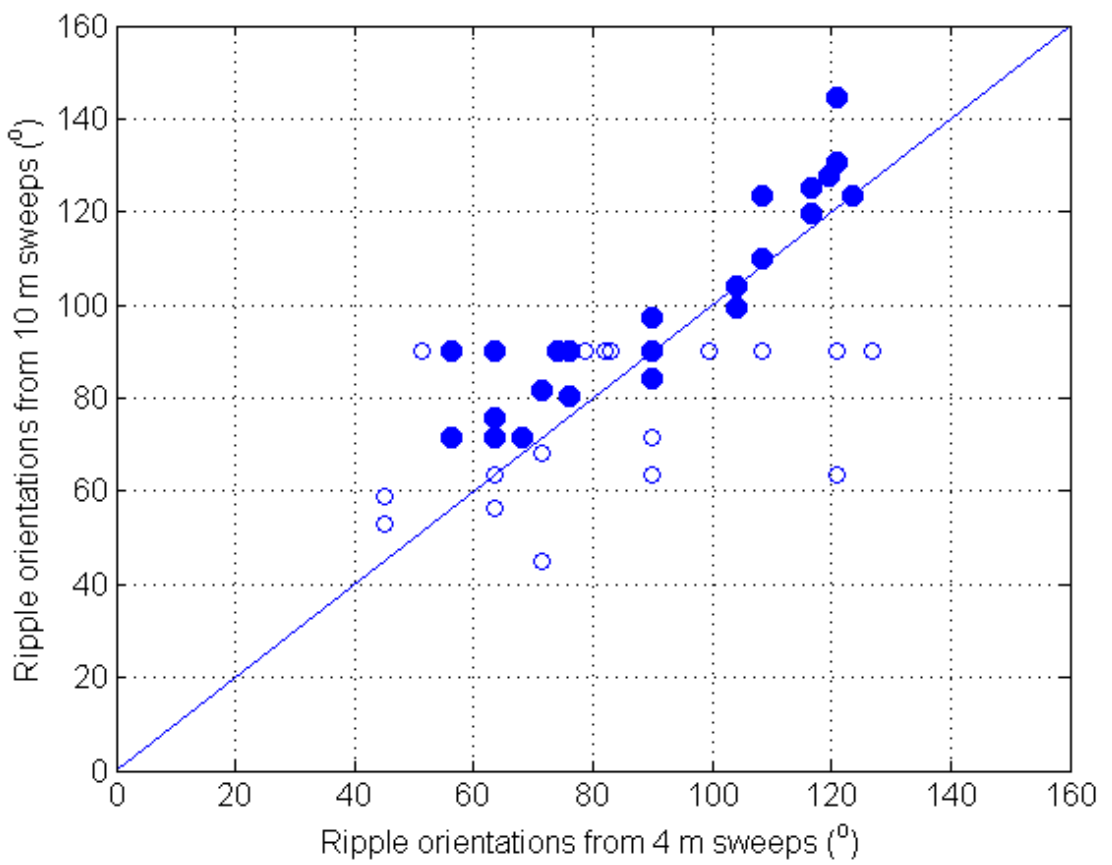

Figure 14. Comparison of ripple (a) wavelengths and (b) orientations obtained with $4 \mathrm{~m}$ and $10 \mathrm{~m}$ sonar sweeps. 


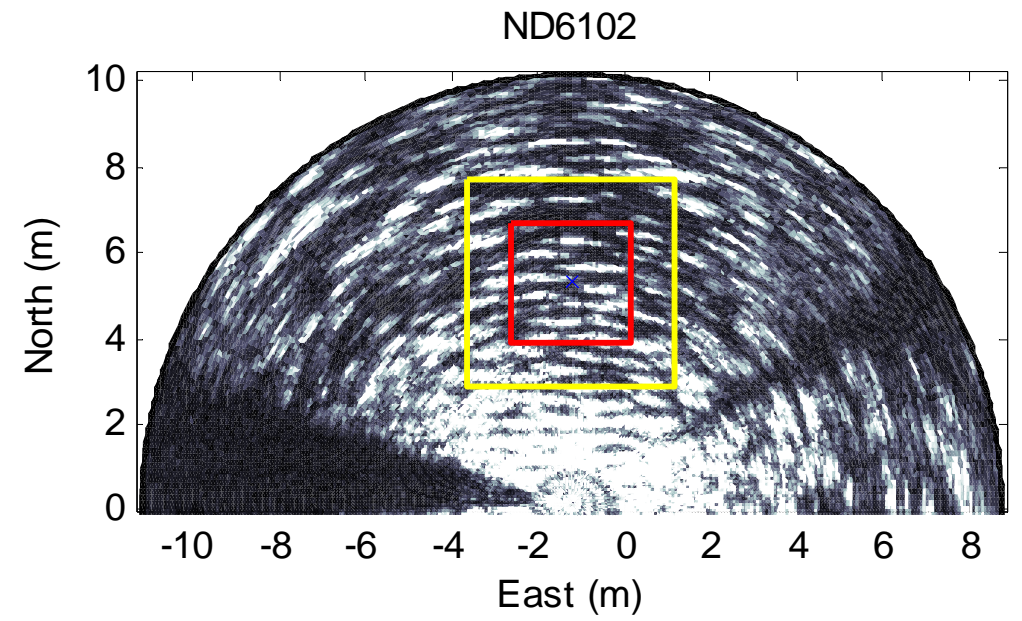

Figure 15. Example of smear and concentricity near the center and edges of 10-m scans. Boxes show large and small areas that might be sampled for 2DFFT. 


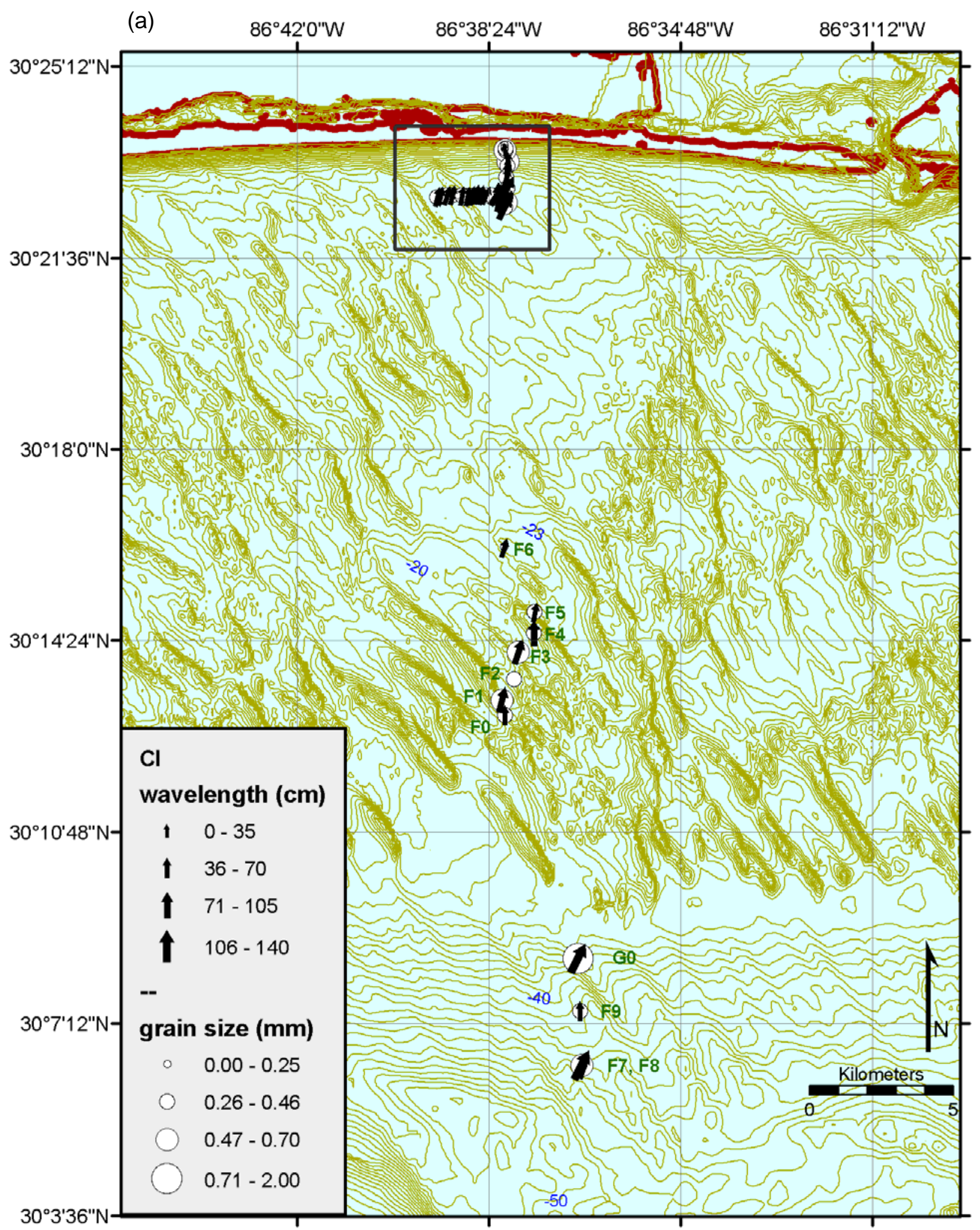

Figure 16. Ripple wavelengths and orientations measured with the INX sonar and sediment grain sizes obtained with the BSC: (a) entire study site, $\mathrm{Cl}$, (b) entire study site, CII, (c) nearshore region, $\mathrm{Cl}$, and (d) nearshore region, Cll. 


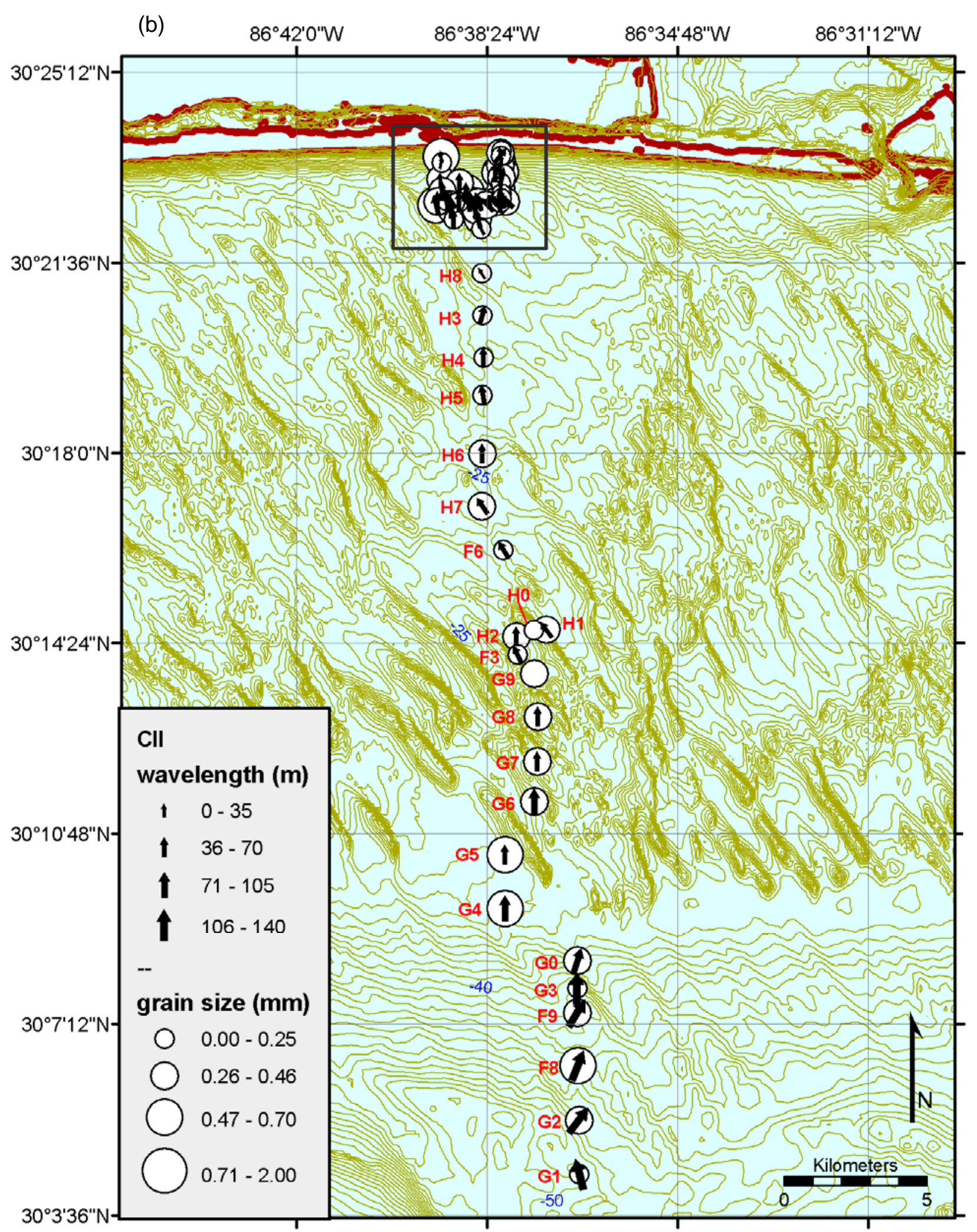

Fig 16. continued 
(c)

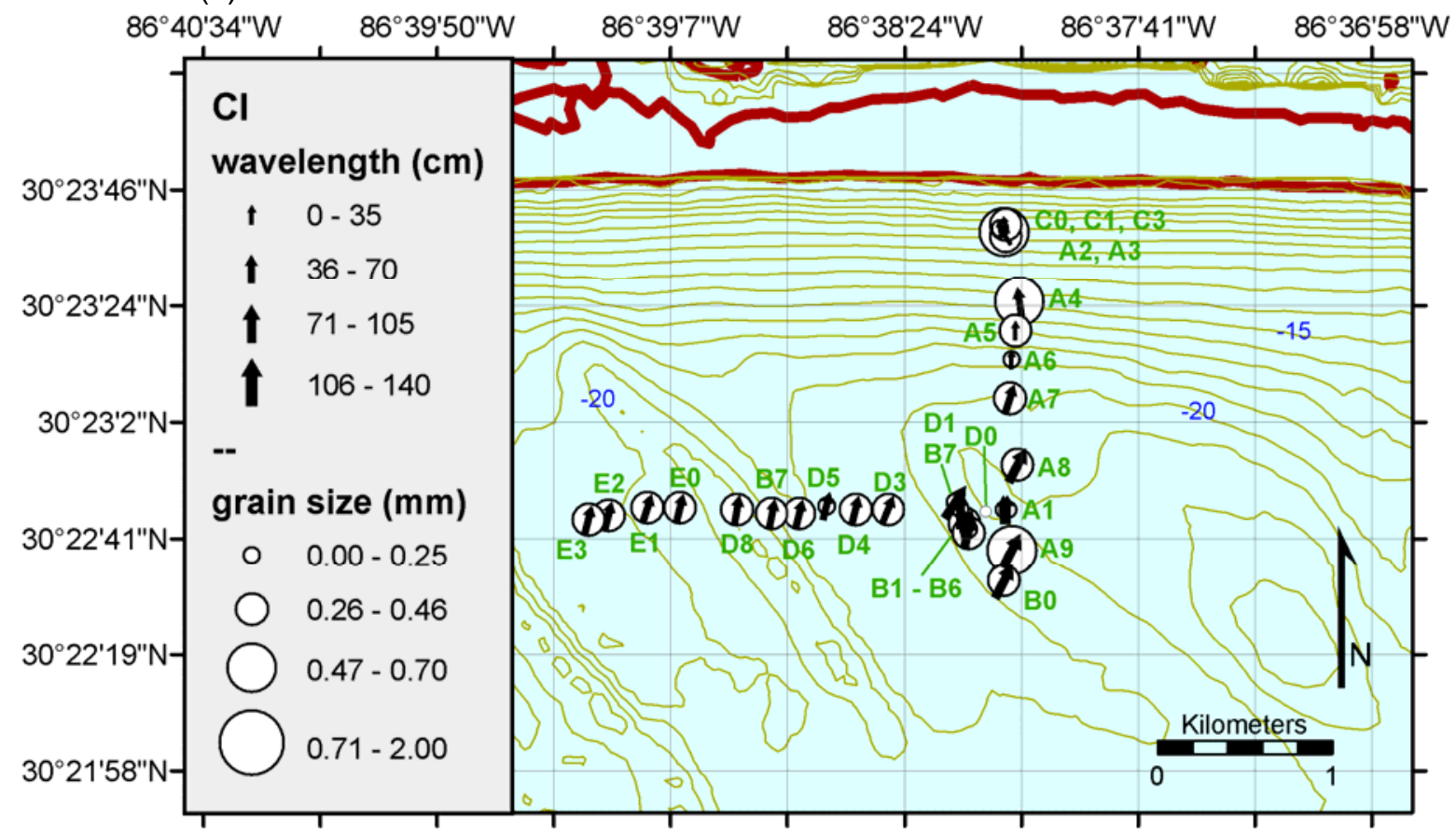

(d)

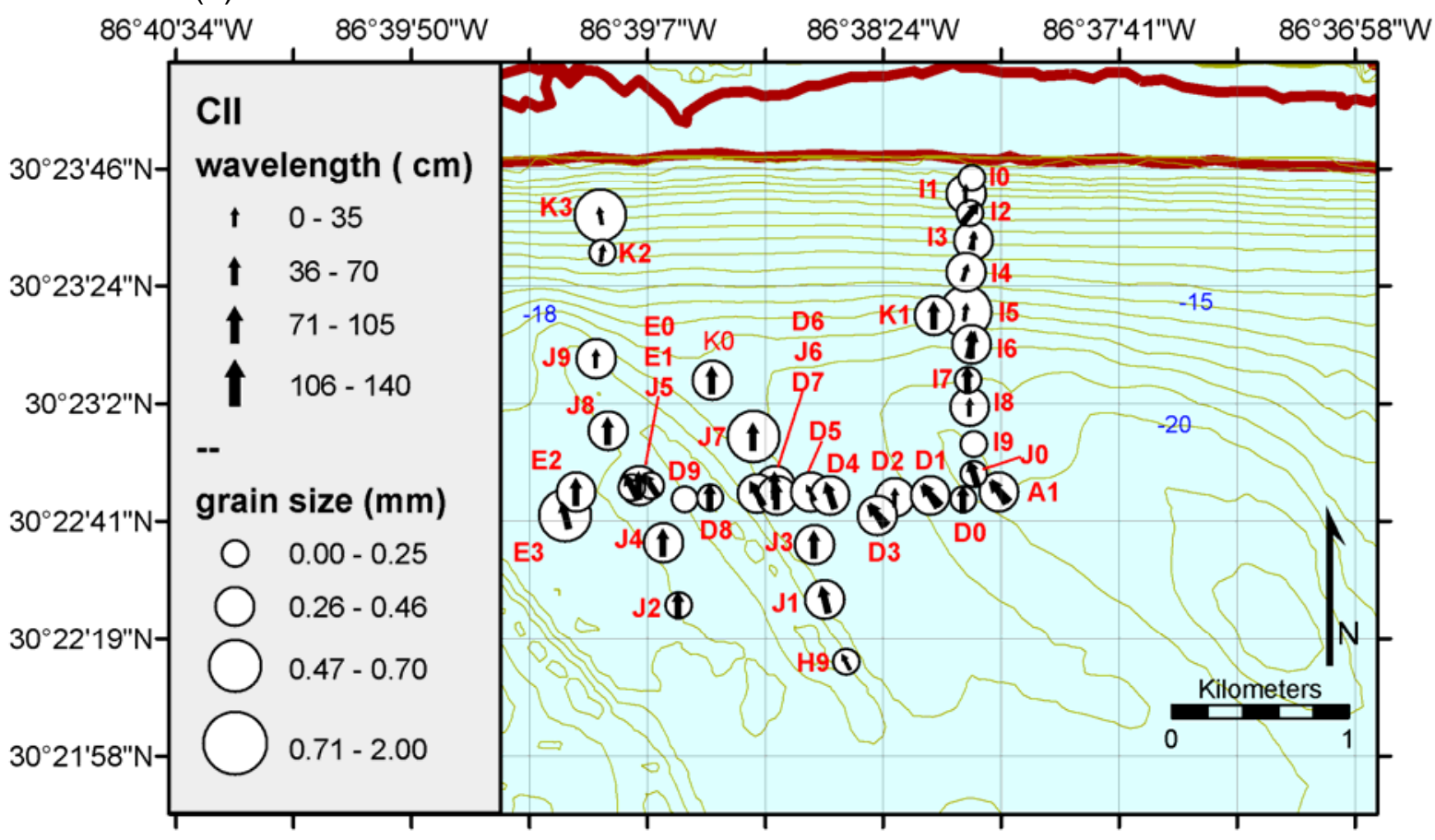

Fig 16. continued 


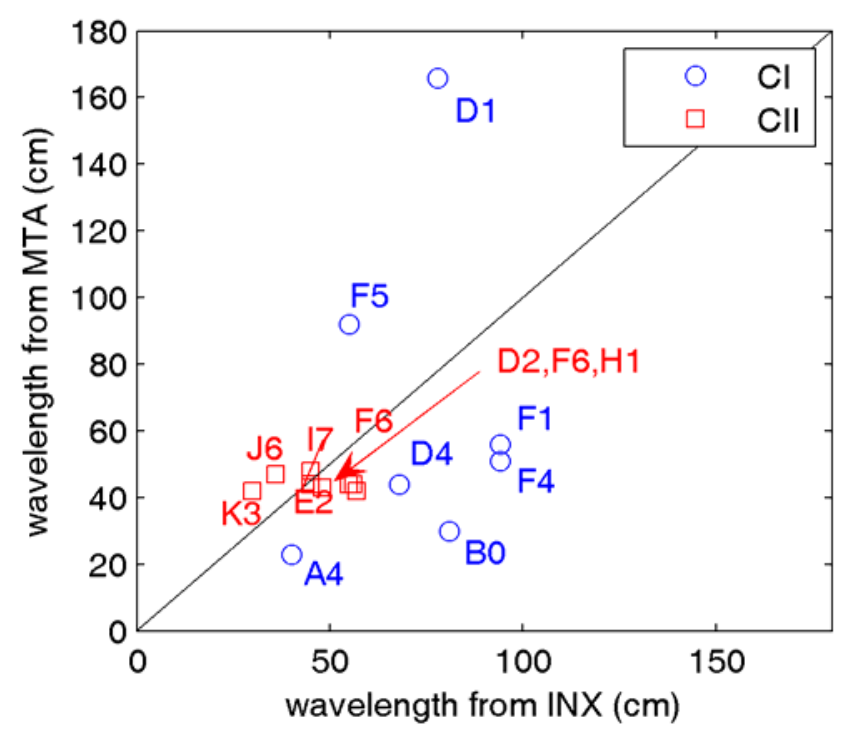

Figure 17. Comparison of wavelengths as measured by the MTA and INX sonar. 

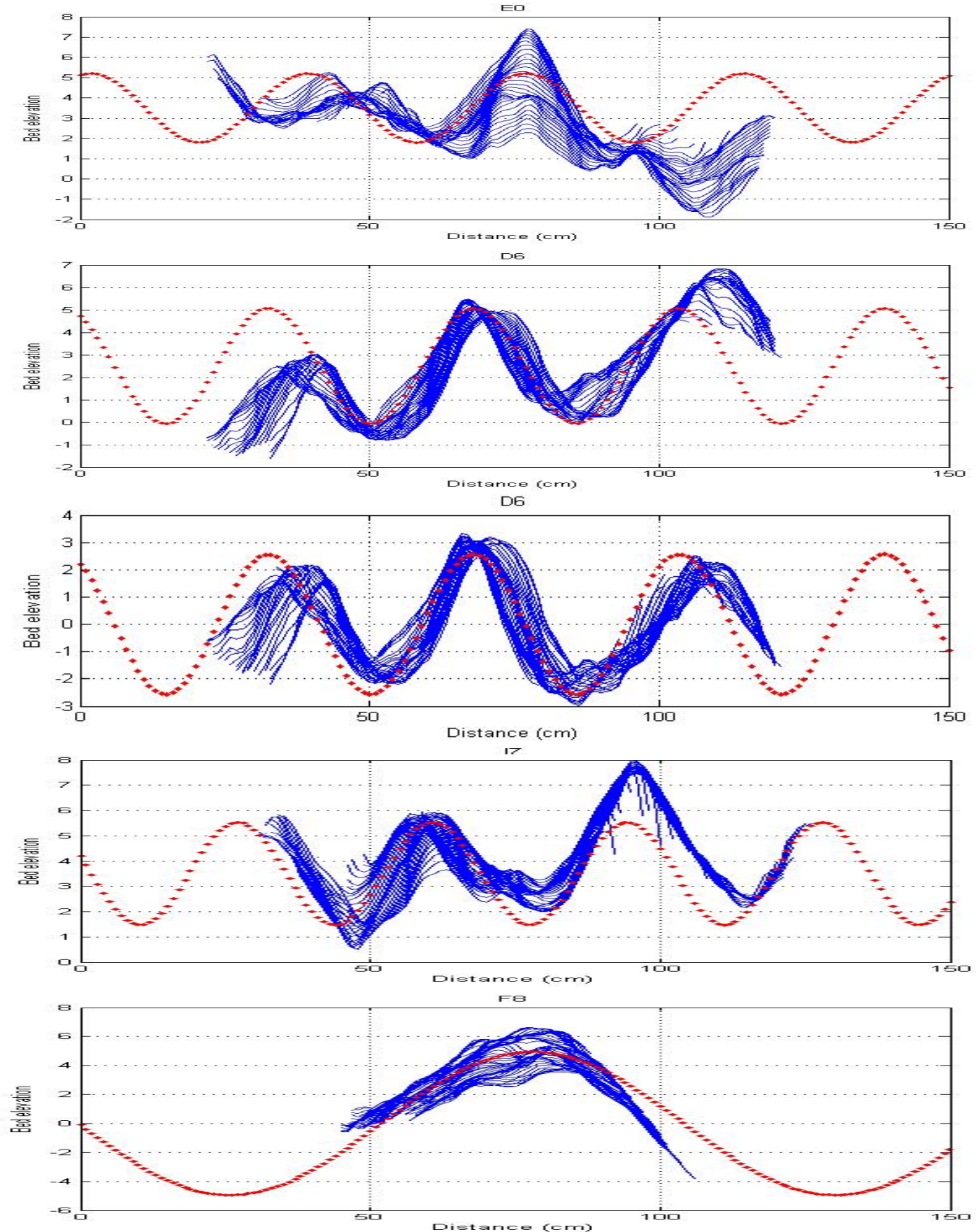

Figure 18. Profiles extracted from parallel slices of SP surface data and least-squares fitted sine curves shown with red circles. 
(a)

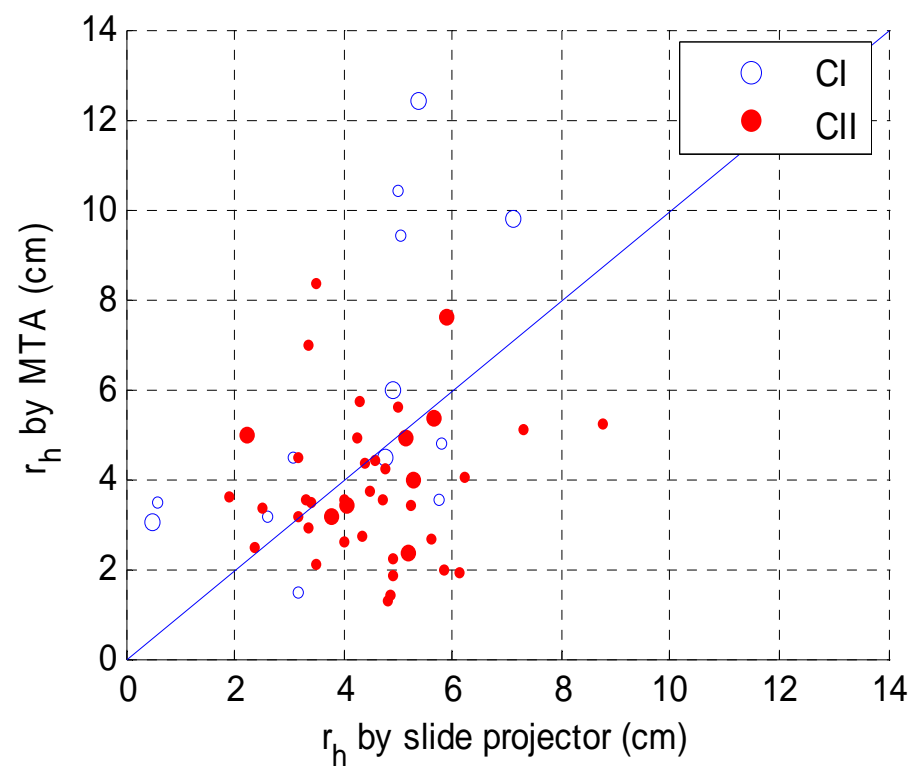

(b)

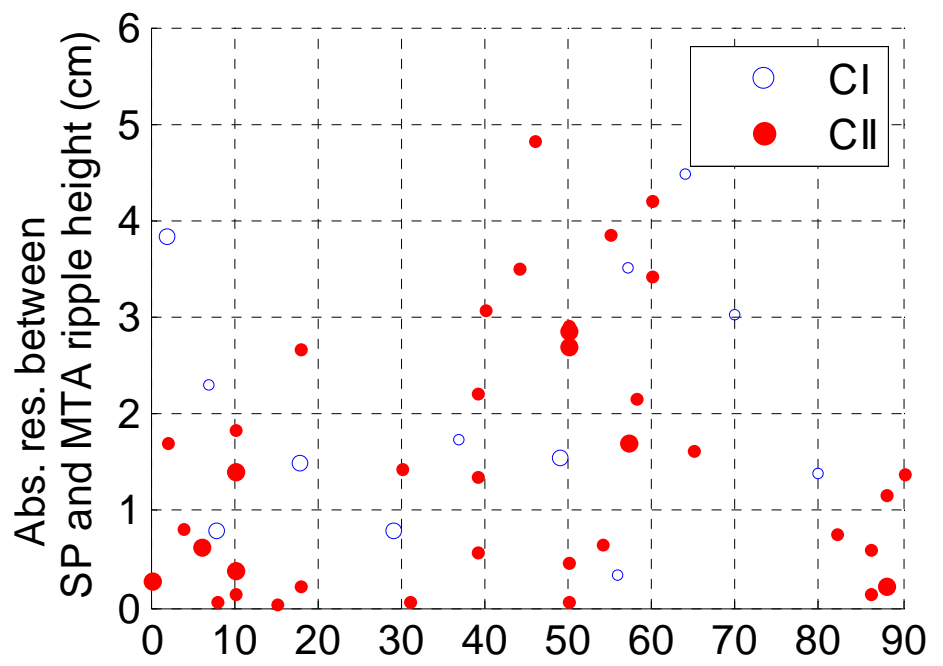

Angle between MTA and ripple orientation (deg)

Figure 19. Comparison of ripple heights as measured by the MTA and SP in (a) and the difference between the two measurements as compared to the angle between MTA transducer array and ripple orientation. Circle size related to subjective quality rating with larger circle representing better quality. 
(a)

$\mathrm{Cl}$

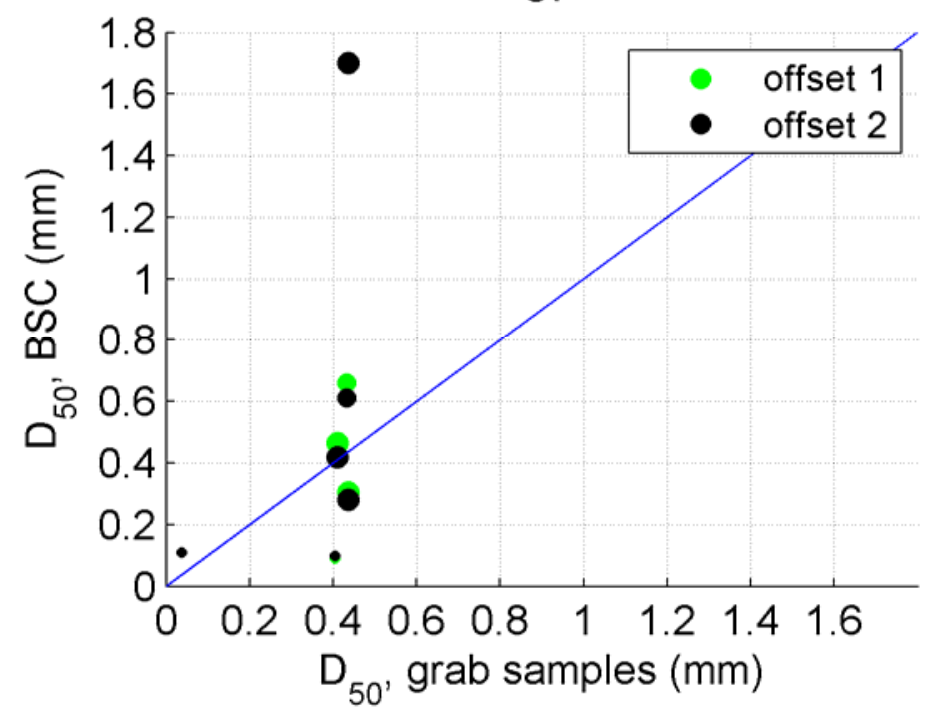

(b) $\quad$ CII

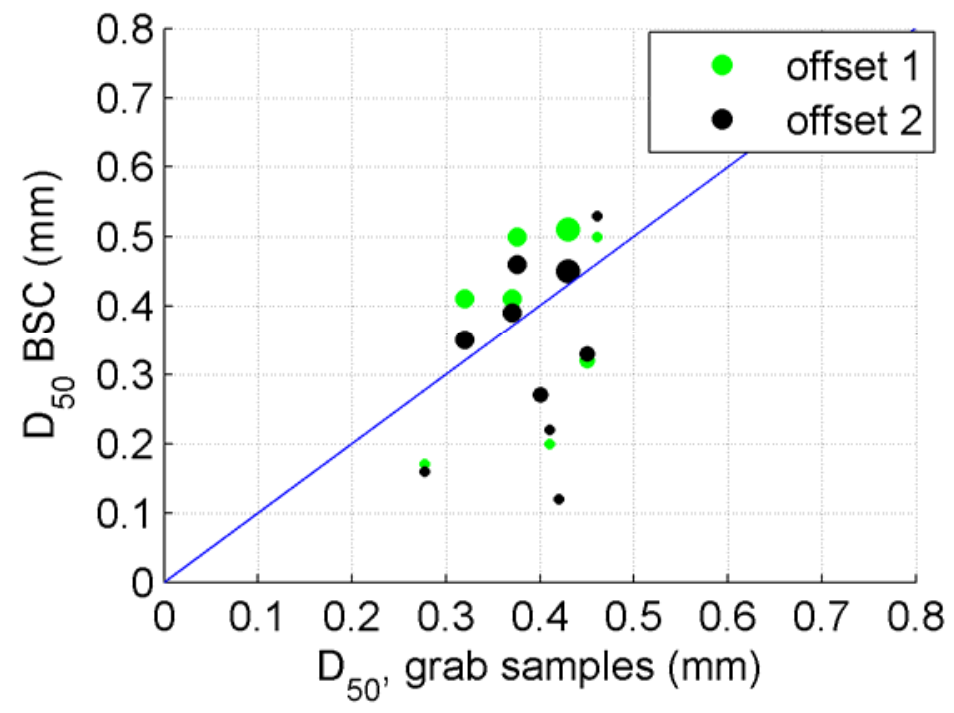

Figure 20. Comparison of median grain sizes obtained with the BSC and grab samples. Note that the differences are likely because the grab samples were dominated by sub-surface sediments, whereas the BSC measures surficial sediment sizes. 


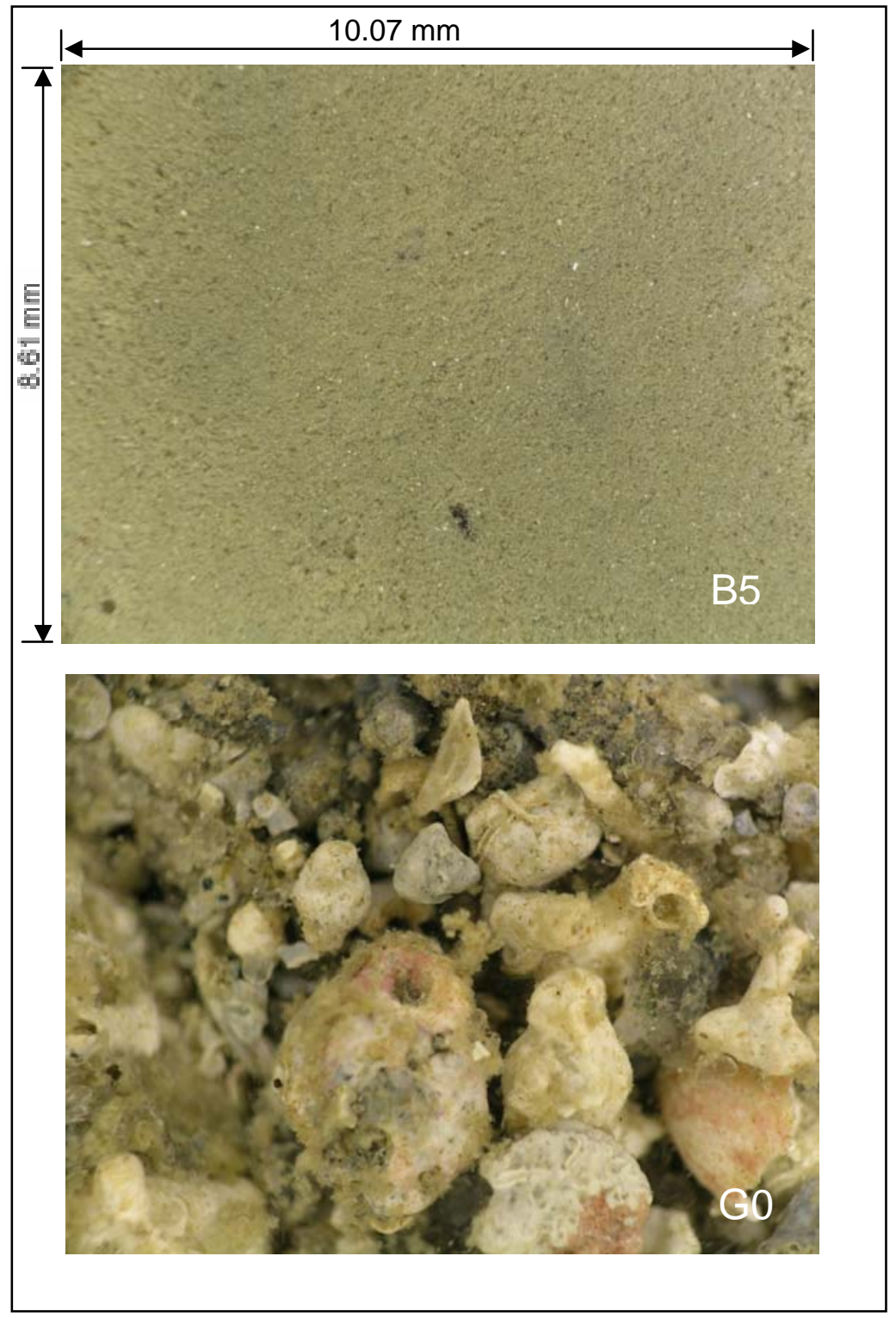

Figure 21. Original BSC images for drops B5 and G0, Cruise I. 

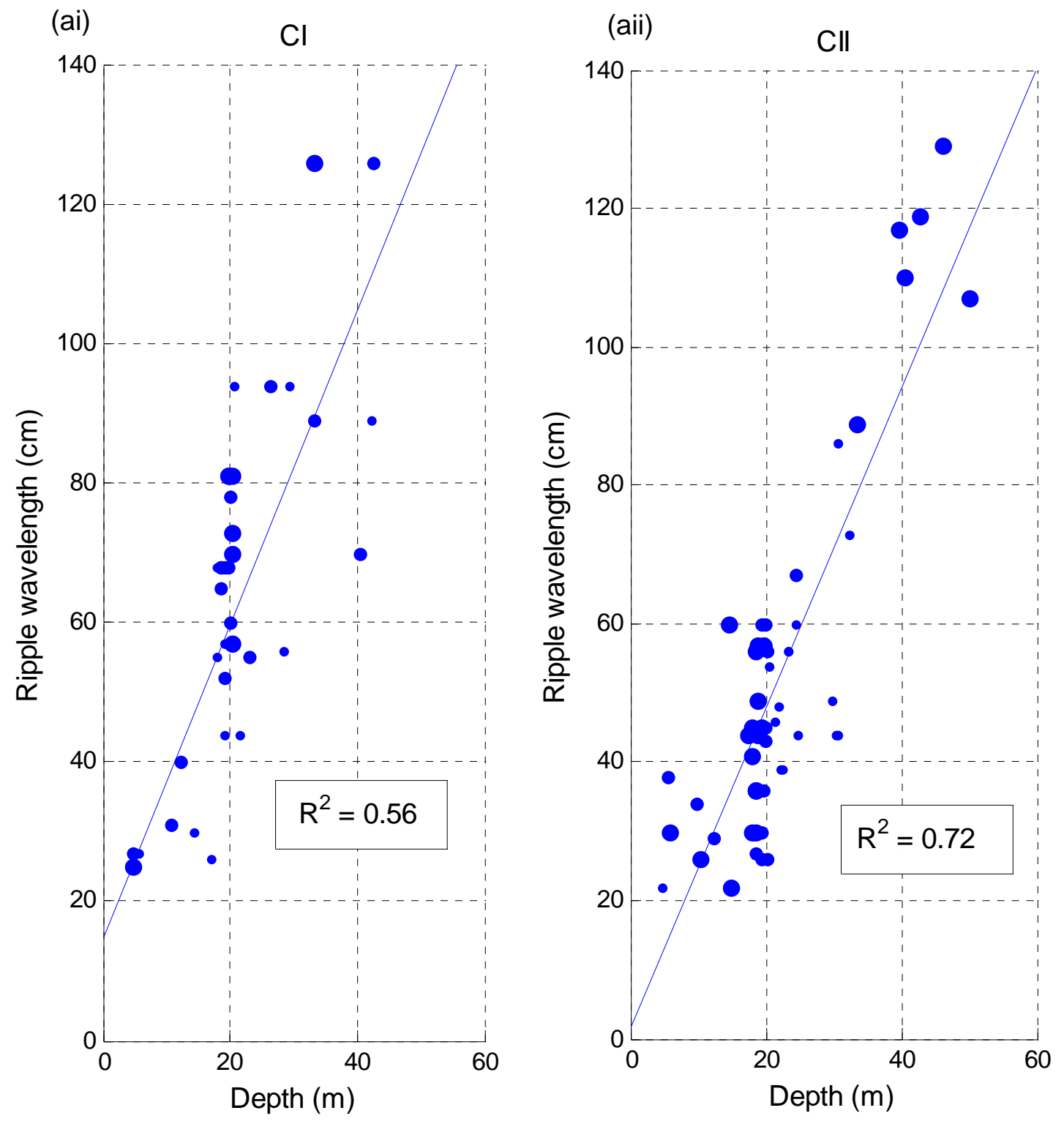

Figure 22. Ripple wavelengths plotted against depth (a) and distance offshore (b). The size of filled circles in (a) indicates quality of data (larger circles indicate greater data quality). Measured depths as a function of distance offshore are shown in (c). The presence of large swales and ridges (on the order of $1 \mathrm{~km}$ between crests) is evidenced by the variation in depth from the mean. 
(b)

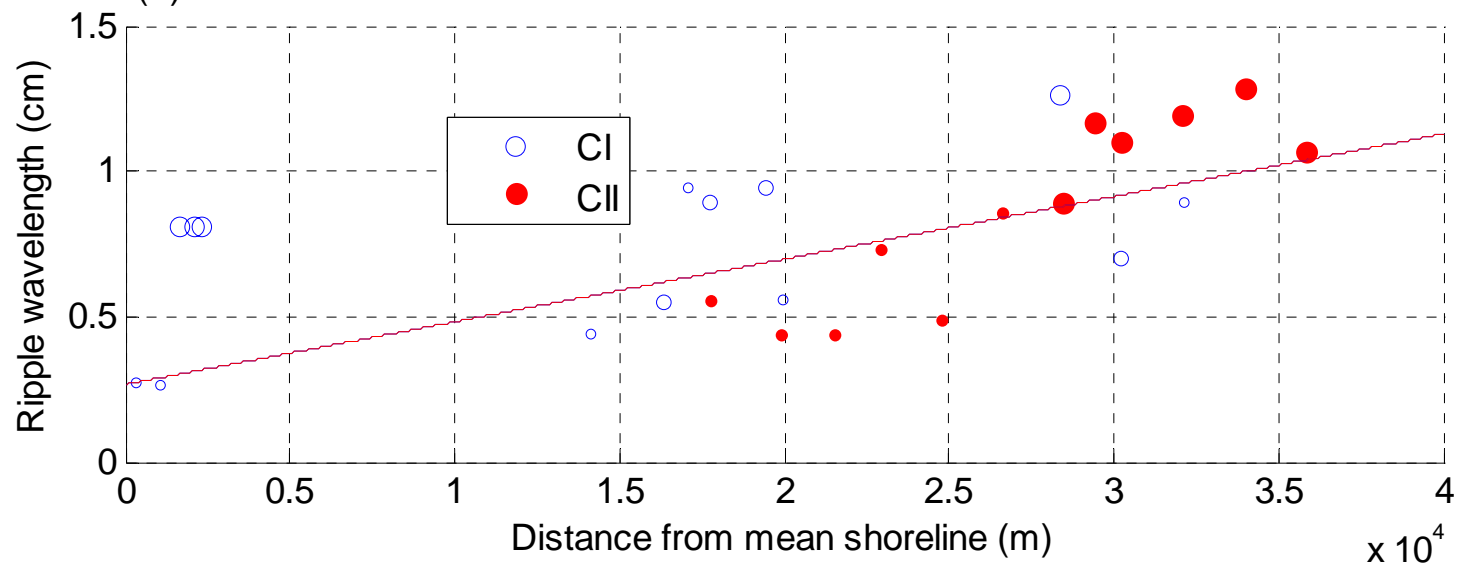

(c)

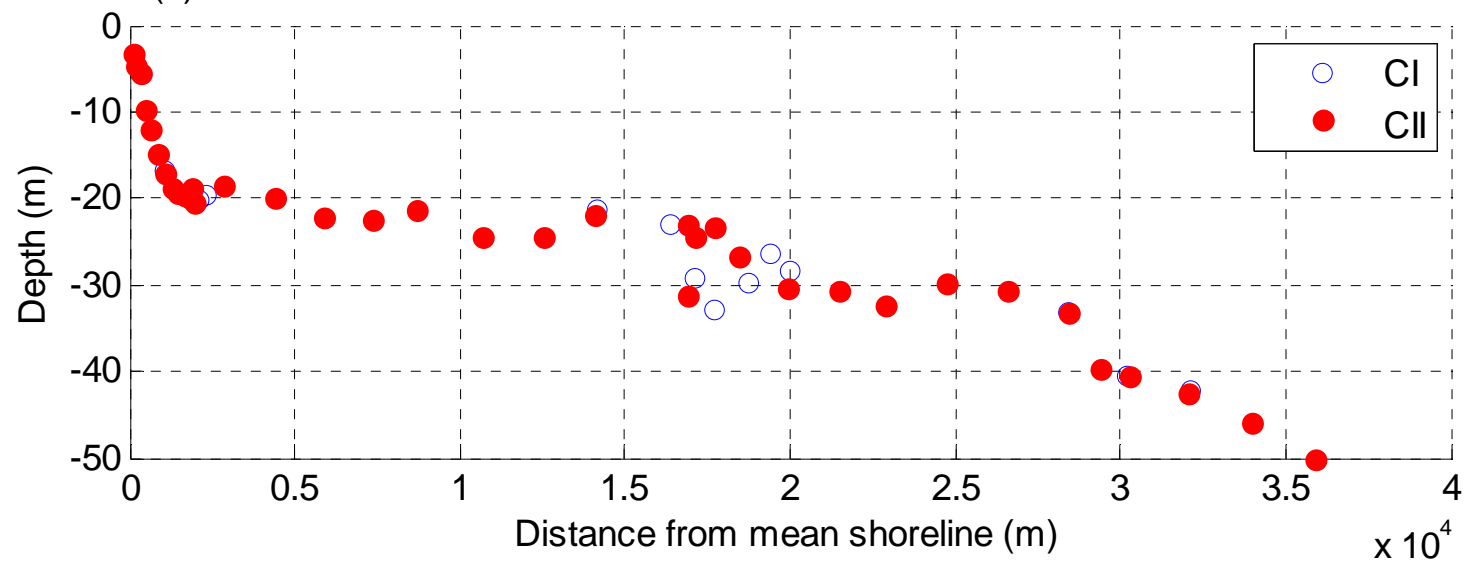

Figure 22. continued 


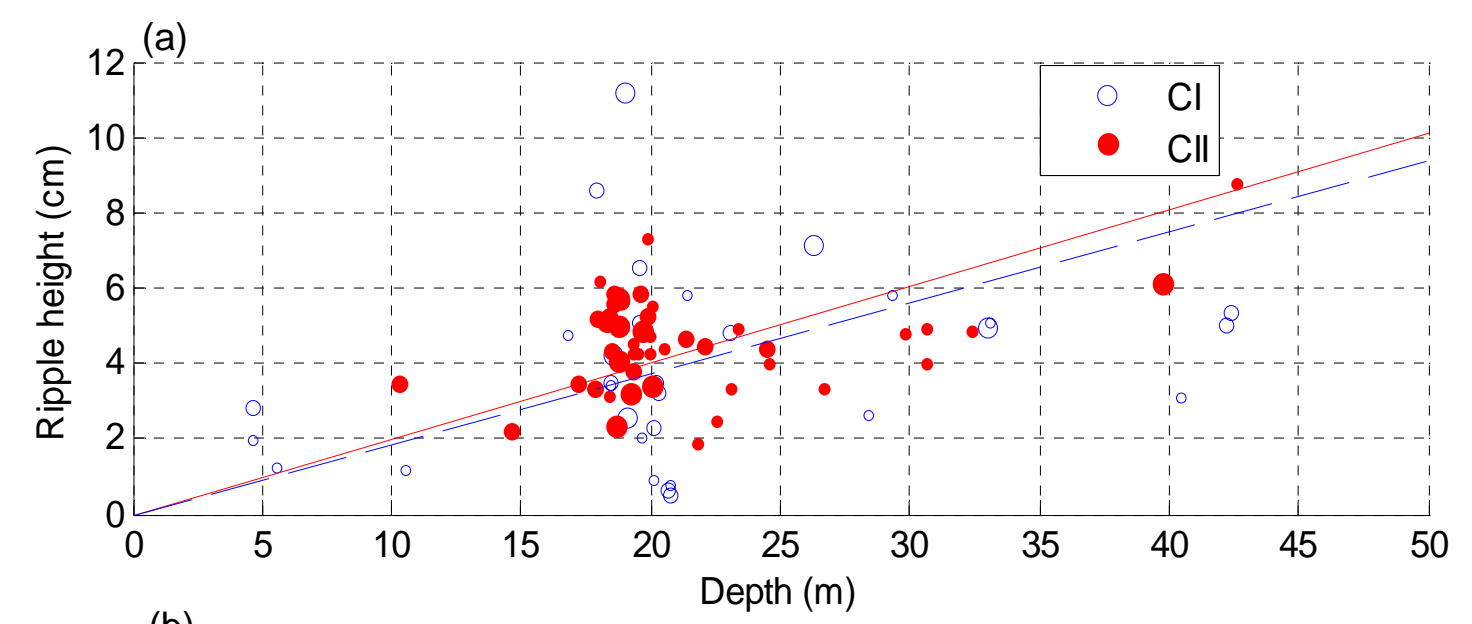

(b)
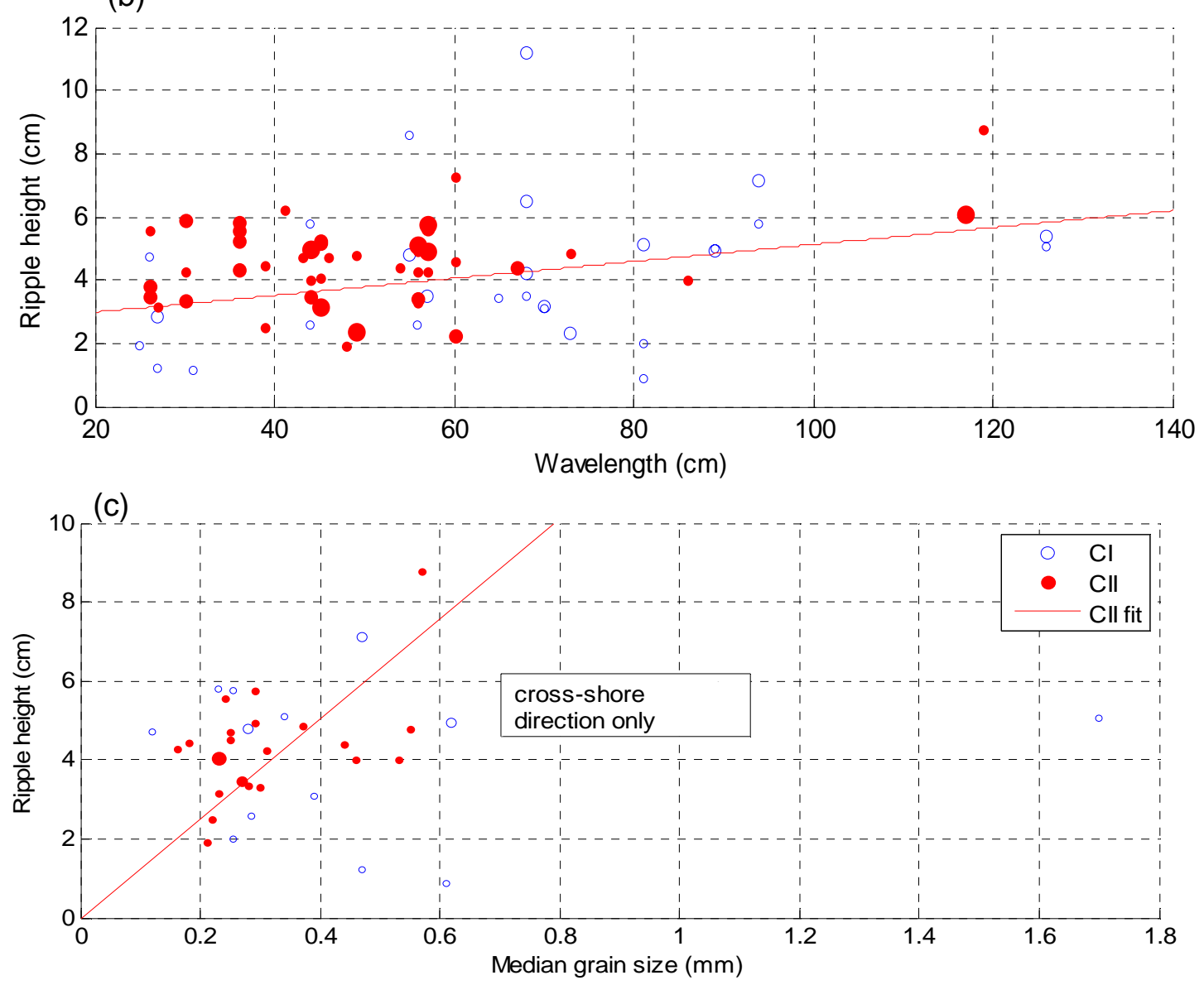

Figure 23. Ripple heights as a function of (a) depth, (b) ripple wavelength, and (c) sediment grain size. Dashed and solid lines are best fits for $\mathrm{Cl}$ and Cll, respectively. 
(a) Cross-shore transect, $\mathrm{Cl}$

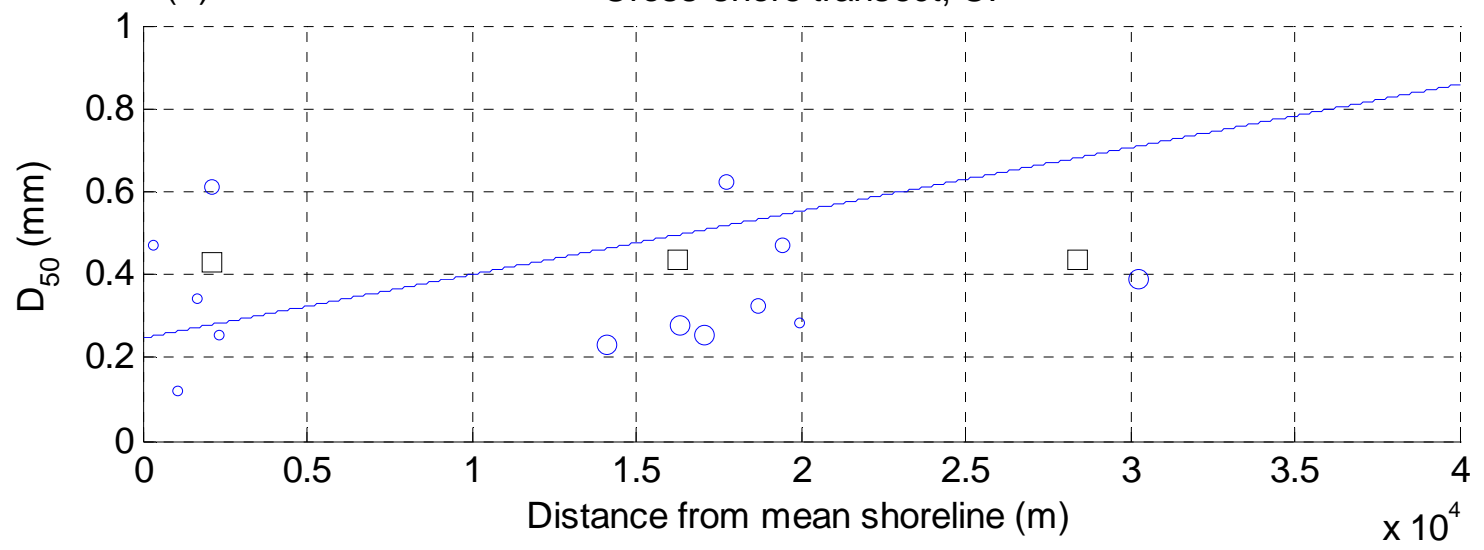

(b) Cross-shore transect, Cll

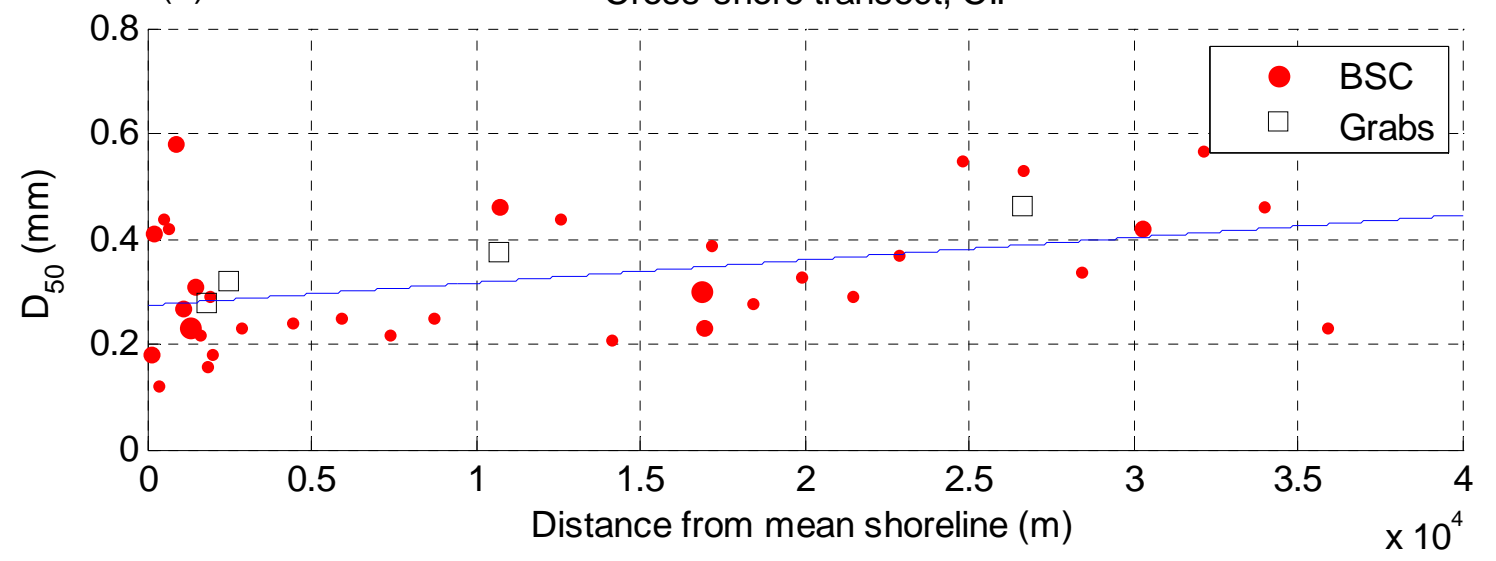

Figure 24. Grain size plotted against cross-shore distance. 
Tables 
Table 1. Mean heading, pitch, and roll measured at each drop (degrees).

\begin{tabular}{|c|c|c|c|c|c|c|c|c|c|}
\hline \multirow[b]{2}{*}{$\begin{array}{l}\text { Station } \\
\text { ID }\end{array}$} & \multicolumn{3}{|c|}{$\mathrm{Cl}$} & \multirow[b]{2}{*}{ Roll } & \multirow[b]{2}{*}{$\begin{array}{l}\text { Station } \\
\text { ID }\end{array}$} & \multicolumn{3}{|c|}{ CII } & \multirow[b]{2}{*}{ Roll } \\
\hline & ADP ID & Heading & Pitch & & & ADP ID & Heading & Pitch & \\
\hline Ala & ND6005 & 136.44 & 0.10 & 1.50 & G1 & ND6060 & 214.38 & -5.85 & 1.22 \\
\hline A1b & ND6006 & 178.49 & -0.60 & 2.80 & G2 & ND6061 & 99.64 & -2.75 & 0.72 \\
\hline A1c & ND6030 & 200.32 & 3.34 & 3.37 & F8 & ND6063 & 156.64 & -4.71 & 0.71 \\
\hline $\mathrm{A} 2$ & ND6007 & 193.69 & -1.50 & 1.50 & F9 & ND6065 & 112.36 & -6.65 & 2.02 \\
\hline A3 & ND6008 & 190.75 & -1.31 & 2.06 & G0 & ND6066 & 341.82 & -5.68 & -0.27 \\
\hline A4 & ND6009 & 139.47 & -1.01 & 2.44 & G3 & ND6068 & 200.66 & -4.22 & 3.11 \\
\hline A5 & ND6010 & 34.94 & -0.51 & 5.08 & G4 & ND6070 & 1.80 & -5.40 & 0.59 \\
\hline A6 & ND6011 & 167.30 & -0.62 & 0.89 & G5 & ND6071 & 178.99 & -4.61 & 1.24 \\
\hline A7 & ND6012 & 214.26 & -1.08 & 2.17 & G6 & ND6072 & 199.17 & -4.78 & 0.20 \\
\hline A8 & ND6013 & 105.48 & 0.42 & 0.31 & G7 & ND6074 & 7.05 & -3.06 & -1.78 \\
\hline A9 & ND6014 & 113.30 & -0.66 & 1.68 & G8 & ND6075 & 168.65 & -3.83 & 0.48 \\
\hline BO & ND6015 & 181.21 & -0.70 & 1.72 & G9 & ND6076 & 218.18 & -5.96 & -0.51 \\
\hline B1 & ND6016 & 238.13 & -0.43 & 1.90 & F3 & ND6077 & 176.87 & -3.54 & 0.10 \\
\hline B2 & ND6017 & 145.98 & 0.00 & 0.91 & HO & ND6078 & 209.59 & -4.47 & 0.22 \\
\hline B3 & ND6018 & 45.62 & -0.52 & 2.04 & H1 & ND6079 & 209.83 & -4.90 & -0.40 \\
\hline B4 & ND6019 & 199.77 & -2.00 & 3.00 & F6 & ND6080 & 230.18 & -4.10 & 0.20 \\
\hline B5 & ND6020 & 297.90 & 0.05 & 1.64 & $\mathrm{H} 2$ & ND6086 & 268.86 & -4.79 & -0.19 \\
\hline B6 & ND6021 & 205.51 & 0.10 & 1.60 & H3 & ND6089 & 9.49 & -4.80 & 0.18 \\
\hline B7 & ND6022 & 291.09 & 1.25 & 2.38 & H4 & ND6090 & 49.86 & -4.22 & 0.17 \\
\hline B8 & ND6024 & 28.10 & 0.10 & 2.39 & H5 & ND6091 & 342.88 & -3.32 & -0.57 \\
\hline B9 & ND6025 & 279.40 & -1.83 & 1.72 & $\mathrm{H} 6$ & ND6092 & 22.82 & -4.09 & 0.18 \\
\hline $\mathrm{CO}$ & ND6026 & 177.25 & -1.09 & 1.68 & H7 & ND6093 & 264.26 & -3.70 & -0.99 \\
\hline C1 & ND6027 & 20.11 & 1.22 & 2.41 & H8 & ND6094 & 291.36 & -4.81 & 0.20 \\
\hline $\mathrm{C} 2$ & ND6028 & 314.43 & 0.00 & 0.00 & H9 & ND6095 & 273.82 & -4.69 & -0.59 \\
\hline C3 & ND6029 & 95.73 & 0.49 & 4.01 & A1 & ND6096 & 262.36 & -4.33 & -0.61 \\
\hline Do & ND6031 & 6.81 & -0.06 & 1.83 & D1 & ND6098 & 253.40 & -4.27 & 0.60 \\
\hline D1 & ND6032 & 177.83 & 1.86 & 4.51 & D3 & ND6099 & 234.82 & -5.15 & 0.00 \\
\hline D2 & ND6033 & 255.07 & 3.04 & 0.72 & D5 & ND6101 & 292.46 & -3.60 & 0.90 \\
\hline D3 & ND6034 & 331.38 & 1.37 & 3.75 & D7 & ND6102 & 304.91 & -4.40 & 0.40 \\
\hline D4 & ND6035 & 235.88 & 0.00 & 0.00 & D9 & ND6103 & 260.71 & -6.67 & -1.70 \\
\hline D5 & ND6037 & 233.68 & 0.22 & 3.07 & E1 & ND6104 & 329.58 & -4.22 & 0.00 \\
\hline D6 & ND6038 & 224.66 & 1.35 & 3.09 & E3 & ND6106 & 135.69 & -4.21 & 0.59 \\
\hline D7 & ND6039 & 219.10 & 2.20 & 4.28 & 10 & ND6108 & 206.81 & -5.52 & -1.41 \\
\hline D8 & ND6040 & 206.95 & -0.91 & 5.65 & I1 & ND6109 & 339.31 & -3.85 & 0.30 \\
\hline D9 & ND6041 & 208.70 & -0.28 & 2.59 & 12 & ND6110 & 65.88 & -3.21 & 0.57 \\
\hline EO & ND6042 & 220.47 & -0.23 & 4.22 & 13 & ND6111 & 8.46 & -4.12 & 0.33 \\
\hline E1 & ND6043 & 218.95 & 1.24 & 3.45 & 14 & ND6113 & 72.77 & -3.99 & 0.90 \\
\hline E2 & ND6044 & 277.04 & 0.29 & 1.97 & 15 & ND6115 & 54.79 & -4.00 & 0.43 \\
\hline E3 & ND6045 & 198.57 & 0.51 & 2.17 & 16 & ND6117 & 50.91 & -4.62 & 1.21 \\
\hline Fo & ND6046 & 54.30 & 2.04 & 4.94 & 17 & ND6119 & 70.88 & -3.43 & 1.82 \\
\hline F1 & ND6049 & 339.12 & 1.44 & 4.92 & 18 & ND6120 & 28.52 & -4.95 & 0.21 \\
\hline F2 & ND6050 & 356.66 & 2.60 & 2.44 & 19 & ND6121 & 212.55 & -3.89 & 0.20 \\
\hline F3 & ND6051 & 3.66 & -1.98 & 3.14 & Jo & ND6122 & 129.10 & -4.66 & -1.34 \\
\hline $\mathrm{F} 4$ & ND6052 & 334.77 & 2.70 & 4.31 & Do & ND6123 & 114.22 & -4.21 & 0.20 \\
\hline
\end{tabular}


Table 1. continued

\begin{tabular}{|c|c|c|c|c|c|c|c|c|c|}
\hline \multirow[b]{2}{*}{$\begin{array}{l}\text { Station } \\
\text { ID }\end{array}$} & \multicolumn{3}{|c|}{$\mathrm{Cl}$} & \multirow[b]{2}{*}{ Roll } & \multirow[b]{2}{*}{$\begin{array}{c}\text { Station } \\
\text { ID }\end{array}$} & \multicolumn{3}{|c|}{ CII } & \multirow[b]{2}{*}{ Roll } \\
\hline & ADP ID & Heading & Pitch & & & ADP ID & Heading & Pitch & \\
\hline F5 & ND6053 & 321.34 & 0.10 & 2.01 & D2 & ND6124 & 73.95 & -4.70 & -0.49 \\
\hline F6 & ND6054 & 240.31 & -0.04 & 3.42 & D4 & ND6125 & 349.77 & -4.50 & 0.27 \\
\hline F7 & ND6055 & 145.40 & -1.46 & 2.92 & D6 & ND6126 & 354.44 & -4.65 & 0.50 \\
\hline F8 & ND6057 & 166.48 & -1.93 & 1.20 & D8 & ND6127 & 17.26 & -5.34 & 1.34 \\
\hline F9 & ND6058 & 254.76 & -3.40 & 0.61 & EO & ND6128 & 206.93 & -4.30 & -0.35 \\
\hline \multirow[t]{14}{*}{ G0 } & ND6059 & 243.81 & -0.45 & 3.00 & E2 & ND6130 & 98.06 & -4.72 & -0.42 \\
\hline & & & & & J1 & ND6131 & 351.7 & -5.33 & -0.12 \\
\hline & & & & & $\mathrm{J} 2$ & ND6133 & 47.68 & -4.46 & 0.59 \\
\hline & & & & & J3 & ND6135 & 35.03 & -5.92 & 0.58 \\
\hline & & & & & J4 & ND6136 & 67.8 & -4.70 & -0.18 \\
\hline & & & & & J5 & ND6138 & 35.52 & -3.65 & 0.90 \\
\hline & & & & & $\mathrm{J} 6$ & ND6139 & 101.36 & -3.95 & 0.77 \\
\hline & & & & & $\mathrm{J7}$ & ND6140 & 6.28 & -3.41 & 0.51 \\
\hline & & & & & $\mathrm{J} 8$ & ND6141 & 307.54 & -4.09 & 0.01 \\
\hline & & & & & j9 & ND6142 & 139.60 & -4.29 & 1.70 \\
\hline & & & & & KO & ND6143 & 18.90 & -3.43 & 0.50 \\
\hline & & & & & K1 & ND6144 & 35.69 & -3.27 & 0.87 \\
\hline & & & & & K2 & ND6145 & 12.85 & -3.73 & 0.20 \\
\hline & & & & & K3 & ND6146 & 254.80 & -4.90 & -0.85 \\
\hline
\end{tabular}


Table 2a. Ripple wavelengths and orientations from INX: $\mathrm{Cl}$

\begin{tabular}{|c|c|c|c|c|c|c|c|c|}
\hline \multirow{2}{*}{$\begin{array}{l}\text { Drop } \\
\text { ID }\end{array}$} & \multicolumn{2}{|c|}{$4 \mathrm{~m}$ scan } & \multicolumn{2}{|c|}{$10 \mathrm{~m}$ scan } & \multirow{2}{*}{$\begin{array}{l}\text { Sweep } \\
\operatorname{radii}^{a}(\mathrm{~m})\end{array}$} & \multicolumn{3}{|c|}{ Employed values } \\
\hline & $\lambda(\mathrm{m})$ & $\theta\left({ }^{\circ}\right)$ & $\lambda(\mathrm{m})$ & $\theta\left({ }^{\circ}\right)$ & & $\lambda(\mathrm{m})$ & $\theta\left(^{\circ}\right)$ & $\begin{array}{c}\text { Sweep } \\
\text { used }\end{array}$ \\
\hline A1a & $-*$ & $-*$ & - & - & 4 & - & - & - \\
\hline A1b & 0.60 & 90 & - & - & $3 / 4$ & 0.60 & 90 & 4 \\
\hline A1c & 0.60 & 90 & - & - & $3 / 4$ & 0.60 & 90 & 1 \\
\hline A2 & 0.27 & 117 & - & - & 4 & 0.27 & 117 & 1 \\
\hline A3 & 0.31 & 121 & - & - & 4 & 0.31 & 121 & 1 \\
\hline A4 & 0.40 & 98 & - & - & 4 & 0.40 & 98 & 1 \\
\hline A5 & 0.30 & 90 & - & - & 4 & 0.30 & 90 & 2 \\
\hline A6 & 0.26 & 90 & - & - & 4 & 0.26 & 90 & 1 \\
\hline A7 & 0.65 & 72 & - & - & 4 & 0.65 & 72 & 1 \\
\hline A8 & 0.81 & 63 & - & - & 4 & 0.81 & 63 & 1 \\
\hline A9 & 0.81 & 63 & - & - & 4 & 0.81 & 63 & 1 \\
\hline B0 & 0.81 & 63 & - & - & 4 & 0.81 & 63 & 1 \\
\hline B1 & 0.73 & 79 & - & - & 4 & 0.73 & 79 & 1 \\
\hline B2 & 0.57 & 74 & - & - & 4 & 0.57 & 74 & 1 \\
\hline B3 & $-*$ & $-*$ & - & - & 4 & - & - & - \\
\hline B4 & $-*$ & -* & - & - & 4 & - & - & - \\
\hline B5 & $-*$ & $-*$ & - & - & 4 & - & - & - \\
\hline B6 & 0.70 & 90 & - & - & 4 & 0.70 & 90 & 1 \\
\hline B7 & -* & $-*$ & 0.94 & 90 & $4 / 10$ & 0.94 & 90 & 2 \\
\hline B8 & $-*$ & $-*$ & - & - & 4 & - & - & - \\
\hline B9 & $-*$ & $-*$ & - & - & 4 & - & - & - \\
\hline $\mathrm{CO}$ & 0.25 & 105 & - & - & 4 & 0.25 & 105 & 1 \\
\hline C1 & -* & $-*$ & - & - & 4 & - & - & - \\
\hline C2 & $-*$ & $-*$ & - & - & 4 & - & - & - \\
\hline C3 & 0.27 & 99 & - & - & 4 & 0.27 & 99 & 1 \\
\hline DO & -* & $-*$ & - & - & 4 & - & - & 2 \\
\hline D1 & 0.78 & 56 & - & - & 4 & 0.78 & 56 & 1 \\
\hline D2 & 0.54 & 65 & - & - & 4 & 0.54 & 65 & 1 \\
\hline D3 & 0.52 & 68 & - & - & 4 & 0.52 & 68 & 1 \\
\hline D4 & 0.68 & 76 & - & - & 4 & 0.68 & 76 & 1 \\
\hline D5 & 0.68 & 76 & - & - & 4 & 0.68 & 76 & 1 \\
\hline D6 & 0.68 & 76 & - & - & 4 & 0.68 & 76 & 1 \\
\hline D7 & 0.55 & 79 & - & - & 4 & 0.55 & 79 & 1 \\
\hline D8 & 0.44 & 80 & - & - & 4 & 0.44 & 80 & 1 \\
\hline D9 & -* & $-*$ & - & - & 4 & - & - & - \\
\hline EO & 0.68 & 76 & - & - & 4 & 0.68 & 76 & 1 \\
\hline
\end{tabular}




\begin{tabular}{|c|c|c|c|c|c|c|c|c|}
\hline \multirow{2}{*}{$\begin{array}{l}\text { Drop } \\
\text { ID }\end{array}$} & \multicolumn{2}{|c|}{$4 \mathrm{~m}$ scan } & \multicolumn{2}{|c|}{$10 \mathrm{~m}$ scan } & \multirow{2}{*}{$\begin{array}{l}\text { Sweep } \\
\text { radii (m) }\end{array}$} & \multicolumn{3}{|c|}{ Employed values } \\
\hline & $\lambda(\mathrm{m})$ & $\theta\left({ }^{\circ}\right)$ & $\lambda(\mathrm{m})$ & $\theta\left(^{\circ}\right)$ & & $\lambda(\mathrm{m})$ & $\theta\left(^{\circ}\right)$ & $\begin{array}{c}\text { Sweep } \\
\text { used }\end{array}$ \\
\hline E1 & $-*$ & $-*$ & 0.57 & 72 & $4 / 10$ & 0.57 & 72 & 2 \\
\hline E2 & 0.68 & 76 & 0.73 & 81 & $4 / 10$ & 0.68 & 76 & 2 \\
\hline E3 & 0.68 & 76 & 0.63 & 90 & $4 / 10$ & 0.68 & 76 & 1 \\
\hline Fo & 0.56 & 90 & - & - & $4 / 20$ & 0.56 & 90 & 2 \\
\hline F1 & 0.81 & 63 & 0.94 & 76 & $4 / 10$ & 0.94 & 76 & 2 \\
\hline F2 & -* & $-*$ & - & - & - & - & - & - \\
\hline F3 & $-*$ & $-*$ & 0.89 & 72 & $4 / 10 / 20$ & 0.89 & 72 & 2 \\
\hline F4 & 0.94 & 90 & 0.94 & 90 & $4 / 10 / 20$ & 0.94 & 90 & 3 \\
\hline F5 & 0.55 & 79 & 2.21 & 90 & $4 / 10$ & 0.55 & 79 & 1 \\
\hline F6 & 0.50 & 56 & 0.44 & 72 & $4 / 10 / 20$ & 0.44 & 72 & 2 \\
\hline F7 & 0.89 & 72 & 1.04 & 45 & $4 / 10 / 20$ & 0.89 & 72 & 2 \\
\hline F8 & 0.81 & 63 & 1.26 & 63 & $4 / 10$ & 1.26 & 63 & 2 \\
\hline F9 & 0.70 & 90 & 1.40 & 72 & $4 / 10 / 20$ & 0.70 & 90 & 1 \\
\hline G0 & 1.26 & 63 & 1.23 & 56 & $4 / 10 / 20$ & 1.26 & 63 & 1 \\
\hline
\end{tabular}

image not useable

a $3 / 4$ denotes one $3 \mathrm{~m}$ and one $4 \mathrm{~m}$ sweep. 
Table 2b. Ripple wavelengths and orientations from INX: CII

\begin{tabular}{|c|c|c|c|c|c|c|c|c|}
\hline \multirow{2}{*}{$\begin{array}{l}\text { Drop } \\
\text { ID }\end{array}$} & \multicolumn{2}{|c|}{$4 \mathrm{~m} \mathrm{scan}$} & \multicolumn{2}{|c|}{$10 \mathrm{~m}$ scan } & \multirow{2}{*}{$\begin{array}{l}\text { Sweep } \\
\text { radii (m) }\end{array}$} & \multicolumn{3}{|c|}{ Employed values } \\
\hline & $\lambda(\mathrm{m})$ & $\theta\left(^{\circ}\right)$ & $\lambda(\mathbf{m})$ & $\theta\left(^{\circ}\right)$ & & $\lambda(\mathrm{m})$ & $\theta\left(^{\circ}\right)$ & $\begin{array}{c}\text { Sweep } \\
\text { used }\end{array}$ \\
\hline G1 & 1.07 & 104 & 1.07 & 104 & $4 / 10 / 20$ & 1.07 & 104 & 2 \\
\hline G2 & 0.64 & 45 & 1.29 & 53 & $4 / 10 / 20$ & 1.29 & 53 & 2 \\
\hline F8 & 0.57 & 72 & 1.19 & 68 & $4 / 10 / 20$ & 1.19 & 68 & 2 \\
\hline F9 & 0.64 & 45 & 1.10 & 59 & $4 / 10 / 20$ & 1.10 & 59 & 2 \\
\hline G0 & 0.81 & 63 & 0.89 & 72 & $4 / 10 / 20$ & 0.89 & 72 & 2 \\
\hline G3 & 0.60 & 90 & 1.17 & 90 & $4 / 10 / 20$ & 1.17 & 90 & 2 \\
\hline G4 & 0.81 & 63 & 0.86 & 90 & $4 / 10 / 20$ & 0.86 & 90 & 2 \\
\hline G5 & 0.49 & 90 & 2.21 & 90 & $4 / 10 / 20$ & 0.49 & 90 & 1 \\
\hline G6 & $-*$ & $-*$ & 0.73 & 90 & $4 / 10 / 20$ & 0.73 & 90 & 2 \\
\hline G7 & -* & -* & 0.44 & 90 & $4 / 10 / 20$ & 0.44 & 90 & 2 \\
\hline G8 & $-*$ & $-*$ & 0.44 & 90 & $4 / 10 / 20$ & 0.44 & 90 & 2 \\
\hline G9 & $-*$ & $-*$ & $-*$ & $-*$ & $4 / 10 / 20$ & - & - & - \\
\hline F3 & $-*$ & $-*$ & 0.56 & 117 & $40 / 10 / 20$ & 0.56 & 117 & 2 \\
\hline HO & $-*$ & -* & $-*$ & $-*$ & $4 / 10 / 20$ & - & - & - \\
\hline $\mathrm{H} 1$ & 0.56 & 127 & 1.47 & 90 & $4 / 10 / 20$ & 0.56 & 127 & 3 \\
\hline F6 & 0.48 & 121 & 2.21 & 90 & $4 / 10 / 20$ & 0.48 & 121 & 1 \\
\hline $\mathrm{H} 2$ & - & - & 0.60 & 90 & 20 & 0.60 & 90 & 1 \\
\hline H3 & 0.39 & 74 & 2.21 & 90 & $4 / 10 / 20$ & 0.39 & 74 & 1 \\
\hline H4 & $-*$ & $-*$ & 0.39 & 76 & $4 / 10 / 20$ & 0.39 & 76 & 2 \\
\hline H5 & 0.46 & 99 & 1.47 & 90 & $4 / 10 / 20$ & 0.46 & 99 & 1 \\
\hline $\mathrm{H} 6$ & - & - & 0.44 & 90 & $10 / 20$ & 0.44 & 90 & 2 \\
\hline H7 & 0.67 & 124 & 0.61 & 124 & $4 / 10$ & 0.67 & 124 & 1 \\
\hline H8 & 0.26 & 117 & 0.55 & 120 & $4 / 10 / 20$ & 0.26 & 117 & 3 \\
\hline H9 & 0.27 & 117 & 0.36 & 125 & $4 / 10$ & 0.27 & 117 & 1 \\
\hline$A 1$ & 0.43 & 121 & 0.48 & 131 & $4 / 10 / 20$ & 0.43 & 121 & 3 \\
\hline D1 & 0.57 & 121 & 0.51 & 144 & $4 / 10$ & 0.57 & 121 & 1 \\
\hline D3 & 0.57 & 121 & 1.98 & 63 & $4 / 10 / 20$ & 0.57 & 121 & 3 \\
\hline D5 & 0.30 & 120 & 0.39 & 128 & $4 / 10$ & 0.30 & 120 & 1 \\
\hline D7 & 0.41 & 121 & 2.21 & 90 & $4 / 10 / 20$ & 0.41 & 121 & 3 \\
\hline D9 & $-*$ & -* & $-*$ & -* & $4 / 10 / 20$ & - & - & - \\
\hline E1 & - & - & 0.60 & 117 & $10 / 20$ & 0.60 & 117 & 2 \\
\hline E3 & 0.49 & 104 & 0.54 & 104 & $4 / 10$ & 0.49 & 104 & 1 \\
\hline 10 & $-*$ & -* & - & - & 4 & - & - & - \\
\hline 11 & 0.22 & 90 & -* & $-*$ & $4 / 10$ & 0.22 & 90 & 1 \\
\hline 12 & 0.38 & 51 & 2.21 & 90 & $4 / 10$ & 0.38 & 51 & 2 \\
\hline 13 & 0.34 & 68 & 0.34 & 72 & $4 / 10$ & 0.34 & 72 & 2 \\
\hline 14 & 0.29 & 72 & 0.31 & 82 & $4 / 10$ & 0.29 & 72 & 2 \\
\hline 15 & 0.22 & 83 & 1.10 & 90 & $4 / 10$ & 0.22 & 83 & 1 \\
\hline 16 & 0.44 & 90 & 2.21 & 90 & $4 / 10$ & 0.44 & 90 & 2 \\
\hline 17 & 0.45 & 90 & 2.21 & 90 & $4 / 10$ & 0.45 & 90 & 1 \\
\hline 18 & 0.30 & 90 & 0.55 & 90 & $4 / 10$ & 0.30 & 90 & 2 \\
\hline 19 & - & - & - & - & - & - & - & - \\
\hline J0 & 0.57 & 90 & 2.21 & 90 & $4 / 10$ & 0.57 & 90 & 2 \\
\hline
\end{tabular}


Table 2b. continued.

\begin{tabular}{|c|c|c|c|c|c|c|c|c|}
\hline \multirow{2}{*}{$\begin{array}{l}\text { Drop } \\
\text { ID }\end{array}$} & \multicolumn{2}{|c|}{$4 \mathrm{~m}$ scan } & \multicolumn{2}{|c|}{$10 \mathrm{~m}$ scan } & \multirow{2}{*}{$\begin{array}{l}\text { Sweep } \\
\text { radii (m) }\end{array}$} & \multicolumn{3}{|c|}{ Employed values } \\
\hline & $\lambda(\mathrm{m})$ & $\theta\left(^{\circ}\right)$ & $\lambda(\mathrm{m})$ & $\theta\left({ }^{\circ}\right)$ & & $\lambda(\mathrm{m})$ & $\theta\left(^{\circ}\right)$ & $\begin{array}{c}\text { Sweep } \\
\text { used }\end{array}$ \\
\hline D0 & 0.60 & 90 & 0.54 & 90 & $4 / 10$ & 0.54 & 90 & 3 \\
\hline D2 & 0.26 & 90 & 0.55 & 97 & $4 / 10 / 20$ & 0.26 & 90 & 3 \\
\hline D4 & 0.57 & 108 & 2.21 & 90 & $4 / 10 / 20$ & 0.57 & 108 & 1 \\
\hline D6 & 0.57 & 108 & 0.56 & 110 & $4 / 10 / 20$ & 0.56 & 110 & 2 \\
\hline D8 & 0.25 & 74 & 0.56 & 90 & $4 / 10 / 20$ & 0.56 & 90 & 2 \\
\hline EO & 0.57 & 108 & 0.56 & 124 & $4 / 10 / 20$ & 0.56 & 124 & 2 \\
\hline E2 & 0.50 & 56 & 0.45 & 90 & $4 / 10$ & 0.45 & 90 & 1 \\
\hline $\mathrm{J1}$ & 0.44 & 104 & 0.36 & 99 & $4 / 10 / 20$ & 0.44 & 104 & 3 \\
\hline $\mathrm{J} 2$ & 0.60 & 90 & 1.40 & 162 & $4 / 10 / 20$ & 0.60 & 90 & 3 \\
\hline J3 & 0.36 & 90 & 1.98 & 63 & $4 / 10 / 20$ & 0.36 & 90 & 1 \\
\hline $\mathrm{J4}$ & 0.45 & 90 & 1.47 & 90 & $4 / 10$ & 0.45 & 90 & 3 \\
\hline$J 5$ & 0.36 & 90 & 0.44 & 84 & $4 / 10 / 20$ & 0.36 & 90 & 1 \\
\hline $\mathrm{J} 6$ & 0.36 & 90 & 1.47 & 90 & $4 / 10 / 20$ & 0.36 & 90 & 3 \\
\hline $\mathrm{J7}$ & 0.36 & 90 & 2.21 & 90 & $4 / 10 / 20$ & 0.36 & 90 & 1 \\
\hline J8 & $-*$ & $-*$ & $-*$ & $-*$ & $4 / 10 / 20$ & - & - & 2 \\
\hline$j 9$ & 0.30 & 90 & 1.47 & 90 & $4 / 10 / 20$ & 0.30 & 90 & 1 \\
\hline KO & 0.45 & 90 & 0.49 & 90 & $4 / 10 / 20$ & 0.45 & 90 & 3 \\
\hline K1 & 0.60 & 90 & 2.21 & 90 & $4 / 10 / 20$ & 0.60 & 90 & 1 \\
\hline K2 & 0.26 & 82 & 2.21 & 90 & $4 / 10 / 20$ & 0.26 & 82 & 3 \\
\hline K3 & 0.30 & 99 & 2.21 & 0 & $4 / 10 / 20$ & 0.30 & 99 & 1 \\
\hline
\end{tabular}

* image not useable 
Table 3. Summary of thresholds chosen to extract MTA data

\begin{tabular}{|c|c|c|c|c|c|c|c|}
\hline \multirow{3}{*}{$\begin{array}{c}\begin{array}{c}\text { Drop } \\
\text { ID }\end{array} \\
\text { A1a }\end{array}$} & \multicolumn{3}{|l|}{ Cruise I } & \multicolumn{4}{|c|}{ Cruise II } \\
\hline & \multirow{2}{*}{$\begin{array}{c}\text { Filename } \\
\text { a1s251436.mta }\end{array}$} & \multicolumn{2}{|c|}{$\begin{array}{c}\text { Threshold } \\
\text { value(s) } \\
\text { employed } \\
(\mathrm{mV}) \\
\end{array}$} & \multirow{2}{*}{$\begin{array}{c}\begin{array}{c}\text { Drop } \\
\text { ID }\end{array} \\
\text { G2 }\end{array}$} & \multirow{2}{*}{$\begin{array}{c}\text { Filename } \\
158 \_5833 . \mathrm{mta}\end{array}$} & \multicolumn{2}{|c|}{$\begin{array}{c}\text { Threshold } \\
\text { value(s) } \\
\text { employed } \\
(\mathrm{mV})\end{array}$} \\
\hline & & - & - & & & - & - \\
\hline$A 1 b$ & a1s251523.mta & 400 & - & F8 & 158_5834.mta & 200 & - \\
\hline Alc & a1s271341.mta & 200 & - & F9 & 158_5835.mta & 150 & 200 \\
\hline A2 & a2s251826.mta & 200 & - & G0 & 158_5836.mta & 250 & - \\
\hline A3 & a3s251927.mta & 200 & - & G3 & $158 \_5837 . \mathrm{mta}$ & 200 & 250 \\
\hline A4 & a4s251956.mta & 200 & - & G4 & 158_5838.mta & 150 & 200 \\
\hline A5 & a5s $252020 . \mathrm{mta}$ & 200 & - & G5 & 158_5839.mta & 150 & 200 \\
\hline A6 & a6s252039.mta & 200 & - & G6 & 158_5840.mta & 200 & 250 \\
\hline A7 & a7s252056.mta & 200 & - & G7 & 158_5841.mta & 200 & - \\
\hline A8 & a8s $252115 . \mathrm{mta}$ & 200 & - & G8 & 158_5842.mta & 50 & 100 \\
\hline A9 & a9s252151.mta & 200 & - & G9 & 158_5843.mta & 50 & 100 \\
\hline BO & b0s252210.mta & 200 & - & F3 & 158_5844.mta & 100 & 150 \\
\hline B1 & b1s261315.mta & 200 & - & HO & 158_5845.mta & 300 & 350 \\
\hline B2 & b2s261330.mta & 200 & - & H1 & 158_5846.mta & 50 & 100 \\
\hline B3 & b3s261347.mta & 250 & - & F6 & 158_5847.mta & 50 & 100 \\
\hline B4 & $\mathrm{b} 4 \mathrm{~s} 261407 . \mathrm{mta}$ & 200 & 150 & $\mathrm{H} 2$ & $158 \_5849 . \mathrm{mta}$ & 150 & 200 \\
\hline B5 & b5s261425.mta & 250 & - & H3 & 158_5881.mta & 200 & 250 \\
\hline B6 & b6s261440.mta & 200 & - & H4 & 158_5882.mta & 100 & - \\
\hline B7 & b7s261501.mta & 200 & - & H5 & $158 \_5884 . \mathrm{mta}$ & 150 & - \\
\hline B8 & b8s261520.mta & 300 & 200 & $\mathrm{H} 6$ & 158_5885.mta & 150 & 200 \\
\hline B9 & b9s261600.mta & 250 & - & H7 & 158_5886.mta & 150 & 200 \\
\hline $\mathrm{CO}$ & $\mathrm{c} 0 \mathrm{~s} 262013 . \mathrm{mta}$ & 200 & - & H8 & 158_5891.mta & - & - \\
\hline C1 & $\mathrm{c} 1 \mathrm{~s} 262100 . \mathrm{mta}$ & 250 & - & H9 & 158_5894.mta & 150 & 200 \\
\hline $\mathrm{C} 2$ & $\mathrm{c} 2 \mathrm{~s} 262202 . \mathrm{mta}$ & - & - & A1 & $158 \_5895 . \mathrm{mta}$ & 250 & 300 \\
\hline C3 & $\mathrm{c} 3 \mathrm{~s} 262247 . \mathrm{mta}$ & 200 & - & D1 & 158_5896.mta & 200 & 250 \\
\hline Do & $\mathrm{d} 0 \mathrm{~s} 271406 . \mathrm{mta}$ & 100 & - & D3 & 158_5897.mta & 150 & - \\
\hline D1 & d1s271459.mta & 100 & - & D5 & 158_5898.mta & 150 & - \\
\hline D2 & $\mathrm{d} 2 \mathrm{~s} 271548 . \mathrm{mta}$ & 100 & 150 & D7 & 158_5899.mta & 50 & 100 \\
\hline D3 & $\mathrm{d} 3 \mathrm{~s} 271645 . \mathrm{mta}$ & 100 & 150 & D9 & 158_5900.mta & 250 & - \\
\hline D4 & $\mathrm{d} 4 \mathrm{~s} 271815 . \mathrm{mta}$ & 150 & - & E1 & 159_5901.mta & 150 & 200 \\
\hline D5 & $\mathrm{d} 5 \mathrm{~s} 271910 . \mathrm{mta}$ & 100 & - & E3 & 159_5902.mta & 150 & 200 \\
\hline D6 & d6s271949.mta & 150 & - & 10 & 159_5915.mta & 50 & 100 \\
\hline D7 & $\mathrm{d} 7 \mathrm{~s} 272018 . \mathrm{mta}$ & 150 & - & I1 & 159_5916.mta & 150 & 200 \\
\hline D8 & d8s272053.mta & 150 & - & 12 & 159_5919.mta & 150 & 200 \\
\hline D9 & d9s272106.mta & 100 & 150 & 13 & 159_5922.mta & 150 & 200 \\
\hline EO & e0s272135.mta & 150 & - & 14 & 159_5925.mta & - & - \\
\hline E1 & e1s272151.mta & 150 & 200 & 15 & 159_5926.mta & 150 & 200 \\
\hline E2 & e2s272228.mta & 150 & 200 & 16 & 159_5931.mta & 150 & - \\
\hline E3 & e3s272244.mta & 200 & - & 17 & 159_5932.mta & 150 & - \\
\hline Fo & f0s281409.mta & 150 & 200 & 18 & 159_5934.mta & 150 & 200 \\
\hline F1 & f1s $281430 . \mathrm{mta}$ & 200 & - & 19 & 159_5936.mta & 150 & 200 \\
\hline F2 & $\mathrm{f} 2 \mathrm{~s} 281520 . \mathrm{mta}$ & 200 & - & Jo & 159_5937.mta & - & - \\
\hline F3 & f3s $281606 . \mathrm{mta}$ & 200 & - & Do & 159_5938.mta & - & - \\
\hline
\end{tabular}


Table 3. continued

\begin{tabular}{|c|c|c|c|c|c|c|c|}
\hline \multirow{3}{*}{$\begin{array}{c}\text { Drop } \\
\text { ID }\end{array}$} & \multicolumn{3}{|c|}{ Cruise I } & \multicolumn{4}{|c|}{ Cruise II } \\
\hline & Filename & \multicolumn{2}{|c|}{$\begin{array}{l}\text { Threshold } \\
\text { value(s) } \\
\text { employed } \\
\text { (mV) }\end{array}$} & \multirow{2}{*}{$\begin{array}{c}\begin{array}{c}\text { Drop } \\
\text { ID }\end{array} \\
\text { D2 }\end{array}$} & \multirow{2}{*}{$\begin{array}{c}\text { Filename } \\
159 \quad 5940 . \mathrm{mta}\end{array}$} & \multicolumn{2}{|c|}{$\begin{array}{c}\text { Threshold } \\
\text { value(s) } \\
\text { employed } \\
\text { (mV) }\end{array}$} \\
\hline & $\mathrm{f} 4 \mathrm{~s} 281627 . \mathrm{mta}$ & 200 & - & & & 200 & - \\
\hline F5 & $\mathrm{f} 5 \mathrm{~s} 281704 . \mathrm{mta}$ & 200 & - & D4 & 159 5942.mta & 150 & 200 \\
\hline F6 & f6s281832.mta & 200 & 250 & D6 & 159_5944.mta & 150 & - \\
\hline F7 & $\mathrm{f} 7 \mathrm{~s} 282039 . \mathrm{mta}$ & 200 & - & D8 & $159 \_5945 . \mathrm{mta}$ & 150 & - \\
\hline F8 & f8s $282105 . \mathrm{mta}$ & 200 & - & E0 & 159_5946.mta & 150 & 200 \\
\hline F9 & f9s282138.mta & 200 & - & E2 & 159_5947.mta & 150 & 200 \\
\hline \multirow[t]{13}{*}{ G0 } & $\mathrm{g} 0 \mathrm{~s} 282229 . \mathrm{mta}$ & 250 & - & J1 & 159_5950.mta & 150 & - \\
\hline & & & & $\mathrm{J} 2$ & 159_5951.mta & 150 & - \\
\hline & & & & J3 & 159_5953.mta & 150 & 200 \\
\hline & & & & J4 & 159_5954.mta & 200 & 250 \\
\hline & & & & J5 & $159 \_5955 . \mathrm{mta}$ & 150 & 200 \\
\hline & & & & $\mathrm{J} 6$ & 159_5956.mta & 100 & - \\
\hline & & & & $\mathrm{J7}$ & 159_5957.mta & 100 & - \\
\hline & & & & $\mathrm{J8}$ & 159_5958.mta & 250 & 300 \\
\hline & & & & J9 & 159_5959.mta & 50 & - \\
\hline & & & & KO & 159_5960.mta & 100 & 150 \\
\hline & & & & K1 & 159 5961.mta & 50 & 100 \\
\hline & & & & K2 & 159_5962.mta & 100 & 150 \\
\hline & & & & K3 & $159-5963 . \mathrm{mta}$ & 100 & - \\
\hline
\end{tabular}


Table 4a. Ripple heights, $r_{h}$, obtained with the MTA: Cl

\begin{tabular}{|c|c|c|c|c|c|c|c|c|c|c|}
\hline $\begin{array}{l}\text { Drop } \\
\text { ID }\end{array}$ & $\begin{array}{l}\text { (orig } \\
\text { data) }\end{array}$ & $\begin{array}{l}a(\mathrm{~cm}) \\
\text { (mean of } \\
\text { nghbrs) }\end{array}$ & $\begin{array}{l}\text { (nghbr \& } \\
\text { smthd } \\
\text { data) }\end{array}$ & $\begin{array}{l}\text { (orig } \\
\text { data) }\end{array}$ & $\begin{array}{c}\lambda(\mathrm{cm}) \\
\text { (mean of } \\
\text { nghbrs) }\end{array}$ & $\begin{array}{c}\text { (nghbr \& } \\
\text { smthd } \\
\text { data) }\end{array}$ & $\begin{array}{l}\text { (orig } \\
\text { data) }\end{array}$ & $\begin{array}{c}R^{2} \\
\text { (mean } \\
\text { of } \\
\text { nghbrs) }\end{array}$ & $\begin{array}{c}\text { (nghbr } \\
\& \\
\text { smthd } \\
\text { data) }\end{array}$ & $\begin{array}{c}r_{h} \\
\text { (cm) }\end{array}$ \\
\hline A1a & - & - & - & - & - & - & - & - & - & - \\
\hline A1b & 2.67 & 1.21 & 0.82 & 25.91 & 17.05 & 17.12 & 0.33 & 0.15 & 0.08 & 5.3 \\
\hline A1c & 0.90 & 1.61 & 1.39 & 17.35 & 17.77 & 17.72 & 0.00 & 0.09 & 0.10 & 2.8 \\
\hline A2 & 1.14 & 0.92 & 0.60 & 29.90 & 27.89 & 28.60 & 0.20 & 0.20 & 0.34 & 1.2 \\
\hline A3 & 0.66 & 0.66 & 0.58 & 32.89 & 32.89 & 34.06 & 0.37 & 0.37 & 0.40 & 1.2 \\
\hline A4 & 0.49 & 0.49 & 2.33 & 22.82 & 22.82 & 152.10 & 0.11 & 0.11 & 0.87 & $1.0^{\mathrm{m}}$ \\
\hline A5 & 1.32 & 1.31 & 1.28 & 56.65 & 54.49 & 54.03 & 0.64 & 0.62 & 0.72 & 2.6 \\
\hline A6 & 2.28 & 2.35 & 2.36 & 143.81 & 133.07 & 130.17 & 0.40 & 0.48 & 0.64 & $2.7^{\mathrm{m}}$ \\
\hline A7 & 1.47 & 1.72 & 1.71 & 129.82 & 120.50 & 120.84 & 0.30 & 0.51 & 0.62 & 3.4 \\
\hline A8 & 0.64 & 0.64 & 0.60 & 25.50 & 25.50 & 25.25 & 0.00 & 0.00 & 0.00 & $\mathrm{np}$ \\
\hline A9 & 0.49 & 0.49 & 0.44 & 33.18 & 33.18 & 34.57 & 0.37 & 0.37 & 0.47 & 0.9 \\
\hline B0 & 0.51 & 0.51 & 0.44 & 30.17 & 30.17 & 30.51 & 0.20 & 0.20 & 0.22 & $1.8^{\mathrm{m}}$ \\
\hline B1 & 0.51 & 0.51 & 0.43 & 23.00 & 23.00 & 22.84 & 0.09 & 0.09 & 0.06 & $\mathrm{np}$ \\
\hline B2 & 0.46 & 0.46 & 0.43 & 25.13 & 25.13 & 24.95 & 0.00 & 0.00 & 0.00 & $1.0^{\mathrm{m}}$ \\
\hline B3 & 1.42 & 1.32 & 1.26 & 38.00 & 23.40 & 23.71 & 0.03 & 0.13 & 0.12 & $1.6^{\mathrm{m}}$ \\
\hline B4 & 2.13 & 2.40 & 1.72 & 42.61 & 26.77 & 42.77 & 0.13 & 0.04 & 0.38 & 3.4 \\
\hline B5 & 1.34 & 1.75 & 1.57 & 25.61 & 26.32 & 25.96 & 0.01 & 0.34 & 0.38 & $2.0^{\mathrm{m}}$ \\
\hline B6 & 0.77 & 0.76 & 0.73 & 42.81 & 44.91 & 44.26 & 0.16 & 0.42 & 0.67 & 1.5 \\
\hline B7 & - & - & - & - & - & - & - & - & - & $1.0^{\mathrm{m}}$ \\
\hline B8 & 4.16 & 4.28 & 4.26 & 44.06 & 43.74 & 43.23 & 0.01 & 0.00 & 0.00 & $3.0^{\mathrm{m}}$ \\
\hline B9 & - & - & - & - & - & - & - & - & - & flat \\
\hline Co & 0.98 & 0.98 & 0.85 & 25.96 & 25.96 & 25.68 & 0.41 & 0.41 & 0.45 & 1.7 \\
\hline C1 & 1.27 & 2.08 & 2.00 & 60.56 & 49.54 & 48.76 & 0.16 & 0.66 & 0.81 & 4.0 \\
\hline $\mathrm{C} 2$ & - & - & - & - & - & - & - & - & - & - \\
\hline C3 & 1.56 & 1.50 & 1.42 & 71.11 & 68.15 & 69.20 & 0.37 & 0.64 & 0.86 & 2.9 \\
\hline Do & 4.89 & 4.56 & 4.48 & 44.73 & 44.97 & 44.18 & 0.33 & 0.29 & 0.31 & $5.0^{\mathrm{m}}$ \\
\hline D1 & 3.14 & 3.34 & 3.36 & 162.35 & 164.49 & 167.40 & 0.46 & 0.74 & 0.80 & $4.3^{\mathrm{m}}$ \\
\hline D2 & 2.26 & 2.07 & 2.06 & 167.09 & 176.57 & 178.71 & 0.42 & 0.78 & 0.98 & $\mathrm{np}$ \\
\hline D3 & 1.86 & 1.83 & 1.76 & 47.55 & 47.02 & 46.14 & 0.62 & 0.60 & 0.64 & 3.5 \\
\hline D4 & 1.56 & 1.96 & 1.92 & 45.71 & 43.98 & 43.37 & 0.04 & 0.13 & 0.13 & $\mathrm{np}$ \\
\hline
\end{tabular}


Table 4a. continued

\begin{tabular}{|c|c|c|c|c|c|c|c|c|c|c|}
\hline $\begin{array}{c}\text { Drop } \\
\text { ID }\end{array}$ & $\begin{array}{l}\text { (orig } \\
\text { data) }\end{array}$ & $\begin{array}{c}a(\mathrm{~cm}) \\
\text { (mean of } \\
\text { nghbrs) }\end{array}$ & $\begin{array}{c}\text { (nghbr \& } \\
\text { smthd } \\
\text { data) }\end{array}$ & $\begin{array}{l}\text { (orig } \\
\text { data) }\end{array}$ & $\begin{array}{c}\lambda(\mathrm{cm}) \\
\text { (mean of } \\
\text { nghbrs) }\end{array}$ & $\begin{array}{c}\text { (nghbr \& } \\
\text { smthd } \\
\text { data) }\end{array}$ & $\begin{array}{l}\text { (orig } \\
\text { data) }\end{array}$ & $\begin{array}{c}R^{2} \\
\text { (mean } \\
\text { of } \\
\text { nghbrs) }\end{array}$ & $\begin{array}{c}\text { (nghbr } \\
\& \\
\text { smthd } \\
\text { data) }\end{array}$ & $\begin{array}{c}r_{h} \\
(\mathrm{~cm})\end{array}$ \\
\hline D5 & 2.15 & 2.28 & 2.20 & 48.03 & 45.26 & 44.83 & 0.19 & 0.35 & 0.54 & $\mathrm{np}$ \\
\hline D6 & 7.23 & 7.22 & 7.18 & 318.44 & 286.96 & 287.73 & 0.85 & 0.93 & 0.97 & $\mathrm{np}$ \\
\hline D7 & - & 5.72 & 4.62 & - & 748.24 & 535.86 & - & 0.69 & 0.85 & $\mathrm{np}$ \\
\hline D8 & 1.3 & 1.3 & 1.28 & 96.81 & 96.81 & 97.65 & 0.9 & 0.9 & 0.95 & 2.6 \\
\hline D9 & 1.69 & 0.95 & 0.84 & 80.00 & 31.49 & 37.32 & 0.34 & 0.44 & 0.62 & 1.7 \\
\hline E0 & 2.92 & 3.31 & 3.25 & 120.70 & 119.14 & 122.61 & 0.25 & 0.58 & 0.81 & 6.5 \\
\hline E1 & 1.53 & 1.56 & 1.48 & 43.51 & 43.81 & 43.28 & 0.53 & 0.59 & 0.67 & 3.0 \\
\hline E2 & 7.19 & 7.25 & 7.33 & 304.97 & 297.64 & 307.67 & 0.93 & 0.94 & 0.97 & $\mathrm{np}$ \\
\hline E3 & 2.20 & 2.20 & 2.09 & 57.17 & 57.17 & 56.25 & 0.89 & 0.89 & 0.93 & 4.2 \\
\hline Fo & 0.40 & 0.96 & 0.86 & 24.32 & 38.80 & 39.78 & 0.01 & 0.17 & 0.21 & $\mathrm{np}$ \\
\hline F1 & 1.77 & 1.77 & 1.65 & 56.15 & 56.15 & 56.10 & 0.82 & 0.82 & 0.90 & 3.3 \\
\hline F2 & 2.47 & 1.71 & 1.67 & 47.27 & 43.88 & 43.14 & 0.16 & 0.17 & 0.27 & $2.6^{\mathrm{m}}$ \\
\hline F3 & 1.78 & 1.81 & 1.72 & 44.11 & 45.95 & 44.89 & 0.03 & 0.19 & 0.29 & 3.5 \\
\hline F4 & 1.53 & 1.86 & 1.73 & 45.58 & 51.02 & 50.82 & 0.10 & 0.71 & 0.78 & 3.5 \\
\hline F5 & 2.78 & 2.80 & 2.79 & 80.67 & 90.74 & 92.86 & 0.64 & 0.81 & 0.92 & 5.6 \\
\hline F6 & - & 5.74 & 4.65 & - & 495.67 & 405.97 & - & 0.91 & 0.96 & $\mathrm{np}$ \\
\hline F7 & 4.73 & 5.22 & 4.91 & 49.95 & 45.43 & 46.04 & 0.32 & 0.66 & 0.87 & $\mathrm{np}$ \\
\hline F8 & 3.34 & 3.14 & 3.08 & 61.41 & 53.05 & 53.82 & 0.86 & 0.85 & 0.91 & 6.2 \\
\hline F9 & 2.67 & 1.73 & 1.72 & 125.55 & 139.13 & 139.18 & 0.21 & 0.42 & 0.53 & $\mathrm{np}$ \\
\hline G0 & 2.96 & 2.50 & 2.50 & 177.69 & 141.93 & 148.89 & 0.12 & 0.69 & 0.86 & $\mathrm{np}$ \\
\hline $\min$ & 0.40 & 0.46 & 0.43 & 17.35 & 17.05 & 17.12 & 0.00 & 0.00 & 0.00 & 0.9 \\
\hline $\max$ & 7.23 & 7.25 & 7.33 & 318.44 & 297.64 & 307.67 & 0.93 & 0.94 & 0.98 & 6.5 \\
\hline mean & 2.08 & 2.07 & 2.02 & 72.65 & 68.95 & 72.93 & 0.33 & 0.44 & 0.55 & 3.0 \\
\hline stdev & 1.58 & 1.58 & 1.58 & 67.49 & 64.26 & 66.04 & 0.28 & 0.29 & 0.32 & 1.5 \\
\hline
\end{tabular}

$\mathrm{m}$ digitized manually

np: MTA was nearly parallel with ripple crests and troughs 
Table 4b. Ripple heights, $r_{\mathrm{h}}$, obtained with the MTA: CII

\begin{tabular}{|c|c|c|c|c|c|c|c|c|c|c|}
\hline $\begin{array}{c}\text { Drop } \\
\text { ID }\end{array}$ & $\begin{array}{l}\text { (orig } \\
\text { data) }\end{array}$ & $\begin{array}{c}a(\mathrm{~cm}) \\
\text { (mean } \\
\text { of } \\
\text { nghbrs } \\
\text { ) }\end{array}$ & $\begin{array}{c}\text { (nghbr } \\
\& \\
\text { smthd } \\
\text { data) }\end{array}$ & $\begin{array}{l}\text { (orig } \\
\text { data) }\end{array}$ & $\begin{array}{c}\lambda(\mathrm{cm}) \\
\text { (mean } \\
\text { of } \\
\text { nghbrs) }\end{array}$ & $\begin{array}{c}\text { (nghbr } \\
\& \\
\text { smthd } \\
\text { data) }\end{array}$ & $\begin{array}{l}\text { (orig } \\
\text { data) }\end{array}$ & $\begin{array}{c}R^{2} \\
\text { (mean } \\
\text { of } \\
\text { nghbrs) }\end{array}$ & $\begin{array}{c}\text { (nghbr } \\
\& \\
\text { smthd } \\
\text { data) }\end{array}$ & $\begin{array}{c}r_{h} \\
(\mathrm{~cm})\end{array}$ \\
\hline G1 & 5.46 & 5.75 & 5.82 & 174.02 & 174.98 & 183.54 & 0.74 & 0.75 & 0.99 & $6.8^{\mathrm{m}}$ \\
\hline $\mathrm{G} 2$ & - & - & - & - & - & - & - & - & - & - \\
\hline F8 & 3.04 & 2.66 & 2.62 & 121.42 & 101.12 & 100.86 & 0.29 & 0.75 & 0.87 & 5.2 \\
\hline F9 & 2.34 & 2.25 & 2.19 & 46.7 & 45.75 & 44.87 & 0.35 & 0.58 & 0.61 & 4.4 \\
\hline G0 & 1.37 & 1.2 & 0.97 & 40.56 & 44.91 & 44.65 & 0.1 & 0.28 & 0.33 & 1.9 \\
\hline G3 & 1.03 & 1 & 0.96 & 41.78 & 41.91 & 41.98 & 0 & 0.04 & 0.06 & np \\
\hline G4 & 1.98 & 1.77 & 1.75 & 44.24 & 44.19 & 43.41 & 0.11 & 0.07 & 0.15 & 3.5 \\
\hline G5 & 0.64 & 0.71 & 0.63 & 65.84 & 56.77 & 57.33 & 0.42 & 0.53 & 0.75 & $\mathrm{np}$ \\
\hline G6 & 0.72 & 0.72 & 0.71 & 40.14 & 40.96 & 40.61 & 0.05 & 0.04 & 0.09 & $n p$ \\
\hline G7 & 1.15 & - & - & 45.59 & - & - & 0.01 & - & - & $\mathrm{np}$ \\
\hline G8 & 2.82 & 2.89 & 2.87 & 45 & 44.23 & 43.53 & 0.01 & 0.02 & 0.03 & $\mathrm{np}$ \\
\hline G9 & 3.28 & 3.57 & 3.5 & 44.75 & 45.15 & 44.5 & 0.15 & 0.24 & 0.25 & $3.5^{\mathrm{m}}$ \\
\hline F3 & 0.98 & 0.99 & 0.93 & 46.5 & 50.48 & 49.06 & 0.19 & 0.41 & 0.53 & 1.9 \\
\hline H0 & 4.97 & 4.99 & 5 & 42.38 & 42.42 & 42.12 & 0.09 & 0.09 & 0.12 & 10.0 \\
\hline H1 & 1.78 & 1.24 & 1.24 & 48.18 & 45.02 & 44 & 0.15 & 0 & 0 & 3.6 \\
\hline F6 & 1.75 & 1.81 & 1.81 & 43.64 & 43.5 & 42.9 & 0.02 & 0.05 & 0.07 & 3.6 \\
\hline $\mathrm{H} 2$ & 2.08 & 2 & 1.99 & 43.85 & 43.51 & 42.82 & 0.04 & 0 & 0 & 4.2 \\
\hline $\mathrm{H} 3$ & 1.87 & 1.72 & 1.72 & 46.73 & 44.42 & 43.51 & 0.07 & 0 & 0.01 & $\mathrm{np}$ \\
\hline $\mathrm{H} 4$ & 1.19 & 1.69 & 1.67 & 46.68 & 43.95 & 43.37 & 0 & 0.31 & 0.65 & 3.3 \\
\hline H5 & 1.28 & 1.79 & 1.77 & 46.24 & 45.11 & 44.47 & 0 & 0.02 & 0.05 & $\mathrm{np}$ \\
\hline H6 & 1.17 & 1.3 & 1.3 & 46.73 & 44.04 & 43.07 & 0.01 & 0.01 & 0.02 & $\mathrm{np}$ \\
\hline $\mathrm{H} 7$ & 2.16 & 2.16 & 2.14 & 44.83 & 44.83 & 44 & 0 & 0 & 0 & 4.3 \\
\hline H8 & - & - & - & - & - & - & - & - & - & - \\
\hline H9 & 2.31 & 2.31 & 2.25 & 47.17 & 47.17 & 45.97 & 0.27 & 0.27 & 0.33 & 4.5 \\
\hline A1 & 2.1 & 1.59 & 1.53 & 31.66 & 41.43 & 41.3 & 0.25 & 0.17 & 0.2 & 4.2 \\
\hline D1 & 0.71 & 1.19 & 1.11 & 52.11 & 48.55 & 47.58 & 0.03 & 0.11 & 0.33 & 2.2 \\
\hline D3 & 2.03 & 2.84 & 2.68 & 43.26 & 41.78 & 41.74 & 0.14 & 0.71 & 0.73 & 5.4 \\
\hline D5 & 1.27 & 3.87 & 3.8 & 50.48 & 202.48 & 185.16 & 0.14 & 0.64 & 0.75 & np \\
\hline D7 & 1.63 & 2.08 & 2.03 & 43.93 & 45.59 & 44.9 & 0.05 & 0.43 & 0.44 & $\mathrm{np}$ \\
\hline D9 & 3.23 & 2.87 & 2.92 & 41.48 & 40.75 & 40.34 & 0.03 & 0.03 & 0.03 & 6.5 \\
\hline
\end{tabular}


Table 4b. continued.

\begin{tabular}{|c|c|c|c|c|c|c|c|c|c|c|}
\hline $\begin{array}{c}\text { Drop } \\
\text { ID }\end{array}$ & $\begin{array}{l}\text { (orig } \\
\text { data) }\end{array}$ & $\begin{array}{c}a(\mathrm{~cm}) \\
\text { (mean } \\
\text { of } \\
\text { nghbrs) }\end{array}$ & $\begin{array}{c}\text { (nghbr } \\
\& \\
\text { smthd } \\
\text { data) }\end{array}$ & $\begin{array}{l}\text { (orig } \\
\text { data) }\end{array}$ & $\begin{array}{c}\lambda(\mathrm{cm}) \\
\text { (mean } \\
\text { of } \\
\text { nghbrs) }\end{array}$ & $\begin{array}{c}\text { (nghbr } \\
\& \\
\text { smthd } \\
\text { data) }\end{array}$ & $\begin{array}{l}\text { (orig } \\
\text { data) }\end{array}$ & $\begin{array}{c}R^{2} \\
\text { (mean } \\
\text { of } \\
\text { nghbrs) }\end{array}$ & $\begin{array}{c}\text { (nghbr } \\
\& \\
\text { smthd } \\
\text { data) }\end{array}$ & $\begin{array}{c}r_{h} \\
(\mathbf{c m})\end{array}$ \\
\hline E1 & 2.28 & 2.21 & 2.12 & 45.5 & 46.7 & 46.59 & 0.29 & 0.62 & 0.61 & $\mathrm{np}$ \\
\hline E3 & 0.82 & 1.22 & 0.75 & 30.81 & 70.69 & 30.45 & 0.12 & 0.5 & 0.25 & 2.4 \\
\hline 10 & 5.14 & 4.69 & 4.6 & 44.21 & 43.98 & 43.45 & 0.26 & 0.12 & 0.11 & 10.3 \\
\hline I1 & 0.73 & 1.03 & 0.98 & 33.49 & 44.18 & 43.61 & 0.12 & 0.35 & 0.36 & $\mathrm{np}$ \\
\hline 12 & 0.95 & 0.82 & 0.83 & 48.76 & 58.98 & 41.01 & 0.23 & 0.27 & 0.35 & 1.7 \\
\hline 13 & 1.08 & 1.75 & 1.67 & 49.81 & 47.87 & 47.06 & 0.17 & 0.63 & 0.74 & $\mathrm{np}$ \\
\hline 14 & - & - & - & - & - & - & - & - & - & - \\
\hline 15 & 0.64 & 0.48 & 0.51 & 43.96 & 44.77 & 43.4 & 0.03 & 0.6 & 0.76 & 1.0 \\
\hline 16 & 1.18 & 0.69 & 0.58 & 30.46 & 26.69 & 26.09 & 0.1 & 0 & 0 & 2.3 \\
\hline 17 & 1.88 & 1.79 & 1.7 & 46.17 & 47.63 & 47.55 & 0.38 & 0.51 & 0.68 & 3.4 \\
\hline 18 & 1.94 & 2.46 & 2.39 & 43.61 & 42.49 & 42.54 & 0 & 0 & 0 & 4.9 \\
\hline 19 & 2.42 & 2.42 & 2.36 & 47.26 & 47.26 & 46.13 & 0.24 & 0.24 & 0.23 & 4.8 \\
\hline $\mathrm{JO}$ & - & - & - & - & - & - & - & - & - & - \\
\hline D0 & - & - & - & - & - & - & - & - & - & - \\
\hline D2 & 1.71 & 1.7 & 1.59 & 44.03 & 44.13 & 43.72 & 0.16 & 0.2 & 0.21 & 3.4 \\
\hline D4 & - & - & - & - & - & - & - & - & - & - \\
\hline D6 & 2.78 & 2.45 & 2.34 & 47.01 & 46.43 & 45.91 & 0.55 & 0.7 & 0.68 & $\mathrm{np}$ \\
\hline D8 & 2.86 & 2.34 & 2.31 & 44.2 & 44.43 & 43.69 & 0.18 & 0.14 & 0.16 & 5.7 \\
\hline E0 & 2.03 & 1.73 & 1.72 & 43.16 & 44.41 & 43.35 & 0.06 & 0.02 & 0.07 & 3.4 \\
\hline E2 & 1.53 & 1.6 & 1.56 & 44.76 & 44.98 & 44.14 & 0.12 & 0.15 & 0.18 & 3.1 \\
\hline J1 & 2.81 & 2.54 & 2.52 & 44.16 & 45.05 & 44.18 & 0.04 & 0 & 0 & np \\
\hline $\mathrm{J} 2$ & 2.71 & 2.59 & 2.54 & 46.44 & 44.41 & 43.68 & 0.17 & 0.6 & 0.69 & 5.1 \\
\hline J3 & 1.34 & 1.34 & 1.29 & 43.05 & 43.05 & 42.47 & 0 & 0 & 0 & 2.7 \\
\hline J4 & 1.71 & 1.42 & 1.4 & 45.88 & 43.58 & 43.35 & 0.16 & 0.06 & 0.07 & 3.4 \\
\hline$J 5$ & 1 & 0.76 & 0.77 & 45.39 & 45.47 & 44.43 & 0.03 & 0 & 0 & 2.0 \\
\hline$J 6$ & 3.87 & 1.42 & 1.35 & 196.4 & 47.32 & 46.98 & 0.18 & 0.26 & 0.29 & 3.9 \\
\hline J7 & 1.74 & 1.39 & 1.36 & 44.35 & 45.72 & 44.62 & 0.27 & 0.35 & 0.57 & $\mathrm{np}$ \\
\hline $\mathrm{J8}$ & 4.29 & 3.61 & 3.67 & 41.58 & 41.04 & 40.71 & 0.12 & 0.23 & 0.27 & 7.3 \\
\hline $\mathrm{J9}$ & 1.16 & 1.45 & 1.44 & 45.09 & 47.2 & 46.31 & 0 & 0.05 & 0.05 & 2.9 \\
\hline
\end{tabular}


Table 4b. continued.

\begin{tabular}{|c|c|c|c|c|c|c|c|c|c|c|}
\hline $\begin{array}{l}\text { Drop } \\
\text { ID }\end{array}$ & $\begin{array}{l}\text { (orig } \\
\text { data) }\end{array}$ & $\begin{array}{c}a(\mathrm{~cm}) \\
\text { (mean } \\
\text { of } \\
\text { nghbrs) }\end{array}$ & $\begin{array}{c}\text { (nghbr } \\
\& \\
\text { smthd } \\
\text { data) }\end{array}$ & $\begin{array}{l}\text { (orig } \\
\text { data) }\end{array}$ & $\begin{array}{c}\lambda(\mathrm{cm}) \\
\text { (mean } \\
\text { of } \\
\text { nghbrs) }\end{array}$ & $\begin{array}{c}\text { (nghbr } \\
\& \\
\text { smthd } \\
\text { data) }\end{array}$ & $\begin{array}{l}\text { (orig } \\
\text { data) }\end{array}$ & $\begin{array}{c}R^{2} \\
\text { (mean } \\
\text { of } \\
\text { nghbrs) }\end{array}$ & $\begin{array}{c}\text { (nghbr } \\
\& \\
\text { smthd } \\
\text { data) }\end{array}$ & $\begin{array}{c}r_{h} \\
(\mathbf{c m})\end{array}$ \\
\hline KO & 1.15 & 1.19 & 1.17 & 49.69 & 46.11 & 44.85 & 0.05 & 0.05 & 0.08 & 2.3 \\
\hline K1 & 2.22 & 2.58 & 2.48 & 49.27 & 48.34 & 47.28 & 0.53 & 0.73 & 0.78 & 5.0 \\
\hline K2 & 0.87 & 1.1 & 1.05 & 47.46 & 47.34 & 46.45 & 0.08 & 0.25 & 0.29 & $\mathrm{np}$ \\
\hline K3 & 1.3 & 1.3 & 1.2 & 41.59 & 41.59 & 41.56 & 0.46 & 0.46 & 0.49 & 2.1 \\
\hline $\min$ & 0.64 & 0.48 & 0.51 & 30.46 & 26.69 & 26.09 & 0.00 & 0.00 & 0.00 & 1.0 \\
\hline $\max$ & 5.46 & 5.75 & 5.82 & 196.40 & 202.48 & 185.16 & 0.74 & 0.75 & 0.99 & 10.3 \\
\hline mean & 1.98 & 1.98 & 1.93 & 50.94 & 51.55 & 49.77 & 0.15 & 0.26 & 0.31 & 4.1 \\
\hline stdev & 1.12 & 1.08 & 1.10 & 28.31 & 28.28 & 27.52 & 0.16 & 0.25 & 0.29 & 2.0 \\
\hline
\end{tabular}

${ }^{\mathrm{m}}$ digitized manually

np: MTA was nearly parallel with ripple crests and troughs 
Table 5a. Ripple heights, $r_{\mathrm{h}}$, obtained with the slide projector: $\mathrm{Cl}$

\begin{tabular}{|c|c|c|c|c|c|c|c|c|c|}
\hline \multirow[t]{2}{*}{ Drop ID } & \multicolumn{4}{|c|}{ from rotated slices } & \multicolumn{4}{|c|}{$\begin{array}{c}\text { from slices parallel to sonar } \\
\text { ripple orientation }\end{array}$} & \multirow{2}{*}{$\begin{array}{c}\text { Final } \\
\text { choice } \\
\text { for } r_{h} \\
(\mathrm{~cm})\end{array}$} \\
\hline & $\max$ & std & mean & $\mathbf{N}$ & $\max$ & std & mean & $\mathbf{N}$ & \\
\hline Ala & - & - & - & - & - & - & - & - & $*$ \\
\hline A1b & - & - & - & - & - & - & - & - & $*$ \\
\hline A1c & - & - & - & - & - & - & - & - & $*$ \\
\hline $\mathrm{A} 2$ & - & - & - & - & - & - & - & - & $*$ \\
\hline A3 & - & - & - & - & - & - & - & - & $*$ \\
\hline A4 & - & - & - & - & - & - & - & - & $*$ \\
\hline A5 & - & - & - & - & - & - & - & - & $*$ \\
\hline A6 & - & - & - & - & - & - & - & - & $*$ \\
\hline A7 & - & - & - & - & - & - & - & - & $*$ \\
\hline A8 & - & - & - & - & - & - & - & - & $*$ \\
\hline A9 & - & - & - & - & - & - & - & - & $*$ \\
\hline BO & - & - & - & - & - & - & - & - & $*$ \\
\hline B1 & - & - & - & - & - & - & - & - & $*$ \\
\hline B2 & - & - & - & - & - & - & - & - & $*$ \\
\hline B3 & - & - & - & - & - & - & - & - & $*$ \\
\hline B4 & 12.78 & 3.02 & 11.57 & 91 & 0.77 & 0.31 & 0.61 & 30 & $0.61^{\mathrm{ps}}$ \\
\hline B5 & 19.99 & 14.61 & 4.59 & 64 & 0.68 & 0.19 & 0.49 & 26 & $0.49^{\mathrm{ps}}$ \\
\hline B6 & 17.75 & 6.77 & 6.93 & 77 & 3.87 & 0.20 & 3.19 & 50 & $3.19^{\mathrm{ps}}$ \\
\hline B7 & - & - & - & - & - & - & - & - & $*$ \\
\hline B8 & - & - & - & - & - & - & - & - & $*$ \\
\hline B9 & -6.80 & 4.41 & 10.14 & 4 & 0.75 & 0.08 & 0.46 & 17 & $0.75^{\mathrm{ps}}$ \\
\hline $\mathrm{CO}$ & - & - & - & - & - & - & - & - & $*$ \\
\hline C1 & - & - & - & - & - & - & - & - & $*$ \\
\hline $\mathrm{C} 2$ & - & - & - & - & - & - & - & - & $*$ \\
\hline C3 & - & - & - & - & - & - & - & - & $*$ \\
\hline Do & - & - & - & - & - & - & - & - & $*$ \\
\hline D1 & - & - & - & - & - & - & - & - & $*$ \\
\hline D2 & - & - & - & - & - & - & - & - & $*$ \\
\hline D3 & - & - & - & - & - & - & - & - & $*$ \\
\hline D4 & - & - & - & - & - & - & - & - & $*$ \\
\hline D5 & - & - & - & - & - & - & - & - & $*$ \\
\hline D6 & - & - & - & - & - & - & - & - & $*$ \\
\hline D7 & - & - & - & - & - & - & - & - & $*$ \\
\hline D8 & - & - & - & - & - & - & - & - & $*$ \\
\hline D9 & - & - & - & - & - & - & - & - & $*$ \\
\hline EO & - & - & - & - & - & - & - & - & $*$ \\
\hline E1 & - & - & - & - & - & - & - & - & $*$ \\
\hline E2 & - & - & - & - & - & - & - & - & $*$ \\
\hline E3 & - & - & - & - & - & - & - & - & $*$ \\
\hline Fo & 6.19 & 3.98 & 2.62 & 91 & 2.59 & 0.44 & 1.68 & 52 & $2.59^{\mathrm{ps}}$ \\
\hline
\end{tabular}


Table5a. continued

\begin{tabular}{|c|c|c|c|c|c|c|c|c|c|}
\hline \multirow[t]{2}{*}{ Drop ID } & \multicolumn{4}{|c|}{ from rotated slices } & \multicolumn{4}{|c|}{$\begin{array}{l}\text { from slices parallel to sonar } \\
\text { ripple orientation }\end{array}$} & \multirow{2}{*}{$\begin{array}{c}\text { Final } \\
\text { choice } \\
\text { for } r_{h} \\
(\mathrm{~cm})\end{array}$} \\
\hline & Max & std & mean & $\mathbf{N}$ & $\max$ & std & mean & $\mathbf{N}$ & \\
\hline F1 & 9.85 & 3.39 & 1.97 & 91 & 7.13 & 0.63 & 5.05 & 40 & $5.05^{\mathrm{ps}}$ \\
\hline F2 & - & - & - & - & - & - & - & - & $*$ \\
\hline F3 & 9.41 & 4.33 & 3.30 & 91 & 4.93 & 1.27 & 3.11 & 59 & $4.93^{\mathrm{ps}}$ \\
\hline $\mathbf{F 4}$ & 16.15 & 9.84 & 4.57 & 88 & 5.77 & 0.39 & 4.73 & 29 & $5.77^{\mathrm{ps}}$ \\
\hline F5 & 4.78 & 2.25 & 1.27 & 91 & 3.75 & 1.23 & 2.66 & 33 & $4.78^{\mathrm{rs}}$ \\
\hline F6 & 5.78 & 2.97 & 0.89 & 91 & 1.80 & 0.64 & 1.26 & 48 & $5.78^{\mathrm{rs}}$ \\
\hline F7 & 6.87 & 4.98 & 0.34 & 62 & 5.34 & 2.18 & 4.21 & 11 & $5.34^{\mathrm{rs}}$ \\
\hline F8 & 6.11 & 3.80 & 1.05 & 90 & 5.36 & 0.63 & 3.64 & 21 & $5.36^{\mathrm{ps}}$ \\
\hline F9 & 11.62 & 2.81 & 3.30 & 75 & 3.10 & 0.64 & 2.55 & 14 & $3.10^{\mathrm{ps}}$ \\
\hline G0 & 8.10 & 5.41 & 1.98 & 56 & 5.04 & 0.24 & 4.30 & 30 & $5.04^{\mathrm{ps}}$ \\
\hline
\end{tabular}

* no data available

ps: parallel slices

rs: rotated slices 
Table 5b. Ripple heights, $r_{\mathrm{h}}$, obtained with the slide projector: CII

\begin{tabular}{|c|c|c|c|c|c|c|c|c|c|}
\hline \multirow[t]{2}{*}{ Drop ID } & \multicolumn{4}{|c|}{ from rotated slices } & \multicolumn{4}{|c|}{$\begin{array}{l}\text { from slices parallel to sonar } \\
\text { ripple orientation }{ }^{\mathrm{a}}\end{array}$} & \multirow{2}{*}{$\begin{array}{l}\text { Final } \\
\text { choice } \\
\text { for } r_{h} \\
(\mathbf{c m})\end{array}$} \\
\hline & Max & std & Mean & $\mathbf{N}$ & $\max$ & std & mean & $\mathbf{N}$ & \\
\hline G1 & - & - & - & - & - & - & - & - & $*$ \\
\hline G2 & - & - & - & - & - & - & - & - & $*$ \\
\hline F8 & 10.03 & 3.25 & 9.24 & 44 & 12.66 & 4.59 & 8.76 & 18 & $8.76^{\mathrm{ps}}$ \\
\hline F9 & - & - & - & - & - & - & - & - & $* *$ \\
\hline G0 & - & - & - & - & - & - & - & - & $*$ \\
\hline G3 & 6.88 & 1.56 & 4.57 & 34 & 6.66 & 3.22 & 6.13 & 9 & $6.13^{\mathrm{ps}}$ \\
\hline G4 & 11.07 & 0.42 & 10.25 & 8 & - & - & - & - & $4.00^{\mathrm{m}}$ \\
\hline G5 & 2.12 & 0.16 & 1.56 & 27 & - & - & - & - & $4.80^{\mathrm{m}}$ \\
\hline G6 & 4.85 & 0.52 & 2.57 & 26 & 3.35 & 0.64 & 1.73 & 15 & $4.85^{\mathrm{rs}}$ \\
\hline G7 & - & - & - & - & - & - & - & - & $4.96^{\mathrm{m}}$ \\
\hline G8 & - & - & - & - & - & - & - & - & $* *$ \\
\hline G9 & 10.54 & 3.26 & 10.35 & 10 & - & - & - & - & $3.34^{\mathrm{m}}$ \\
\hline F3 & 2.75 & 0.45 & 1.92 & 38 & - & - & - & - & $4.92^{\mathrm{m}}$ \\
\hline $\mathrm{HO}$ & - & - & - & - & - & - & - & - & $* *$ \\
\hline $\mathrm{H1}$ & 6.81 & 1.13 & 3.32 & 25 & 2.62 & 0.02 & 2.60 & 2 & $3.32^{\mathrm{rs}}$ \\
\hline F6 & 31.81 & 3.32 & 15.08 & 10 & 5.61 & 0.00 & 5.61 & 1 & $1.90^{\mathrm{m}}$ \\
\hline $\mathrm{H} 2$ & - & - & - & - & - & - & - & - & $*$ \\
\hline H3 & 7.89 & 2.45 & 4.07 & 13 & - & - & - & - & $4.50^{\mathrm{m}}$ \\
\hline $\mathrm{H} 4$ & 1.57 & 0.49 & 1.29 & 12 & 2.51 & 0.72 & 1.37 & 24 & $2.51^{\mathrm{ps}}$ \\
\hline H5 & 7.54 & 0.16 & 7.17 & 3 & - & - & - & - & $4.70^{\mathrm{m}}$ \\
\hline $\mathrm{H} 6$ & 11.29 & 3.81 & 9.20 & 20 & - & - & - & - & $4.00^{\mathrm{m}}$ \\
\hline $\mathrm{H7}$ & 10.77 & 0.01 & 10.76 & 2 & 5.14 & 0.51 & 4.38 & 7 & $4.38^{\mathrm{ps}}$ \\
\hline $\mathrm{H8}$ & 5.61 & 2.31 & 5.06 & 43 & 5.56 & 1.81 & 3.48 & 28 & $5.56^{\mathrm{ps}}$ \\
\hline H9 & - & - & - & - & 3.15 & 0.11 & 2.85 & 20 & $3.15^{\mathrm{ps}}$ \\
\hline $\mathrm{A} 1$ & 4.05 & 0.27 & 2.52 & 40 & 24.17 & 3.58 & 4.76 & 30 & $4.76^{\mathrm{ps}}$ \\
\hline D1 & 7.14 & 2.33 & 4.63 & 28 & 7.89 & 1.05 & 4.90 & 22 & $4.90^{\mathrm{ps}}$ \\
\hline D3 & 7.85 & 0.60 & 6.22 & 54 & 7.27 & 2.63 & 5.65 & 39 & $5.65^{\mathrm{ps}}$ \\
\hline D5 & 10.34 & 1.25 & 7.42 & 35 & 8.79 & 2.50 & 5.88 & 23 & $5.88^{\mathrm{ps}}$ \\
\hline D7 & - & - & - & - & 7.26 & 0.38 & 6.23 & 24 & $6.23^{\mathrm{ps}}$ \\
\hline D9 & - & - & - & - & - & - & - & - & $*$ \\
\hline E1 & 3.48 & 1.51 & 2.92 & 18 & 5.15 & 1.97 & 4.57 & 6 & $4.57^{\mathrm{ps}}$ \\
\hline E3 & 4.20 & 1.46 & 2.86 & 41 & 2.90 & 1.00 & 2.38 & 25 & $2.38^{\mathrm{ps}}$ \\
\hline 10 & - & - & - & - & - & - & - & - & $*$ \\
\hline I1 & - & - & - & - & - & - & - & - & $*$ \\
\hline 12 & - & - & - & - & - & - & - & - & $*$ \\
\hline 13 & - & - & - & - & - & - & - & - & $*$ \\
\hline 14 & - & - & - & - & - & - & - & - & $*$ \\
\hline 15 & - & - & - & - & - & - & - & - & $*$ \\
\hline 16 & 11.57 & 5.14 & 10.04 & 36 & 3.59 & 0.03 & 3.48 & 5 & $3.48^{\mathrm{ps}}$ \\
\hline
\end{tabular}


Table 6a. Data Summary: CI

\begin{tabular}{|c|c|c|c|c|c|c|c|c|c|c|c|c|c|c|}
\hline Index & Drop ID & $\begin{array}{c}h^{1} \\
(\mathrm{~m})\end{array}$ & $\begin{array}{l}\text { Lat. } \\
\text { (decima }\end{array}$ & $\begin{array}{c}\text { Long. } \\
\text { degrees) }\end{array}$ & C-S & a-s & $\begin{array}{c}\lambda \\
(\mathrm{cm})\end{array}$ & $\left(\begin{array}{l}\theta^{2} \\
(\mathrm{CCW})\end{array}\right.$ & $\begin{array}{c}\lambda \& \theta \\
\text { QR }\end{array}$ & $\begin{array}{c}r_{h} \\
(\mathrm{~cm})\end{array}$ & $\begin{array}{l}r_{h} \\
Q R\end{array}$ & \multicolumn{2}{|c|}{$\begin{array}{l}\mathrm{D}_{50}^{3} \\
(\mathrm{~mm})\end{array}$} & $\begin{array}{l}\mathrm{D}_{50} \\
\mathrm{QR}\end{array}$ \\
\hline 1 & A1a & 20.43 & 30.3792 & -86.6347 & & $\mathrm{x}$ & - & - & - & - & - & 0.26 & $\mathrm{~ms}$ & 4 \\
\hline 2 & A1b & 20.24 & 30.3795 & -86.6349 & & $\mathrm{x}$ & 60 & 90 & 3 & 5.3 & 2 & 0.24 & fs.m & 3 \\
\hline 3 & A1c & 20.07 & 30.3795 & -86.6347 & & $\mathrm{x}$ & 60 & 90 & 2 & 2.8 & 2 & 0.17 & $\mathrm{fs}, \mathrm{m}$ & 4 \\
\hline 4 & A2 & 5.56 & 30.3938 & -86.6349 & $\mathrm{x}$ & & 27 & 117 & 2 & 1.2 & 2 & 0.47 & $\mathrm{fs}, \mathrm{m}$ & 2 \\
\hline 5 & A3 & 10.57 & 30.3936 & -86.6348 & & & 31 & 121 & 3 & 1.2 & 2 & 0.40 & $\mathrm{~ms}$ & 1 \\
\hline 6 & A4 & 12.28 & 30.3902 & -86.6341 & & & 40 & 98 & 3 & 1.0 & 2 & 0.64 & $\mathrm{fs}, \mathrm{m}$ & 1 \\
\hline 7 & A5 & 14.22 & 30.3887 & -86.6343 & & & 30 & 90 & 2 & - & - & 0.43 & $\mathrm{fs}, \mathrm{m}$ & 4 \\
\hline 8 & A6 & 16.85 & 30.3872 & -86.6345 & $\mathrm{x}$ & & 26 & 90 & 1 & 2.7 & 2 & 0.12 & $\mathrm{~ms}$ & 1 \\
\hline 9 & A7 & 18.48 & 30.3852 & -86.6346 & & & 65 & 72 & 2 & 3.4 & 2 & 0.37 & $\mathrm{fs}$ & 3 \\
\hline 10 & A8 & 19.61 & 30.3818 & -86.6342 & $\mathrm{x}$ & & 81 & 63 & 3 & - & - & 0.34 & $\mathrm{~ms}$ & 1 \\
\hline 11 & A9 & 20.15 & 30.3774 & -86.6345 & $\mathrm{x}$ & & 81 & 63 & 3 & 0.9 & 2 & 0.61 & $\mathrm{~ms}$ & 3 \\
\hline 12 & B0 & 19.69 & 30.3758 & -86.6349 & $\mathrm{x}$ & & 81 & 63 & 4 & 1.8 & 2 & 0.26 & $\mathrm{~ms}$ & 1 \\
\hline 13 & B1 & 20.16 & 30.3785 & -86.6367 & & & 73 & 79 & 4 & - & - & 0.11 & $\mathrm{~ms}$ & 1 \\
\hline 14 & B2 & 20.21 & 30.3783 & -86.6367 & & & 57 & 74 & 4 & 1.0 & 3 & 0.41 & $\mathrm{~ms}$ & 3 \\
\hline 15 & B3 & 20.69 & 30.3787 & -86.6364 & & & - & - & - & 1.6 & 2 & 0.13 & $\mathrm{fs}, \mathrm{m}$ & 1 \\
\hline 16 & B4 & 20.69 & 30.3787 & -86.6363 & & & - & - & - & 0.6 & 3 & 0.11 & $\mathrm{~ms}$ & 1 \\
\hline 17 & B5 & 20.76 & 30.3789 & -86.6365 & & & - & - & - & $0.5 \mathrm{f}$ & 3 & 0.10 & $\mathrm{~ms}$ & 1 \\
\hline 18 & B6 & 20.28 & 30.3788 & -86.6369 & & & 70 & 90 & 4 & 3.2 & 3 & 0.42 & $\mathrm{~ms}$ & 4 \\
\hline 19 & B7 & 20.59 & 30.3795 & -86.6371 & & $\mathrm{x}$ & 94 & 90 & 1 & - & - & 0.10 & $\mathrm{fs}, \mathrm{ms}$ & 1 \\
\hline 20 & B8 & 20.81 & 30.3795 & -86.6368 & & $\mathrm{x}$ & - & - & - & 3.0 & 2 & 0.11 & $\mathrm{~ms}$ & 1 \\
\hline 21 & B9 & 20.80 & 30.3793 & -86.6367 & & $\mathrm{x}$ & - & - & - & 0.8 & 2 & - & - & - \\
\hline 22 & CO & 4.65 & 30.3942 & -86.6348 & & & 25 & 105 & 3 & 1.7 & 2 & 0.30 & fs & 3 \\
\hline 23 & C1 & 2.96 & 30.3952 & -86.6351 & & & - & - & - & 4.0 & 1 & 0.15 & fs & 4 \\
\hline 24 & C2 & 5.93 & 30.3945 & -86.6352 & & & - & - & - & - & - & - & - & - \\
\hline 25 & C3 & 4.66 & 30.3940 & -86.6351 & & & 27 & 99 & 2 & 2.8 & 3 & 0.17 & fs & 4 \\
\hline 26 & Do & 20.47 & 30.3794 & -86.6358 & & $\mathrm{x}$ & - & - & - & 5.0 & 1 & 0.12 & $\mathrm{~ms}$ & 1 \\
\hline 27 & D1 & 19.88 & 30.3799 & -86.6374 & & & 78 & 56 & 2 & 4.3 & 2 & 0.24 & $\mathrm{~ms}$ & 1 \\
\hline
\end{tabular}


Table 6a. continued.

\begin{tabular}{|c|c|c|c|c|c|c|c|c|c|c|c|c|c|c|}
\hline Index & Drop ID & $\begin{array}{c}h^{1} \\
(\mathrm{~m})\end{array}$ & $\begin{array}{l}\text { Lat. } \\
\text { (decima }\end{array}$ & $\begin{array}{c}\text { Long. } \\
\text { legrees) }\end{array}$ & C-s & a-s & $\begin{array}{c}\lambda \\
(\mathrm{cm})\end{array}$ & $\left({ }^{0} \stackrel{\theta^{2}}{C C W}\right)$ & $\begin{array}{c}\lambda \& \theta \\
\text { QR }\end{array}$ & $\begin{array}{c}r_{h} \\
(\mathrm{~cm})\end{array}$ & $\begin{array}{l}r_{h} \\
Q R\end{array}$ & \multicolumn{2}{|c|}{$\begin{array}{l}D_{50}{ }^{3} \\
(\mathrm{~mm})\end{array}$} & $\begin{array}{l}D_{50} \\
\text { QR }\end{array}$ \\
\hline 28 & D2 & 19.10 & 30.3795 & -86.6391 & & $\mathrm{x}$ & 54 & 65 & 3 & - & - & 0.30 & $\mathrm{~s}$ & 4 \\
\hline 29 & D3 & 18.95 & 30.3795 & -86.6408 & & $\mathrm{x}$ & 52 & 68 & 2 & 3.5 & 3 & 0.37 & $\mathrm{~s}, \mathrm{~m}$ & 3 \\
\hline 30 & D4 & 18.48 & 30.3795 & -86.6425 & & $\mathrm{x}$ & 68 & 76 & 1 & - & - & 0.37 & s & 4 \\
\hline 31 & D5 & 18.34 & 30.3797 & -86.6440 & & $\mathrm{x}$ & 68 & 76 & 3 & - & - & 0.19 & $\mathrm{~ms}$ & 1 \\
\hline 32 & D6 & 17.92 & 30.3793 & -86.6454 & & $\mathrm{x}$ & 68 & 76 & 3 & - & - & 0.43 & $\mathrm{~s}$ & 3 \\
\hline 33 & D7 & 17.93 & 30.3793 & -86.6468 & & $\mathrm{x}$ & 55 & 79 & 3 & - & - & 0.34 & $\mathrm{~s}$ & 4 \\
\hline 34 & D8 & 19.08 & 30.3795 & -86.6486 & & $\mathrm{x}$ & 44 & 80 & 2 & 2.6 & 3 & 0.34 & $\mathrm{~s}$ & 3 \\
\hline 35 & D9 & 20.55 & 30.3796 & -86.6499 & & $\mathrm{x}$ & - & & - & 1.7 & 2 & 0.11 & $\mathrm{~ms}$ & 1 \\
\hline 36 & E0 & 19.59 & 30.3796 & -86.6515 & & $\mathrm{x}$ & 68 & 76 & 3 & 6.5 & 3 & 0.36 & $\mathrm{~s}, \mathrm{~m}$ & 2 \\
\hline 37 & E1 & 18.96 & 30.3796 & -86.6532 & & $\mathrm{x}$ & 57 & 72 & 3 & 3.0 & 2 & 0.27 & $\mathrm{~s}, \mathrm{~m}$ & 3 \\
\hline 38 & E2 & 19.03 & 30.3792 & -86.6552 & & $\mathrm{x}$ & 68 & 76 & 3 & - & - & 0.34 & $\mathrm{~ms}$ & 2 \\
\hline 39 & E3 & 18.52 & 30.3790 & -86.6562 & & $\mathrm{x}$ & 68 & 76 & 3 & 4.2 & 4 & 0.27 & $\mathrm{~ms}$ & 2 \\
\hline 40 & Fo & 28.44 & 30.2164 & -86.6350 & $\mathrm{x}$ & & 56 & 90 & 1 & 2.6 & 2 & 0.29 & $\mathrm{~s}, \mathrm{~m}$ & 2 \\
\hline 41 & F1 & 26.32 & 30.2214 & -86.6359 & $\mathrm{x}$ & & 94 & 76 & 2 & 5.1 & 4 & 0.47 & s & 3 \\
\hline 42 & F2 & 29.84 & 30.2277 & -86.6322 & $\mathrm{x}$ & & - & - & - & 2.6 & 2 & 0.33 & $\mathrm{~s}, \mathrm{~m}$ & 3 \\
\hline 43 & F3 & 33.00 & 30.2365 & -86.6308 & $\mathrm{x}$ & & 89 & 72 & 2 & 4.9 & 4 & 0.62 & s & 3 \\
\hline 44 & F4 & 29.34 & 30.2422 & -86.6259 & $\mathrm{x}$ & & 94 & 90 & 2 & 5.8 & 2 & 0.26 & $\mathrm{~s}$ & 4 \\
\hline 45 & F5 & 23.06 & 30.2491 & -86.6257 & $\mathrm{x}$ & & 55 & 79 & 3 & 4.8 & 3 & 0.28 & $\mathrm{~s}$ & 4 \\
\hline 46 & F6 & 21.45 & 30.2691 & -86.6354 & $\mathrm{x}$ & & 44 & 72 & 2 & 5.8 & 1 & 0.23 & $\mathrm{~s}$ & 4 \\
\hline 47 & F7 & 42.20 & 30.1066 & -86.6106 & $\mathrm{x}$ & & 89 & 72 & 1 & 5.2 & 3 & - & - & - \\
\hline 48 & F8 & 42.40 & 30.1070 & -86.6109 & & & 126 & 63 & 4 & 5.4 & 3 & 0.53 & $\mathrm{~s}$ & 3 \\
\hline 49 & F9 & 40.44 & 30.1238 & -86.6115 & $\mathrm{x}$ & & 70 & 90 & 2 & 3.1 & 2 & 0.39 & $\mathrm{~s}$ & 4 \\
\hline 50 & Go & 33.10 & 30.1403 & -86.6121 & $\mathrm{x}$ & & 126 & 63 & 4 & 5.0 & 2 & 1.70 & $\mathrm{~s}$ & 4 \\
\hline
\end{tabular}

measured at time of survey (not corrected for tide level)

2 counter clockwise from East (arithmetic coordinates)

3 footnotes refer to sediment descriptions: $f s$ : fine sand; $m$ : mud; $s$ : sand; $s m$ : sand in mud matrix; ms: muddy sand

c-s and a-s refer to cross-shore and along-shore transects, respectively

$\mathrm{QR}$ is a subjective quality rating from 1 to 5 with 5 being the best 
Table 6b. Data summary: CII

\begin{tabular}{|c|c|c|c|c|c|c|c|c|c|c|c|c|c|c|}
\hline \multirow{2}{*}{$\begin{array}{c}\text { Index } \\
1\end{array}$} & \multirow{2}{*}{$\begin{array}{c}\text { Drop ID } \\
\text { G1 }\end{array}$} & \multirow{2}{*}{$\begin{array}{c}\begin{array}{c}h^{1} \\
(\mathbf{m})\end{array} \\
50.00\end{array}$} & \multicolumn{2}{|c|}{$\begin{array}{l}\text { Lat. Long. } \\
\text { (decimal degrees) }\end{array}$} & \multirow{2}{*}{$\frac{\text { C-s }}{x}$} & \multirow{2}{*}{ a-s } & \multirow{2}{*}{$\begin{array}{c}\begin{array}{c}\lambda \\
(\mathbf{c m})\end{array} \\
107\end{array}$} & \multirow{2}{*}{$\begin{array}{c}\left.{ }^{\theta^{2}} \text { CcW }\right) \\
104\end{array}$} & \multirow{2}{*}{$\begin{array}{c}\lambda \& \theta \\
\text { QR } \\
4\end{array}$} & \multirow{2}{*}{$\begin{array}{c}\begin{array}{c}r_{h} \\
(\mathbf{c m})\end{array} \\
11.6\end{array}$} & \multirow{2}{*}{$\begin{array}{c}\mathbf{r}_{\mathrm{h}} \\
\mathbf{Q R} \\
3\end{array}$} & \multicolumn{2}{|c|}{$\begin{array}{c}D_{50}{ }^{3} \\
(\mathrm{~mm})\end{array}$} & \multirow{2}{*}{$\begin{array}{c}\mathbf{D}_{50} \\
\text { QR } \\
1\end{array}$} \\
\hline & & & 30.0729 & -86.6110 & & & & & & & & 0.23 & $\mathrm{sm}$ & \\
\hline 2 & G2 & 46.00 & 30.0898 & -86.6110 & $\mathrm{x}$ & & 129 & 53 & 4 & - & - & 0.46 & $\mathrm{~m}, \mathrm{~s}$ & 2 \\
\hline 3 & F8 & 42.60 & 30.1070 & -86.6113 & $\mathrm{x}$ & & 119 & 68 & 4 & 8.8 & 2 & 0.57 & $\mathrm{sm}$ & 2 \\
\hline 4 & F9 & 40.46 & 30.1236 & -86.6115 & $\mathrm{x}$ & & 110 & 59 & 4 & - & - & 0.42 & $\mathrm{~s}$ & 3 \\
\hline 5 & G0 & 33.30 & 30.1399 & -86.6116 & $\mathrm{x}$ & & 89 & 72 & 4 & - & - & 0.34 & $\mathrm{sm}$ & 1 \\
\hline 6 & G3 & 39.70 & 30.1312 & -86.6115 & $\mathrm{x}$ & & $117 / 86^{*}$ & 90 & 4 & 6.1 & 5 & - & & - \\
\hline 7 & G4 & 30.60 & 30.1565 & -86.6344 & $\mathrm{x}$ & & 86 & 90 & 1 & 4.0 & 1 & 0.53 & $\mathrm{~s}$ & 1 \\
\hline 8 & G5 & 29.76 & 30.1733 & -86.6344 & $\mathrm{x}$ & & 49 & 90 & 1 & 4.8 & 1 & 0.55 & s & 2 \\
\hline 9 & G6 & 32.38 & 30.1901 & -86.6251 & $\mathrm{x}$ & & 73 & 90 & 2 & 4.9 & 2 & 0.37 & $\mathrm{fs}, \mathrm{m}$ & 1 \\
\hline 10 & G7 & 30.58 & 30.2027 & -86.6241 & $\mathrm{x}$ & & 44 & 90 & 1 & 5.0 & 2 & 0.29 & $\mathrm{fs}, \mathrm{m}$ & 1 \\
\hline 11 & G8 & 30.24 & 30.2168 & -86.6239 & $\mathrm{x}$ & & 44 & 90 & 1 & - & - & 0.33 & $\mathrm{fs}, \mathrm{m}$ & 2 \\
\hline 12 & G9 & 26.65 & 30.2304 & -86.6251 & $\mathrm{x}$ & & - & - & - & 3.3 & 1 & 0.28 & $\mathrm{~m}, \mathrm{~s}$ & 1 \\
\hline 13 & F3 & 23.36 & 30.2365 & -86.6303 & $\mathrm{x}$ & & 56 & 117 & 2 & 4.9 & 2 & - & $\mathrm{fs}, \mathrm{m}$ & - \\
\hline 14 & $\mathrm{HO}$ & 31.12 & 30.2441 & -86.6253 & $\mathrm{x}$ & & - & - & - & - & - & 0.23 & $\mathrm{fs}, \mathrm{m}$ & 3 \\
\hline 15 & $\mathrm{H1}$ & 23.11 & 30.2444 & -86.6213 & $\mathrm{x}$ & & 56 & 127 & 2 & 3.3 & 1 & 0.30 & $\mathrm{fs}, \mathrm{m}$ & 4 \\
\hline 16 & F6 & 21.79 & 30.2695 & -86.6348 & $\mathrm{x}$ & & 48 & 121 & 2 & 1.9 & 2 & 0.21 & fs & 2 \\
\hline 17 & $\mathrm{H} 2$ & 24.38 & 30.2420 & -86.6307 & $\mathrm{x}$ & & 60 & 90 & 1 & - & - & 0.39 & fs & 1 \\
\hline 18 & H3 & 22.07 & 30.3435 & -86.6415 & $\mathrm{x}$ & & 39 & 74 & 2 & 4.5 & 2 & 0.25 & fs & 2 \\
\hline 19 & H4 & 22.48 & 30.3301 & -86.6410 & $\mathrm{x}$ & & 39 & 76 & 1 & 2.5 & 2 & 0.22 & fs & 2 \\
\hline 20 & H5 & 21.35 & 30.3183 & -86.6415 & $\mathrm{x}$ & & 46 & 99 & 1 & 4.7 & 3 & 0.25 & $\mathrm{fs}, \mathrm{m}$ & 2 \\
\hline 21 & H6 & 24.51 & 30.2999 & -86.6414 & $\mathrm{x}$ & & 44 & 90 & 1 & 4.0 & 2 & 0.46 & s & 3 \\
\hline 22 & $\mathrm{H7}$ & 24.46 & 30.2833 & -86.6416 & $\mathrm{x}$ & & 67 & 124 & 3 & 4.4 & 3 & 0.44 & fs & 1 \\
\hline 23 & H8 & 20.05 & 30.3568 & -86.6416 & $\mathrm{x}$ & & 26 & 117 & 3 & 5.6 & 1 & 0.24 & fs & 2 \\
\hline 24 & H9 & 18.38 & 30.3708 & -86.6419 & $\mathrm{x}$ & & 27 & 117 & 3 & 3.2 & 1 & 0.23 & $\mathrm{fs}$ & 1 \\
\hline
\end{tabular}


Table 6b. continued.

\begin{tabular}{|c|c|c|c|c|c|c|c|c|c|c|c|c|c|c|}
\hline \multirow{2}{*}{$\begin{array}{c}\text { Index } \\
25\end{array}$} & \multirow{2}{*}{$\begin{array}{c}\text { Drop ID } \\
\text { A1 }\end{array}$} & \multirow{2}{*}{$\begin{array}{c}\begin{array}{c}h^{1} \\
(\mathbf{m})\end{array} \\
19.93\end{array}$} & \multicolumn{2}{|c|}{$\begin{array}{l}\text { Lat. Long. } \\
\text { (decimal degrees) }\end{array}$} & \multirow[t]{2}{*}{ c-s } & \multirow{2}{*}{$\frac{a-s}{x}$} & \multirow{2}{*}{$\begin{array}{c}\begin{array}{c}\lambda \\
(\mathbf{c m})\end{array} \\
43\end{array}$} & \multirow{2}{*}{$\begin{array}{c}{ }^{\theta^{2}} \\
121\end{array}$} & \multirow{2}{*}{$\begin{array}{c}\lambda \& \theta \\
\text { QR }\end{array}$} & \multirow{2}{*}{$\begin{array}{c}\begin{array}{c}r_{h} \\
(\mathbf{c m})\end{array} \\
4.8\end{array}$} & \multirow{2}{*}{$\begin{array}{c}\mathbf{r}_{\mathrm{h}} \\
\mathbf{Q R} \\
2\end{array}$} & \multicolumn{2}{|c|}{$\begin{array}{c}D_{50}{ }^{3} \\
(\mathrm{~mm})\end{array}$} & \multirow{2}{*}{$\begin{array}{r}\mathbf{D}_{50} \\
\mathbf{Q R} \\
2\end{array}$} \\
\hline & & & 30.3795 & -86.6341 & & & & & & & & 0.27 & fs & \\
\hline 26 & D1 & 19.62 & 30.3793 & -86.6376 & & $\mathrm{x}$ & 57 & 121 & 4 & 4.9 & 4 & 0.27 & fs & 3 \\
\hline 27 & D3 & 18.84 & 30.3783 & -86.6403 & & $\mathrm{x}$ & 57 & 121 & 3 & 5.6 & 3 & 0.27 & $\mathrm{fs}, \mathrm{m}$ & 1 \\
\hline 28 & D5 & 18.51 & 30.3795 & -86.6437 & & $\mathrm{x}$ & 30 & 120 & 4 & 5.9 & 3 & 0.33 & $\mathrm{fs}, \mathrm{m}$ & 2 \\
\hline 29 & D7 & 17.98 & 30.3794 & -86.6464 & & $\mathrm{x}$ & 41 & 121 & 4 & 6.2 & 2 & 0.39 & $\mathrm{~m}$ & 1 \\
\hline 30 & D9 & 21.07 & 30.3791 & -86.6501 & & $\mathrm{x}$ & - & - & - & - & 3 & 0.12 & $\mathrm{~m}$ & 1 \\
\hline 31 & E1 & 19.28 & 30.3797 & -86.6528 & & $\mathrm{x}$ & 60 & 117 & 3 & 4.6 & 2 & 0.20 & $\mathrm{fs}, \mathrm{m}$ & 1 \\
\hline 32 & E3 & 18.65 & 30.3783 & -86.6562 & & $\mathrm{x}$ & 49 & 104 & 4 & 2.4 & 4 & 0.70 & fs & 3 \\
\hline 33 & 10 & 3.22 & 30.3955 & -86.6355 & $\mathrm{x}$ & & - & - & - & - & - & 0.18 & fs & 3 \\
\hline 34 & I1 & 4.73 & 30.3947 & -86.6358 & $\mathrm{x}$ & & 22 & 90 & 1 & - & - & 0.41 & fs & 3 \\
\hline 35 & 12 & 5.47 & 30.3937 & -86.6356 & $\mathrm{x}$ & & 38 & 51 & 3 & 1.7 & 2 & 0.12 & fs & 2 \\
\hline 36 & 13 & 9.67 & 30.3923 & -86.6354 & $\mathrm{x}$ & & 34 & 72 & 3 & - & - & 0.44 & fs & 2 \\
\hline 37 & 14 & 12.13 & 30.3907 & -86.6358 & $\mathrm{x}$ & & 29 & 72 & 3 & - & - & 0.42 & fs & 1 \\
\hline 38 & 15 & 14.90 & 30.3887 & -86.6358 & $\mathrm{x}$ & & 22 & 83 & 4 & 1.0 & 2 & 0.58 & $\mathrm{fs}, \mathrm{m}$ & 3 \\
\hline 39 & 16 & 17.19 & 30.3870 & -86.6355 & $\mathrm{x}$ & & 44 & 90 & 4 & 3.5 & 3 & 0.27 & $\mathrm{~ms}$ & 3 \\
\hline 40 & 17 & 18.75 & 30.3852 & -86.6357 & $\mathrm{x}$ & & 45 & 90 & 2 & 4.1 & 4 & 0.23 & $\mathrm{fs}, \mathrm{m}$ & 4 \\
\hline 41 & 18 & 19.43 & 30.3838 & -86.6356 & $\mathrm{x}$ & & 30 & 90 & 3 & 4.3 & 2 & 0.31 & $\mathrm{sm}$ & 3 \\
\hline 42 & 19 & 19.65 & 30.3819 & -86.6354 & $\mathrm{x}$ & & - & - & - & 4.8 & 2 & 0.22 & $\mathrm{sm}$ & 1 \\
\hline 43 & $\mathrm{JO}$ & 19.96 & 30.3804 & -86.6354 & $\mathrm{x}$ & & 57 & 90 & 3 & 4.3 & 2 & 0.16 & $\mathrm{~ms}$ & 1 \\
\hline 44 & DO & 20.48 & 30.3791 & -86.6359 & $\mathrm{x}$ & $\mathrm{x}$ & 54 & 90 & 1 & 4.4 & 2 & 0.18 & $\mathrm{~s}, \mathrm{~m}$ & 1 \\
\hline 45 & D2 & 19.29 & 30.3792 & -86.6394 & & $\mathrm{x}$ & 26 & 90 & 3 & 3.8 & 3 & 0.42 & fs & 1 \\
\hline 46 & D4 & 18.75 & 30.3793 & -86.6427 & $\mathrm{x}$ & $\mathrm{x}$ & 57 & 108 & 4 & 5.7 & 4 & 0.29 & fs & 1 \\
\hline 47 & D6 & 18.32 & 30.3793 & -86.6454 & & $\mathrm{x}$ & 56 & 110 & 4 & 5.1 & 4 & 0.37 & $\mathrm{fs}, \mathrm{m}$ & 1 \\
\hline 48 & D8 & 19.33 & 30.3792 & -86.6488 & & $\mathrm{x}$ & 56 & 90 & 1 & 4.3 & 2 & 0.13 & $\mathrm{~m}, \mathrm{fs}$ & 1 \\
\hline 49 & EO & 20.02 & 30.3798 & -86.6518 & & $\mathrm{x}$ & 56 & 124 & 3 & 3.4 & 4 & 0.25 & $\mathrm{fs}$ & 3 \\
\hline
\end{tabular}


Table 6b. continued.

\begin{tabular}{|c|c|c|c|c|c|c|c|c|c|c|c|c|c|c|}
\hline Index & Drop ID & $\begin{array}{c}h^{1} \\
(\mathrm{~m})\end{array}$ & $\begin{array}{l}\text { Lat. } \\
\text { (decima }\end{array}$ & $\begin{array}{c}\text { Long. } \\
\text { degrees) }\end{array}$ & C-s & a-s & $\begin{array}{c}\lambda \\
(\mathrm{cm})\end{array}$ & $\left({ }^{0} \mathrm{C}\right.$ CW $)$ & $\begin{array}{c}\lambda \& \theta \\
\text { QR }\end{array}$ & $\begin{array}{c}r_{h} \\
(\mathrm{~cm})\end{array}$ & $\begin{array}{l}r_{h} \\
Q R\end{array}$ & $\begin{array}{l}D_{50}{ }^{3} \\
(\mathrm{~mm}\end{array}$ & & $\begin{array}{l}D_{50} \\
\text { QR }\end{array}$ \\
\hline 50 & E2 & 19.21 & 30.3795 & -86.6556 & & $\mathrm{x}$ & 45 & 90 & 4 & 3.2 & 4 & 0.27 & $\mathrm{fs}, \mathrm{m}$ & 3 \\
\hline 51 & $\mathrm{J1}$ & 18.73 & 30.3740 & -86.6430 & & & 44 & 104 & 4 & 5.0 & 4 & 0.35 & fs & 3 \\
\hline 52 & $\mathrm{~J} 2$ & 19.82 & 30.3737 & -86.6504 & & & 60 & 90 & 3 & 7.3 & 2 & 0.22 & fs & 1 \\
\hline 53 & $\mathrm{J3}$ & 18.54 & 30.3768 & -86.6435 & & & 36 & 90 & 4 & 5.6 & 3 & 0.28 & $\mathrm{fs}, \mathrm{m}$ & 1 \\
\hline 54 & $\mathrm{J4}$ & 19.87 & 30.3769 & -86.6512 & & & 45 & 90 & 3 & 5.3 & 3 & 0.35 & $\mathrm{~s}, \mathrm{~m}$ & 2 \\
\hline 55 & $\mathrm{J5}$ & 19.61 & 30.3798 & -86.6524 & & $\mathrm{x}$ & 36 & 90 & 3 & 5.8 & 3 & 0.39 & s & 3 \\
\hline 56 & $\mathrm{J6}$ & 18.41 & 30.3798 & -86.6455 & & $\mathrm{x}$ & 36 & 90 & 4 & 5.3 & 3 & 0.45 & s & 5 \\
\hline 57 & $\mathrm{J7}$ & 18.42 & 30.3823 & -86.6466 & & & 36 & 90 & 4 & 4.3 & 3 & 0.53 & $\mathrm{~s}$ & 1 \\
\hline 58 & $\mathrm{J8}$ & 20.53 & 30.3826 & -86.6540 & & & - & - & - & 7.3 & 1 & 0.30 & $\mathrm{~ms}$ & 3 \\
\hline 59 & $\mathrm{J9}$ & 17.81 & 30.3863 & -86.6546 & & & 30 & 90 & 4 & 3.4 & 3 & 0.36 & $\mathrm{~ms}$ & 2 \\
\hline 60 & KO & 17.88 & 30.3852 & -86.6487 & & & 45 & 90 & 4 & 5.2 & 3 & 0.32 & s & 2 \\
\hline 61 & K1 & 14.58 & 30.3885 & -86.6374 & & & 60 & 90 & 4 & 2.2 & 3 & 0.44 & $\mathrm{~s}$ & 2 \\
\hline 62 & K2 & 10.31 & 30.3917 & -86.6543 & & & 26 & 82 & 4 & 3.5 & 3 & - & $\mathrm{s}, \mathrm{m}$ & - \\
\hline 63 & K3 & 5.85 & 30.3936 & -86.6544 & & & 30 & 99 & 4 & 2.1 & 3 & 0.62 & $\mathrm{~s}, \mathrm{~m}$ & 2 \\
\hline
\end{tabular}

${ }^{1}$ measured at time of survey (not corrected for tide level)

${ }^{2}$ counter clockwise from East (arithmetic coordinates)

${ }^{3}$ footnotes refer to sediment descriptions: $f s$ : fine sand; $m$ : mud; $s$ : sand; sm: sand in mud matrix; ms: muddy sand

c-s and a-s refer to cross-shore and along-shore transects, respectively

QR is a subjective quality rating from 1 to 5 with 5 being the best

* bimodal: 2 wavelengths are evident 


\section{Appendix A: Cruise I Data Summary}

The following pages consist of data images and plots from the INX sonar, multiple transducer array (MTA), slide projector (SP), and bed sediment camera. The MTA bed level is referenced to the horizontal plane passing through the tripod bottom; the slide projector is referenced to a plane approximate parallel and equal to $6 \mathrm{~cm}$ above the base of the tripod. Although more than one sonar image exists for nearly each drop, only the image of highest quality is shown. 


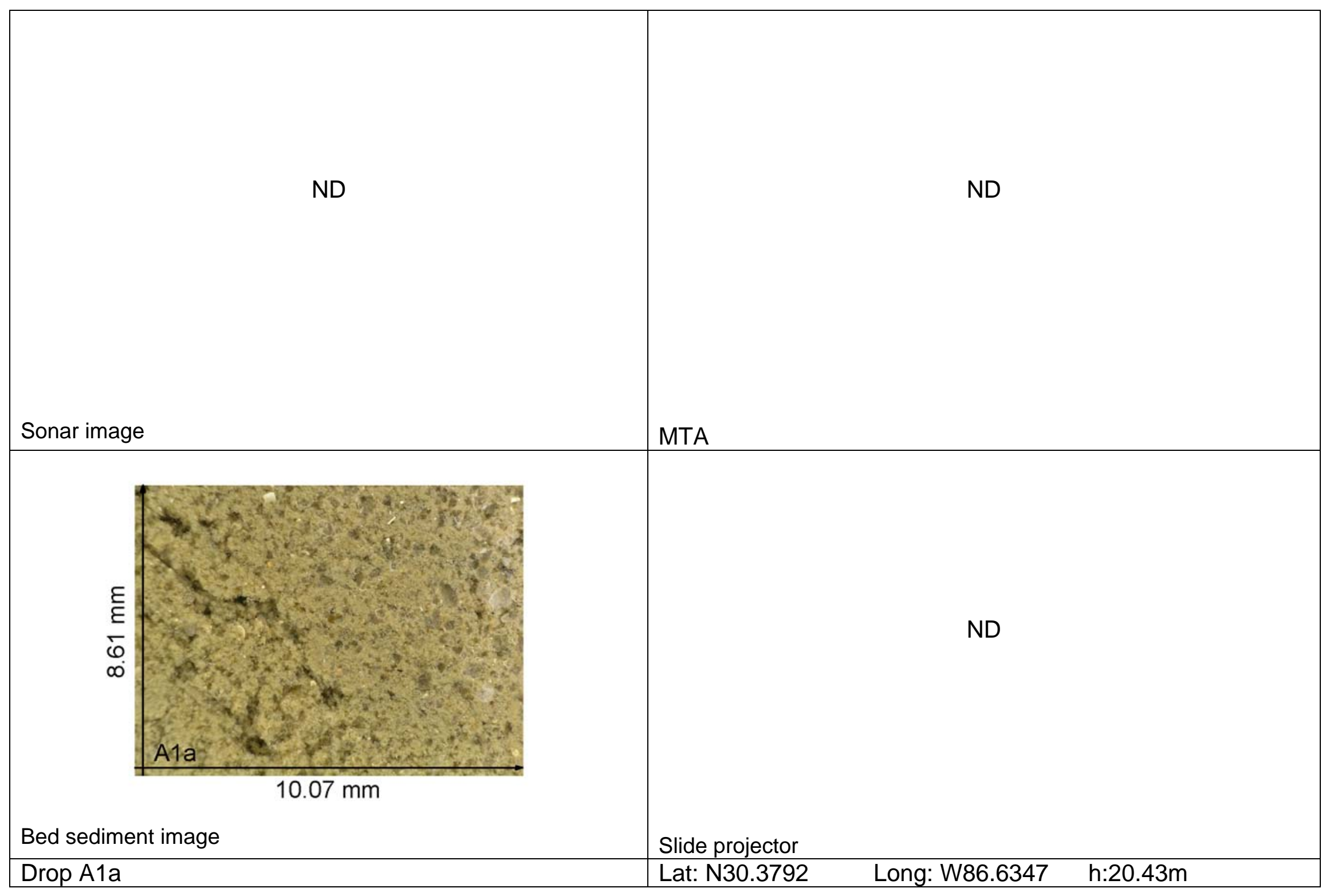




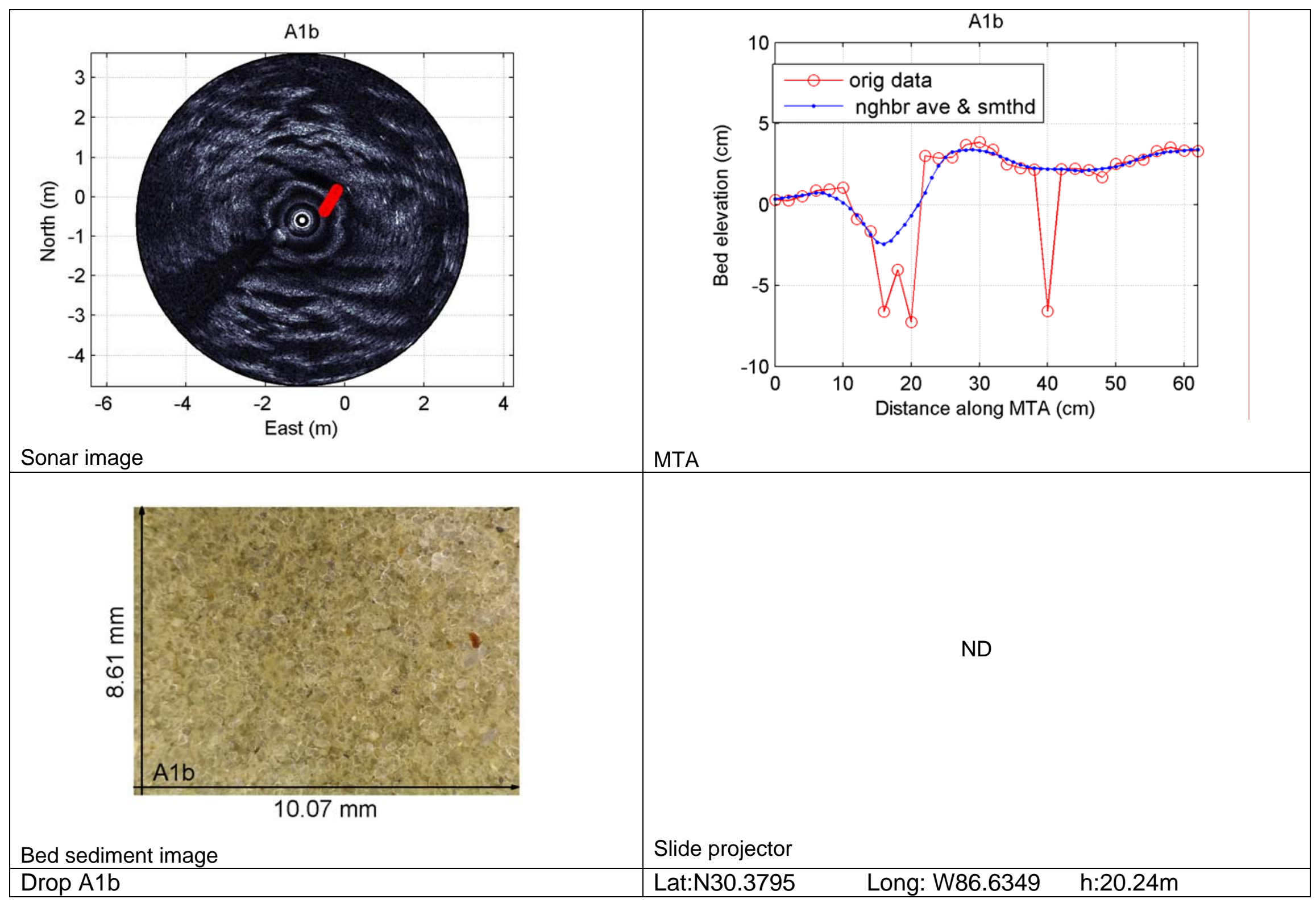




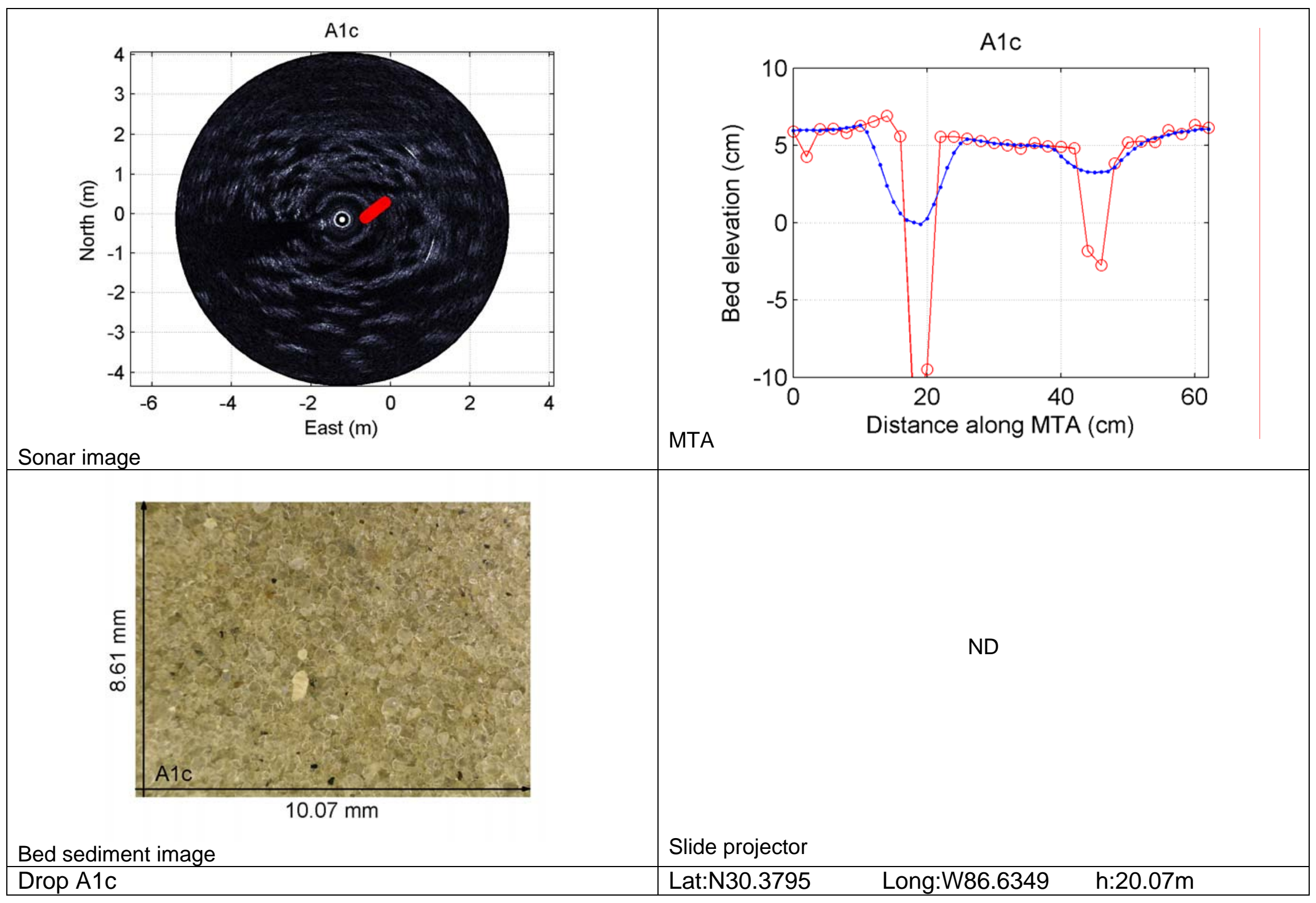




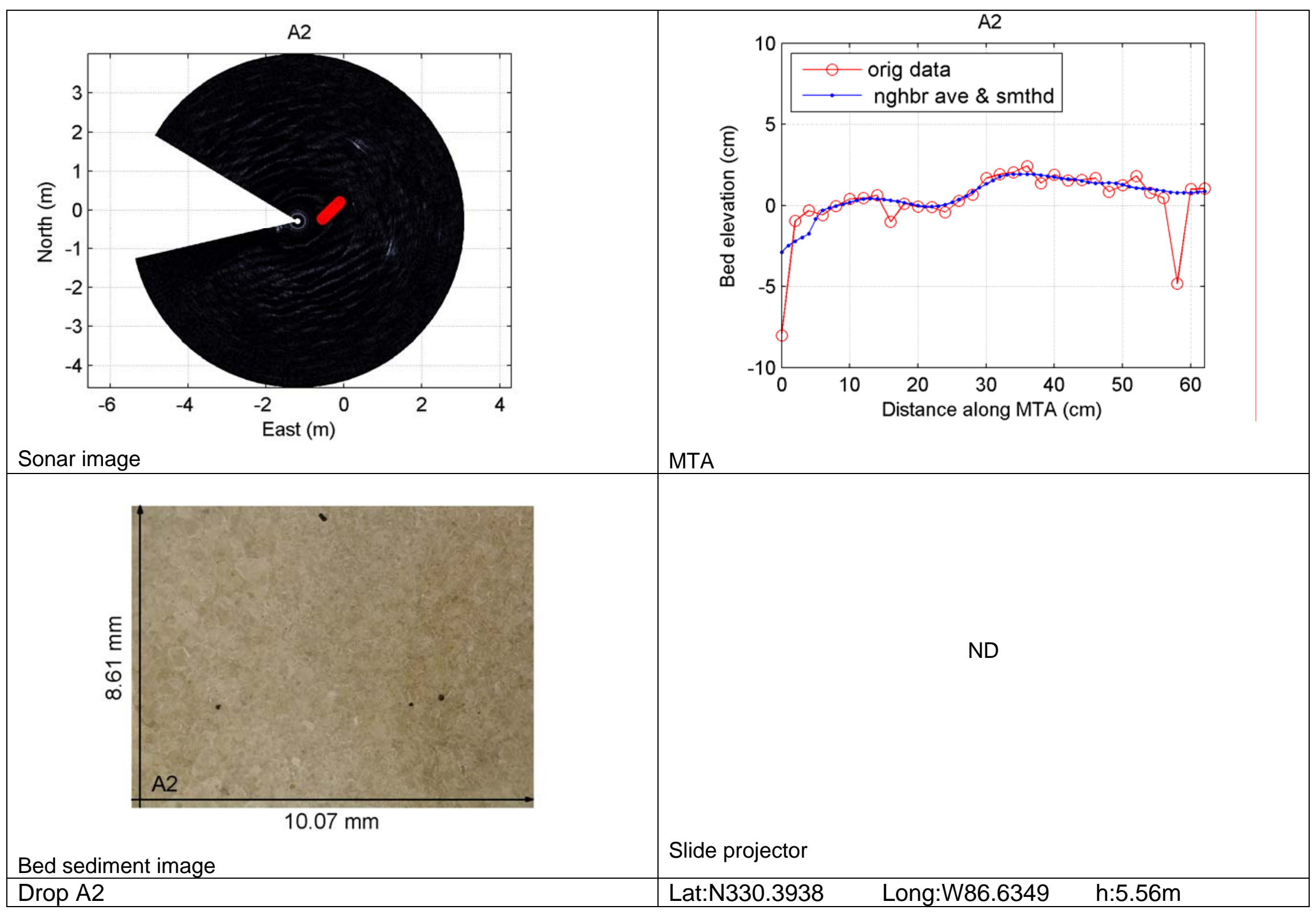




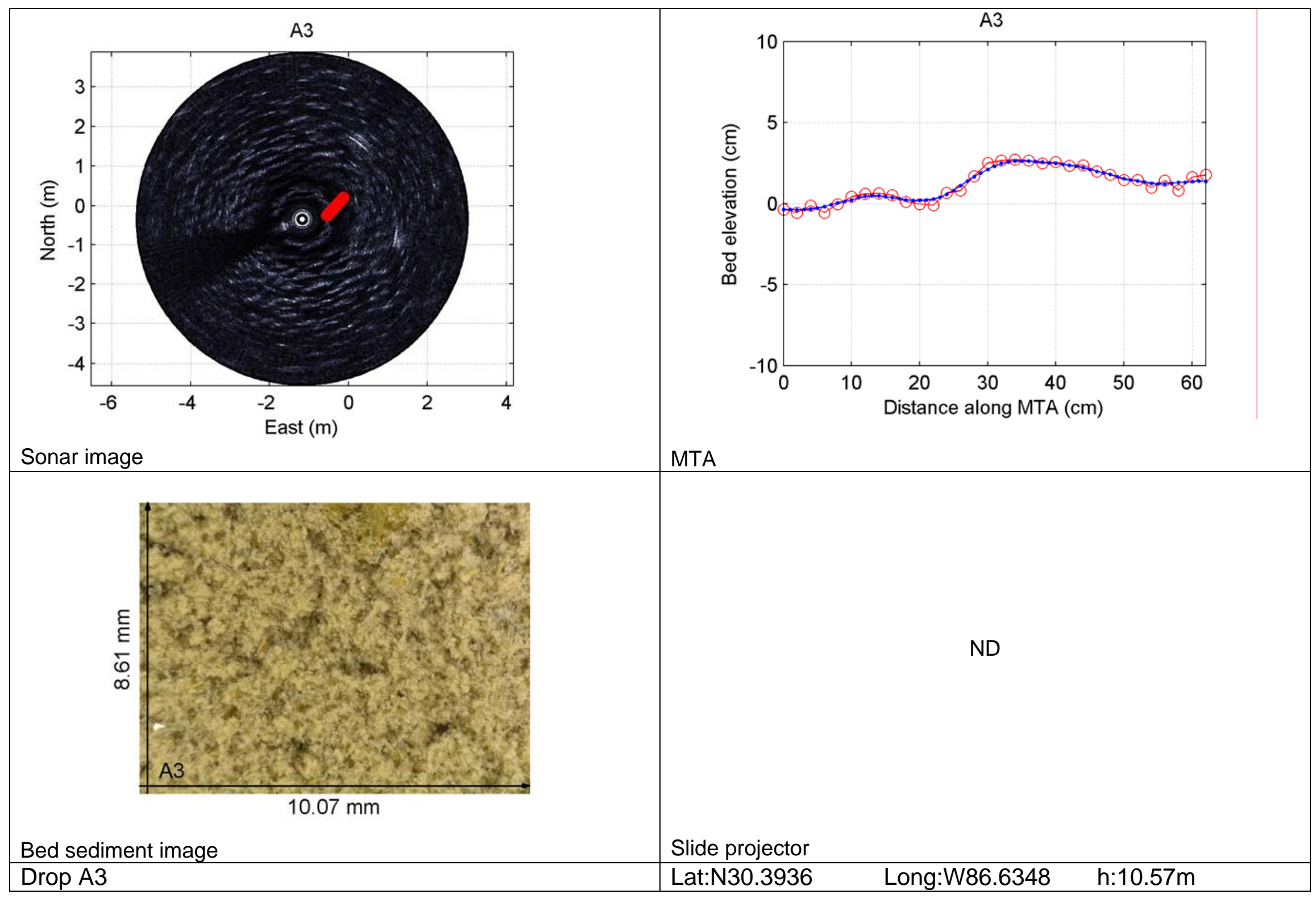




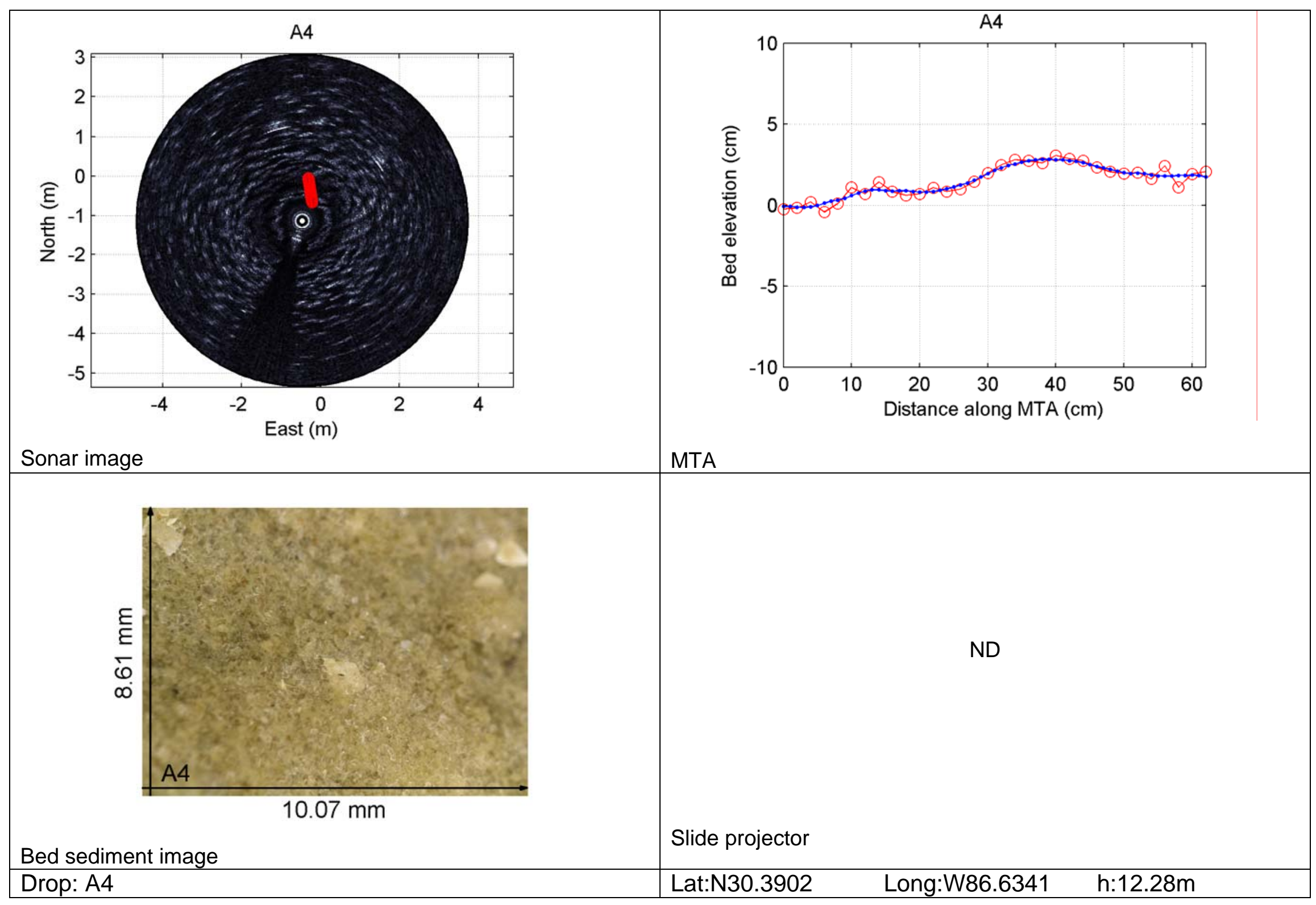




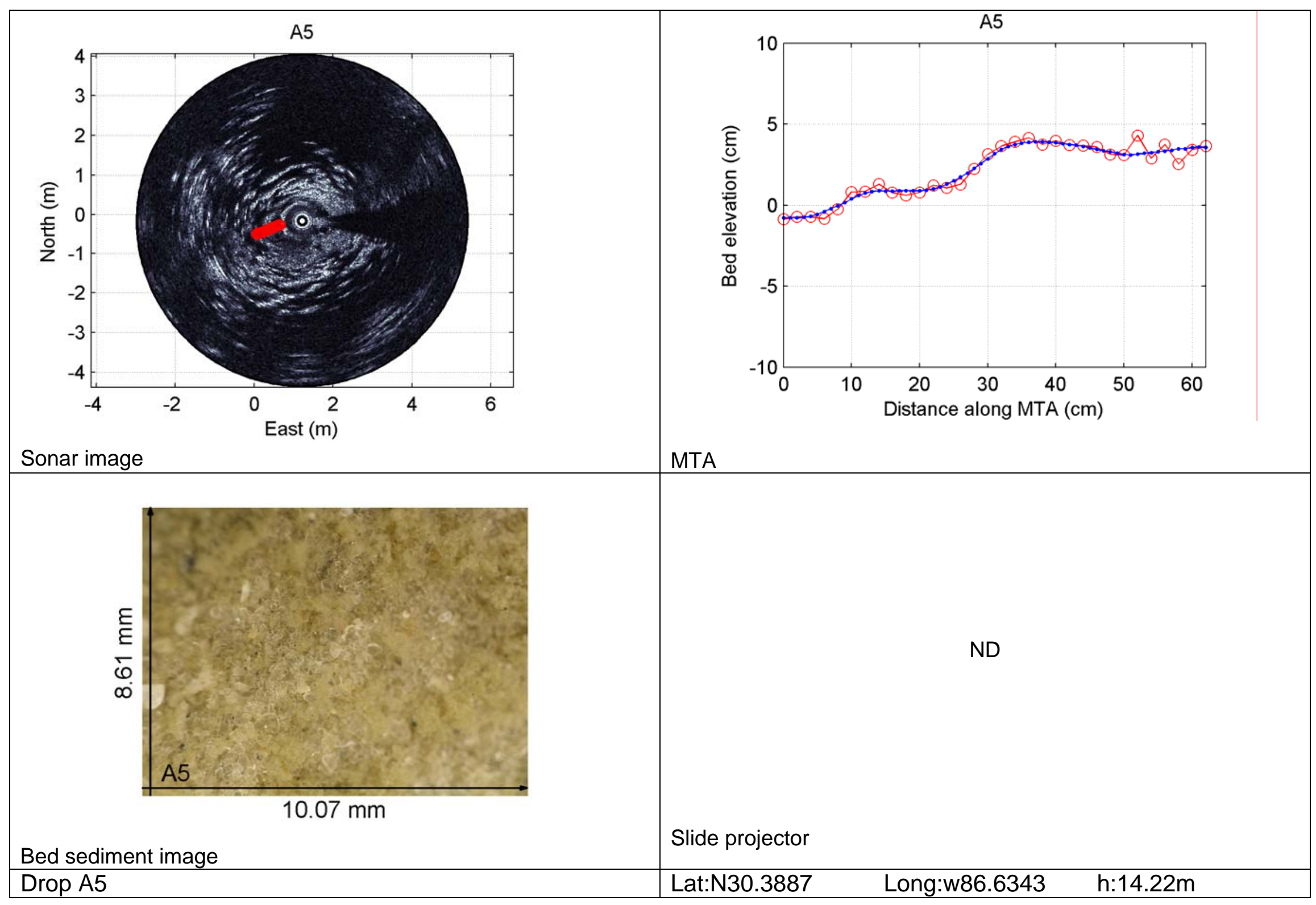




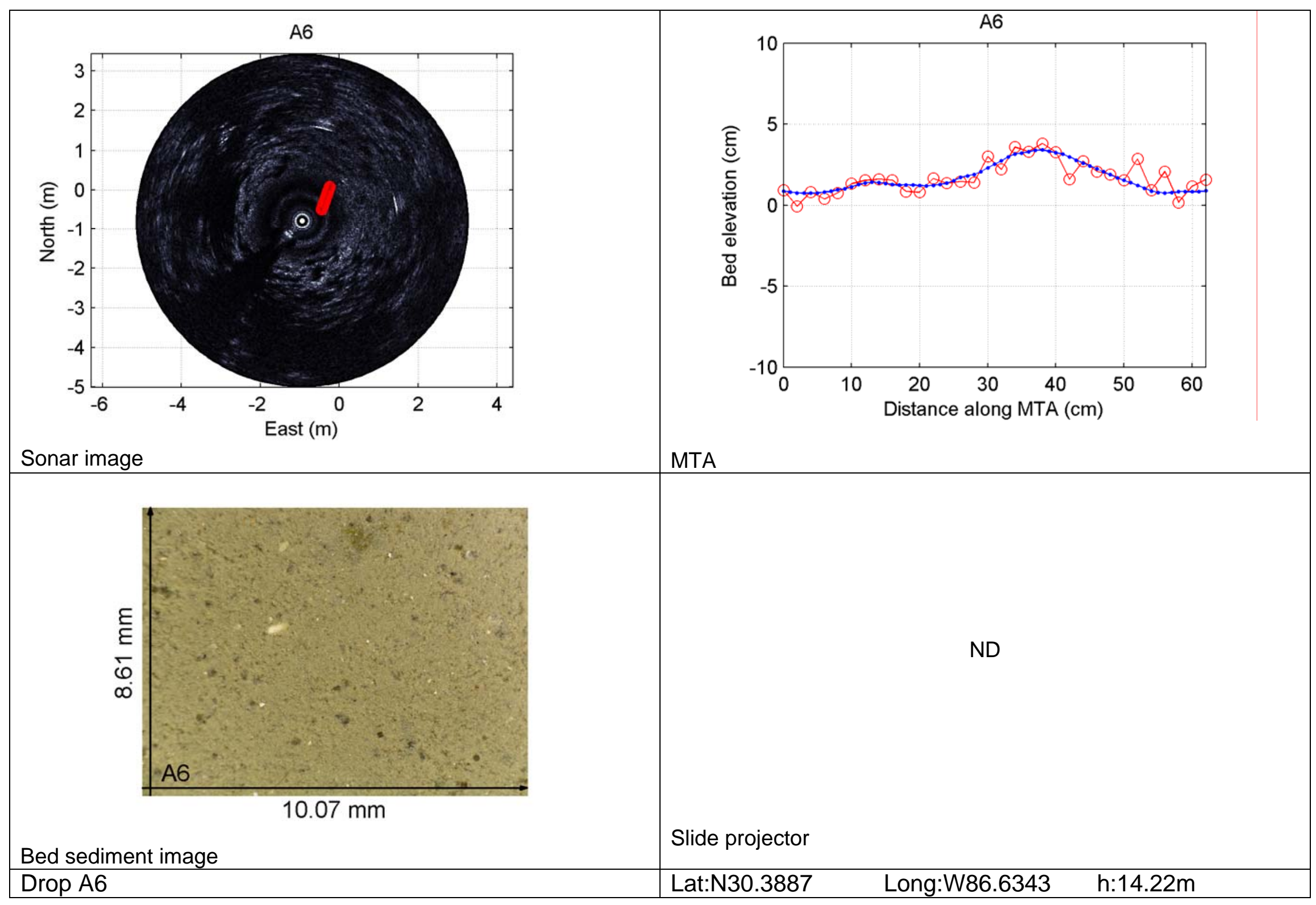




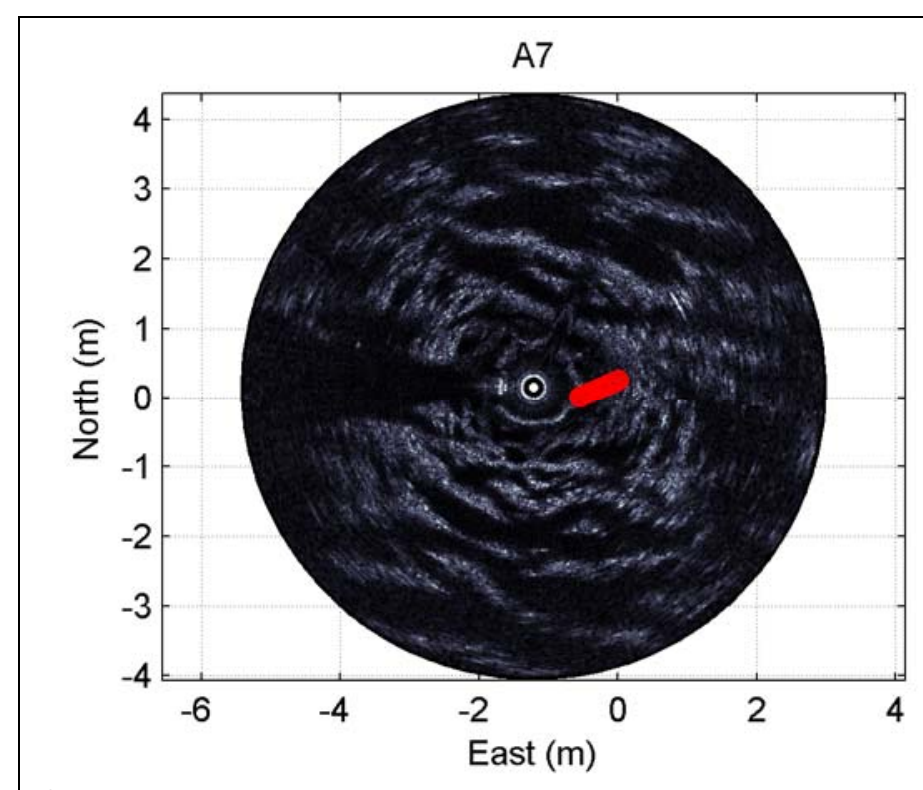

Sonar image

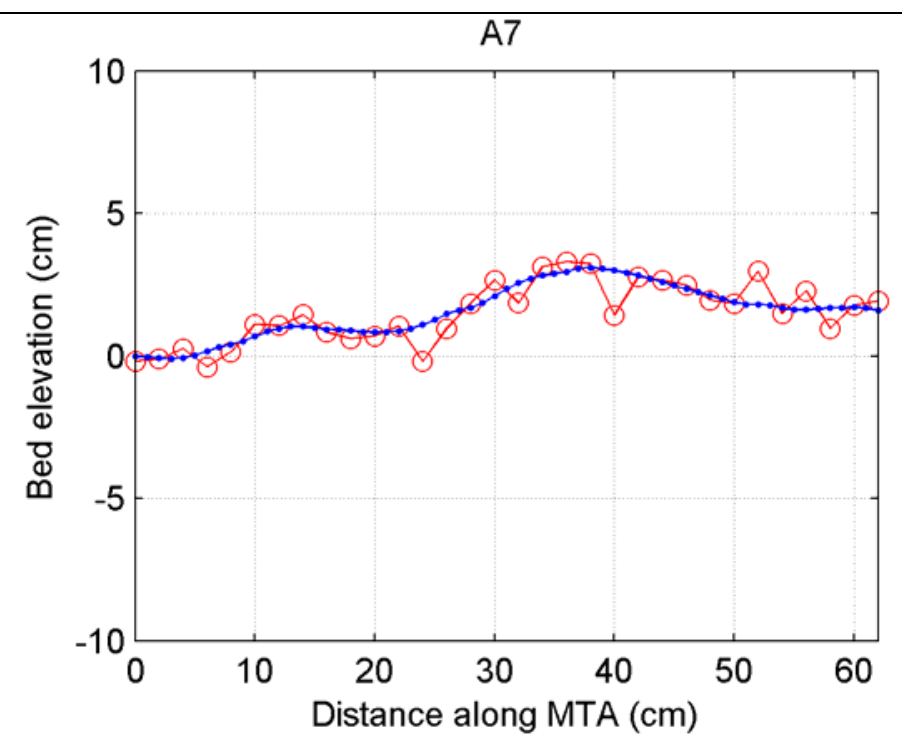

MTA

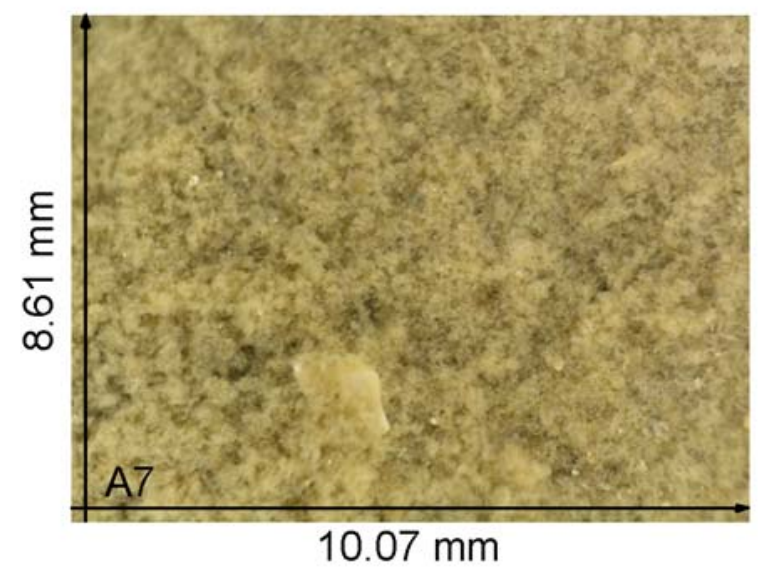

Bed sediment image

Drop A7

Slide projector

Lat:N30.3852




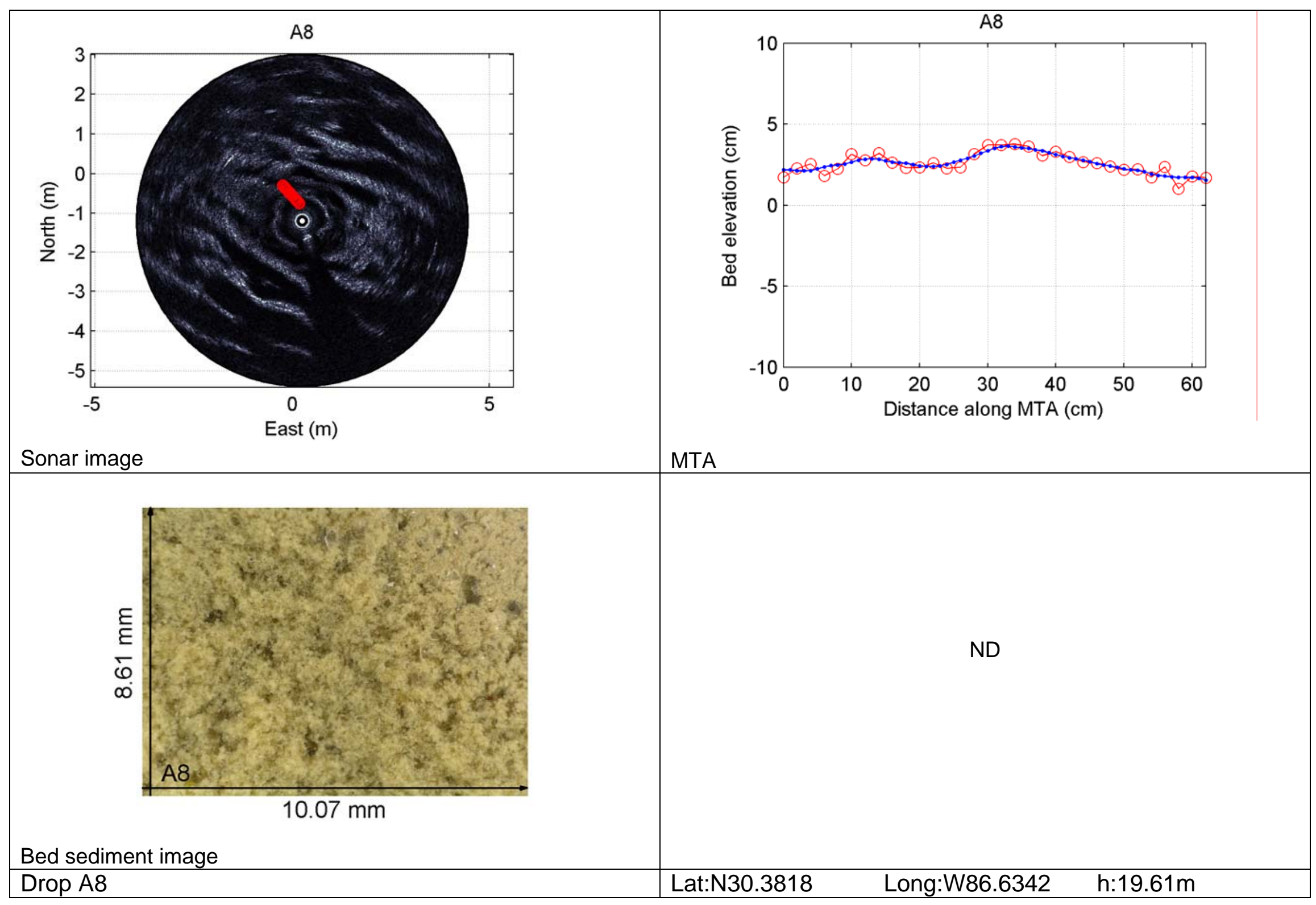



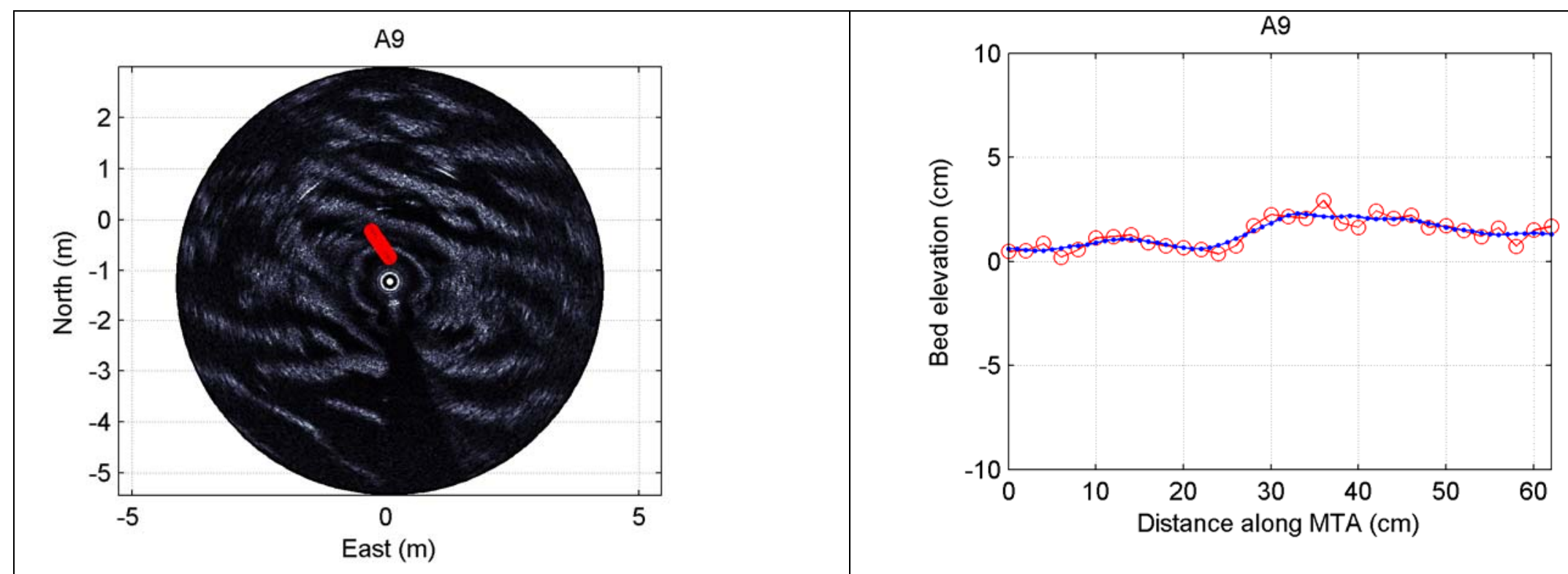

Sonar image

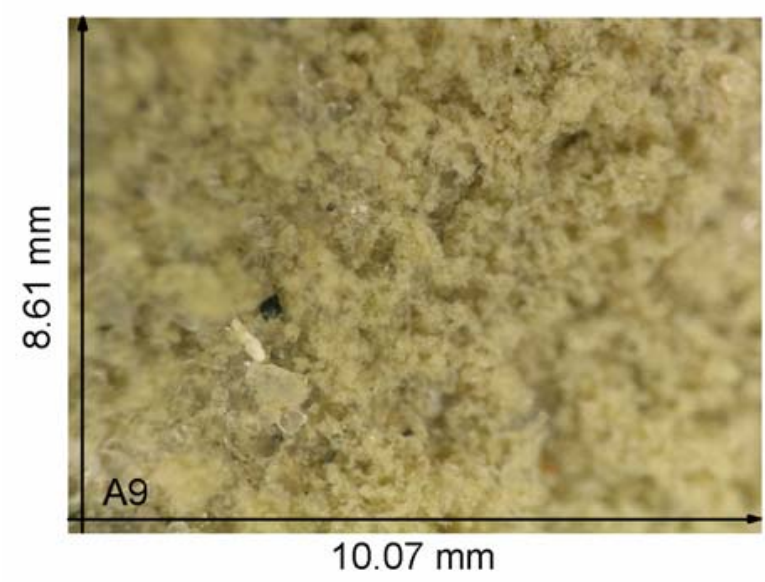

Bed sediment image 


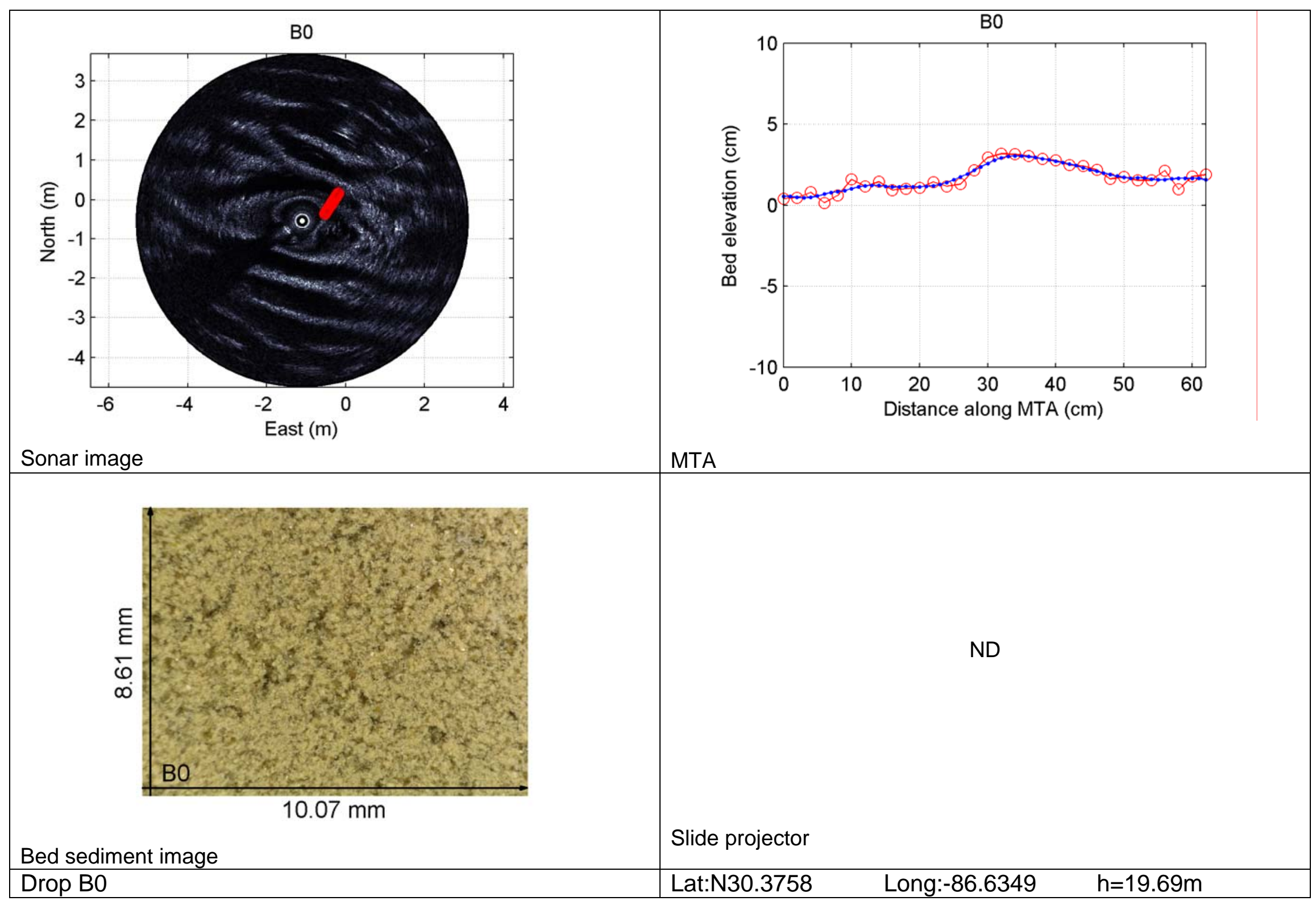




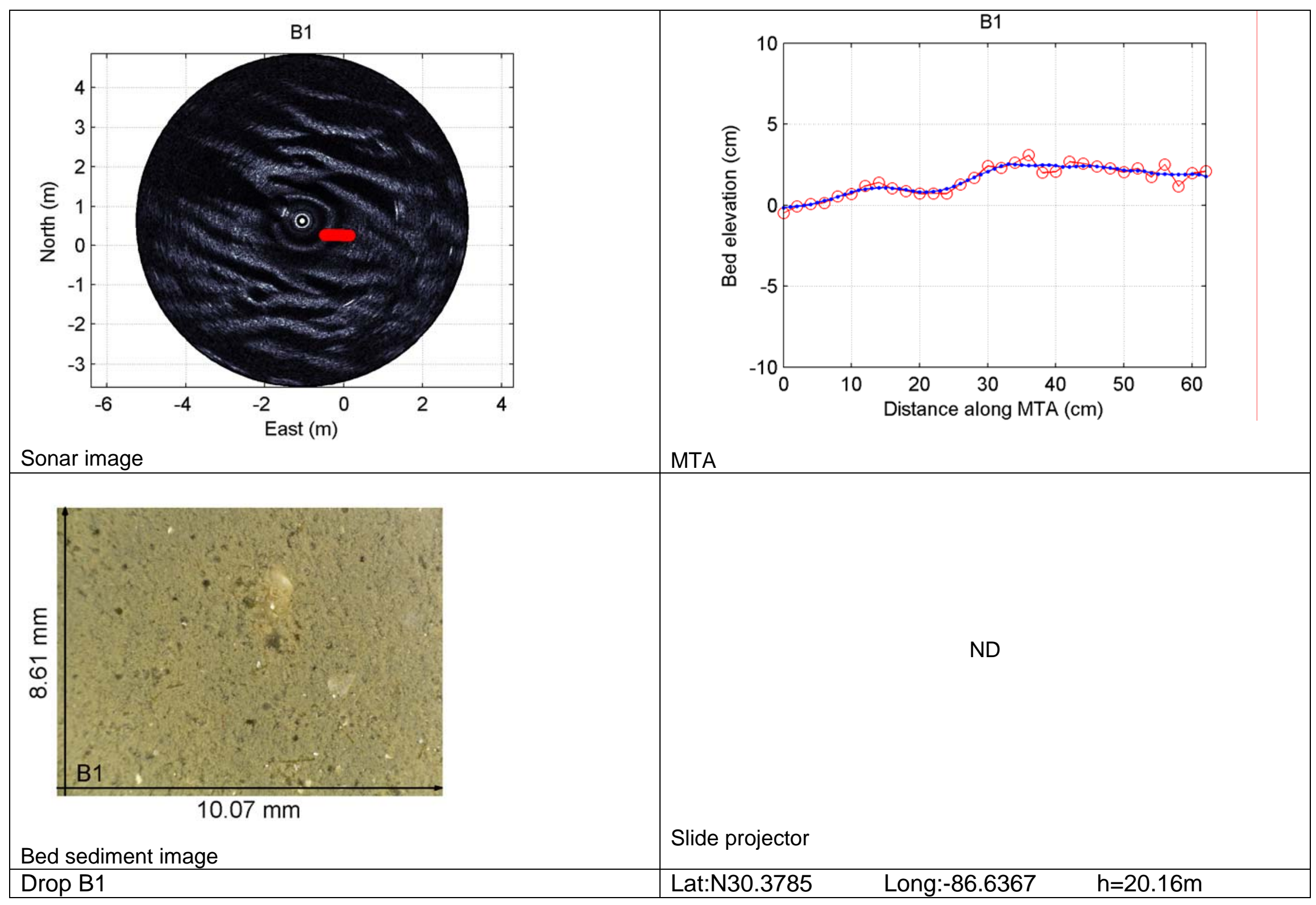




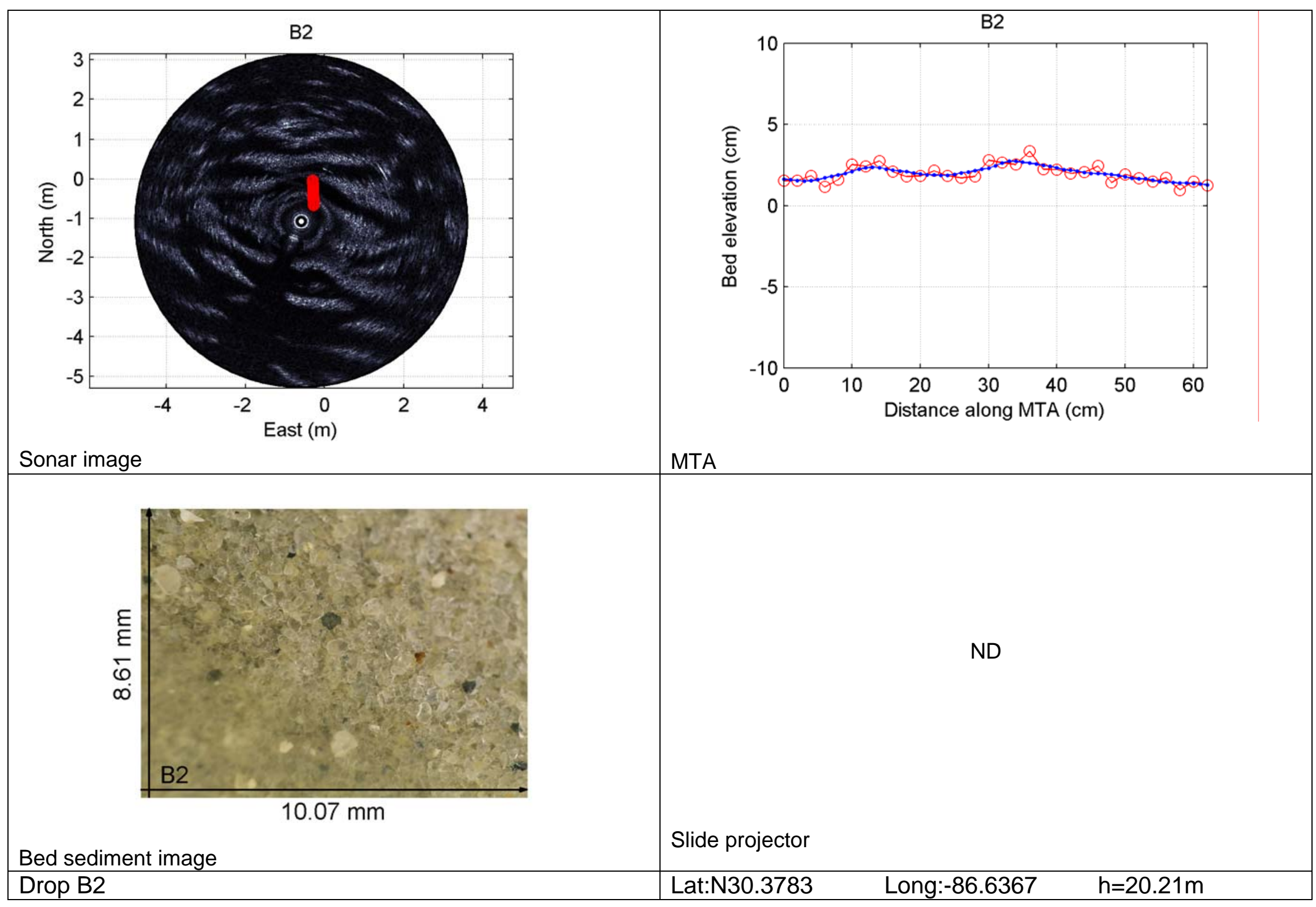




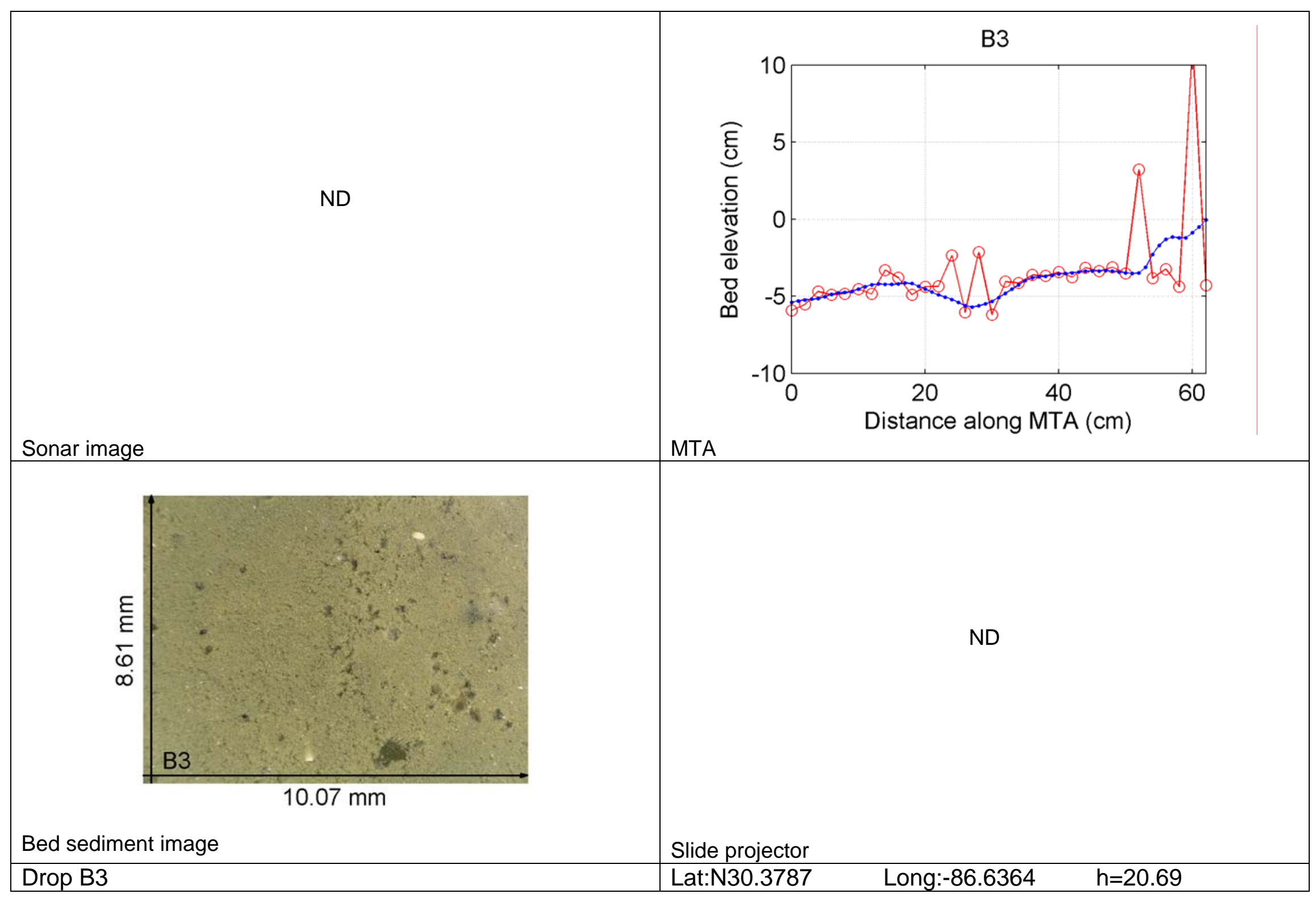




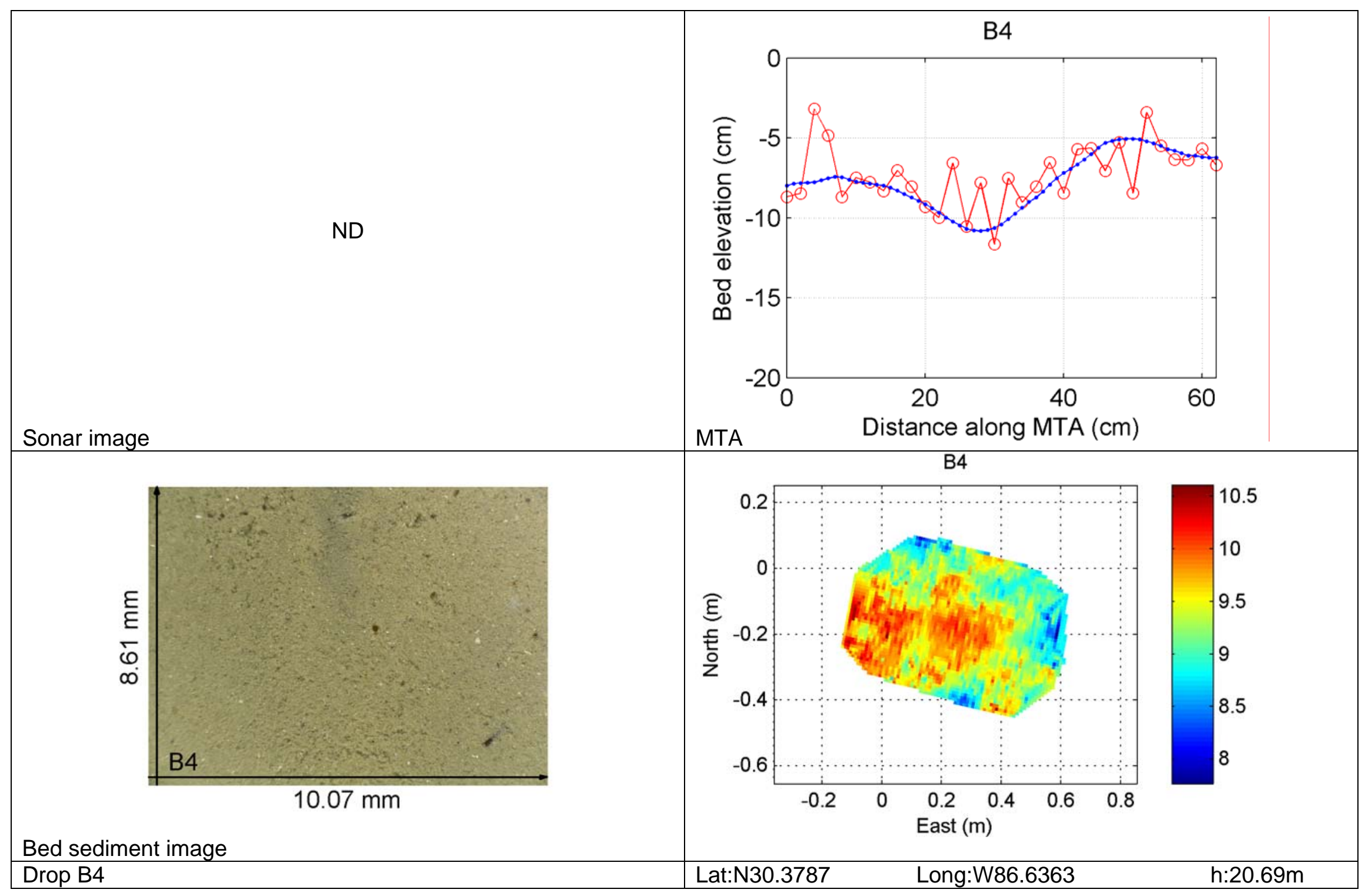




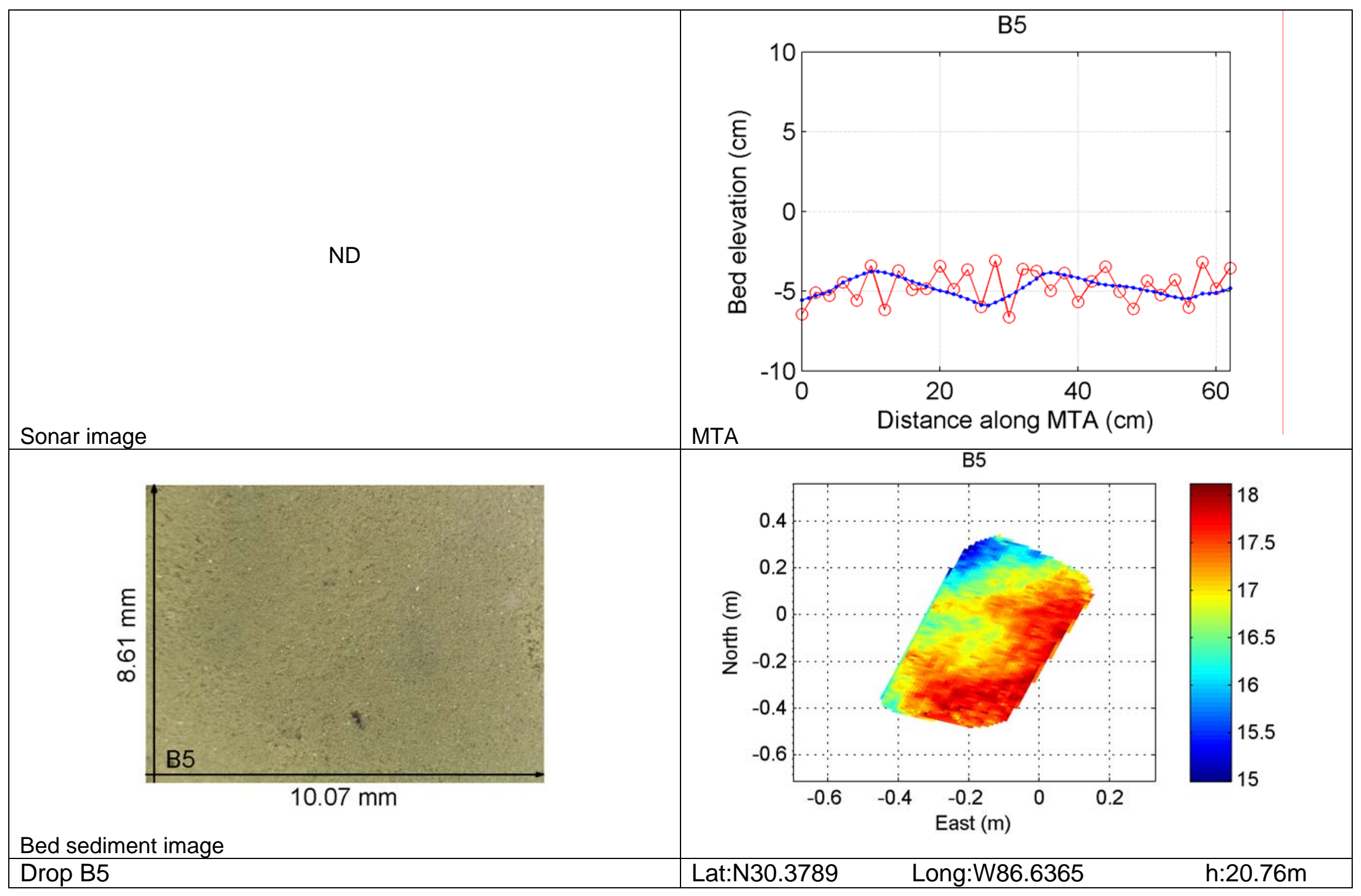




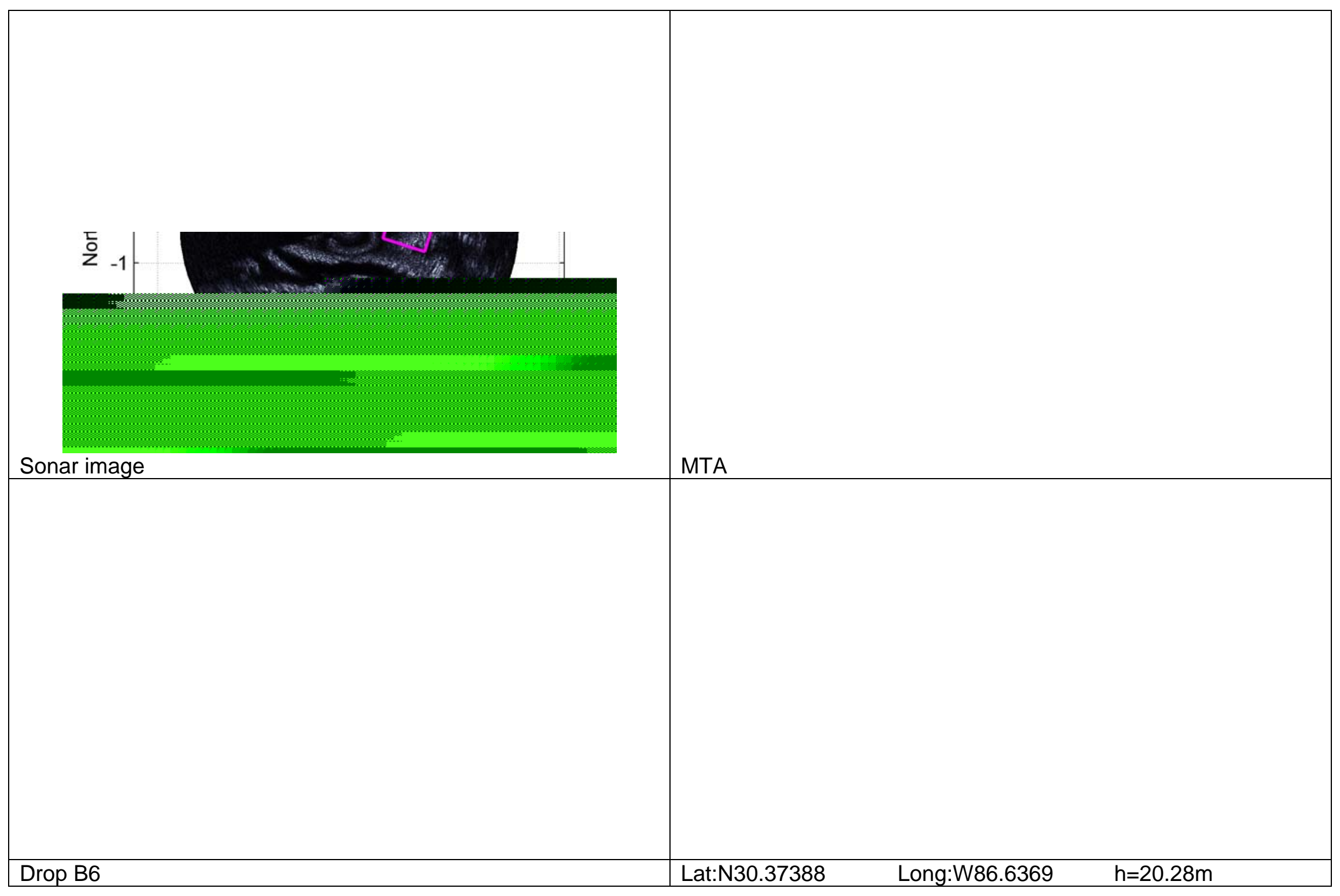




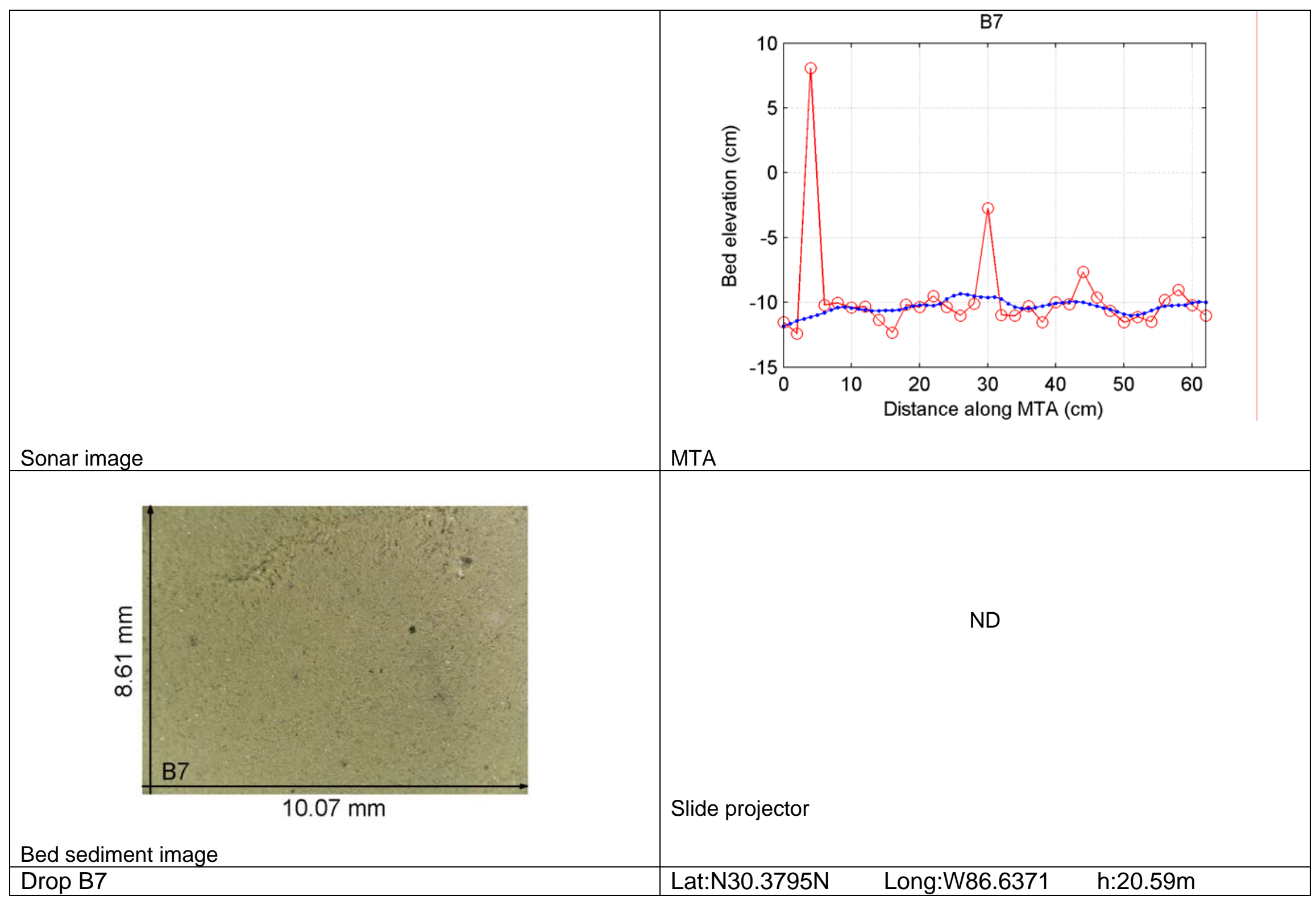




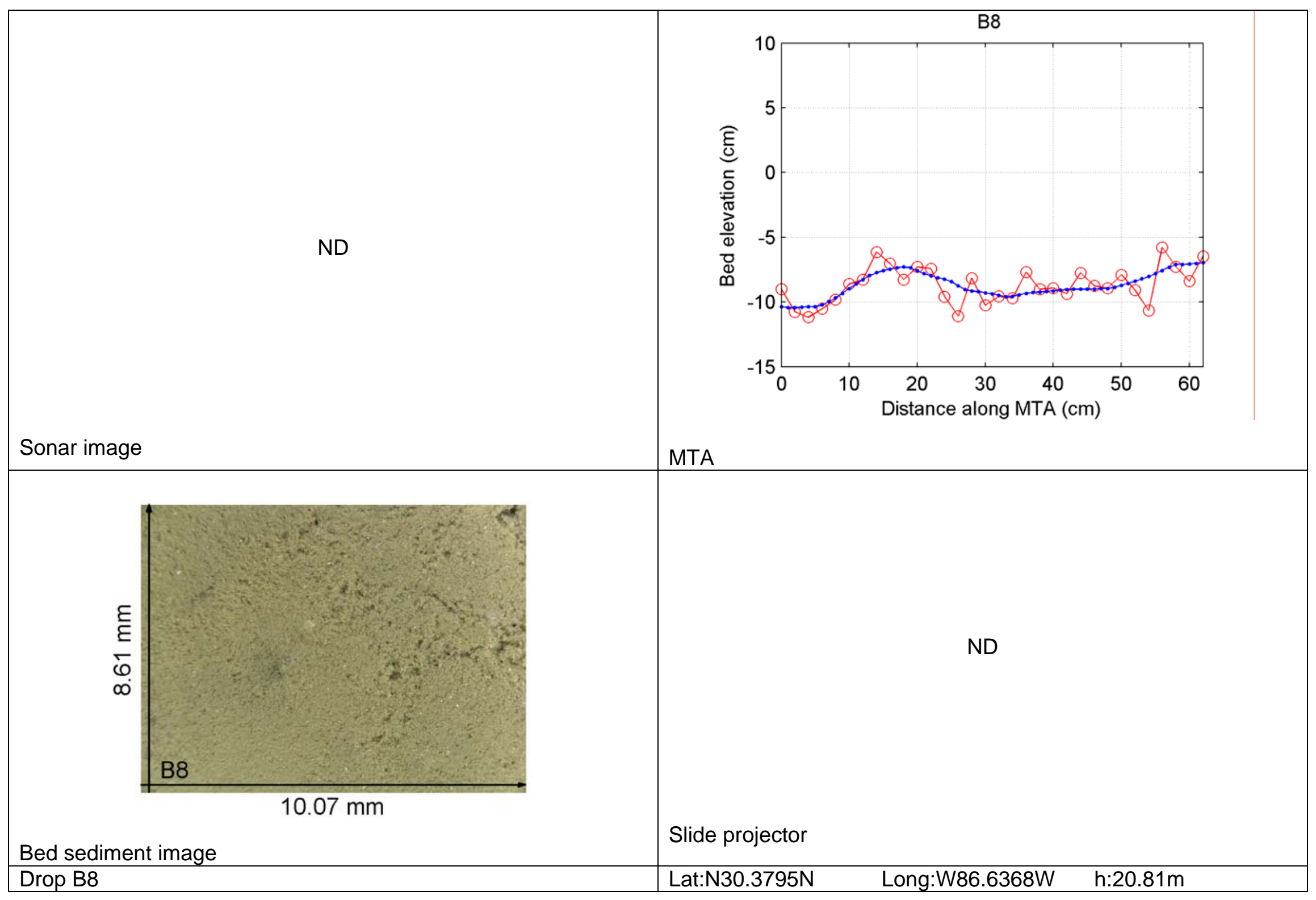




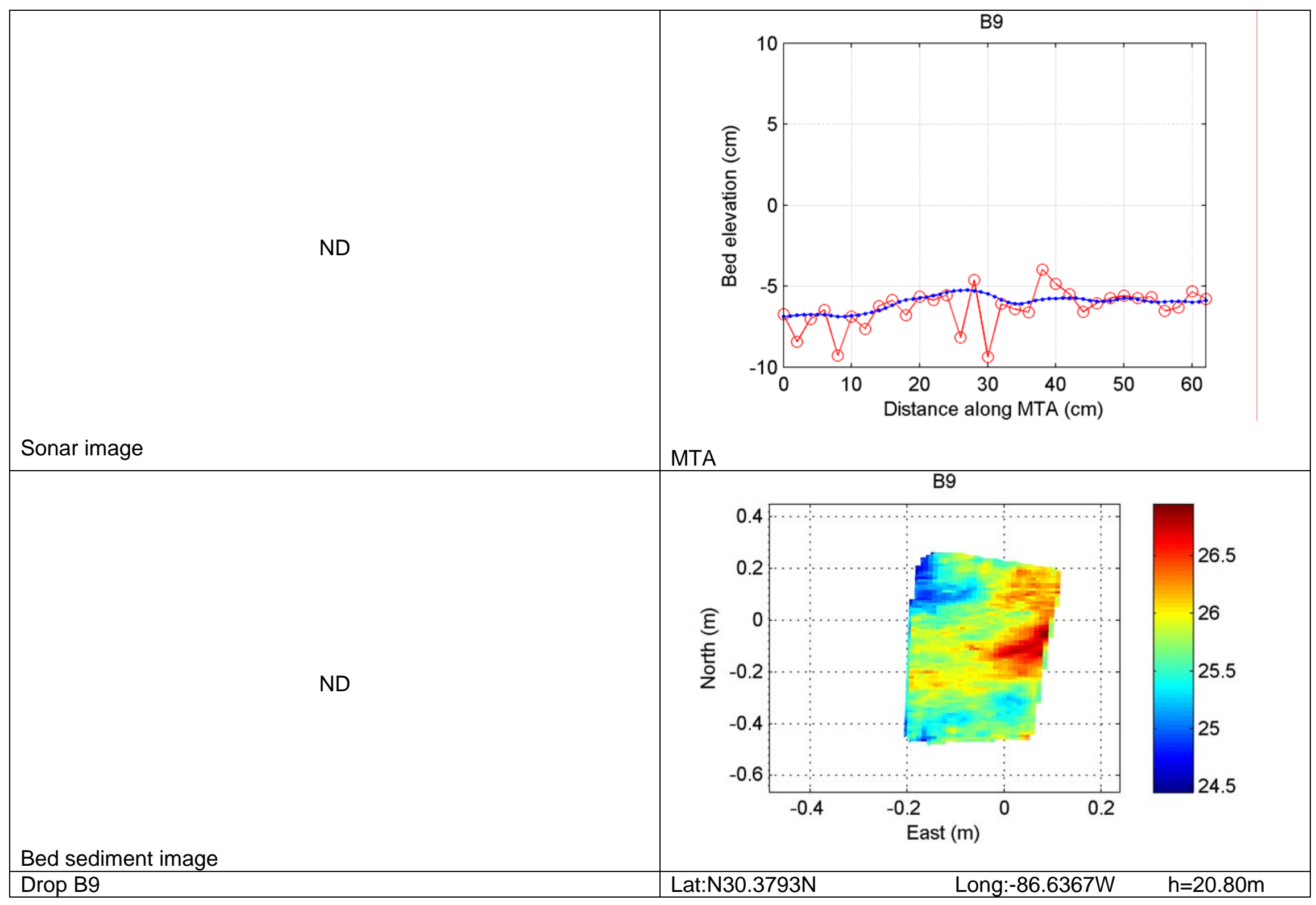




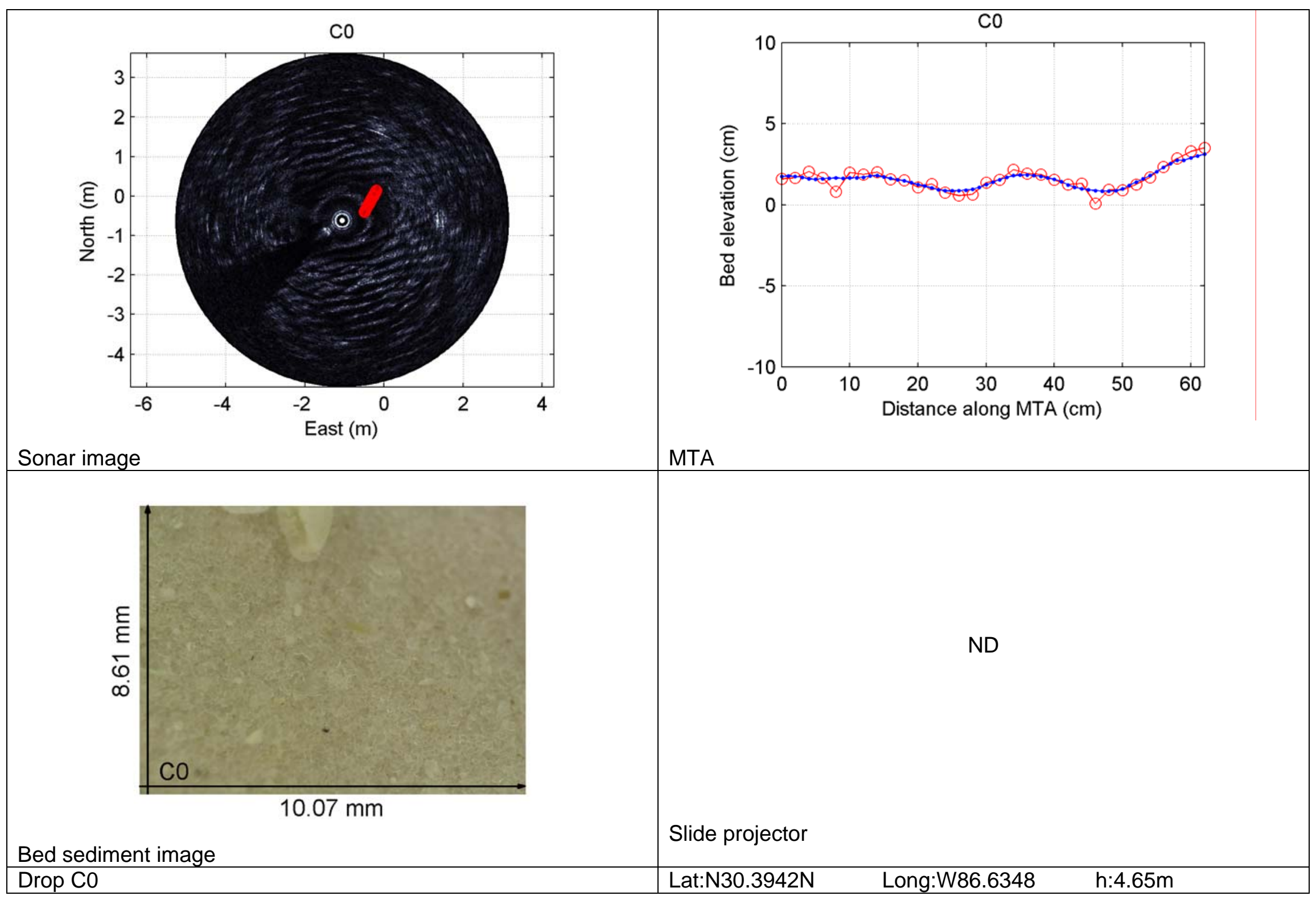




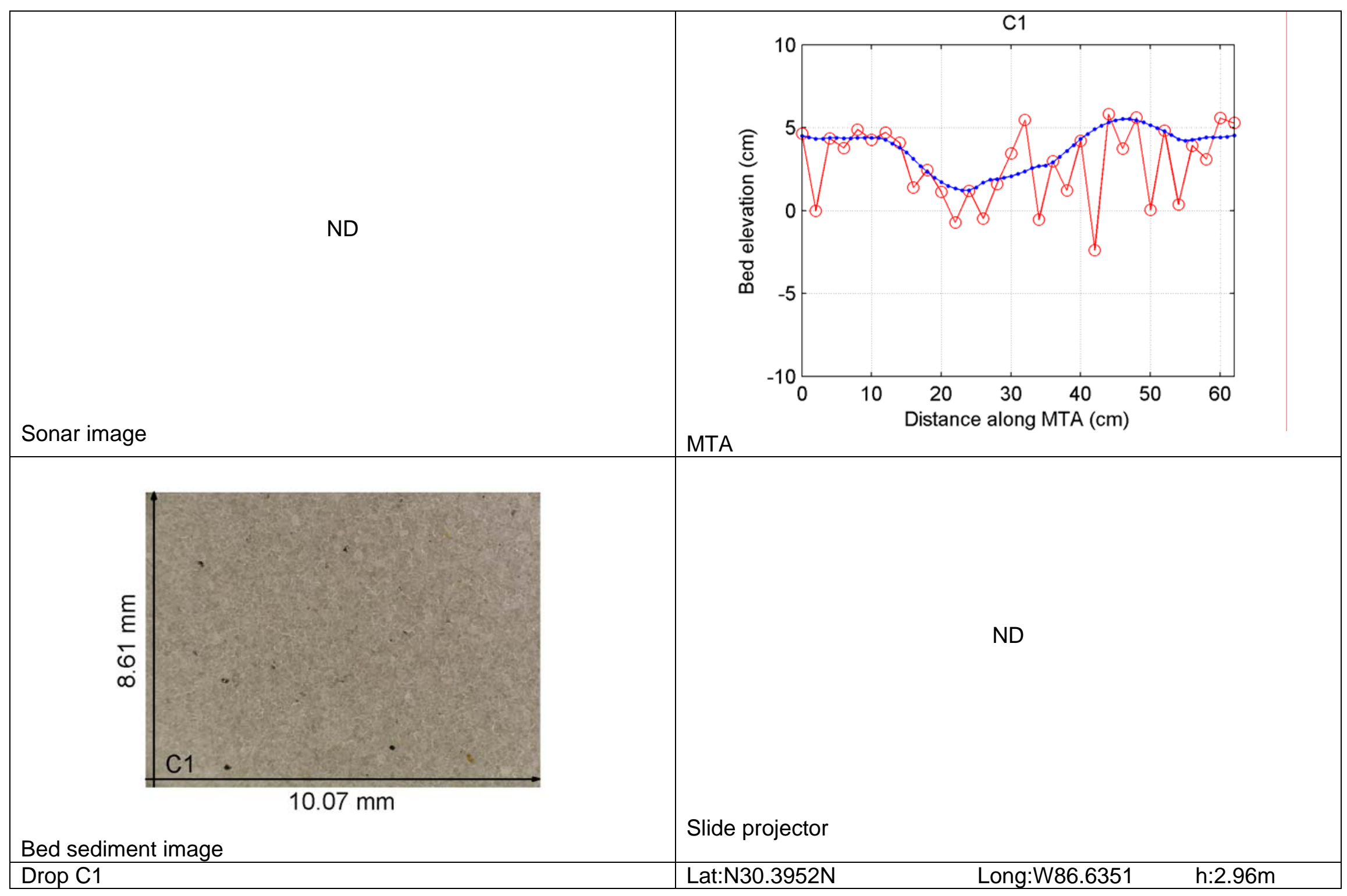




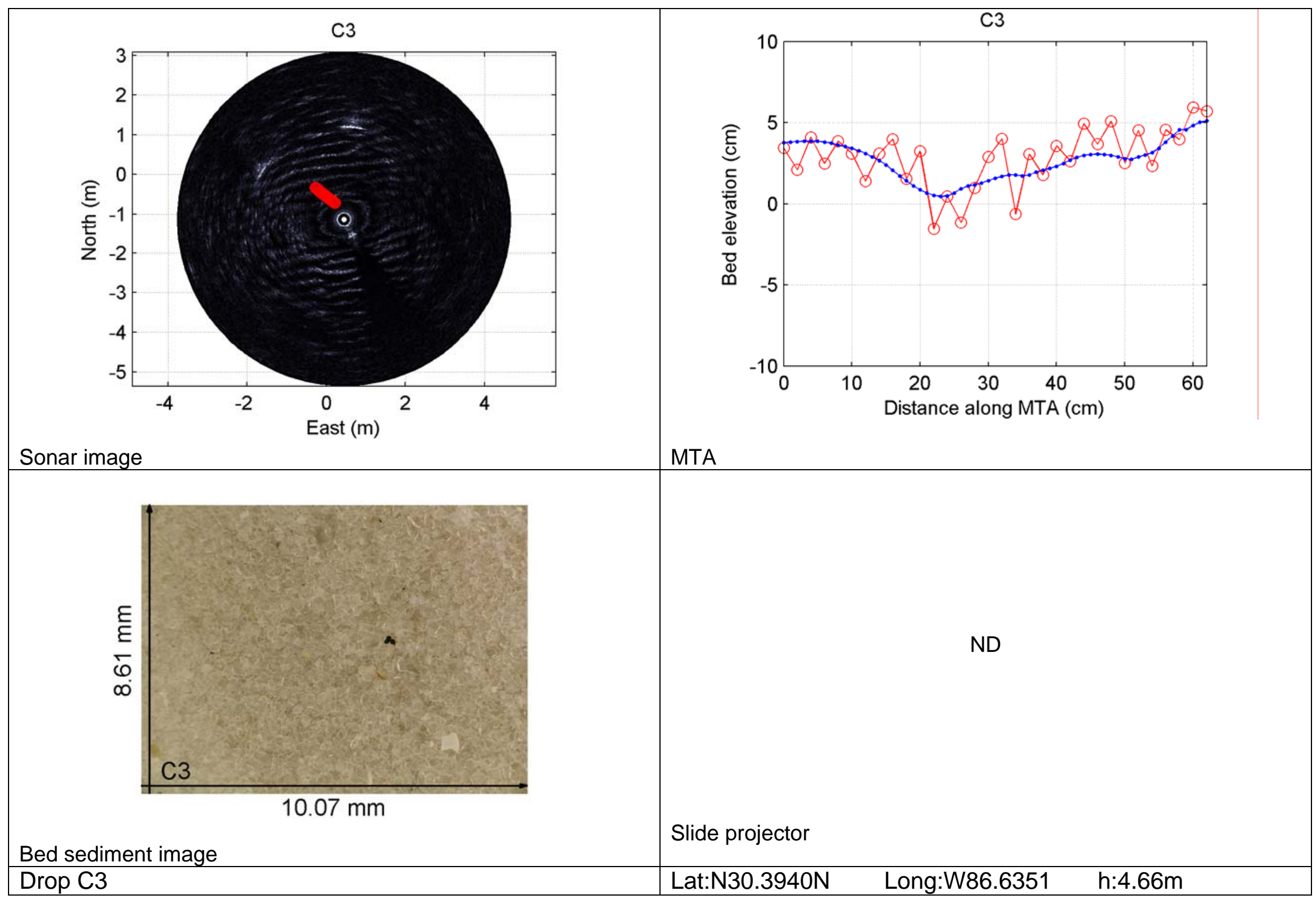




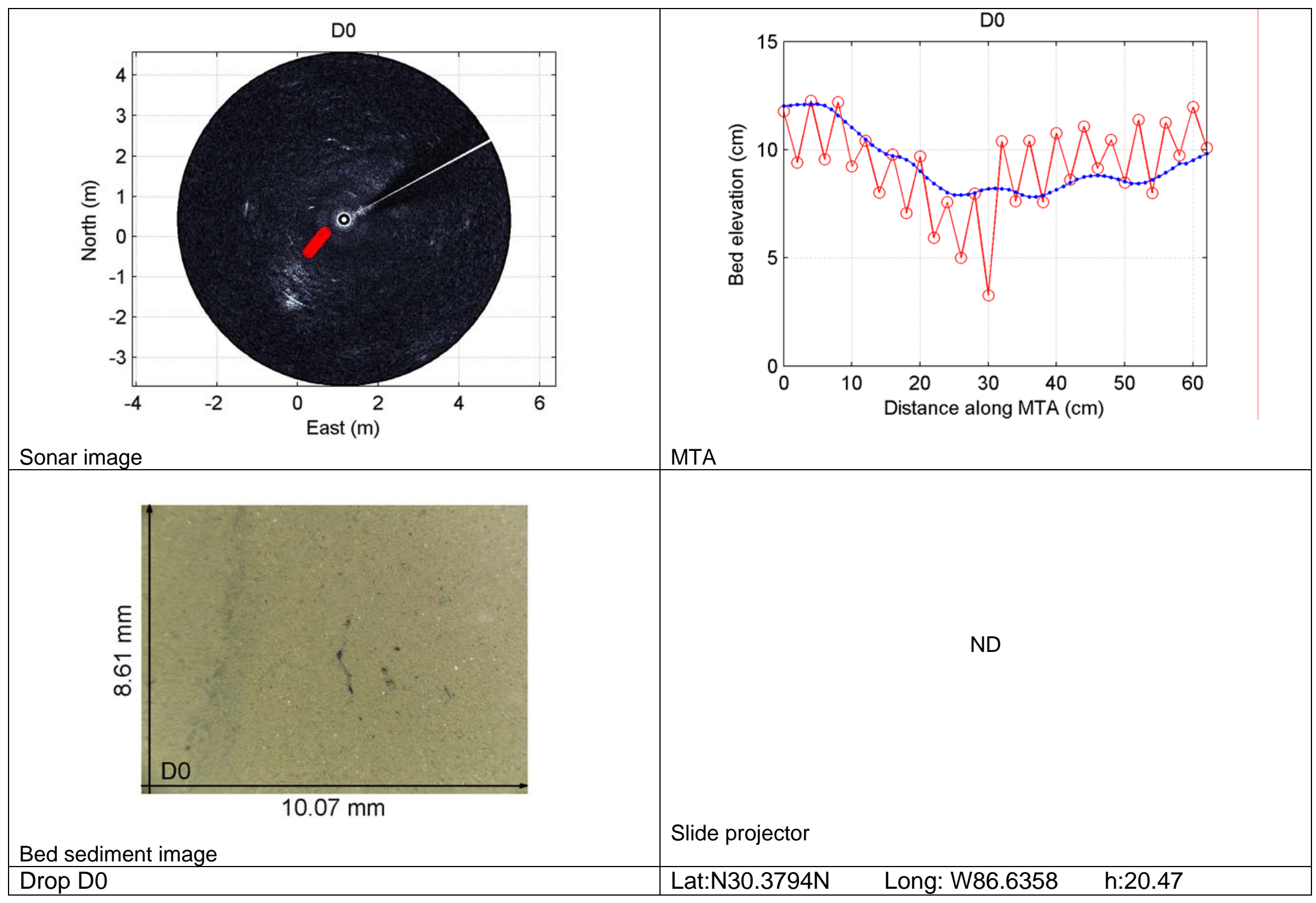




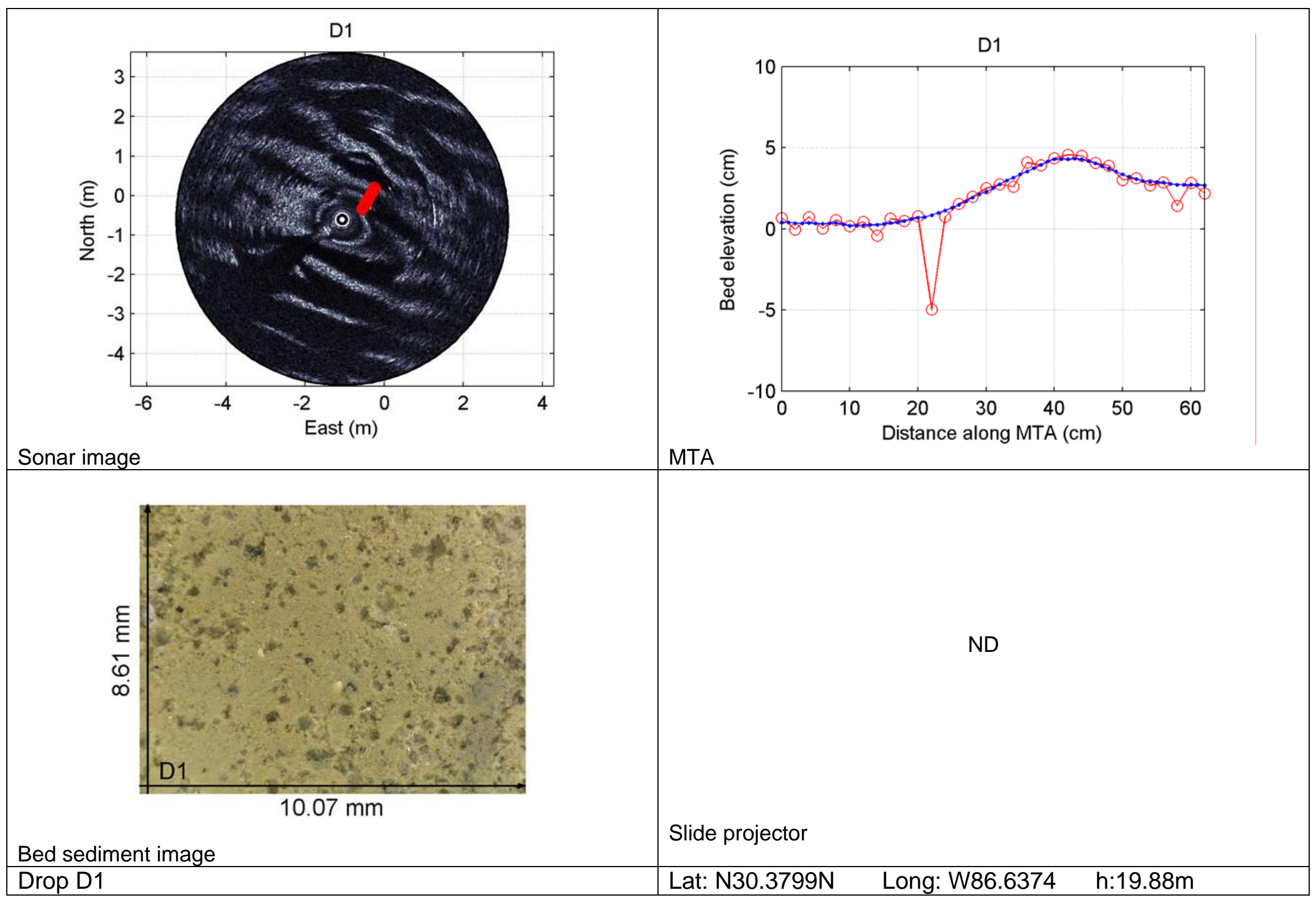




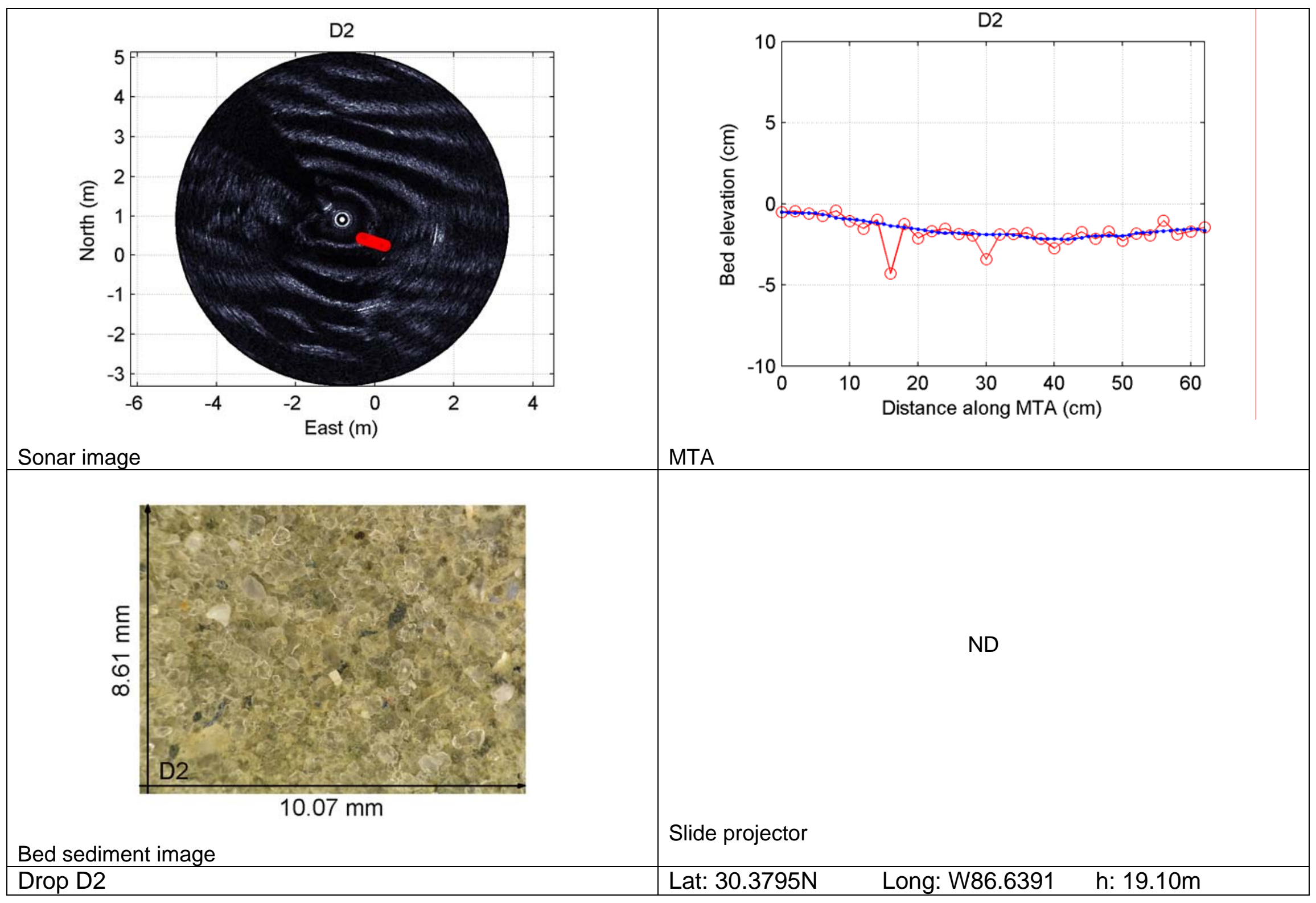




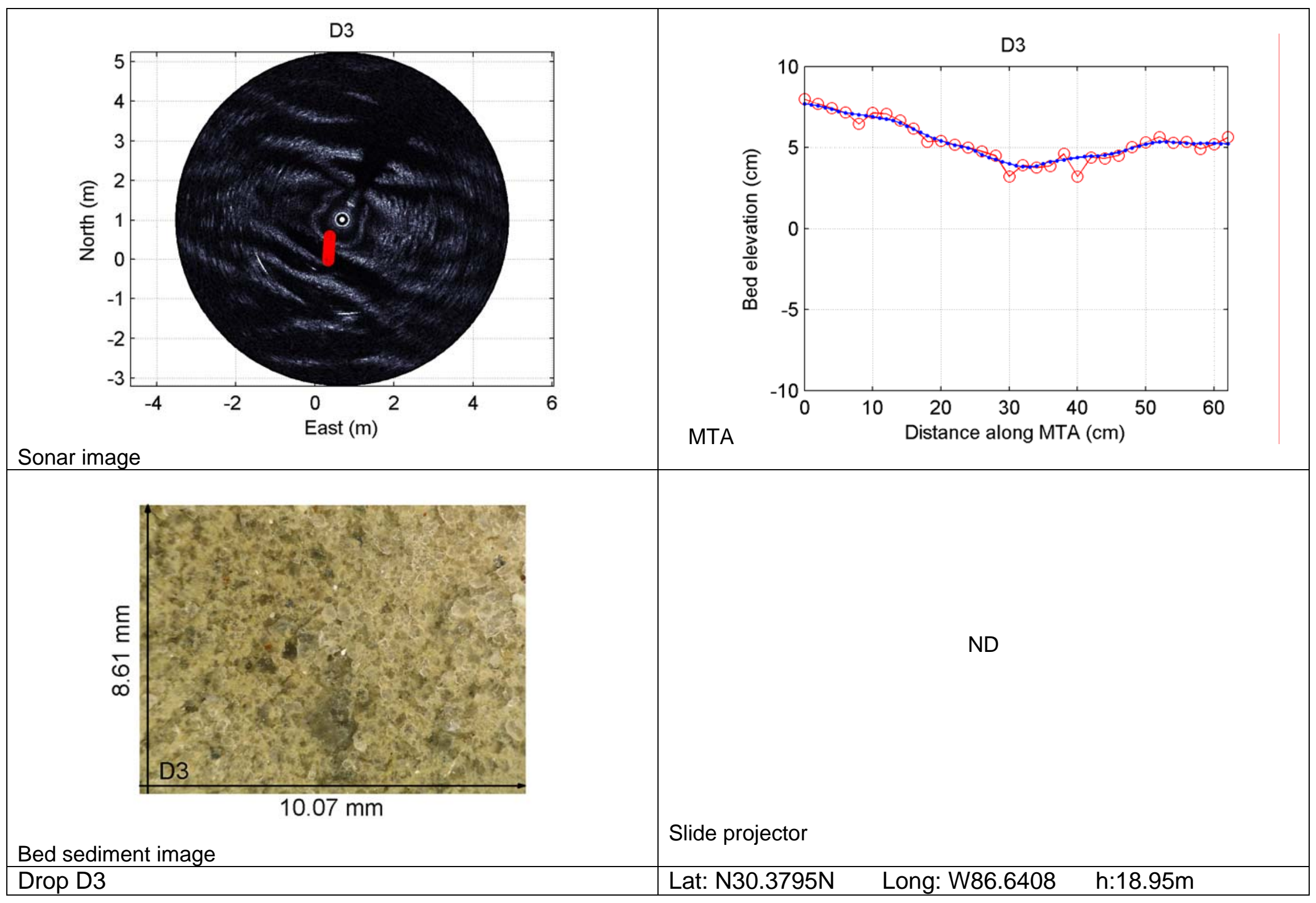




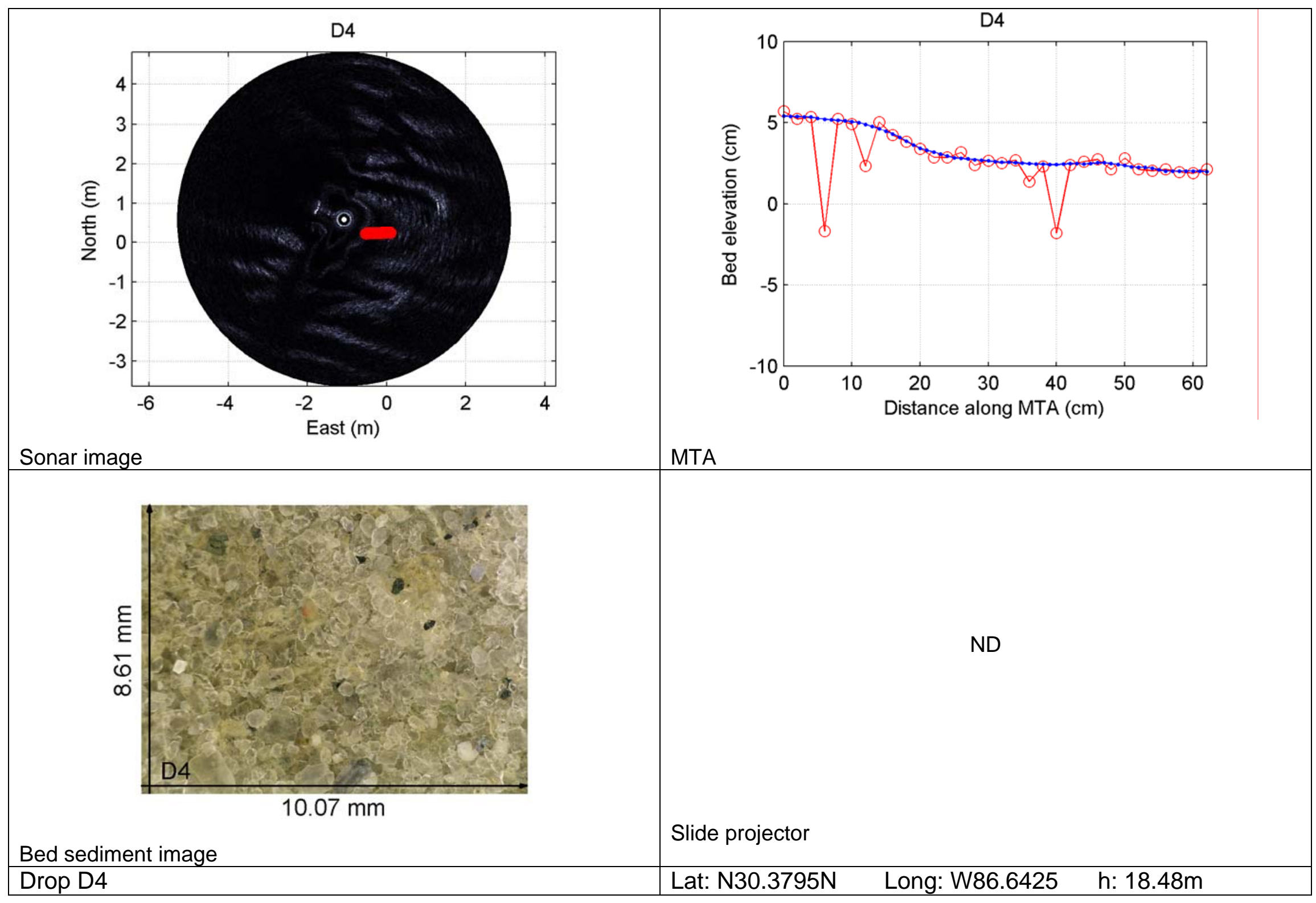




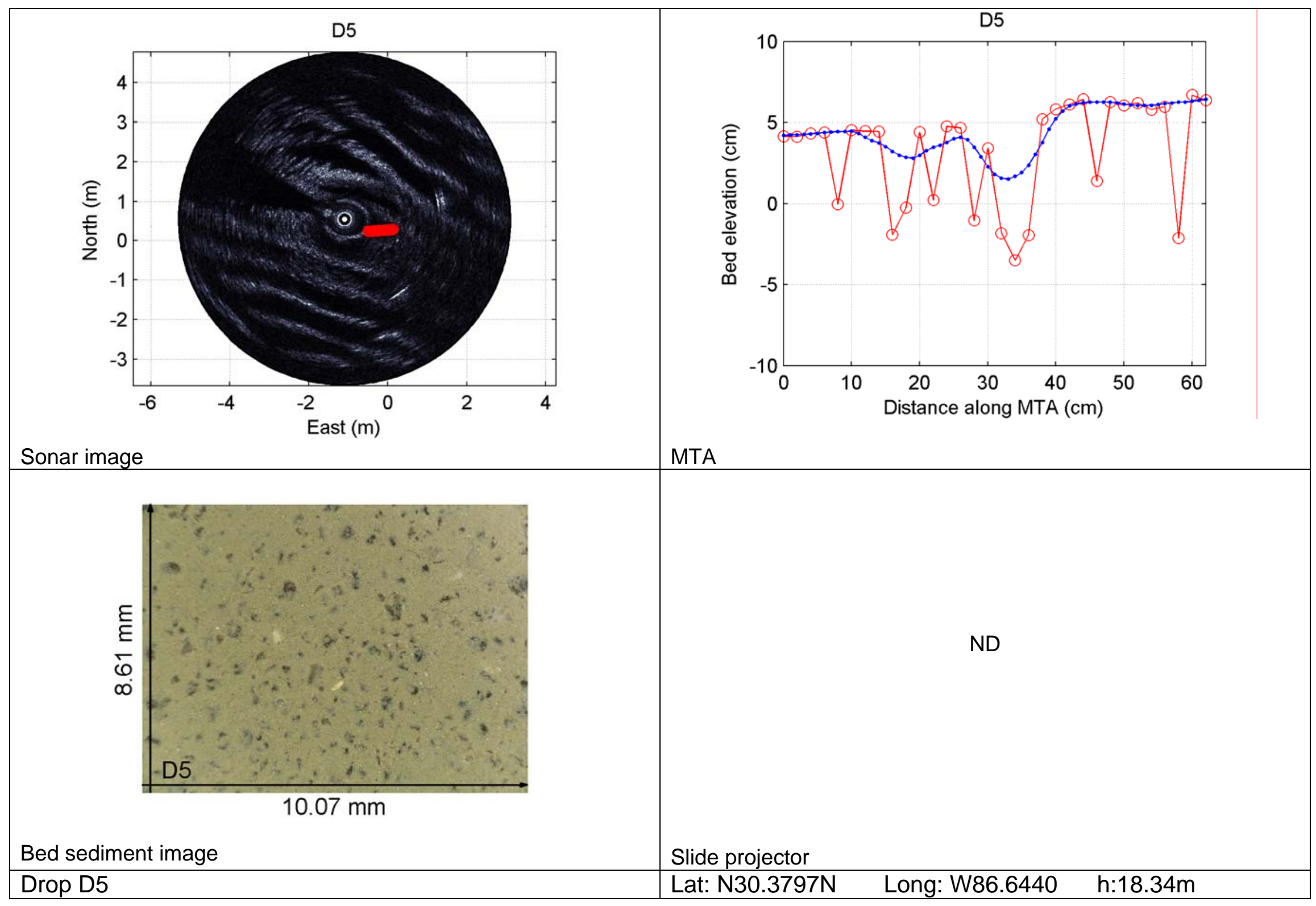




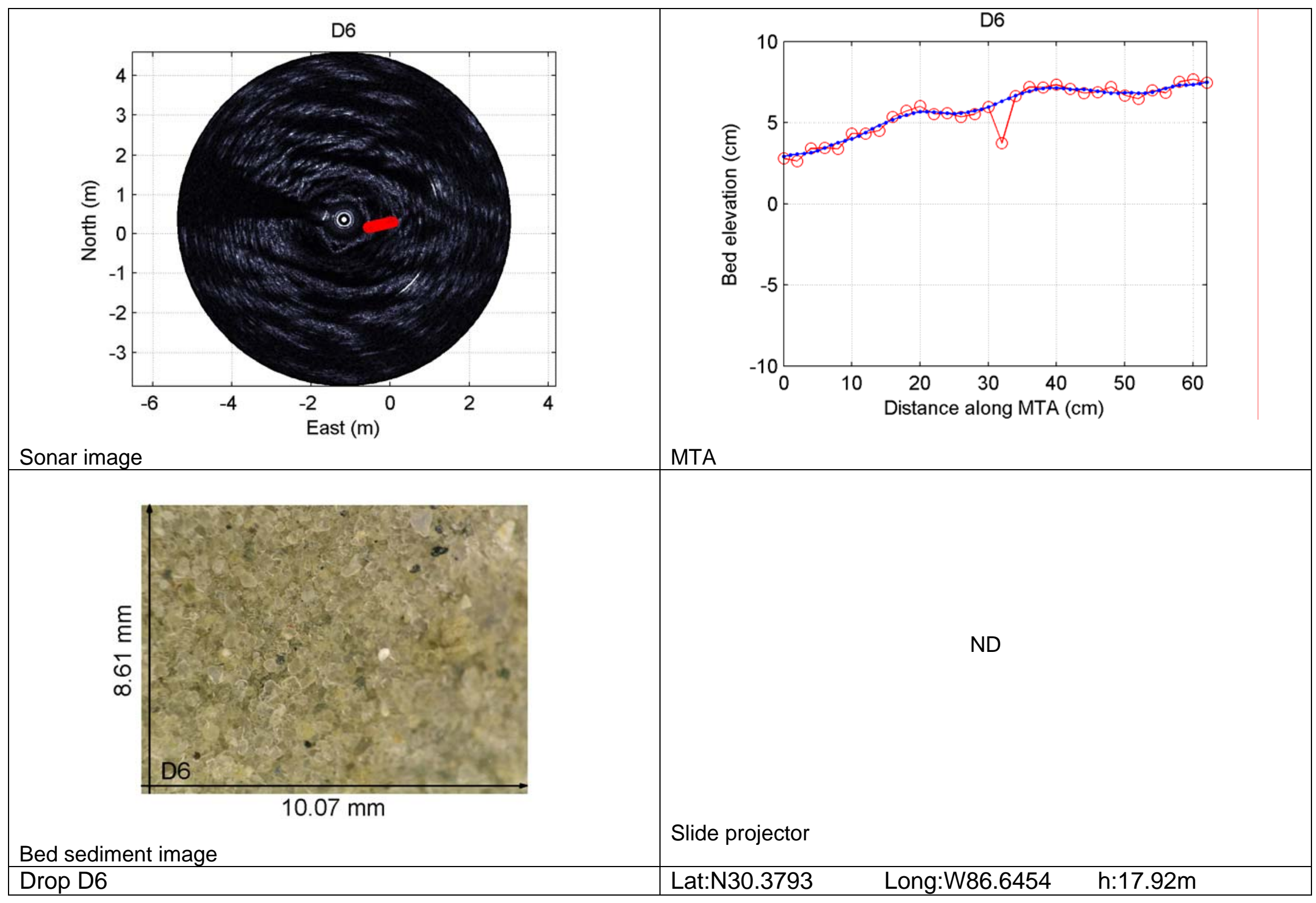




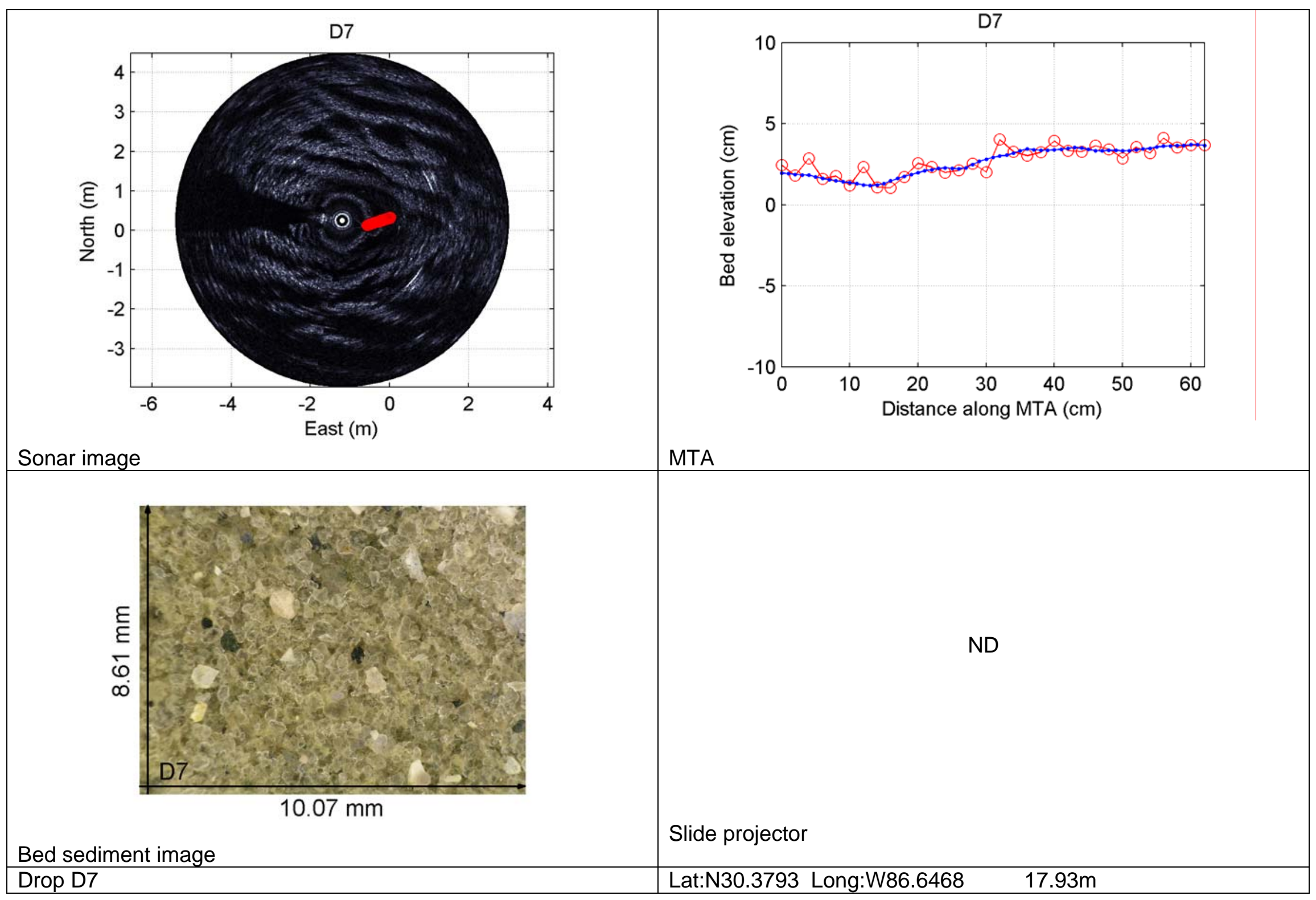




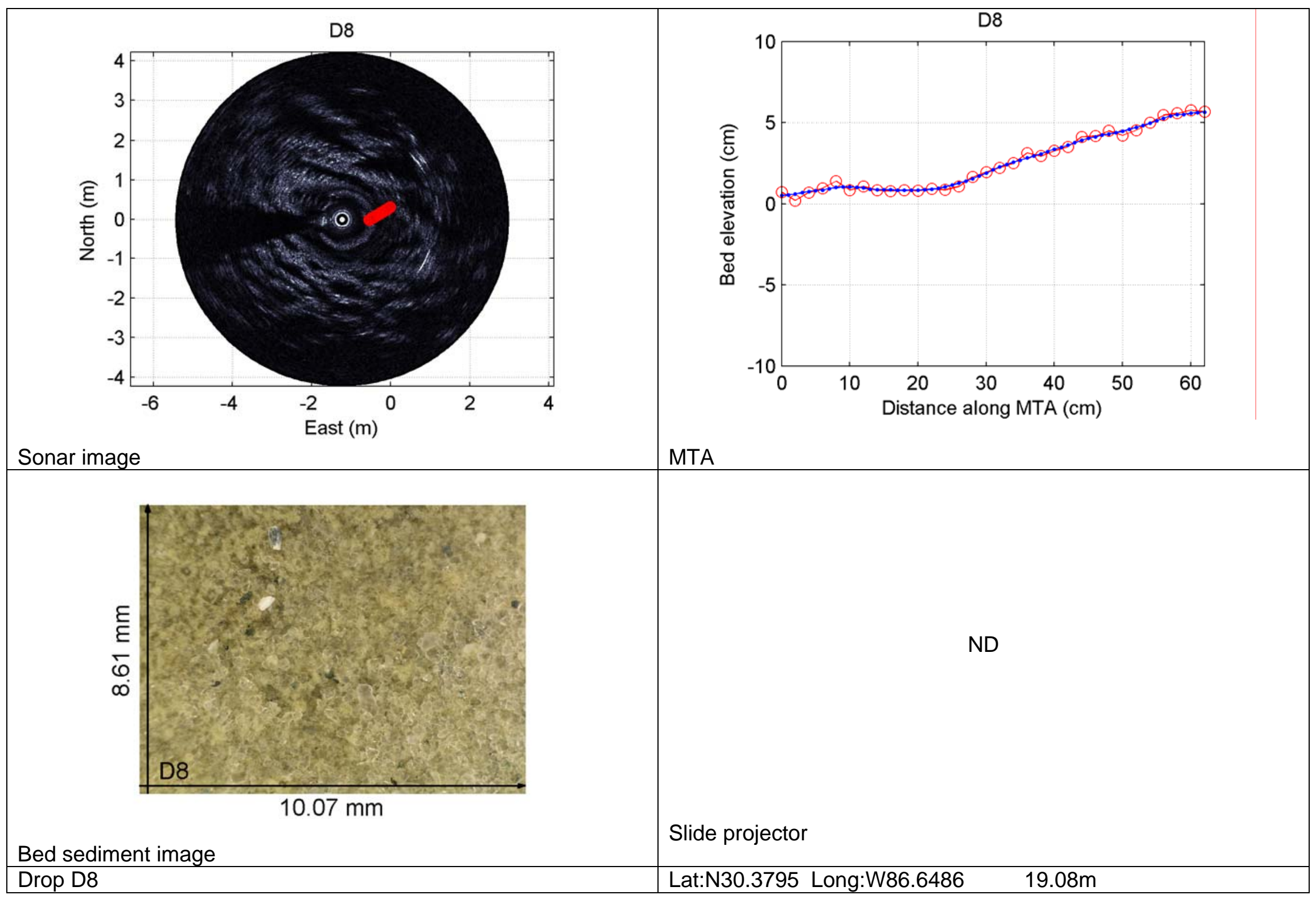




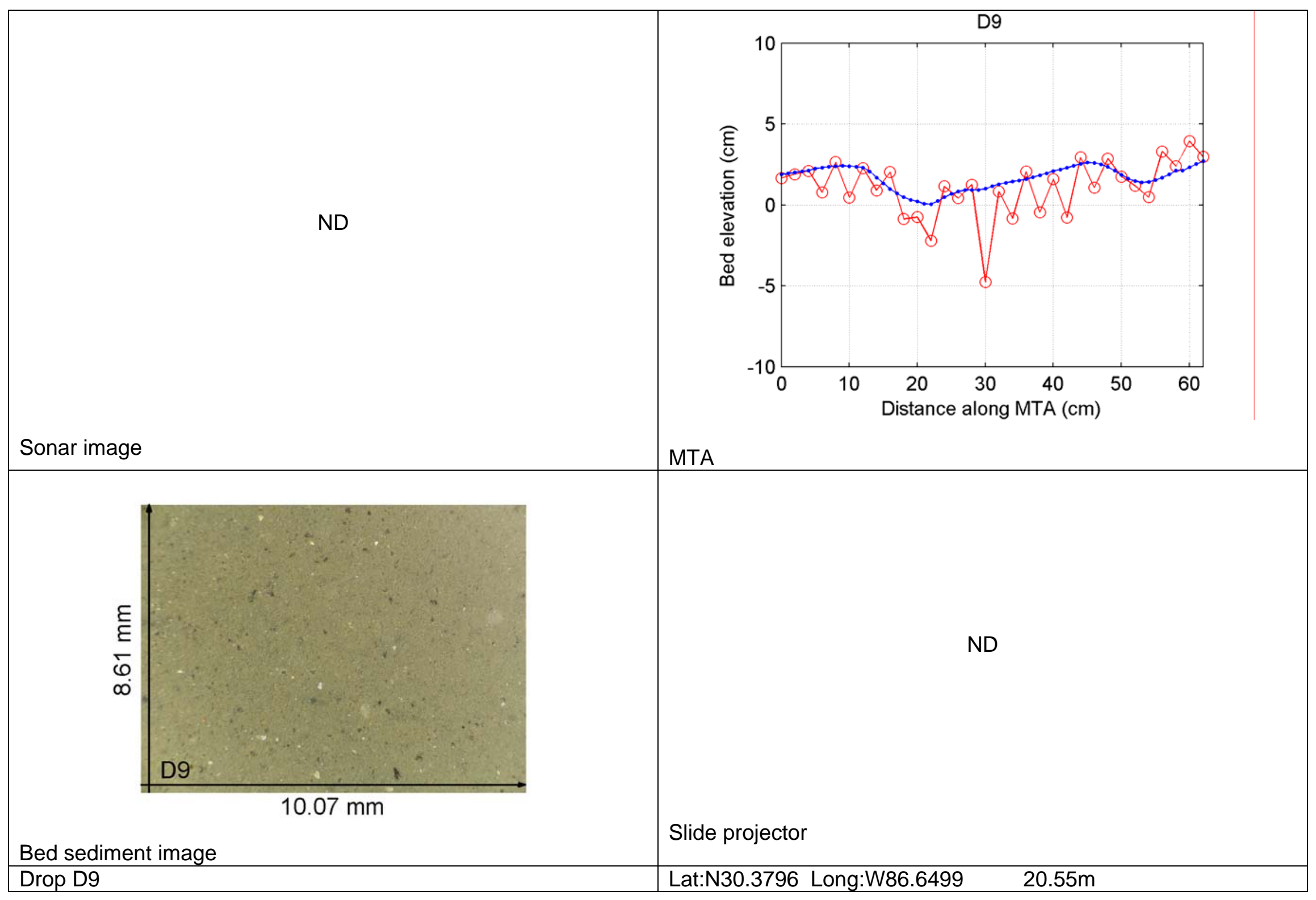




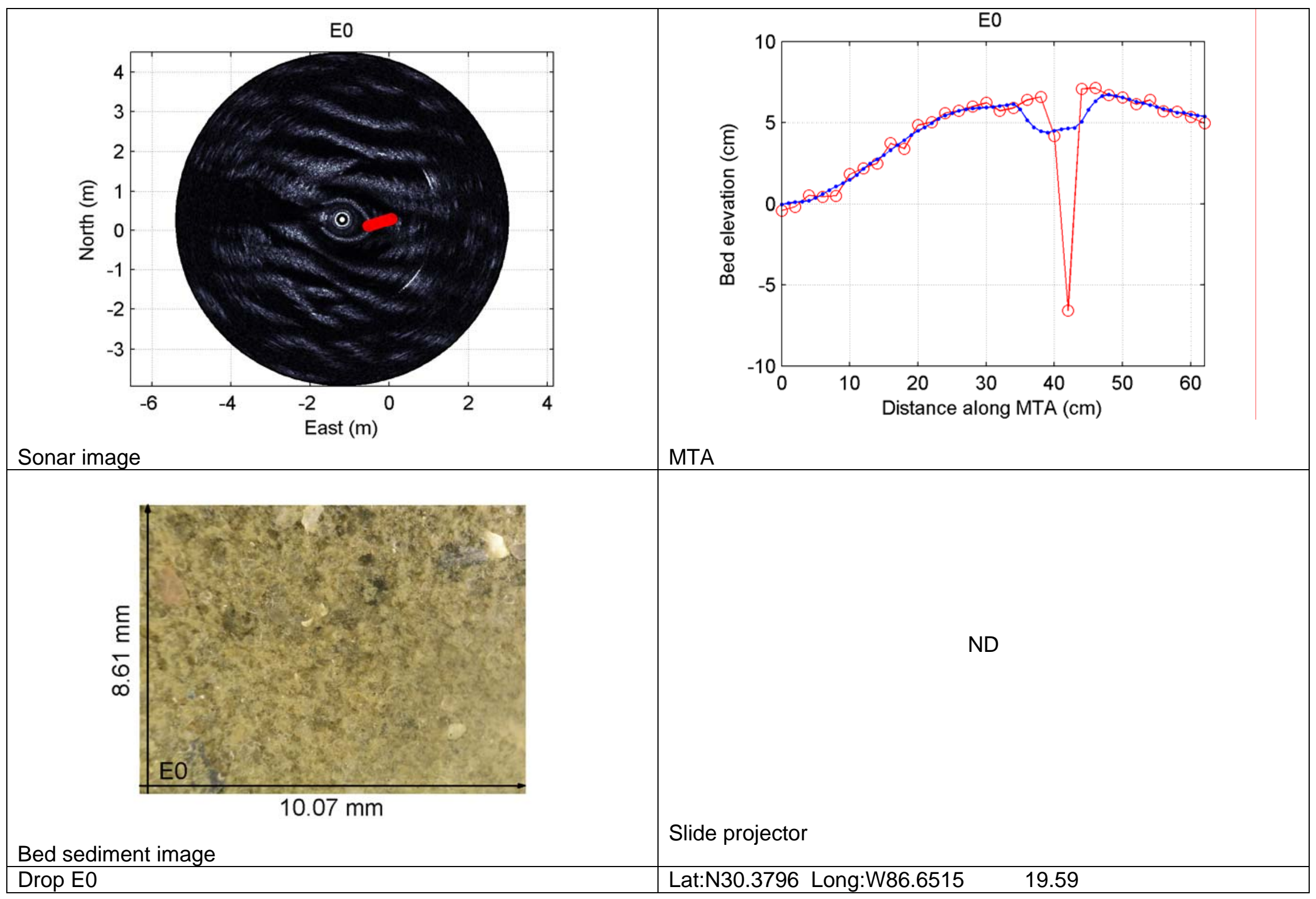




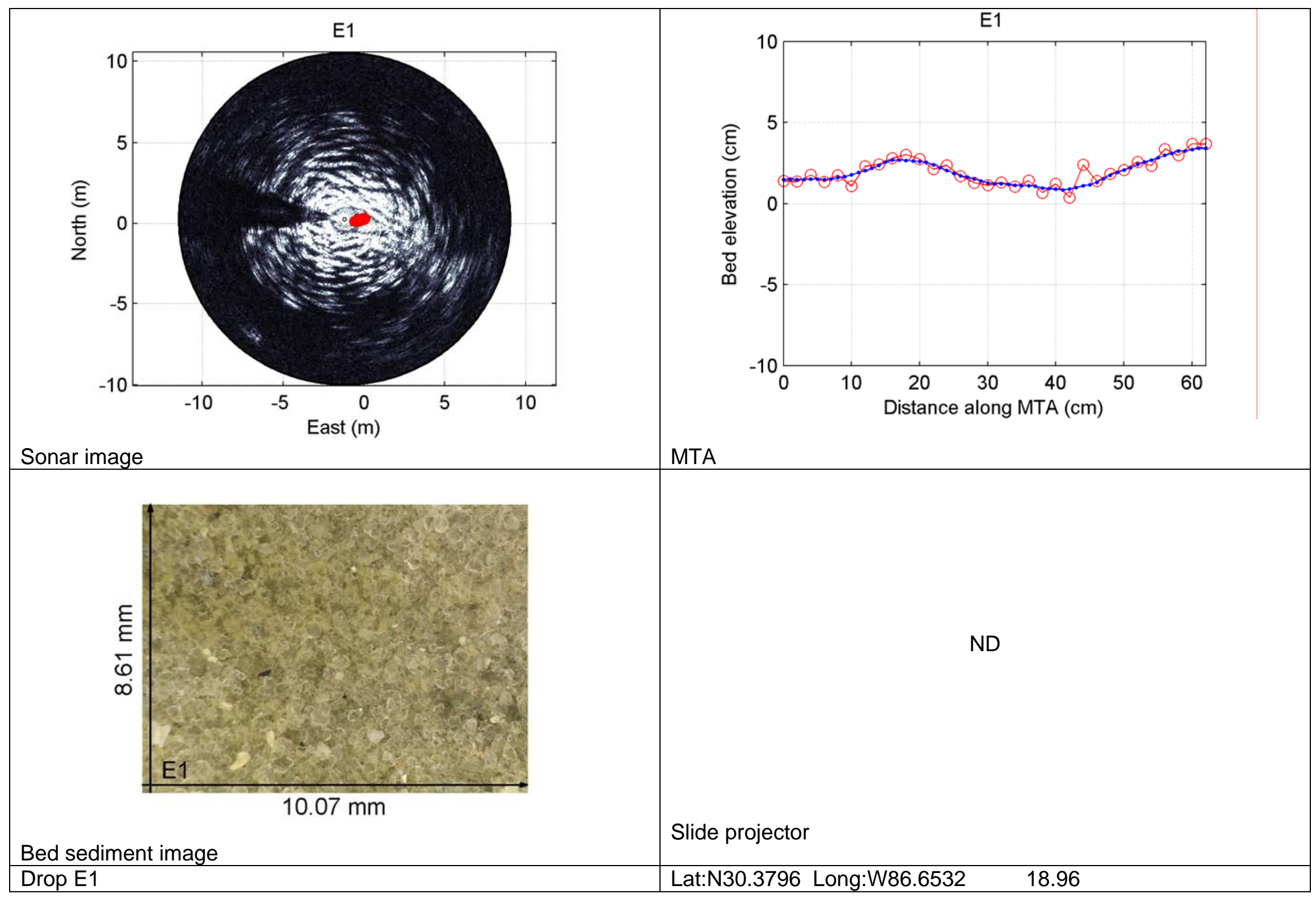




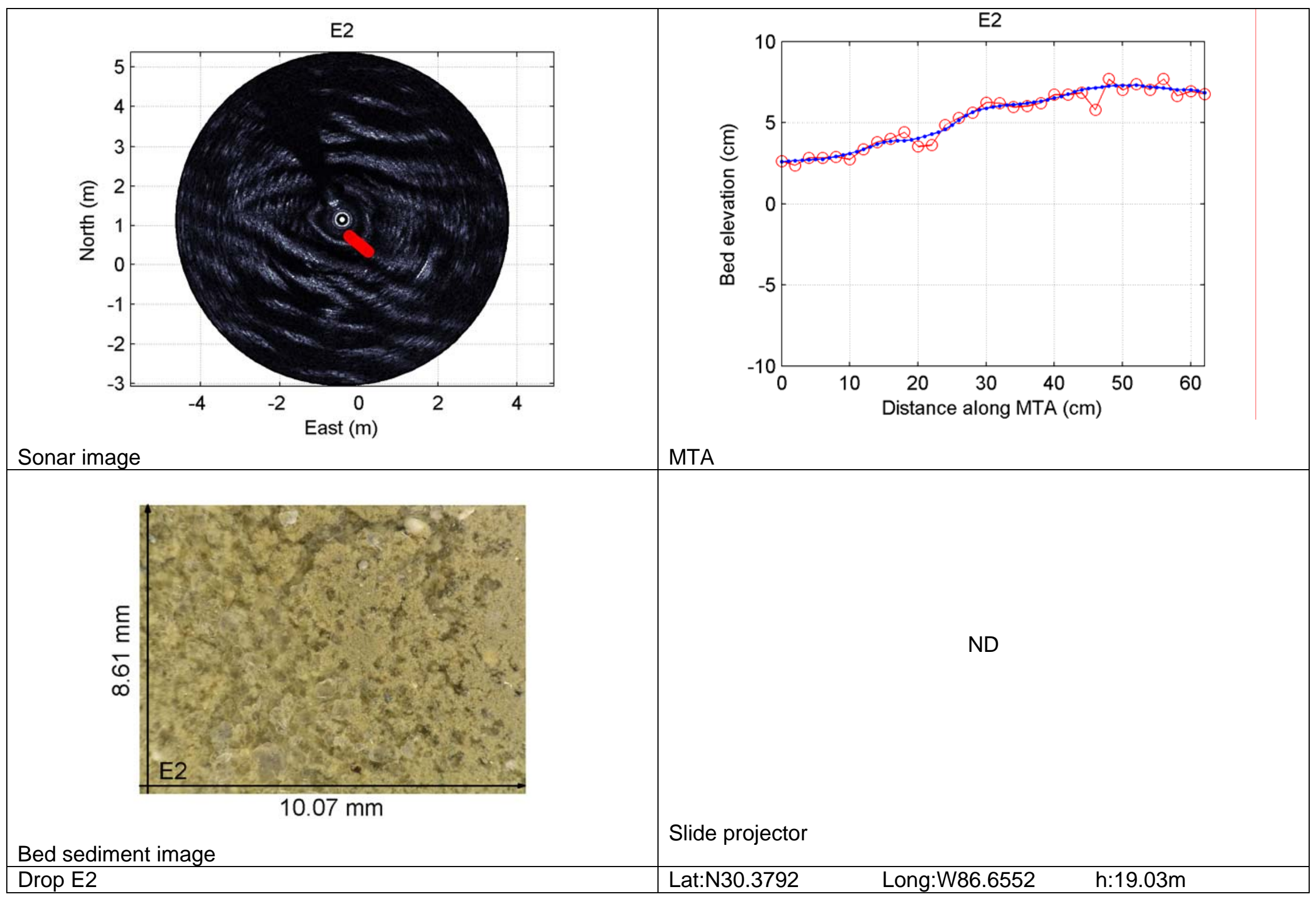




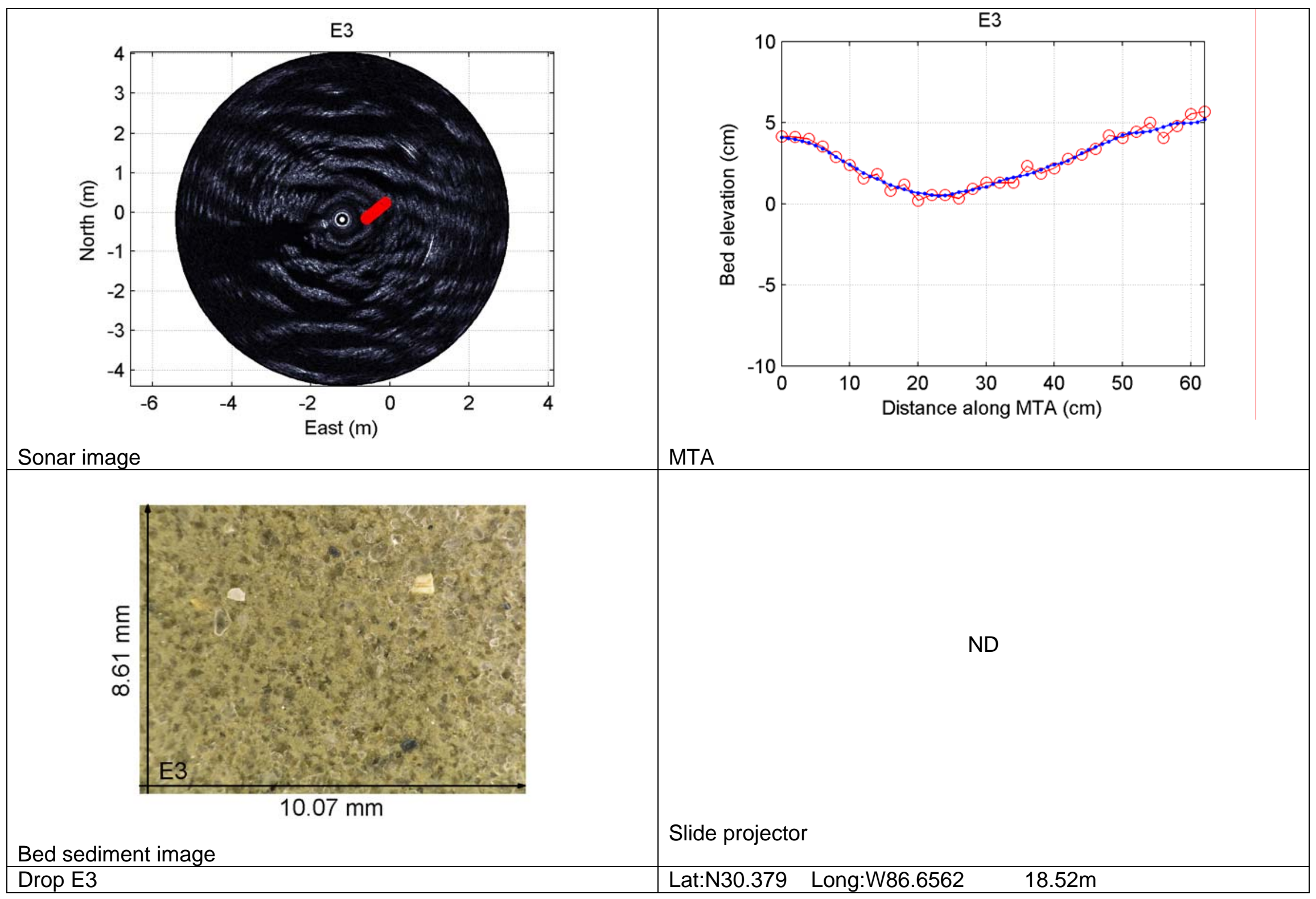




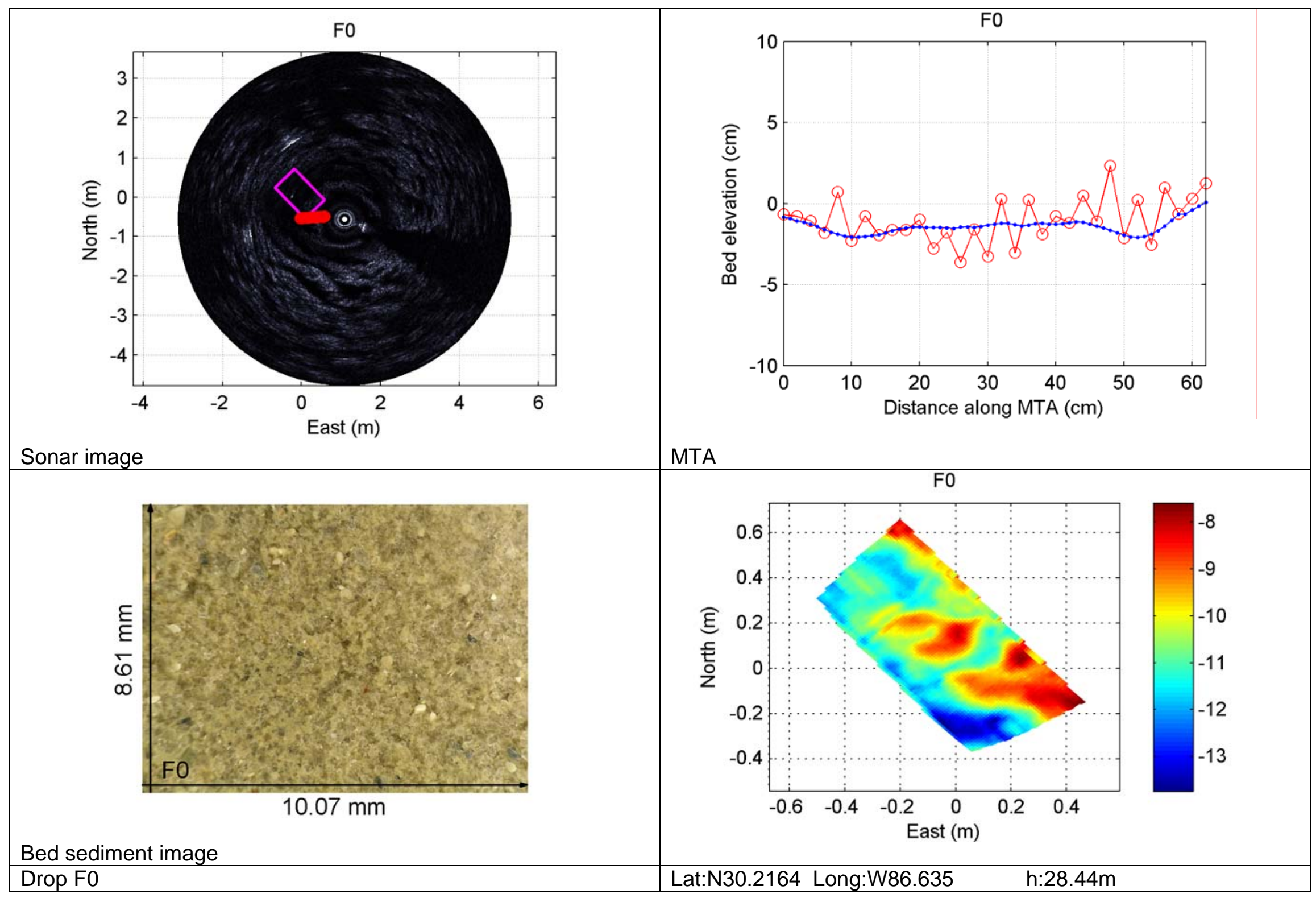




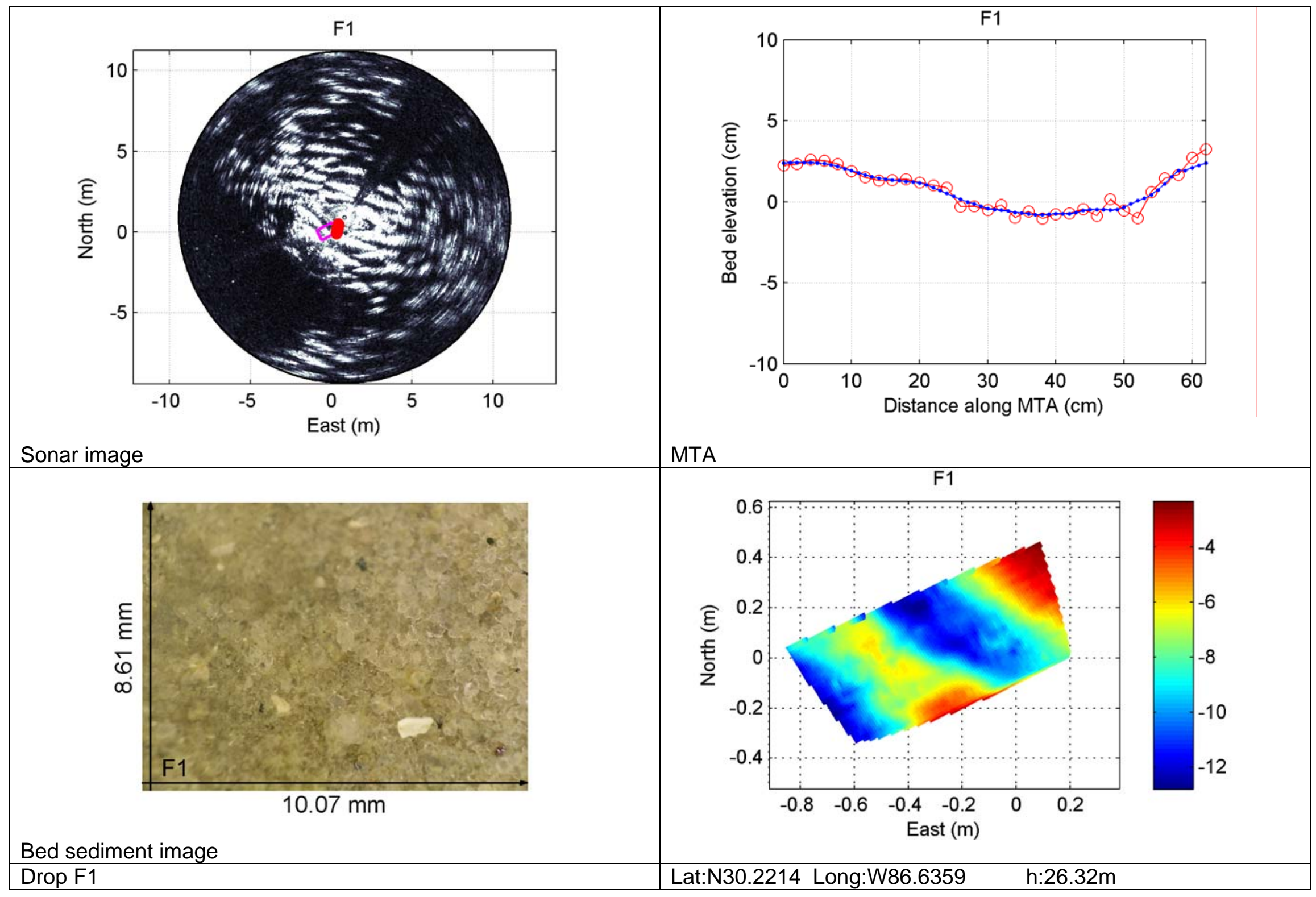




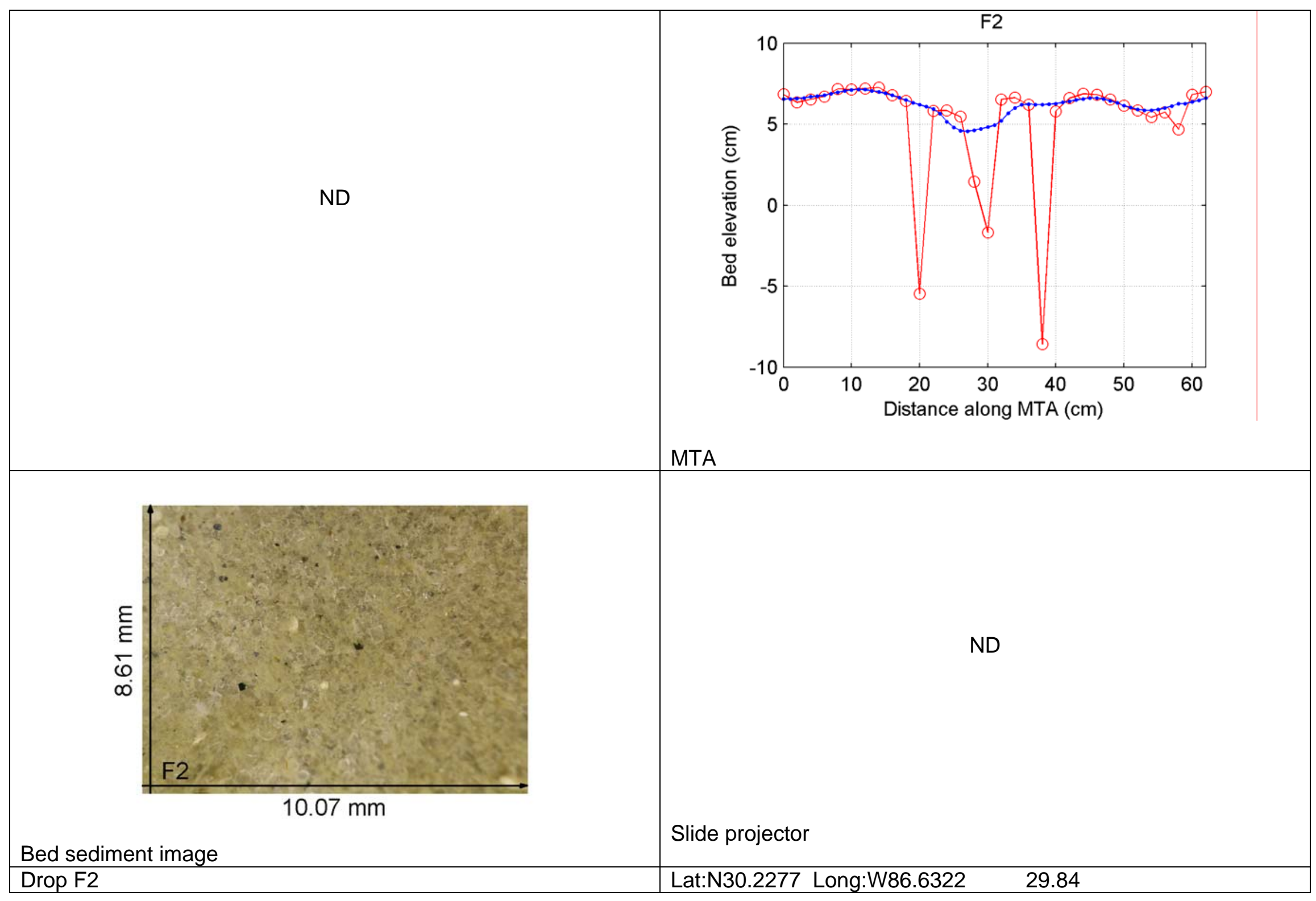




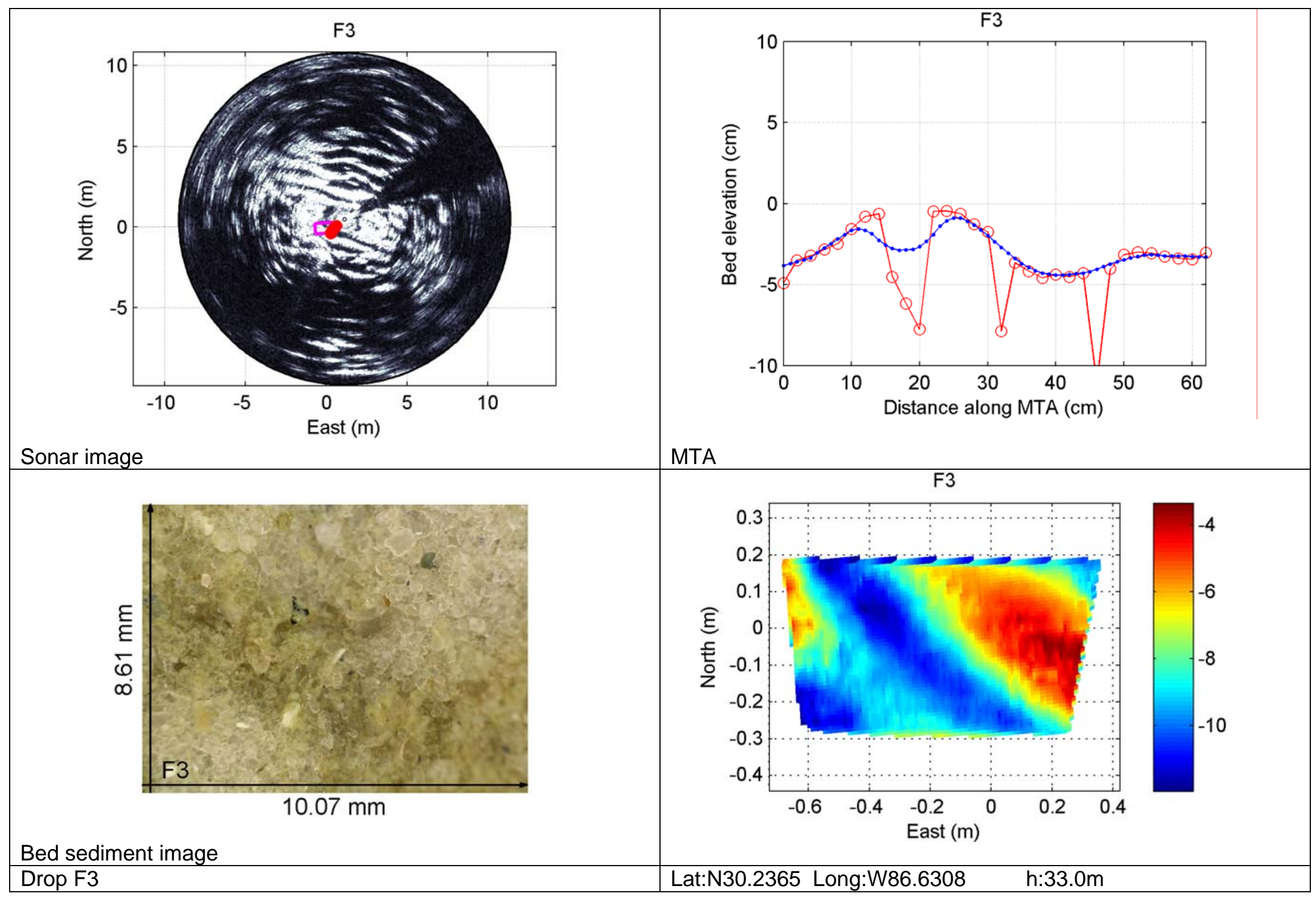




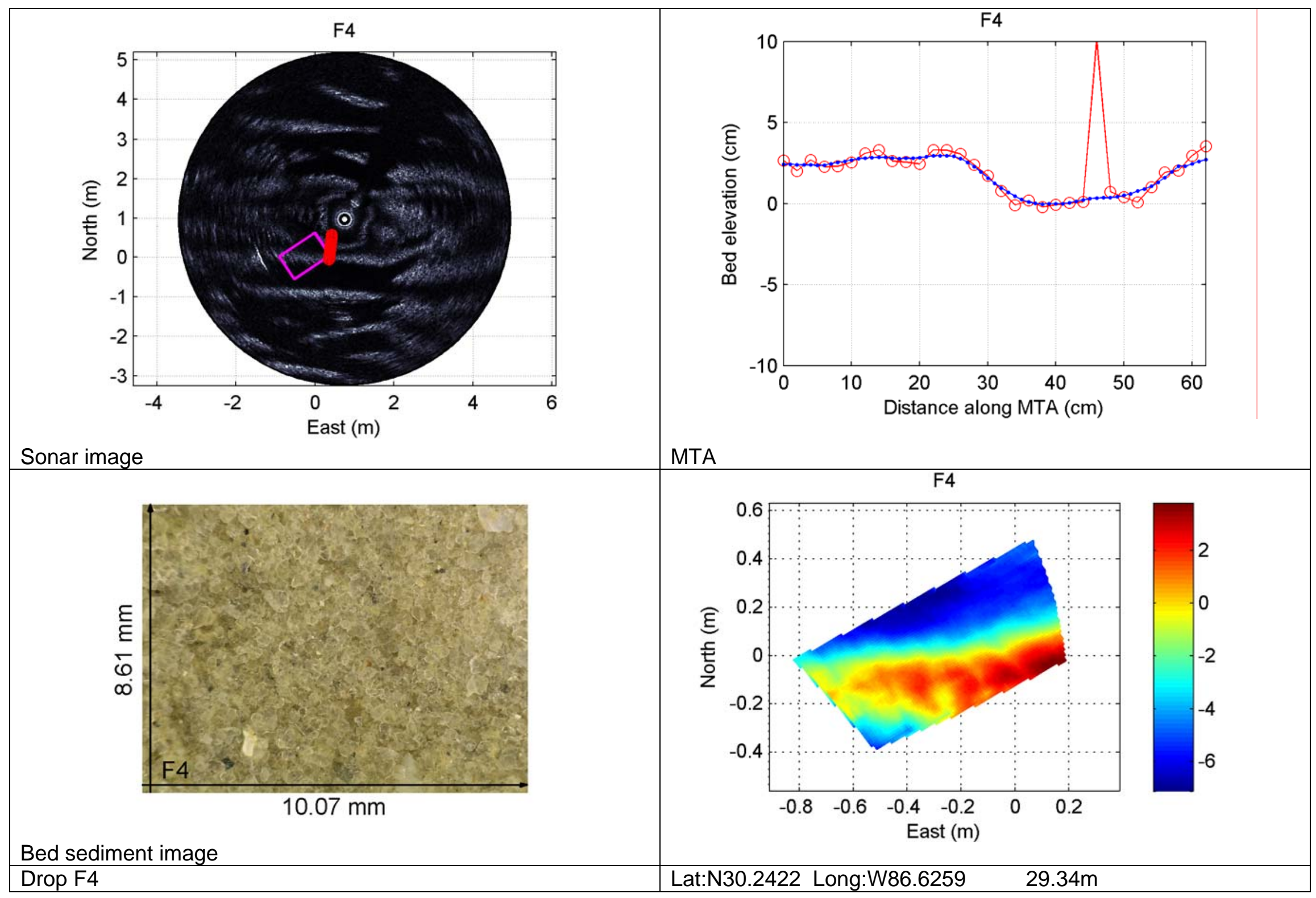




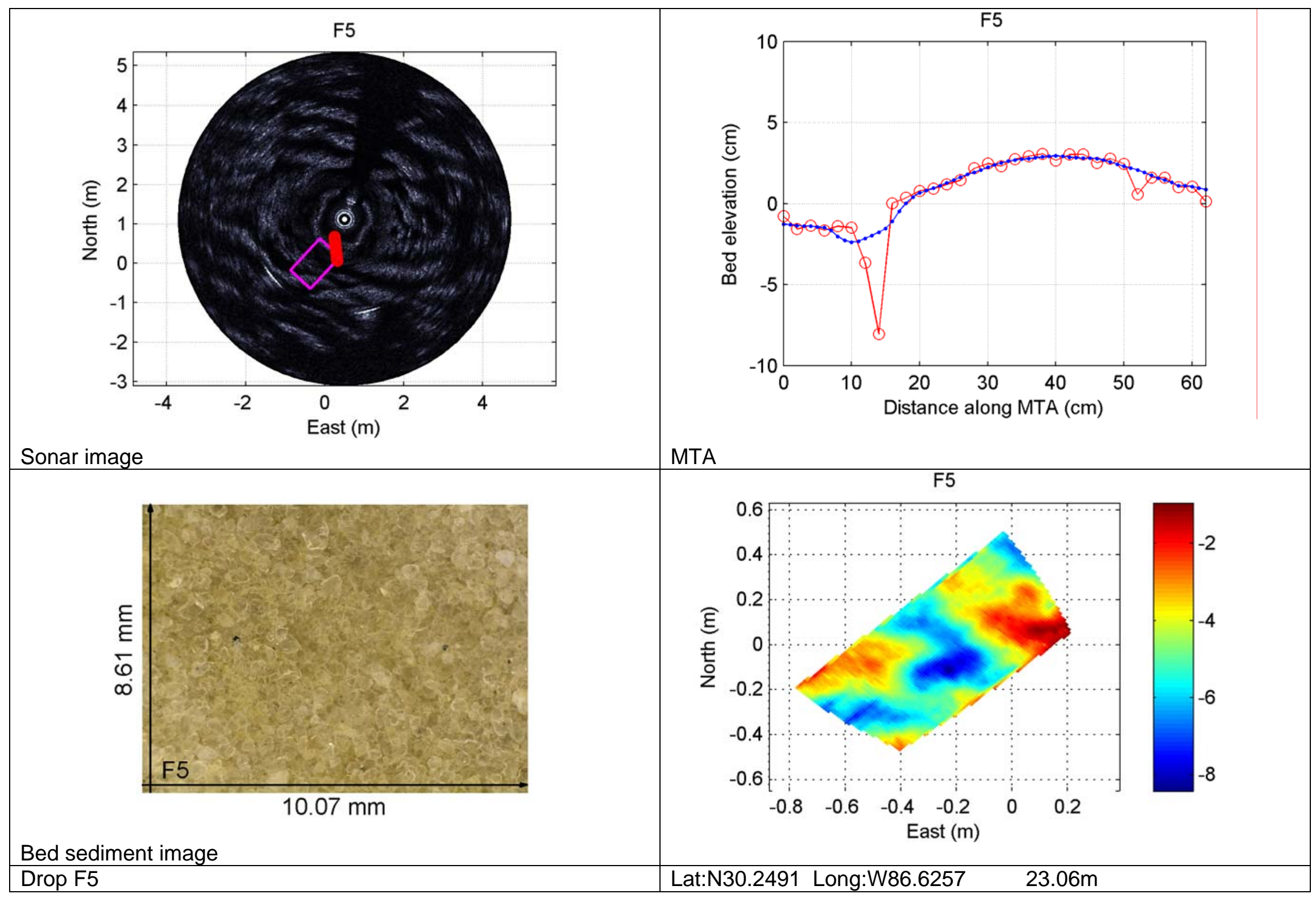




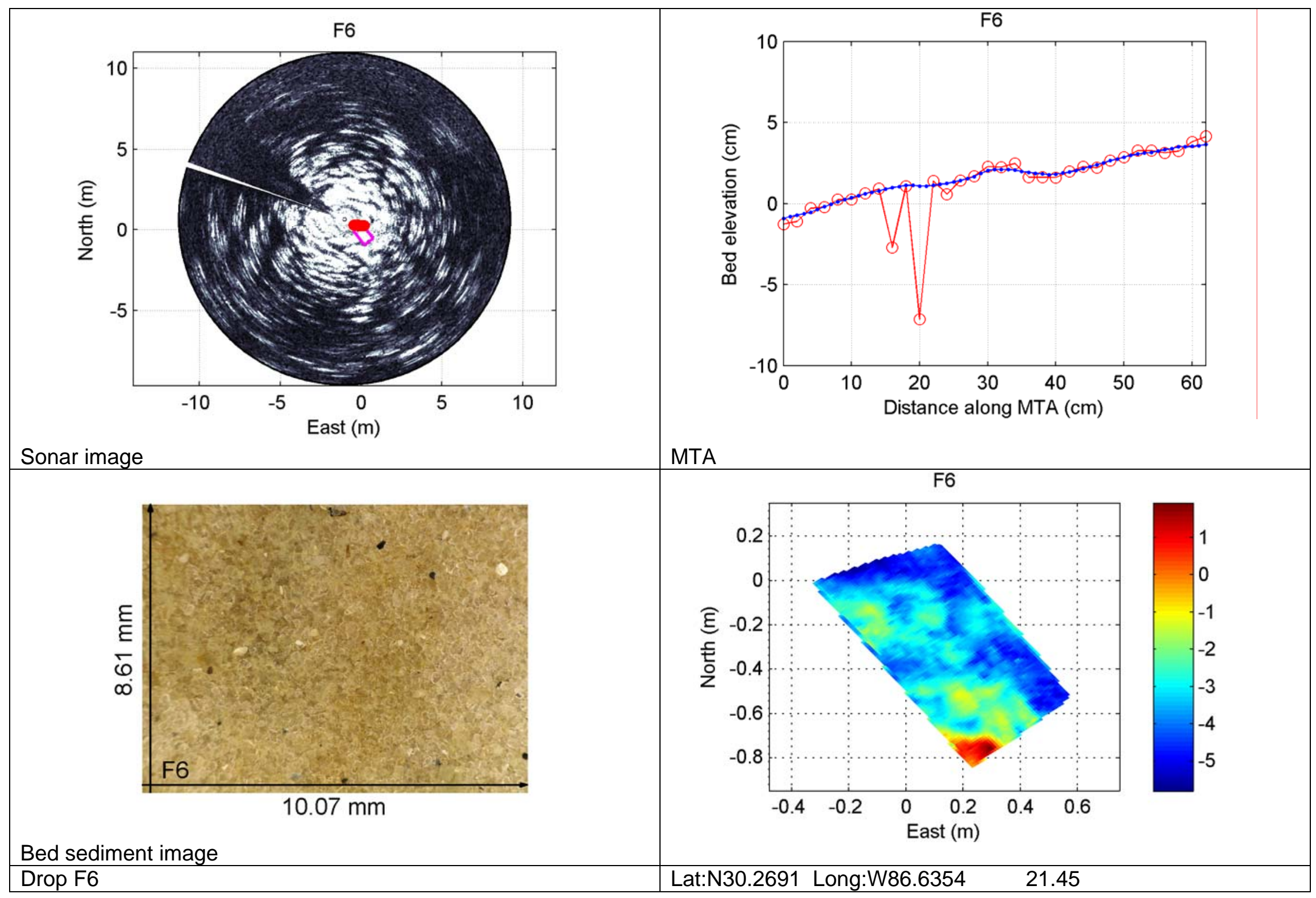




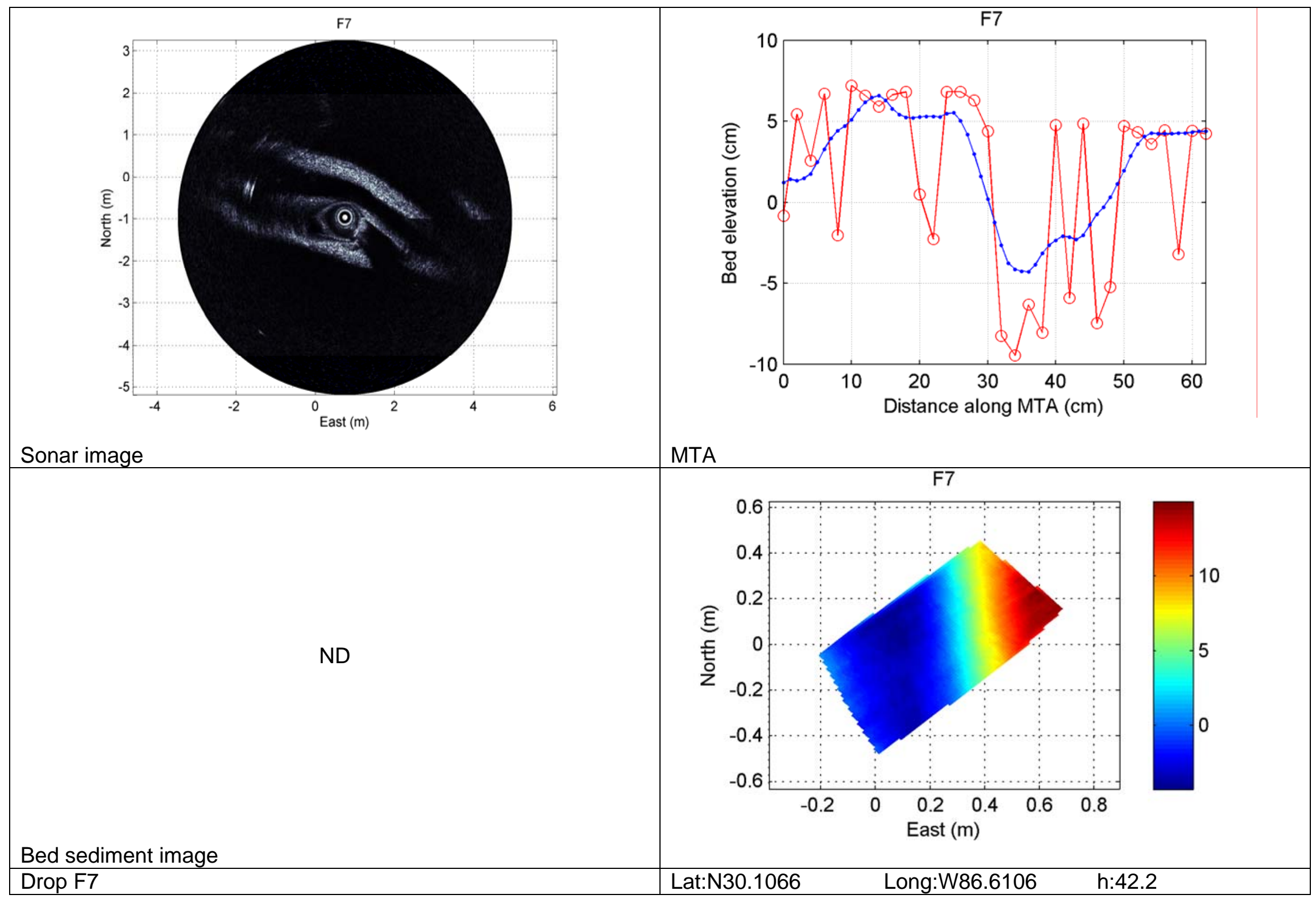




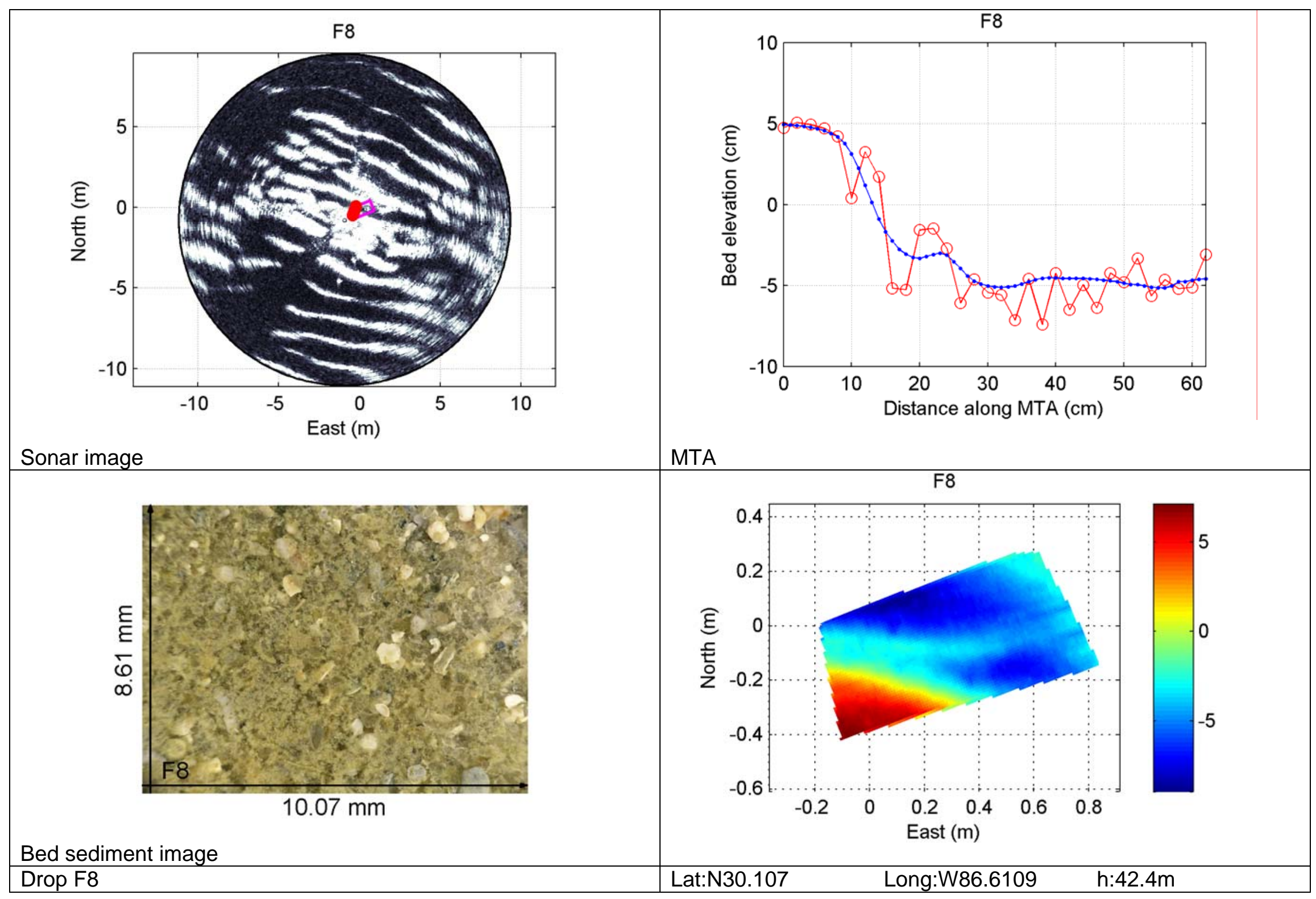




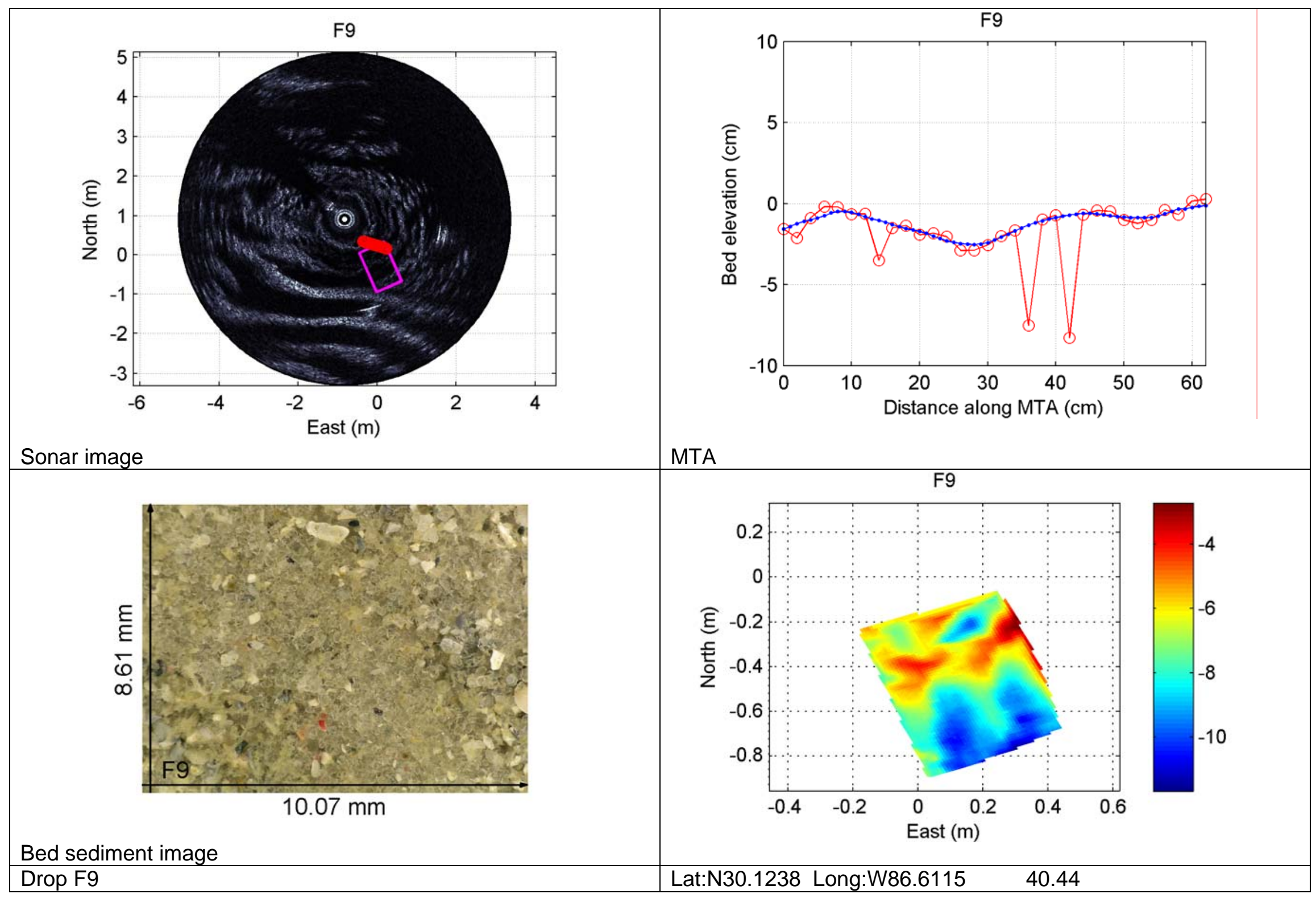




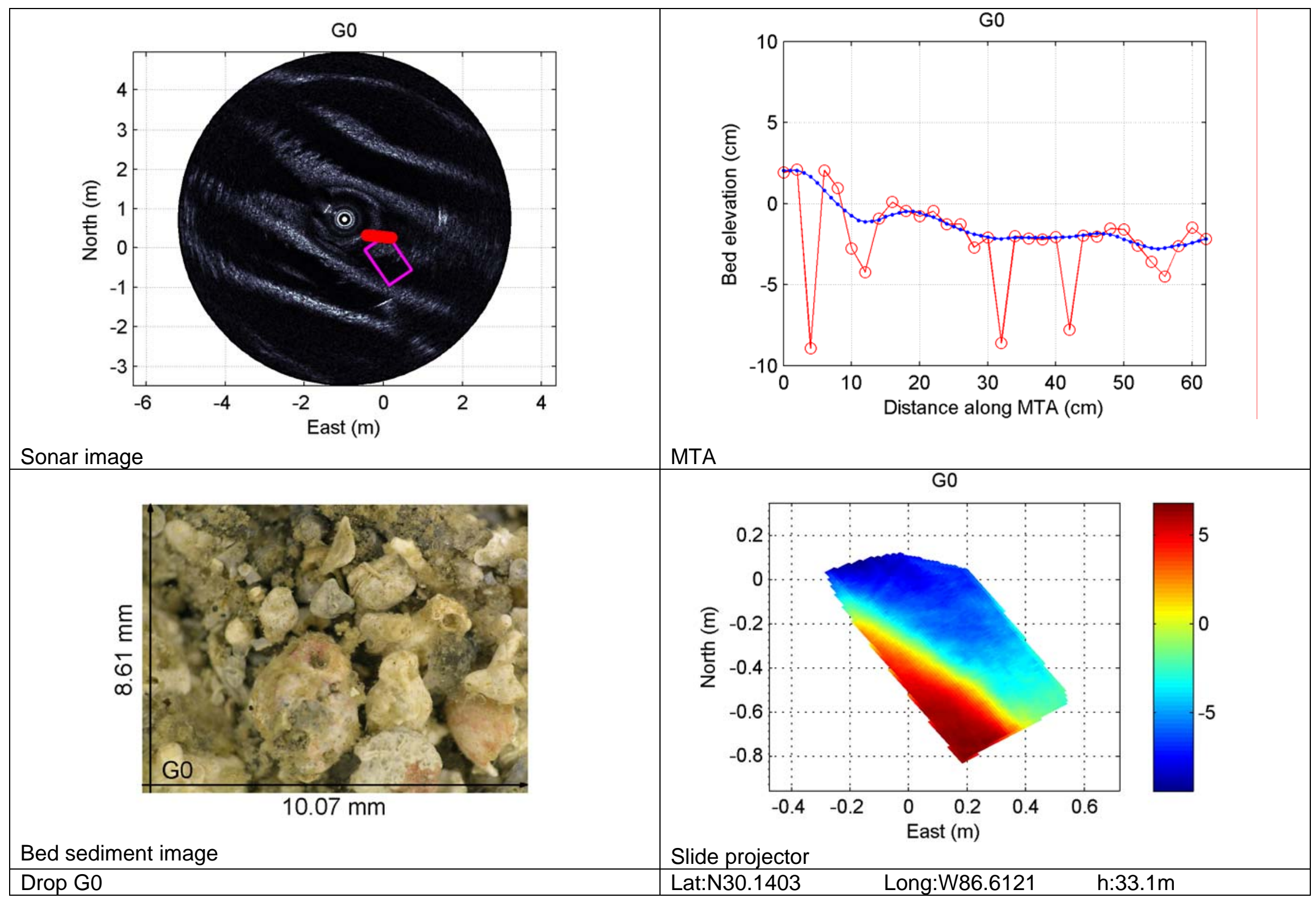




\section{Appendix B: Cruise II Data Summary}

The following pages consist of data images and plots from the INX sonar, multiple transducer array (MTA), slide projector $(\mathrm{SP})$, and bed sediment camera. The MTA bed level is referenced to the horizontal plane passing through the tripod bottom; the slide projector is referenced to a plane approximate parallel and equal to $6 \mathrm{~cm}$ above the base of the tripod. Although more than one sonar image exists for nearly each drop, only the image of highest quality is shown. 


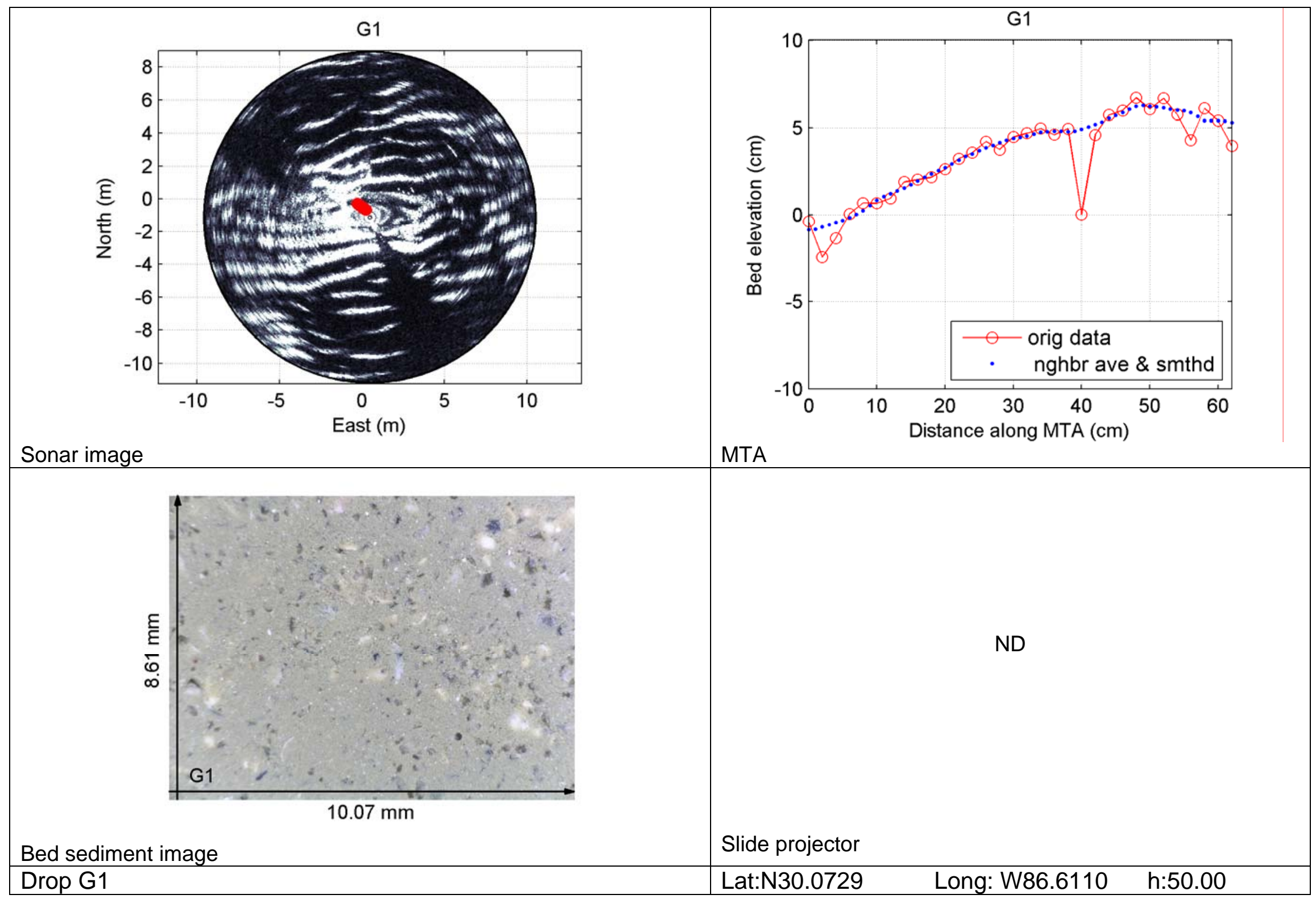




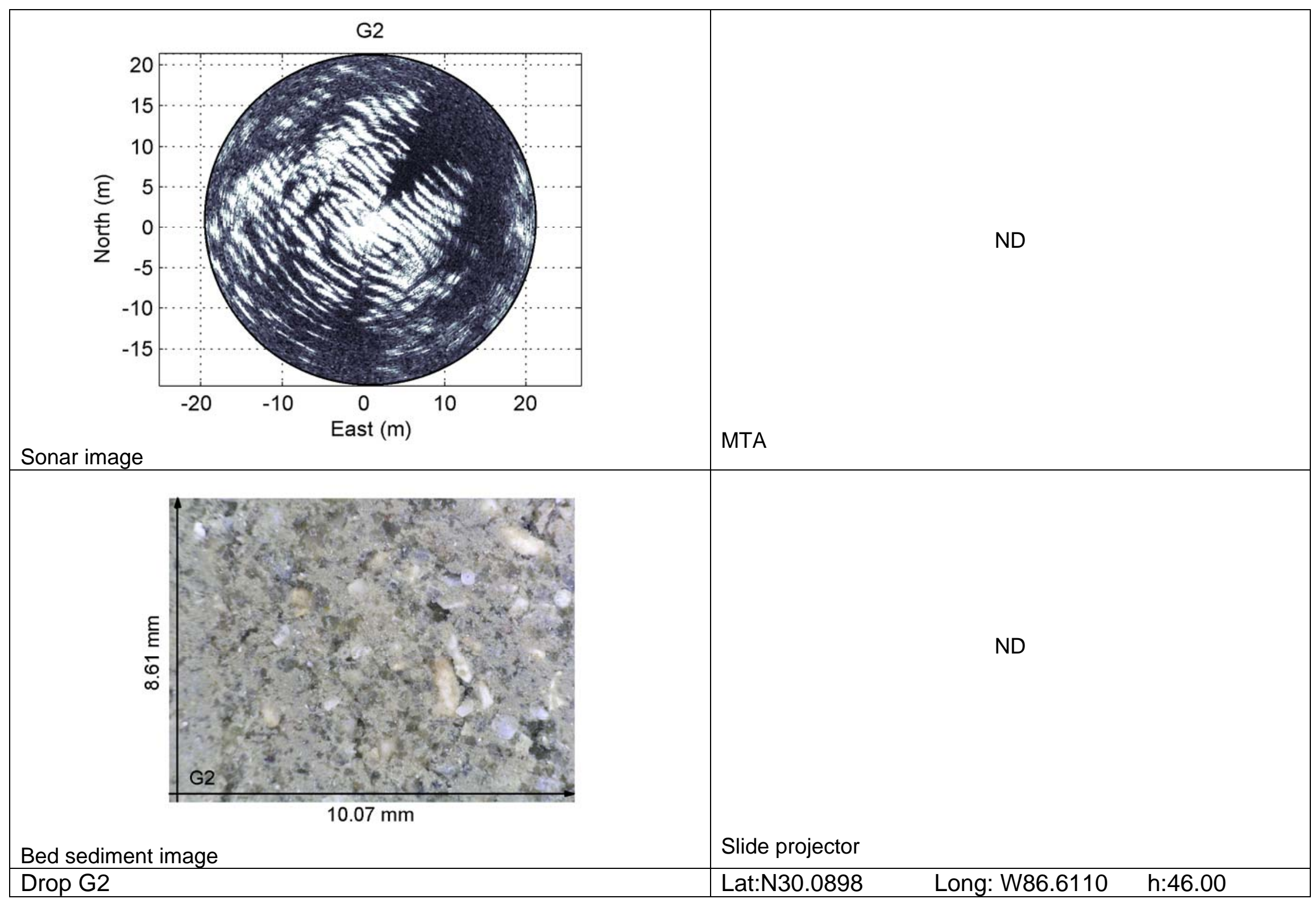




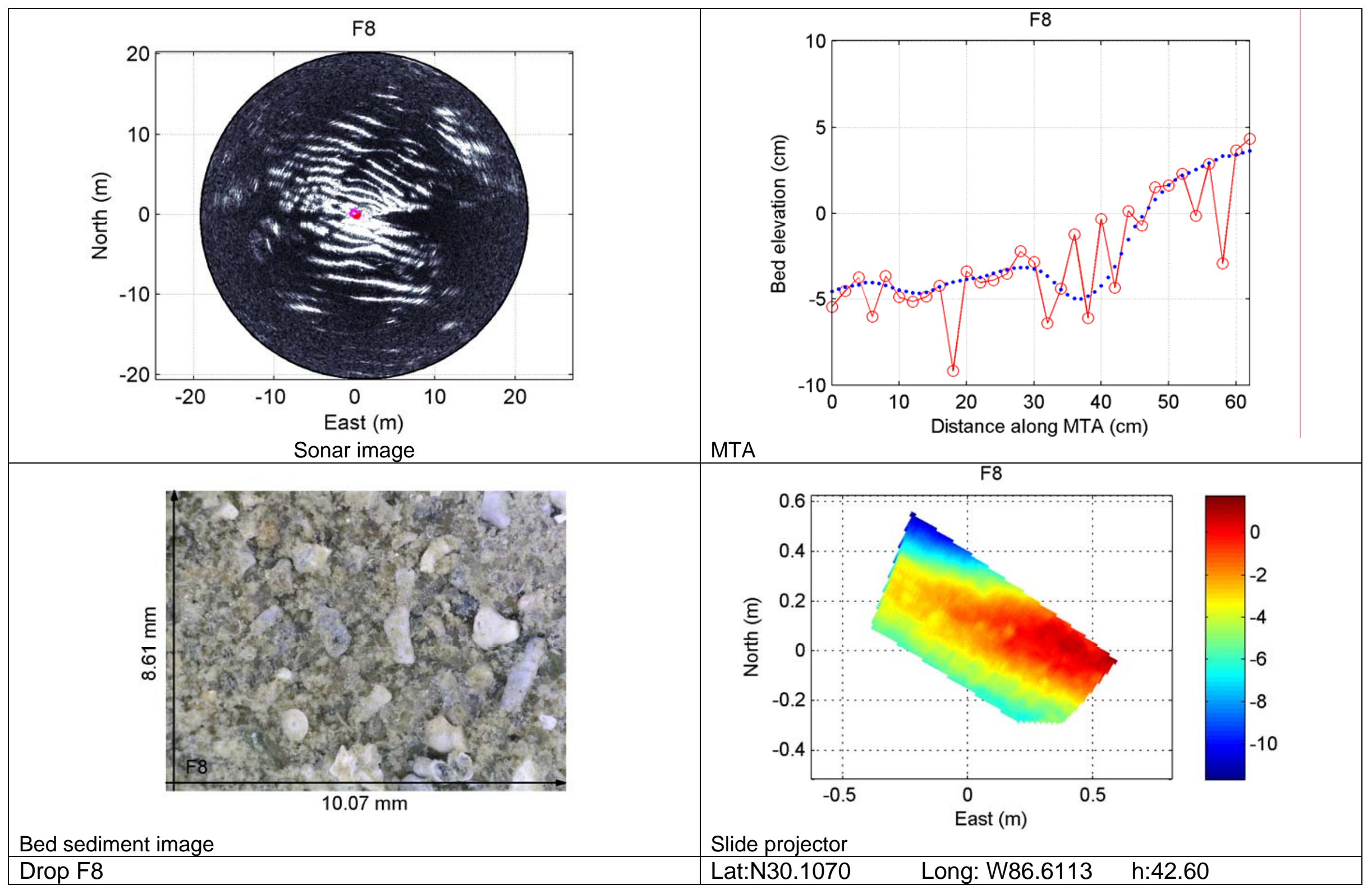




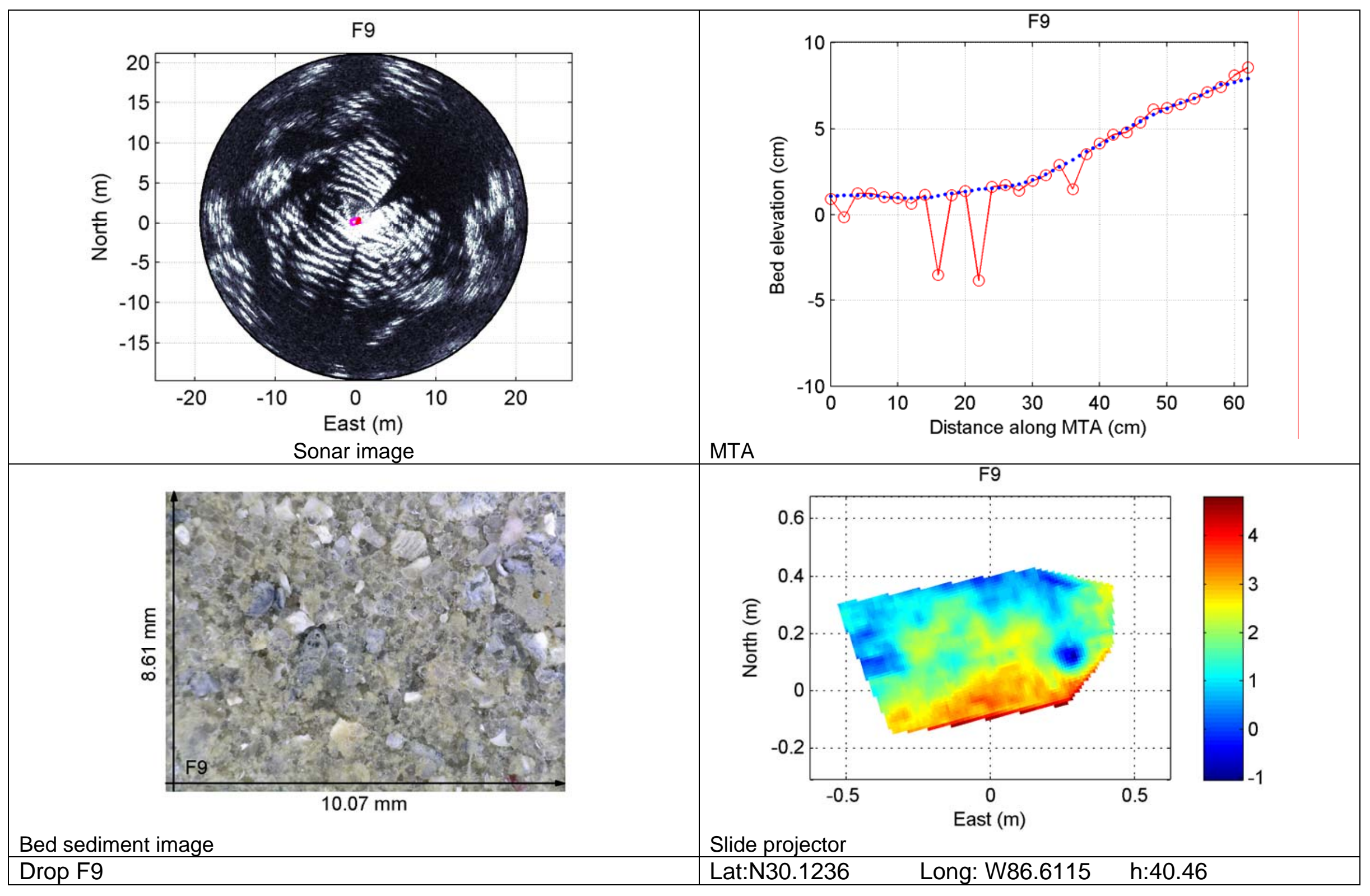




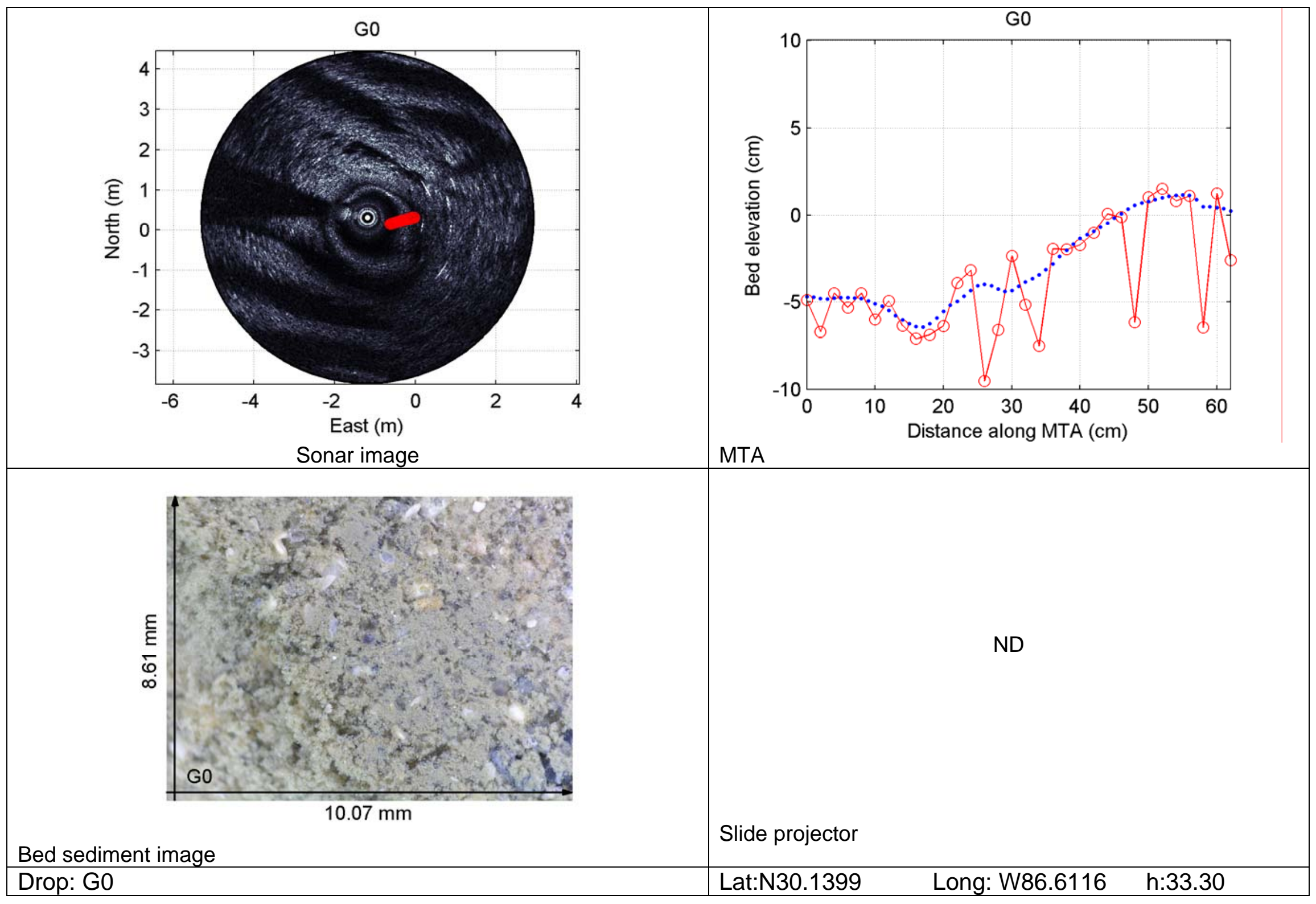




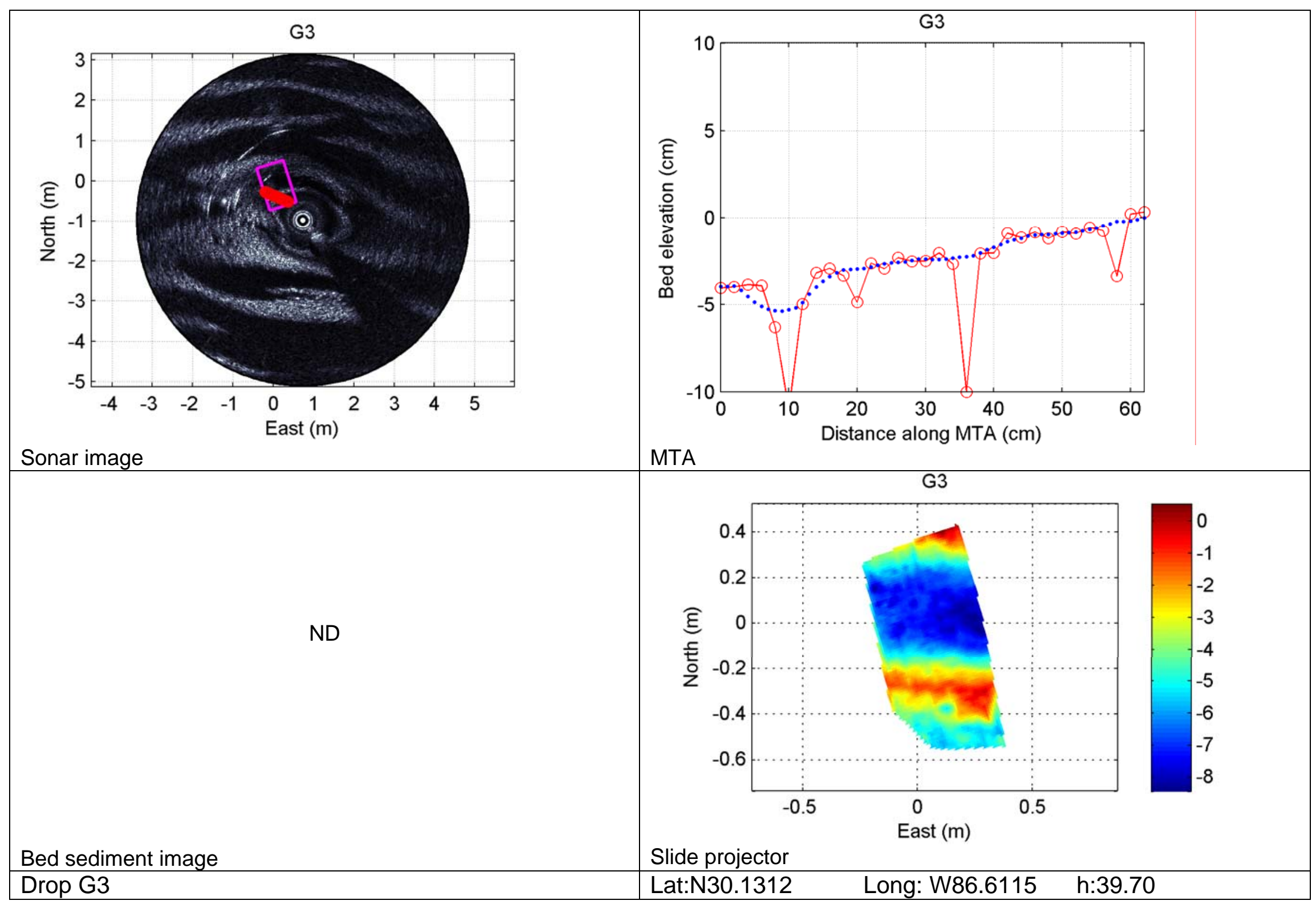




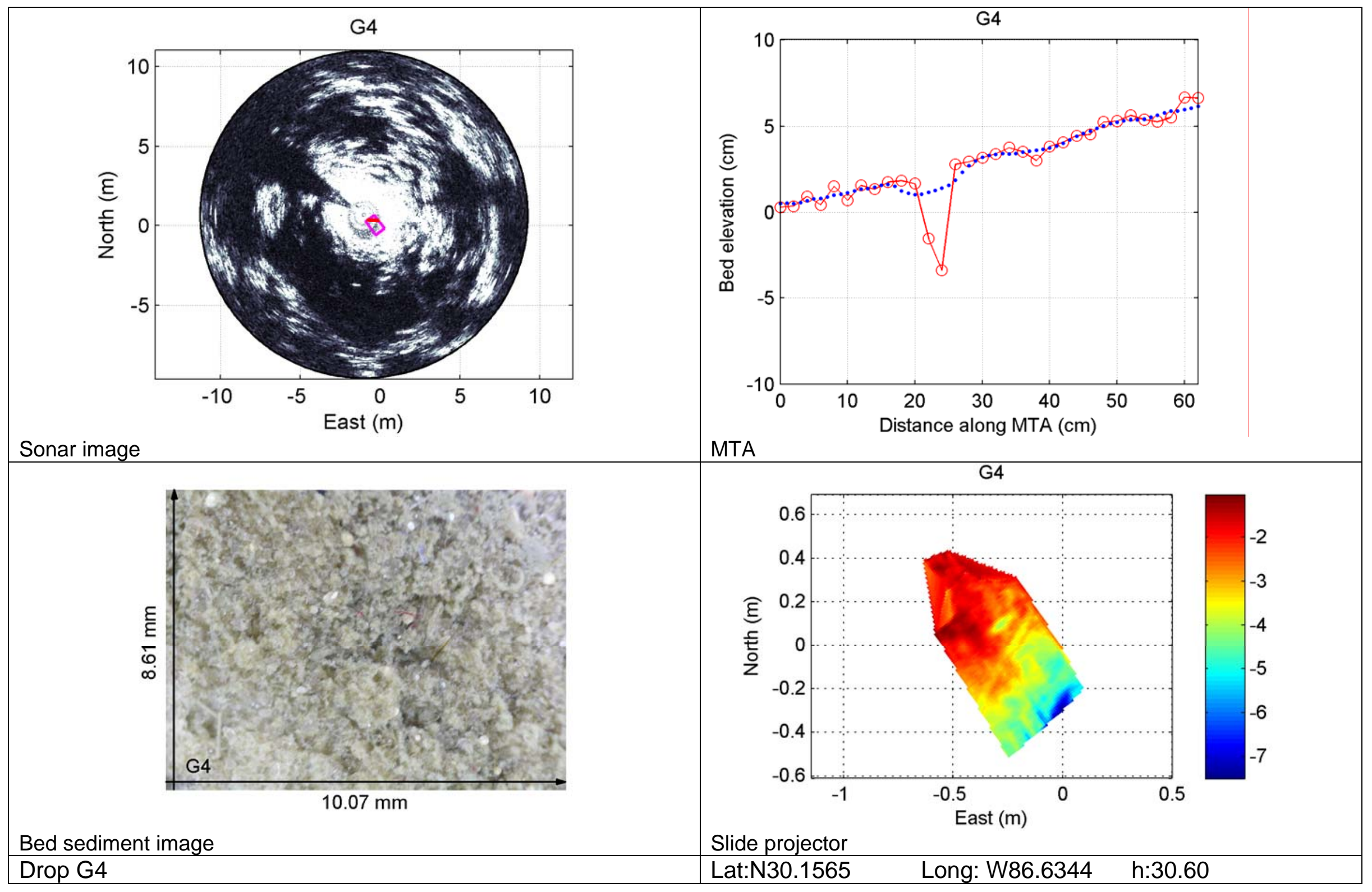




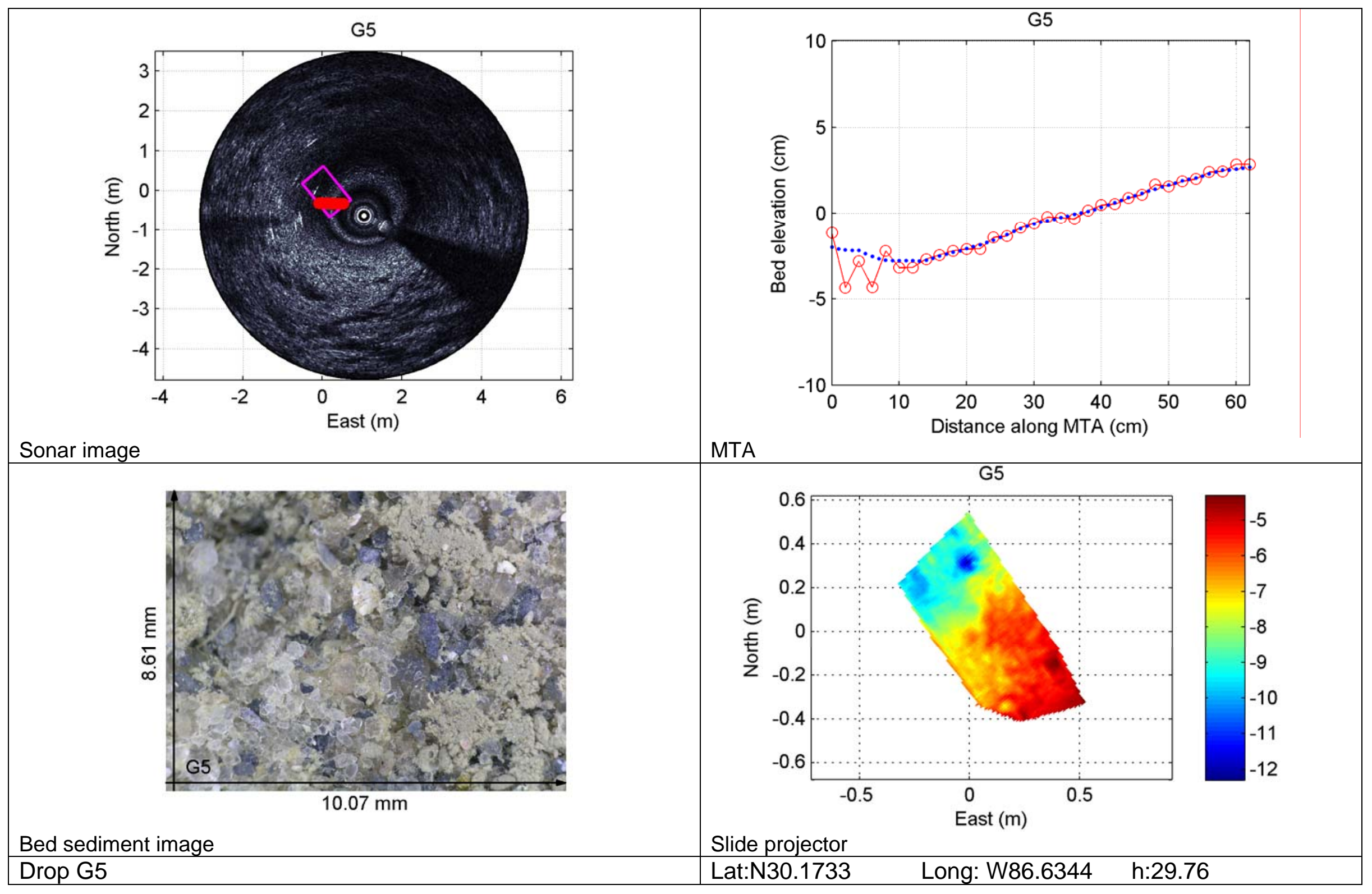




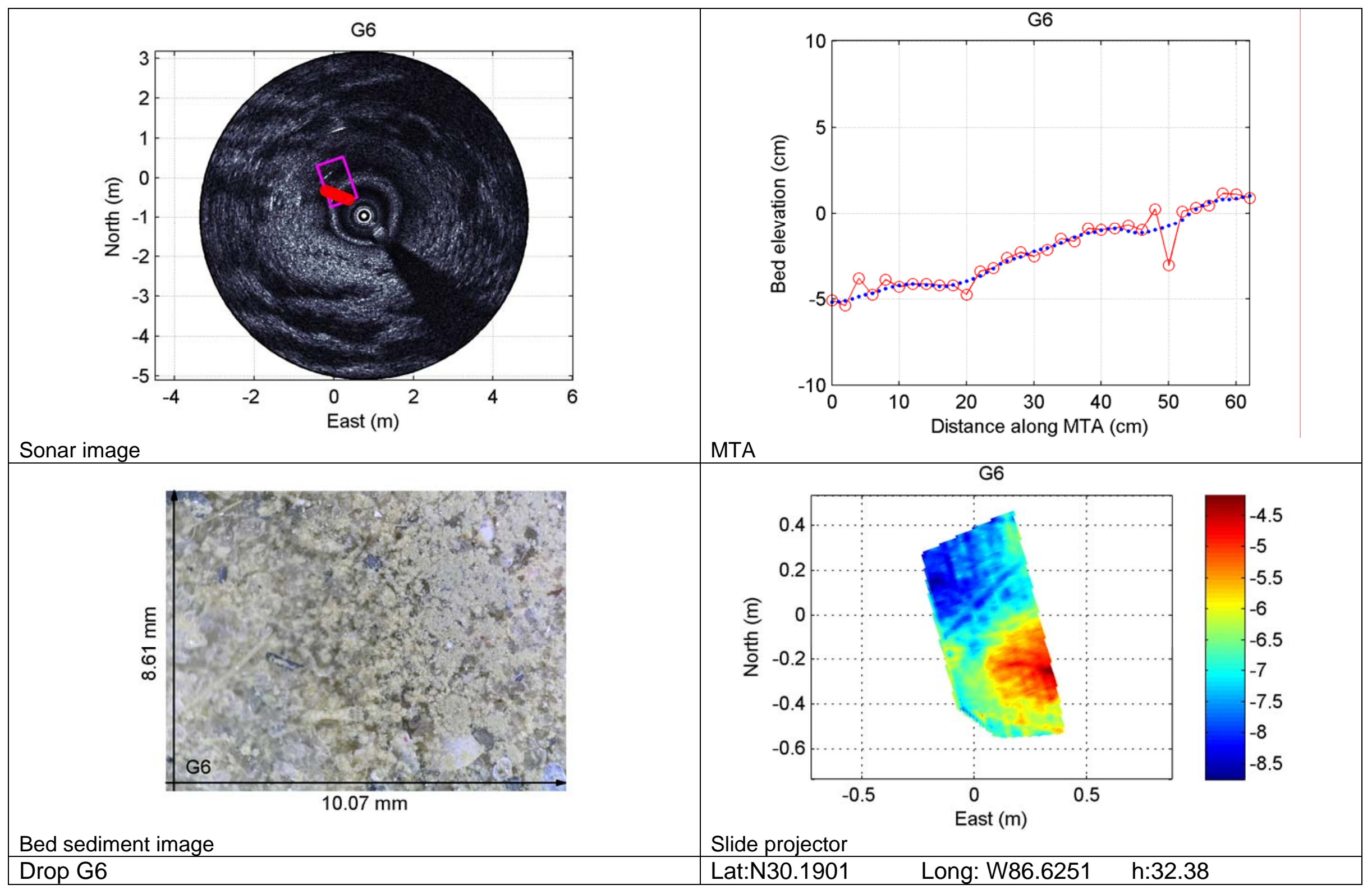




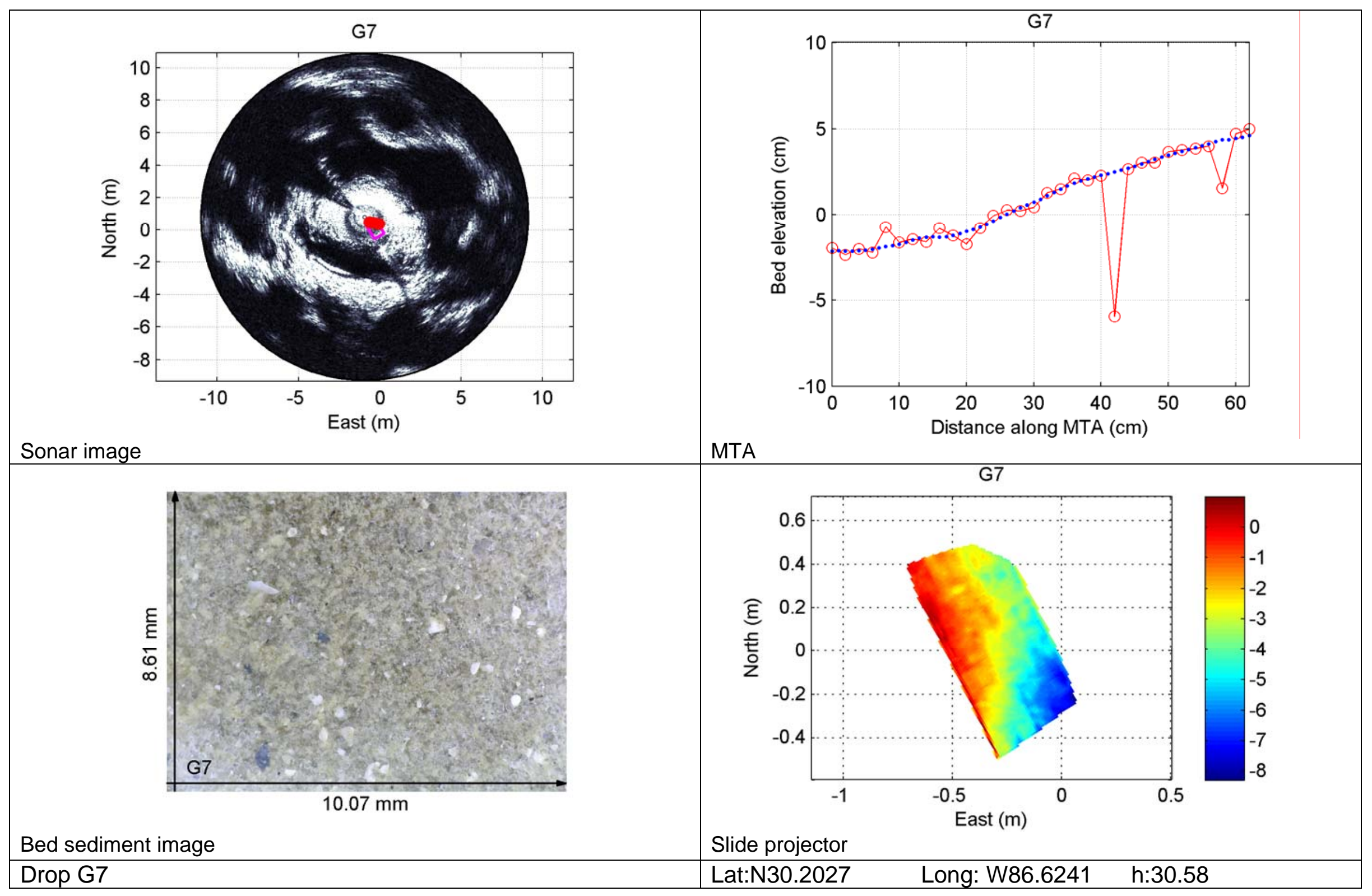




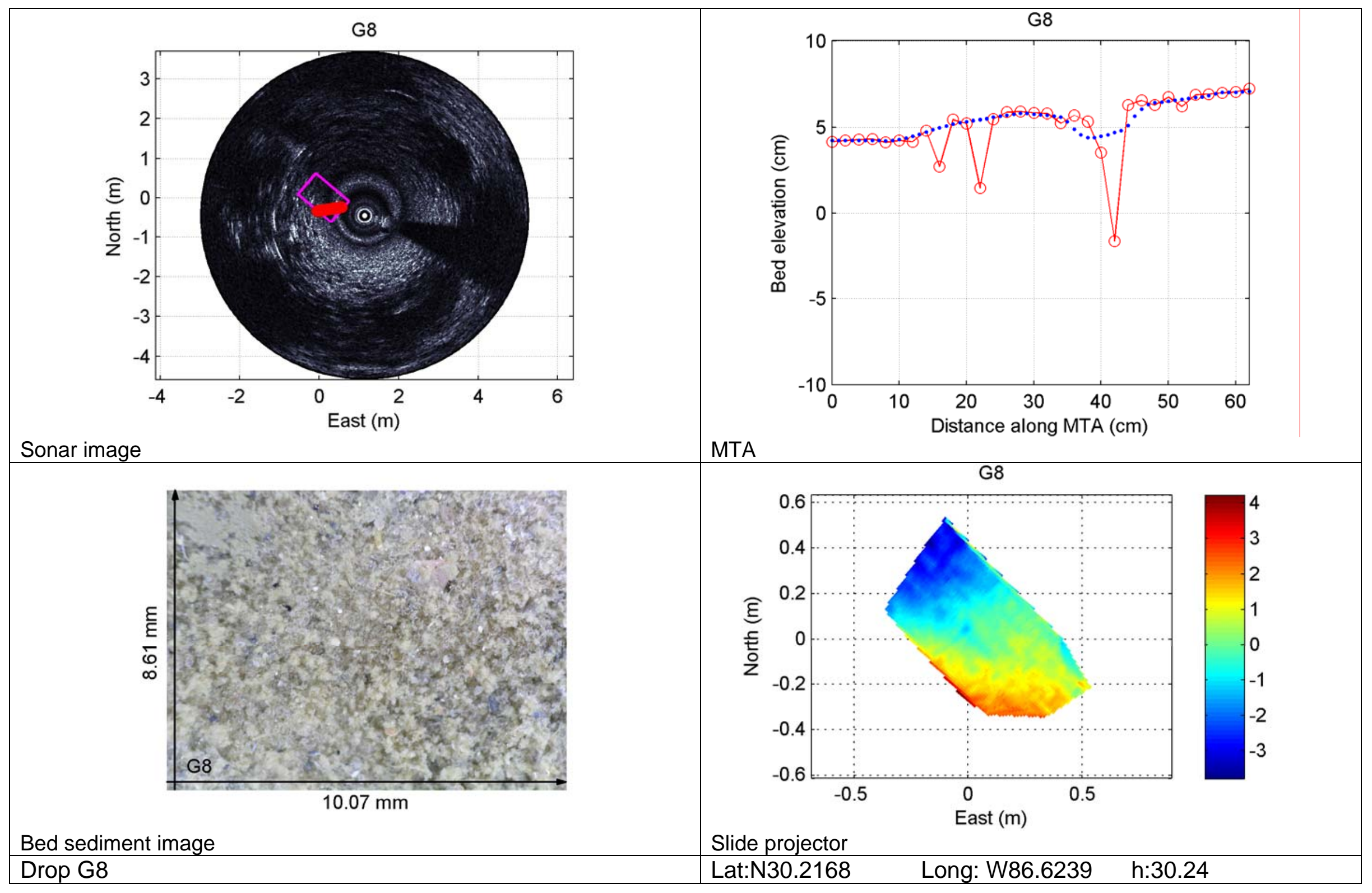




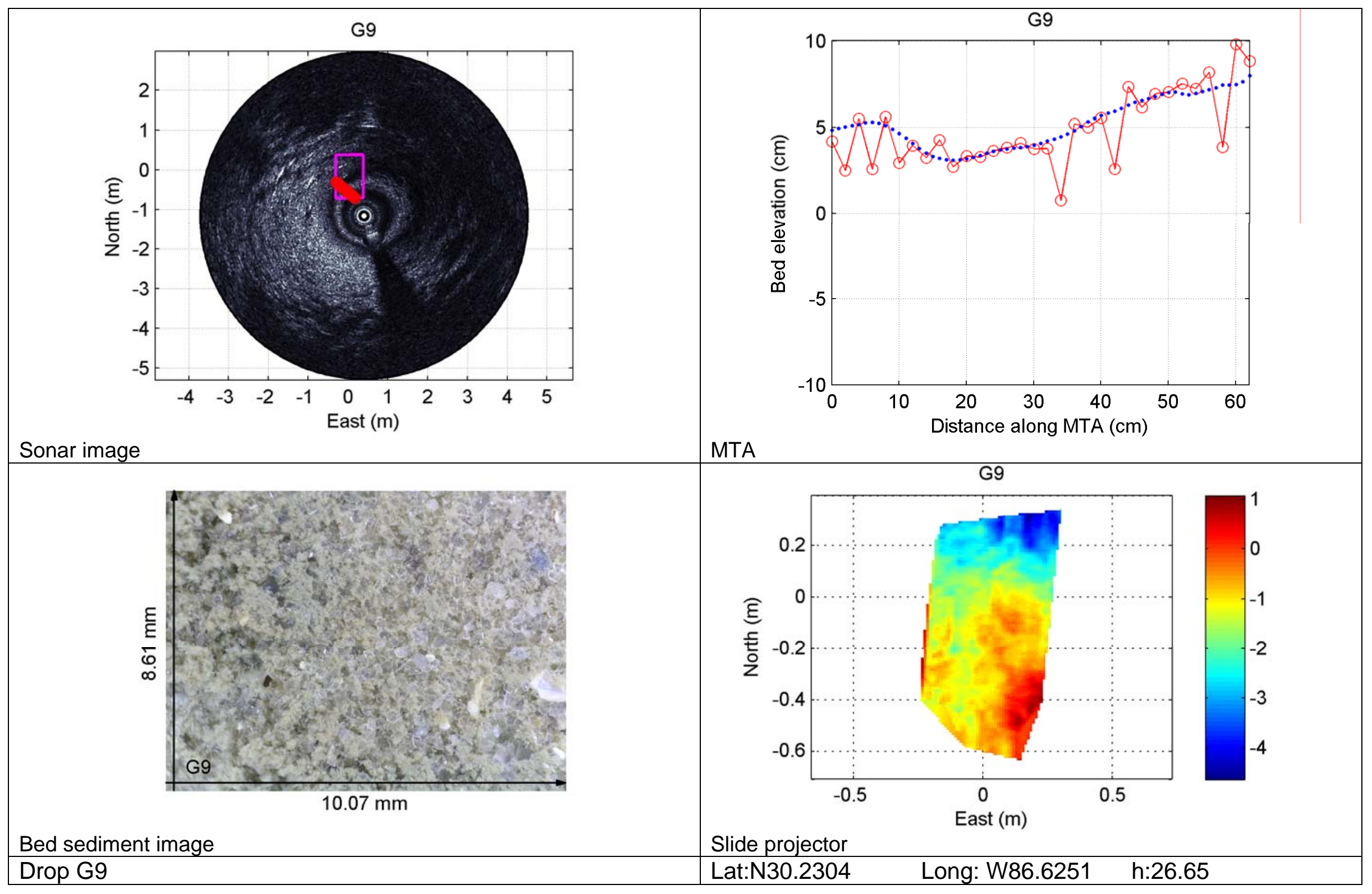




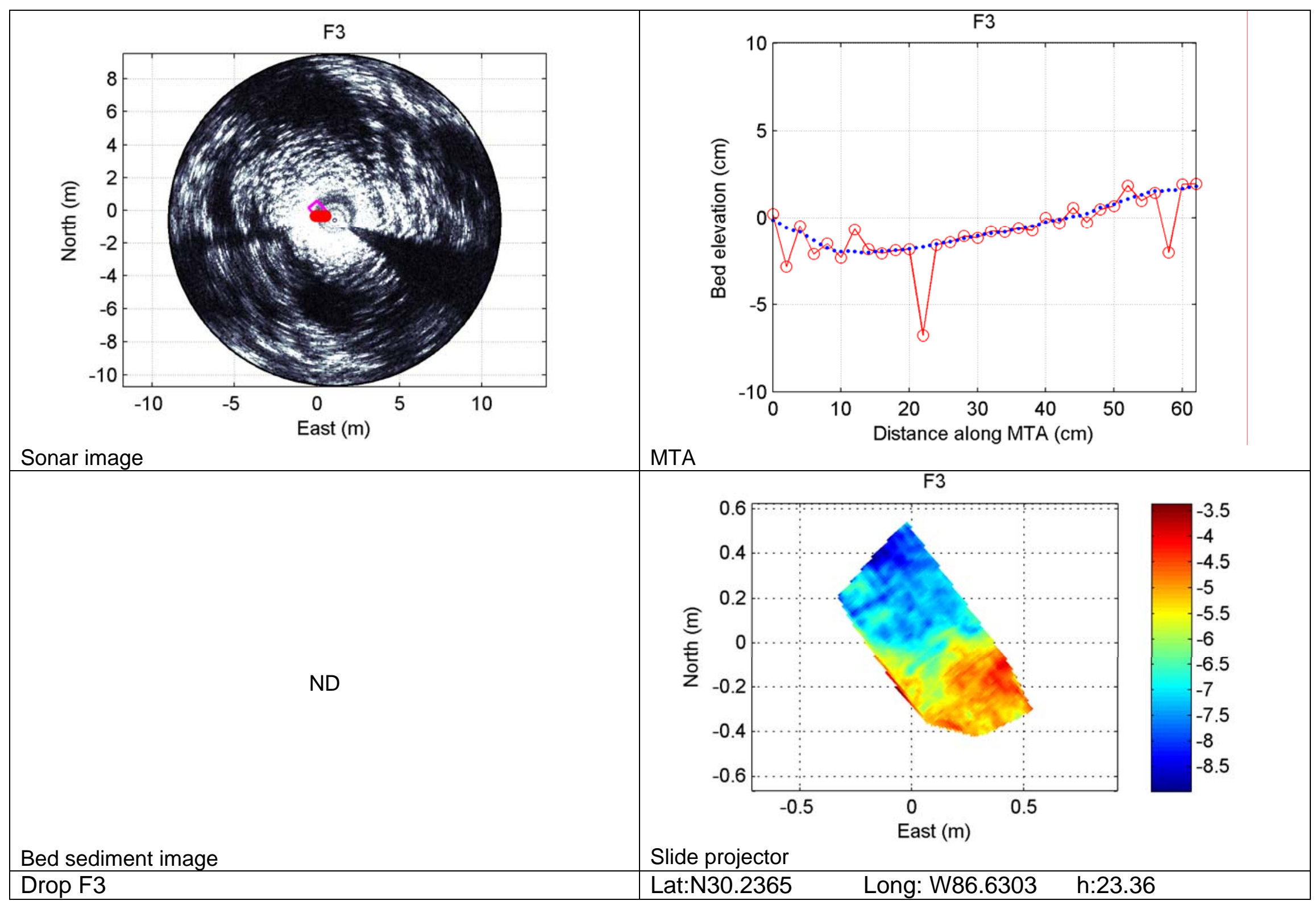




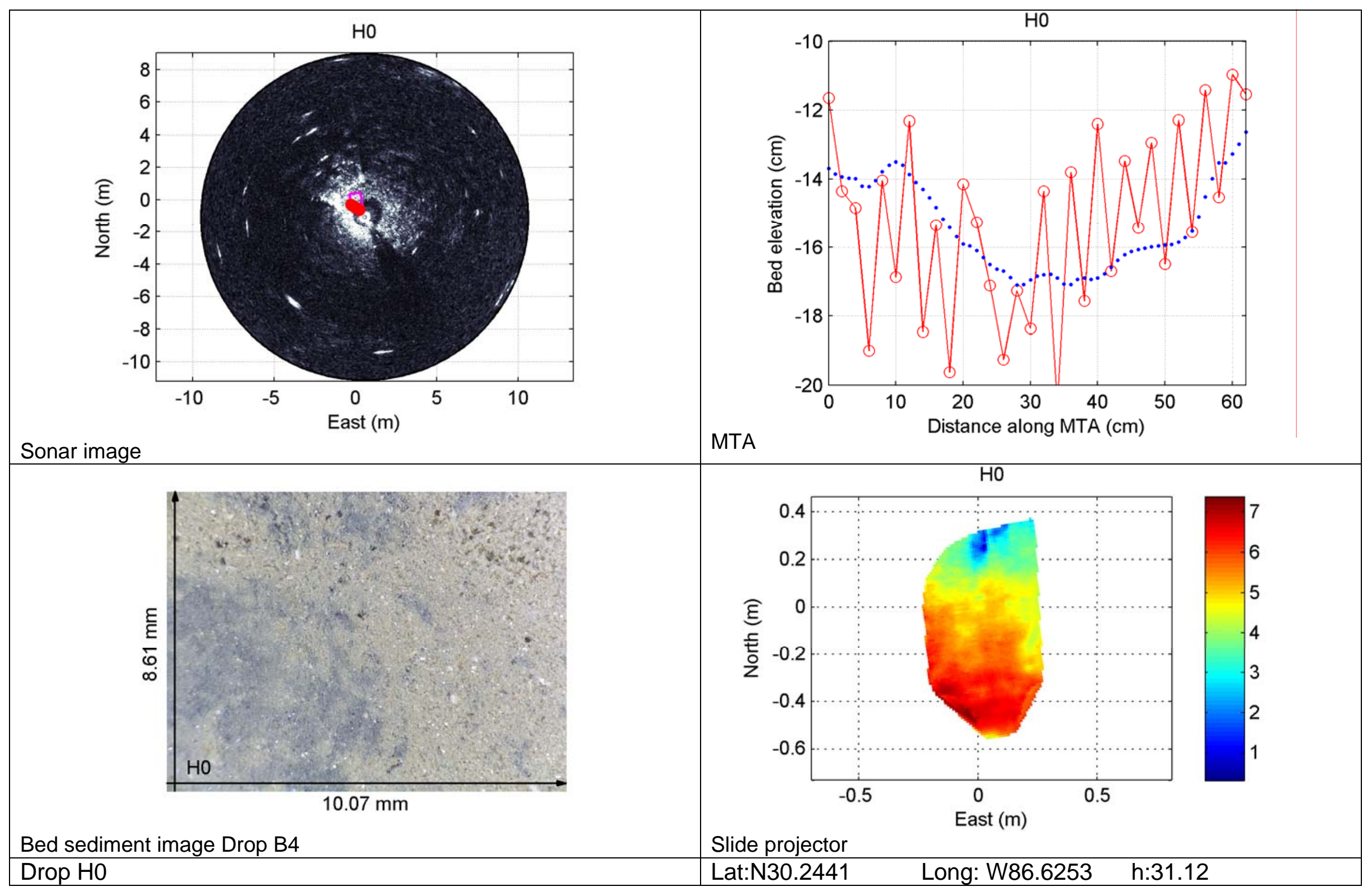




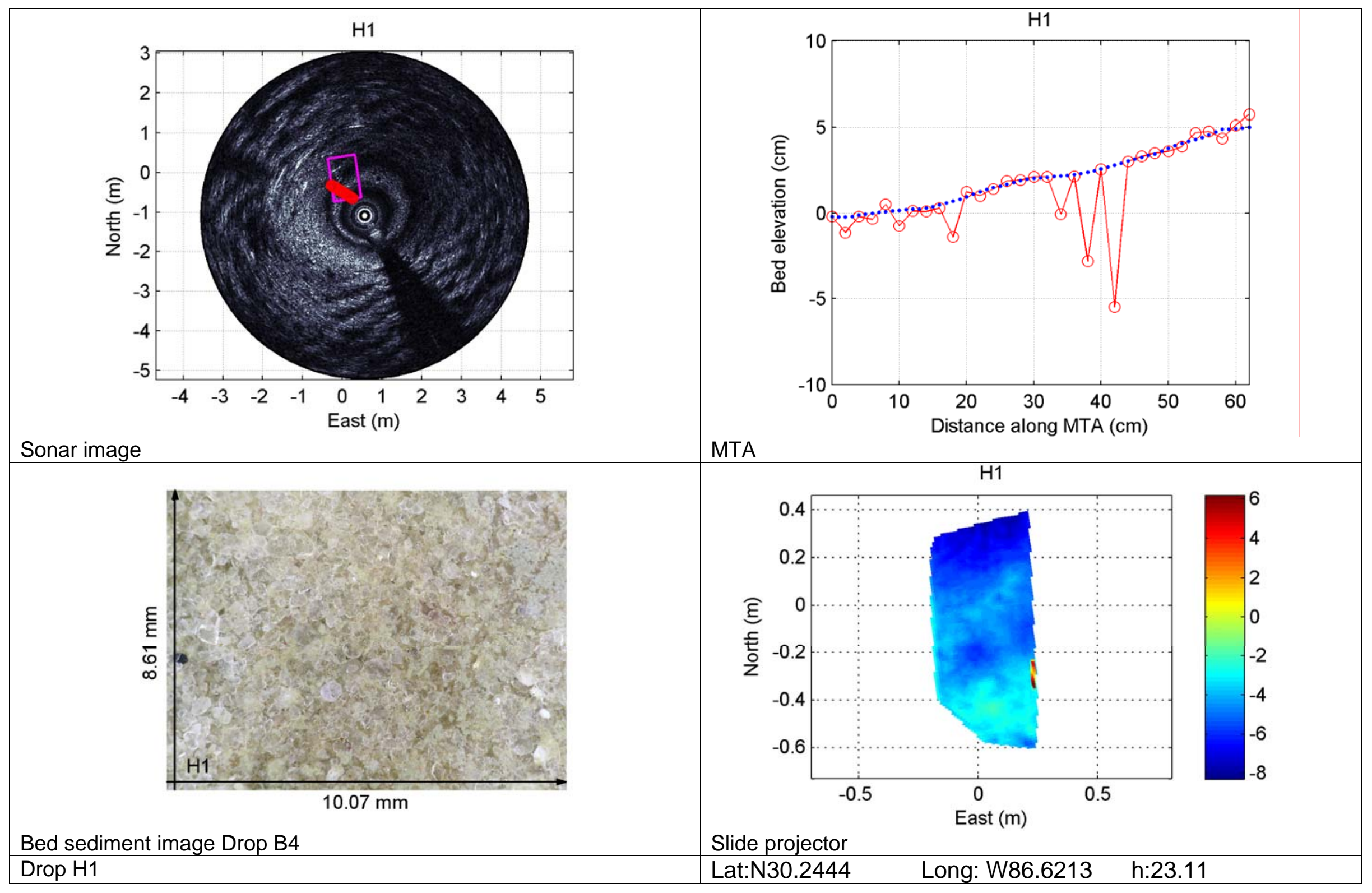




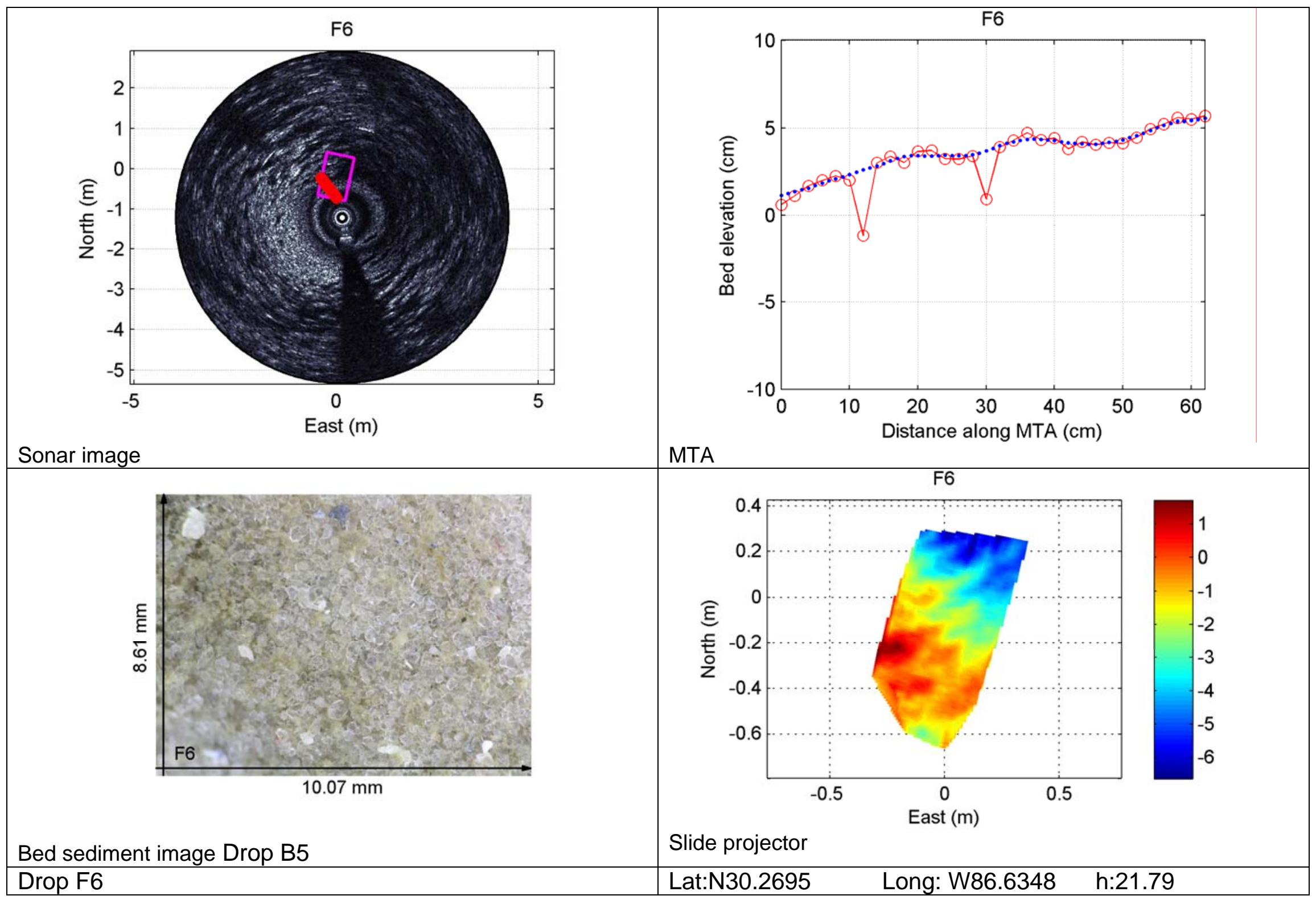




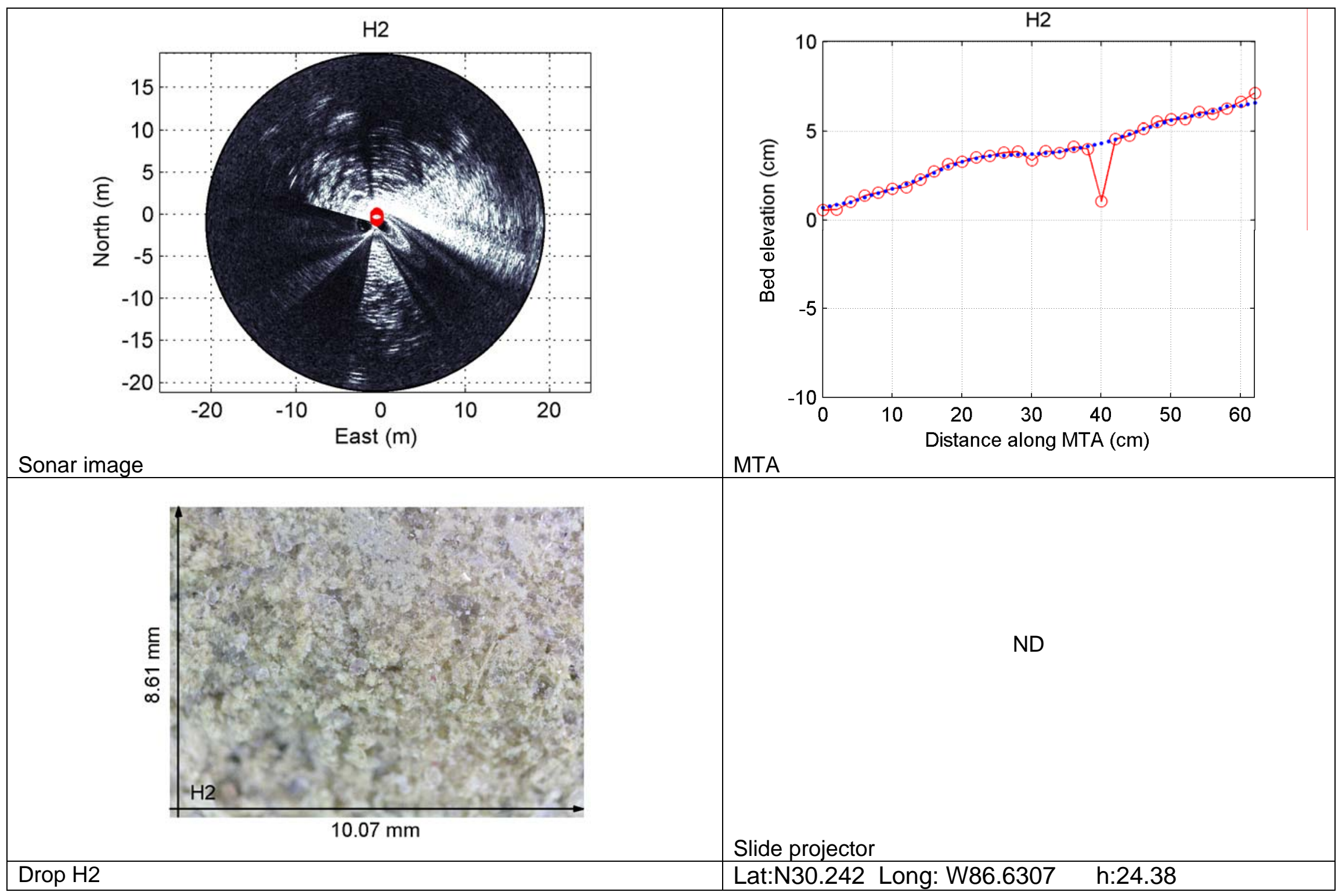




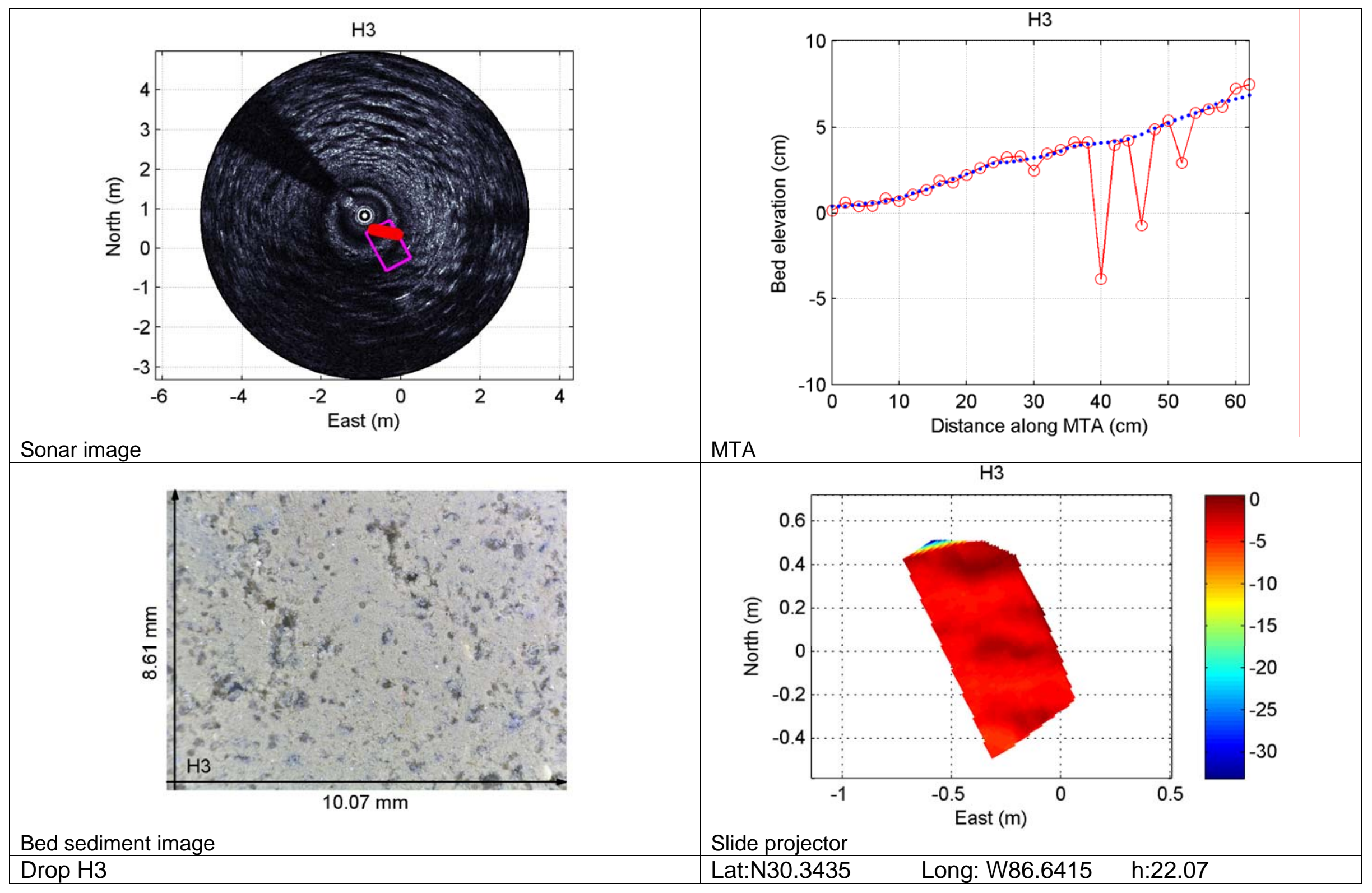




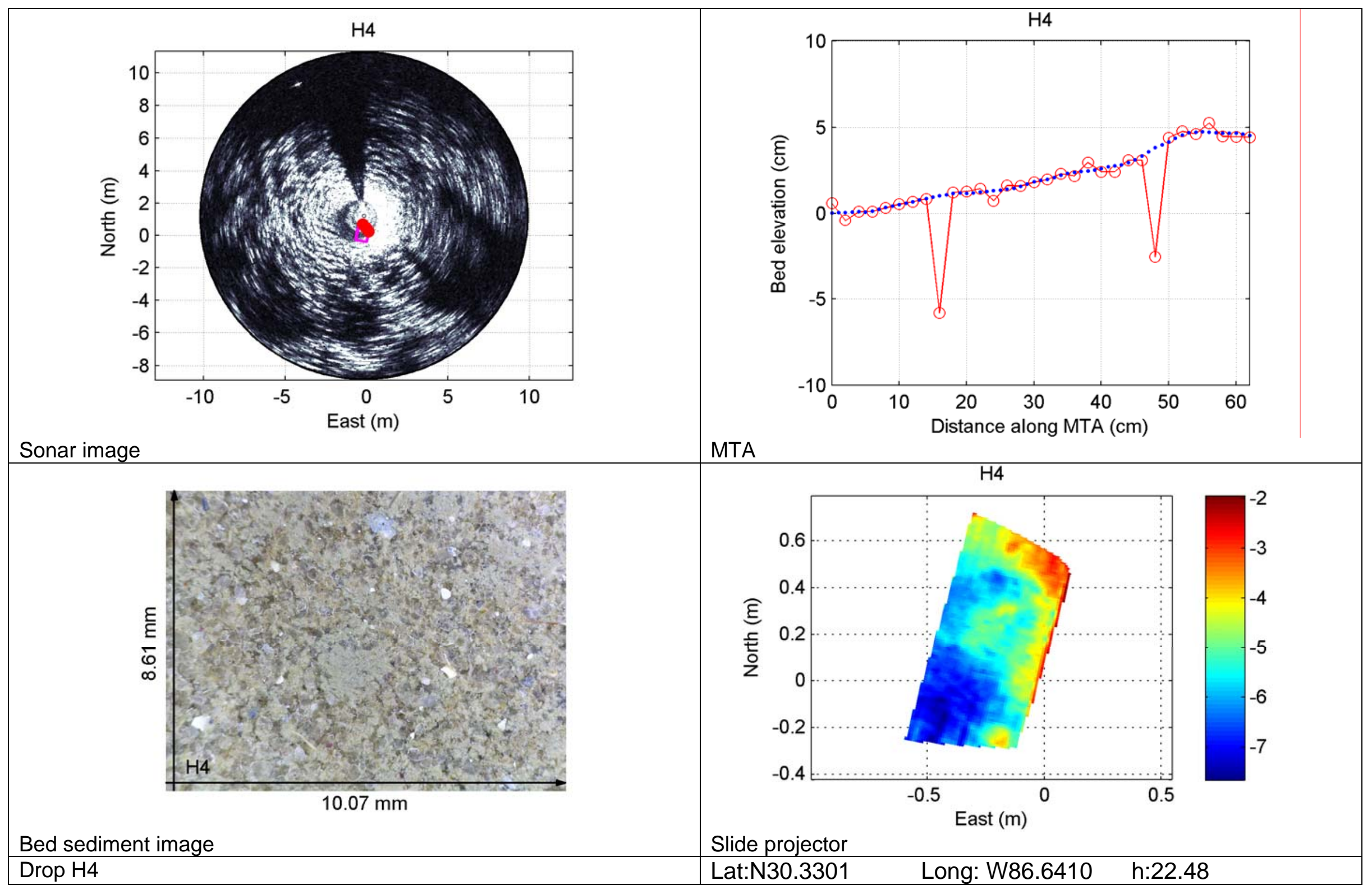




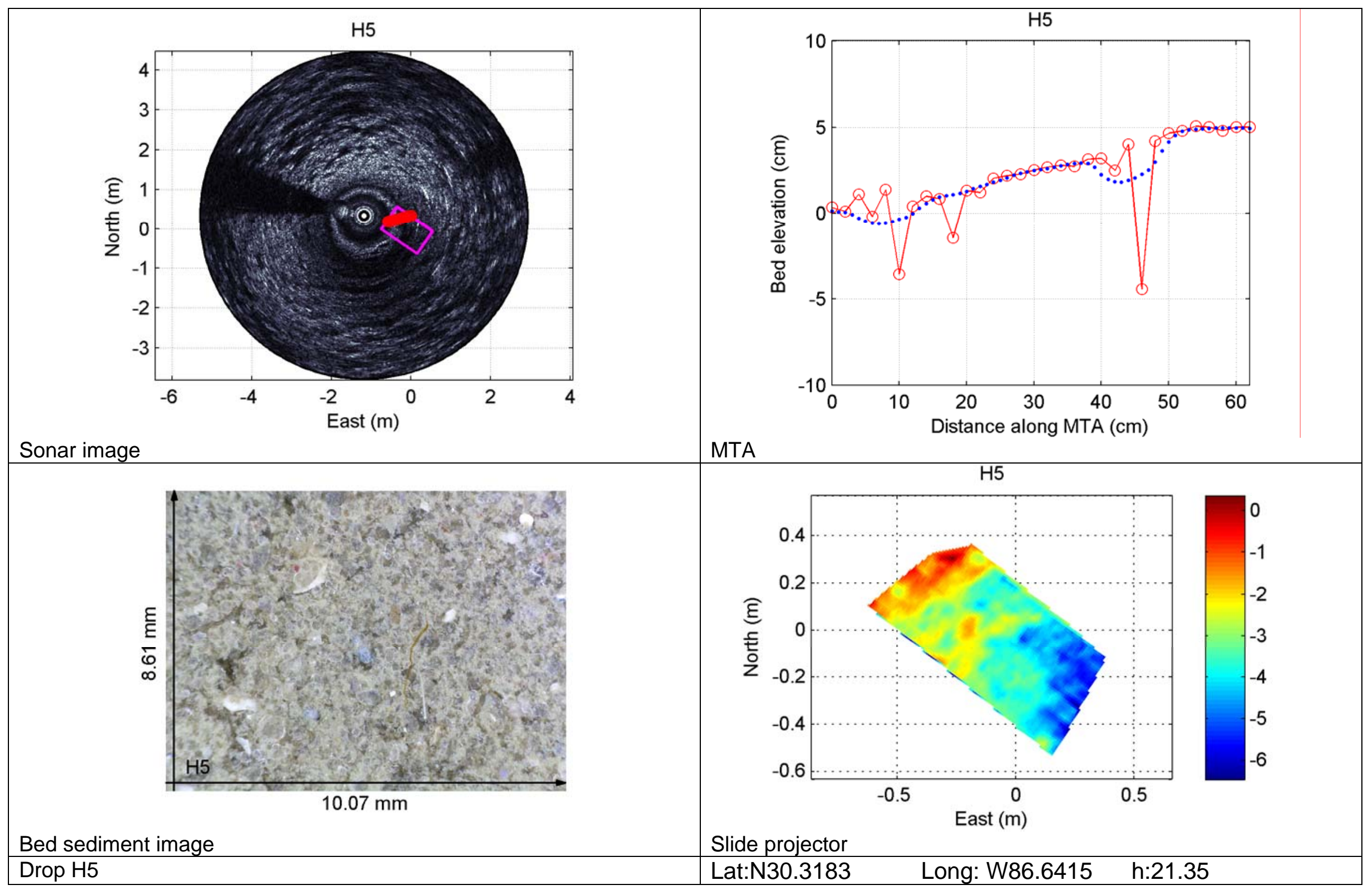




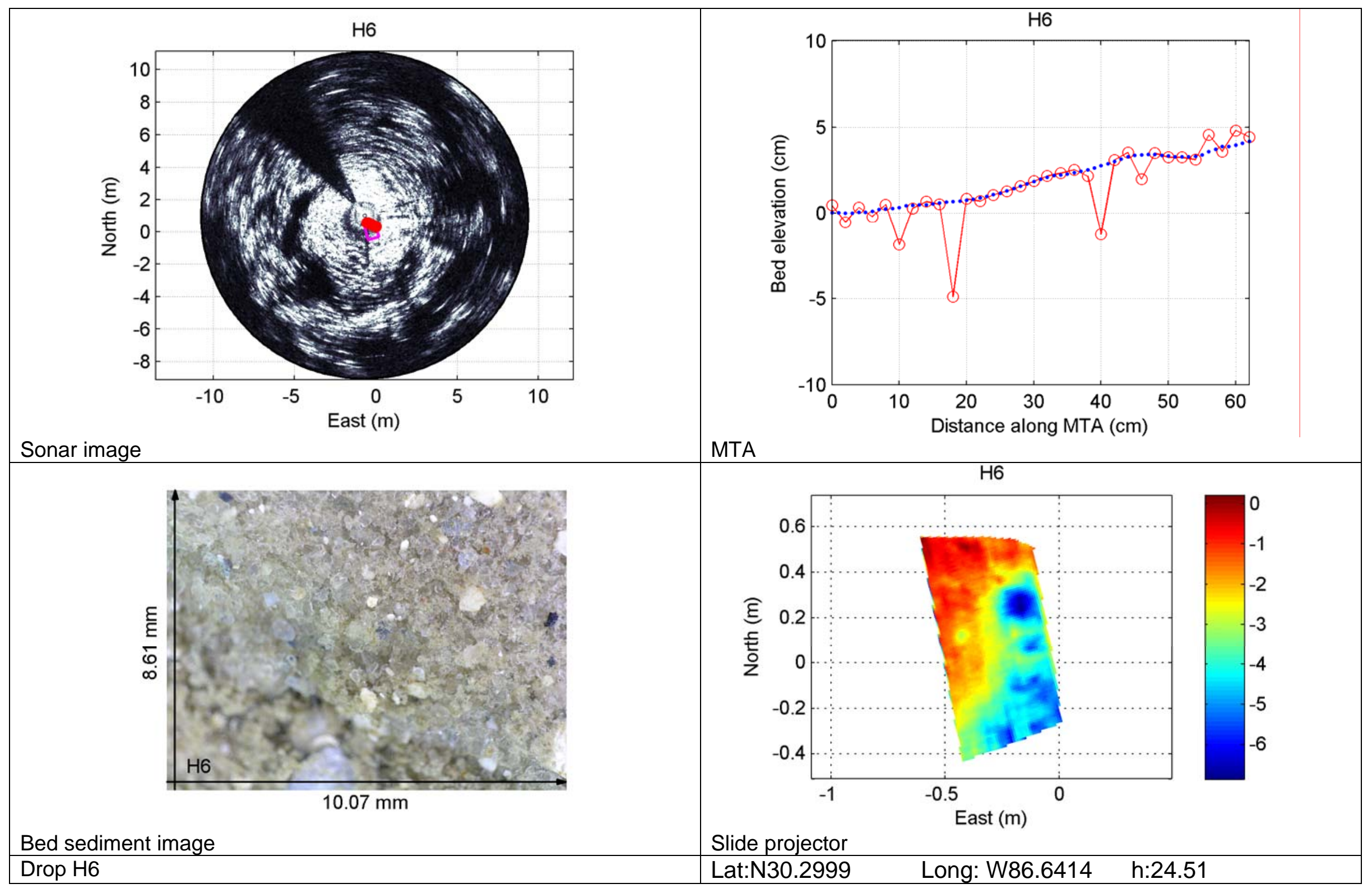




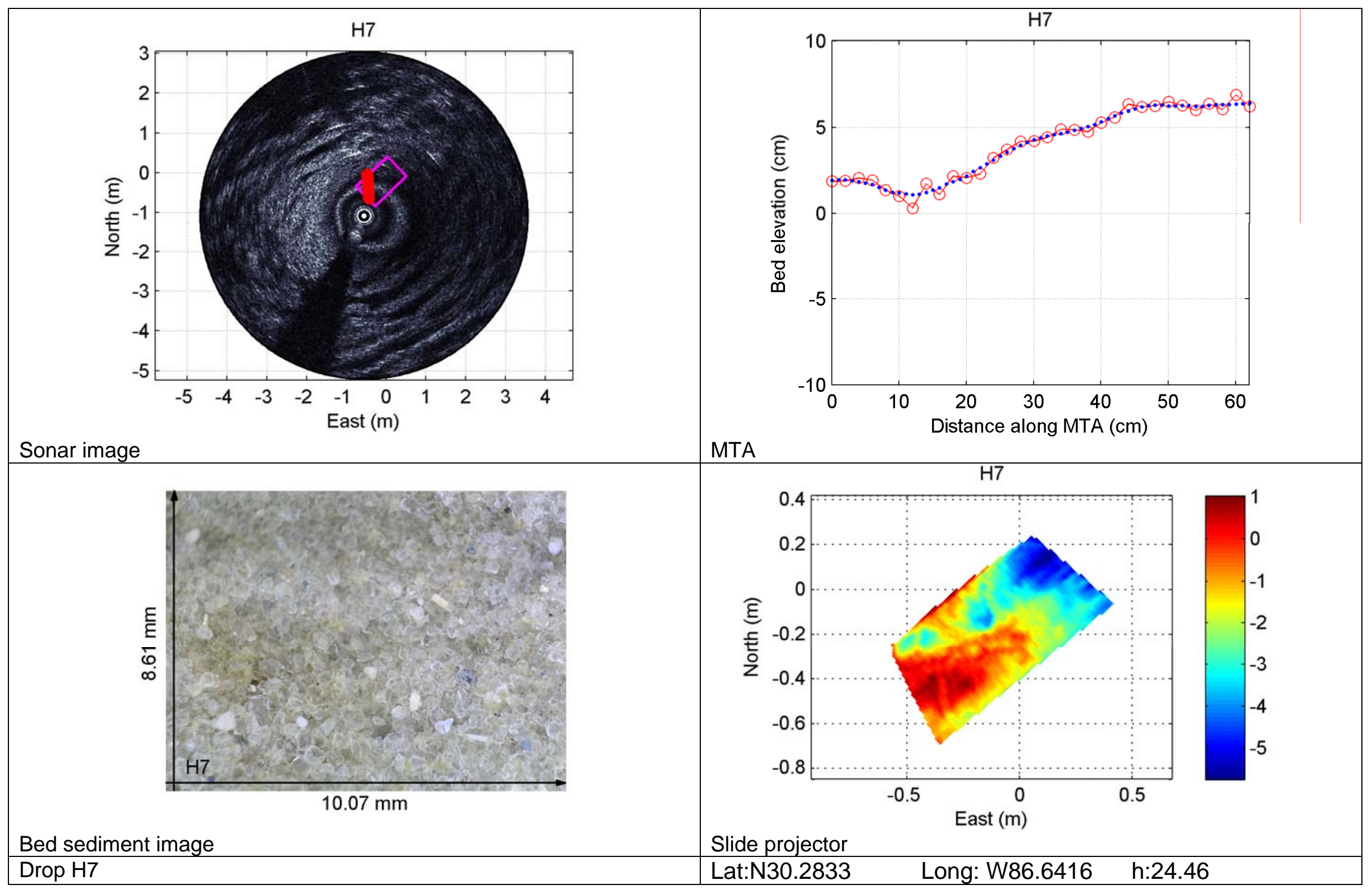




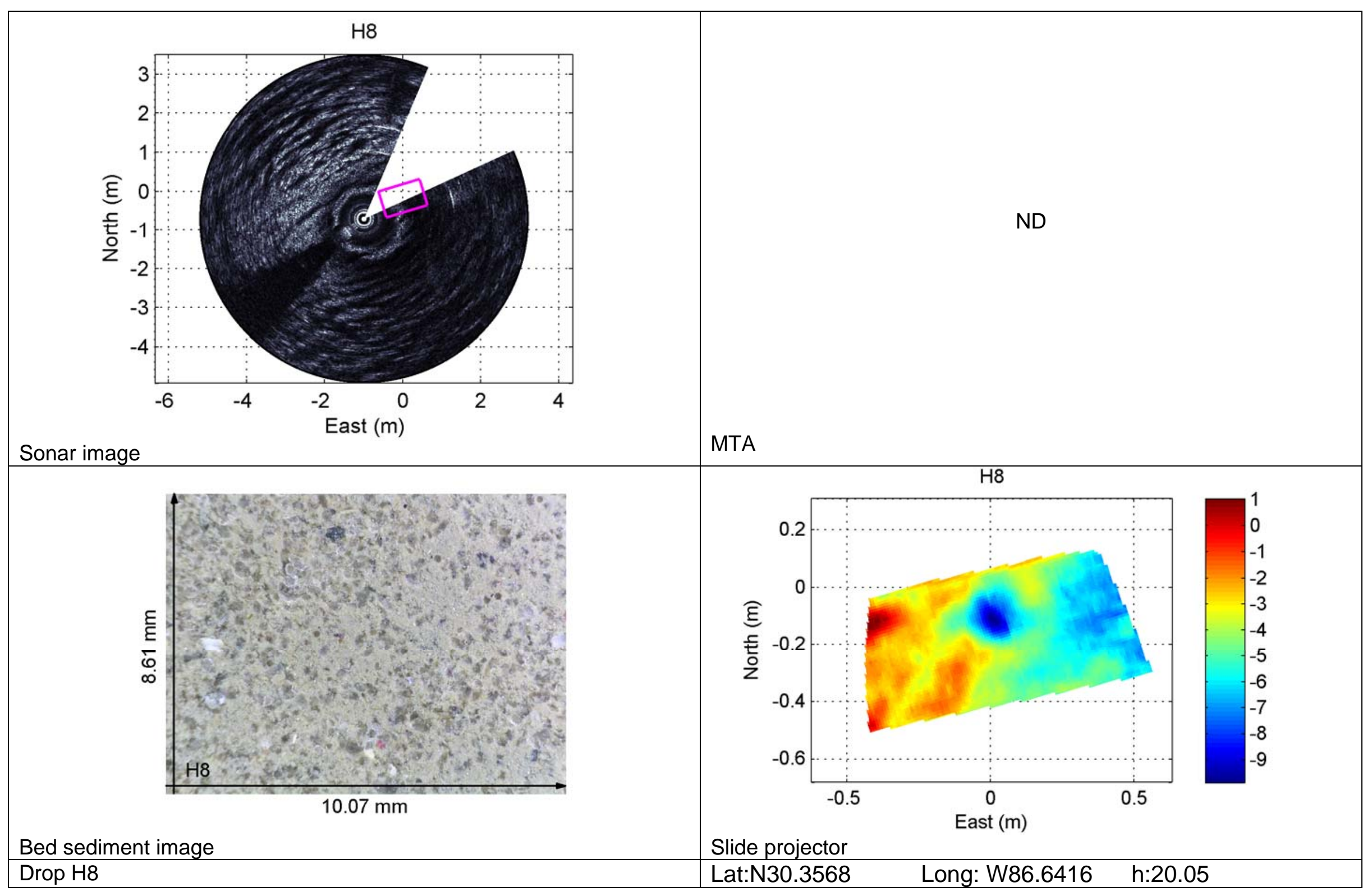




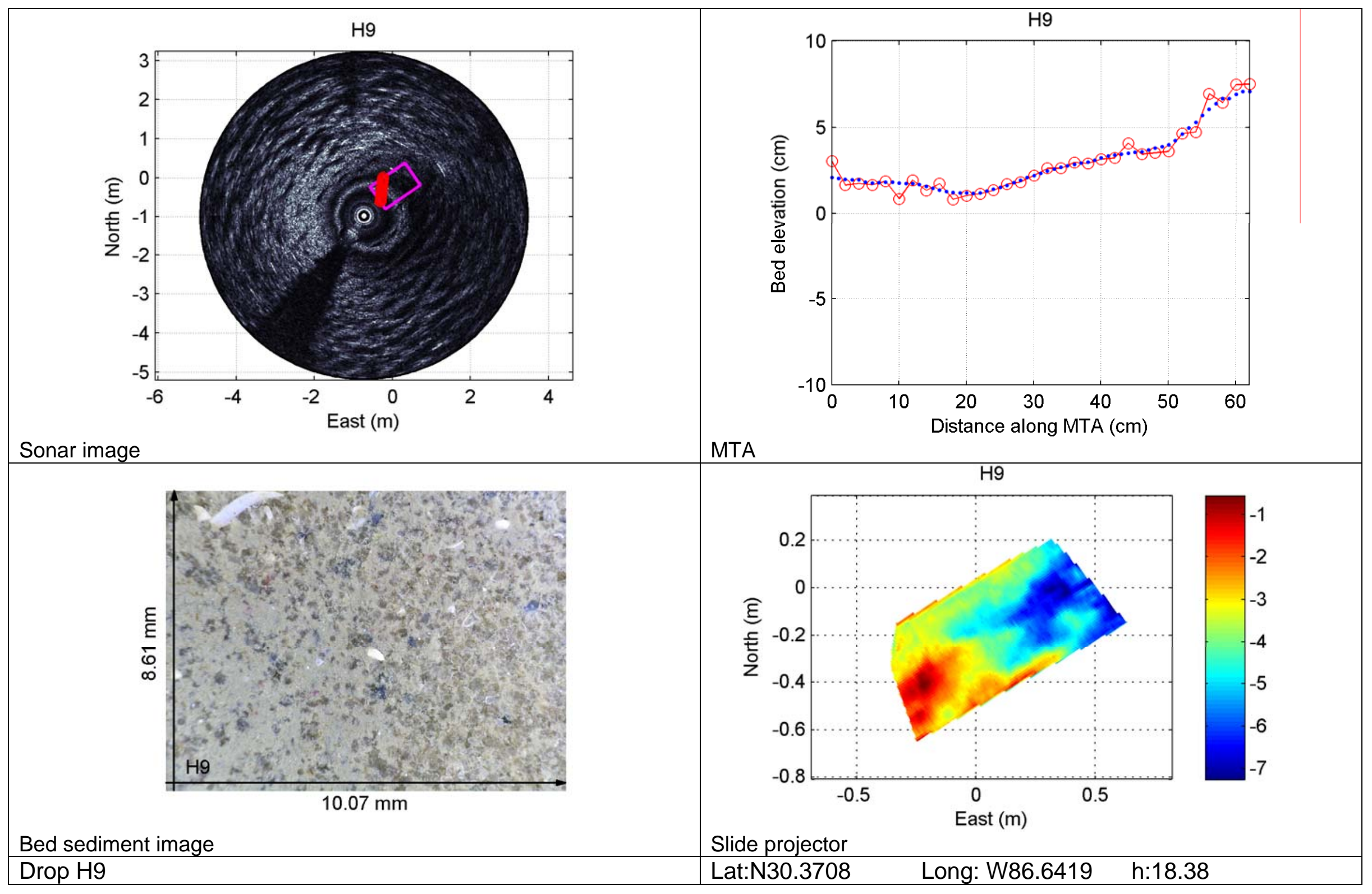




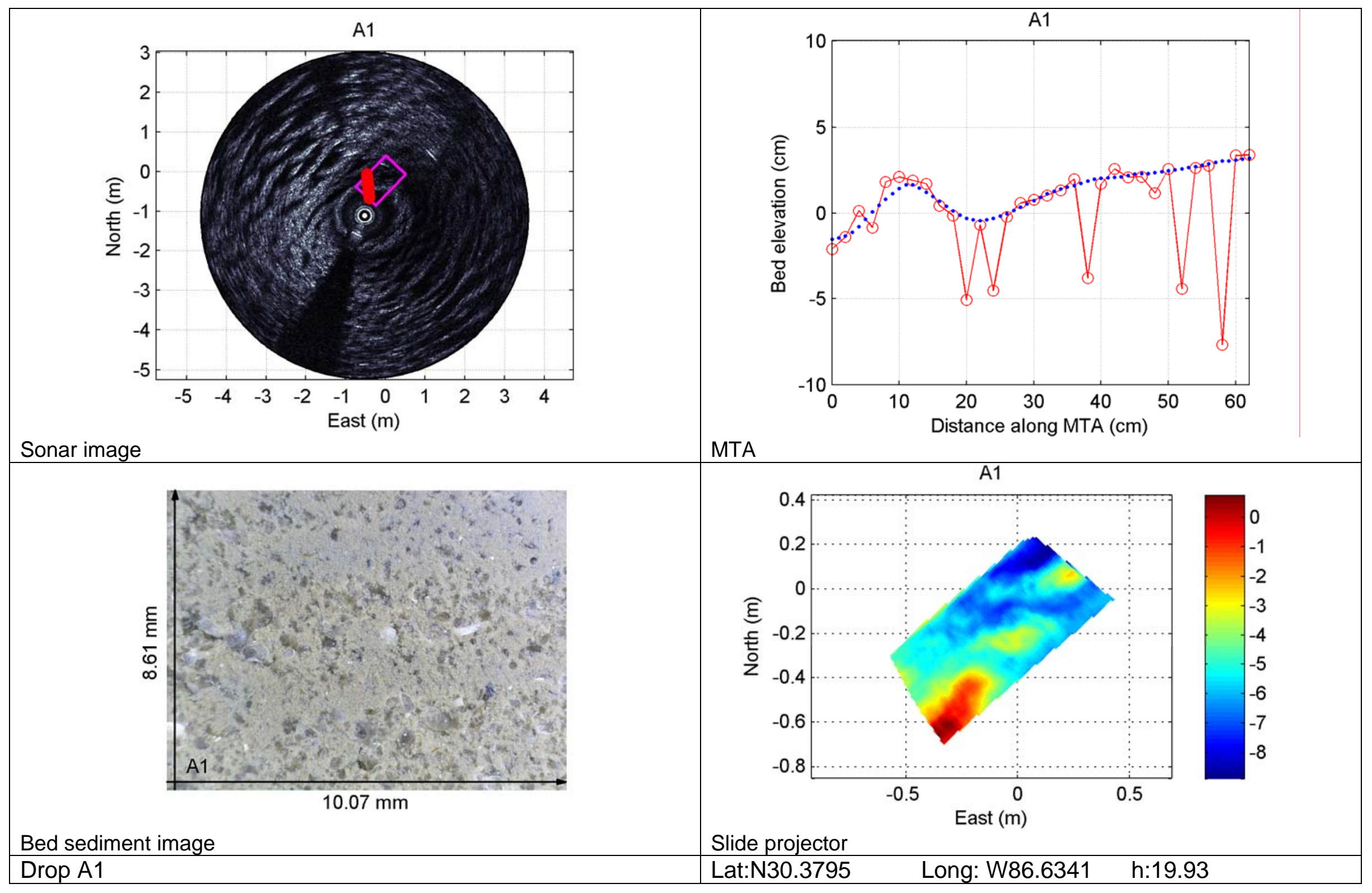




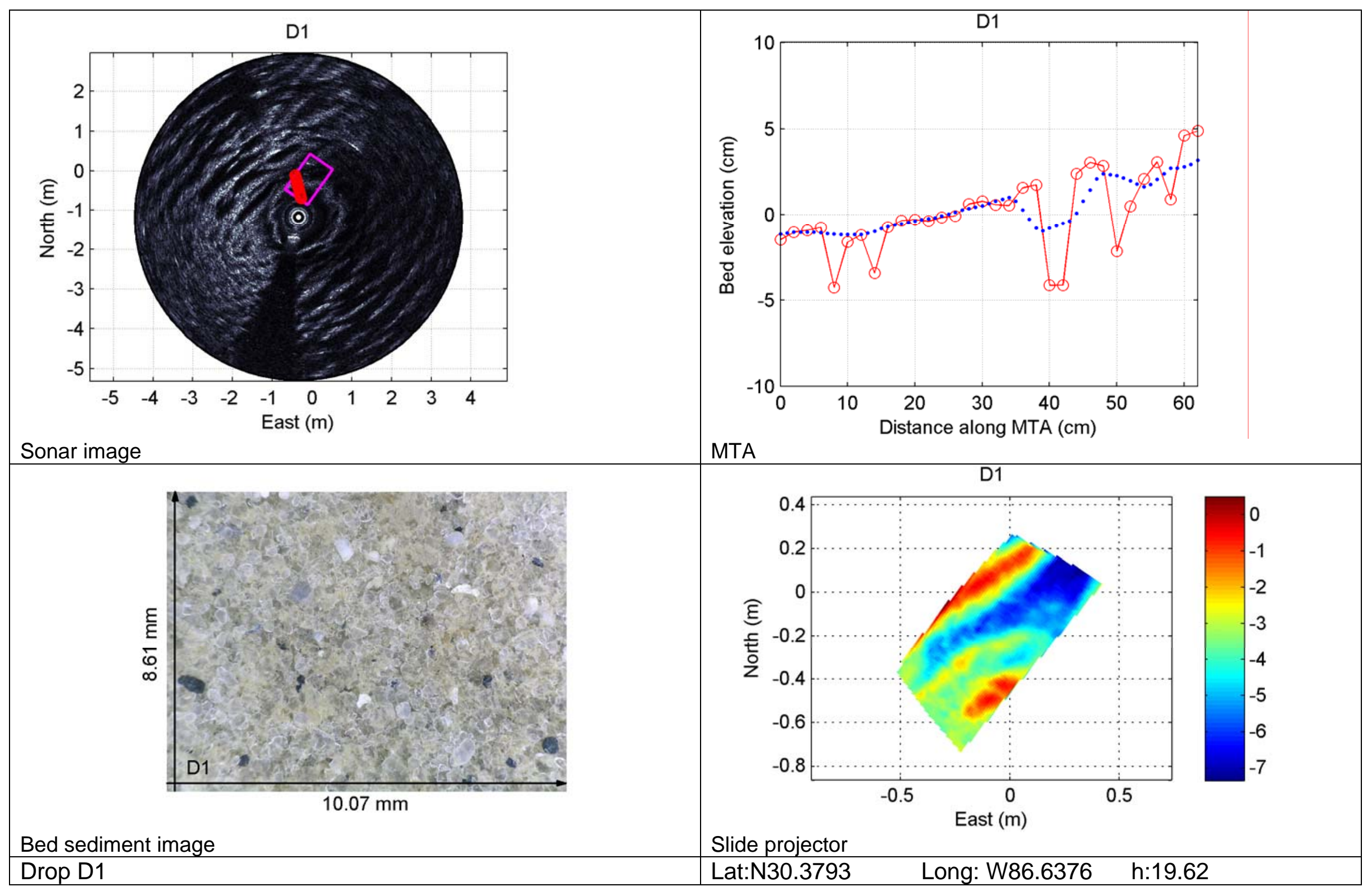




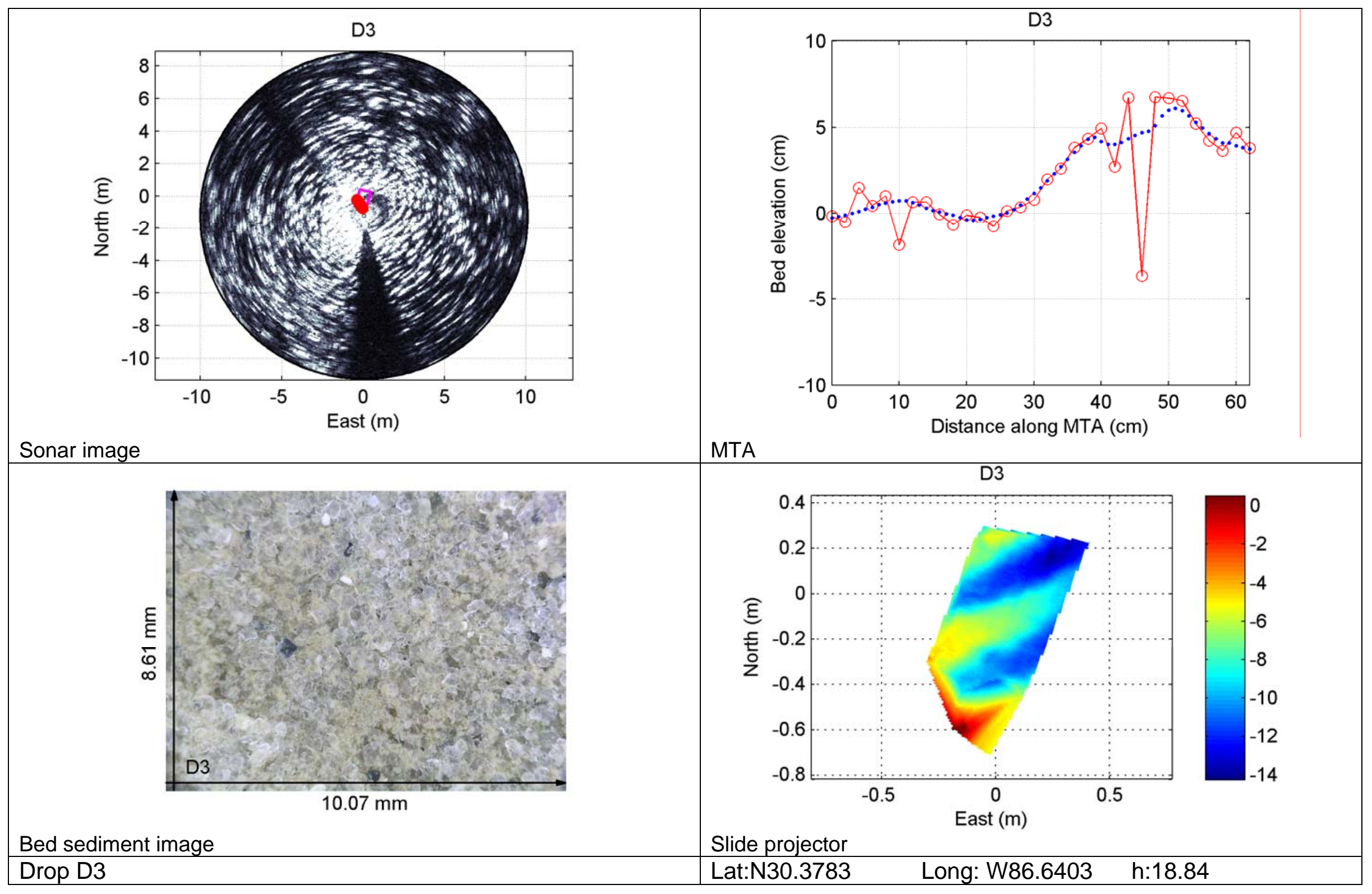




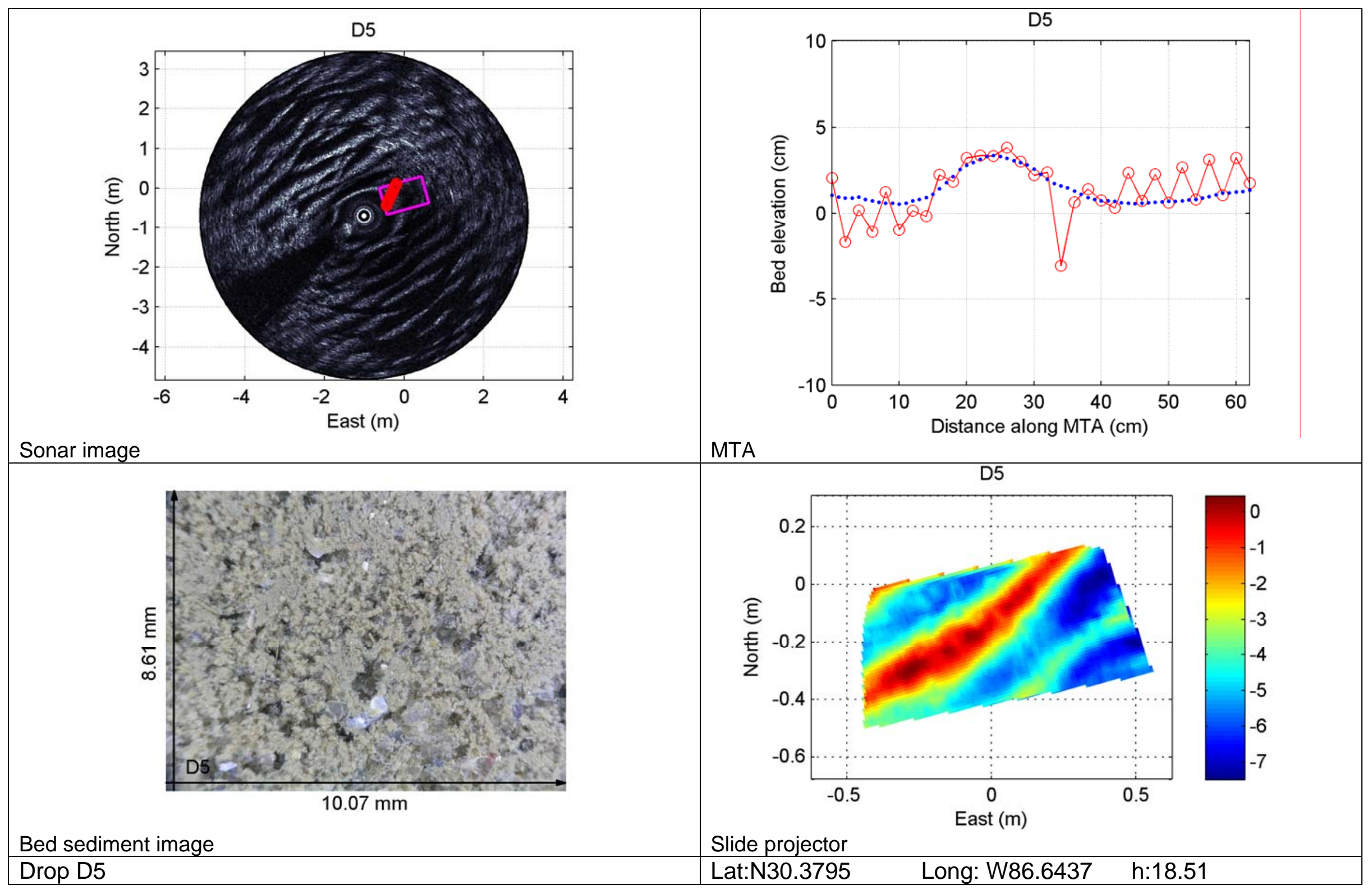




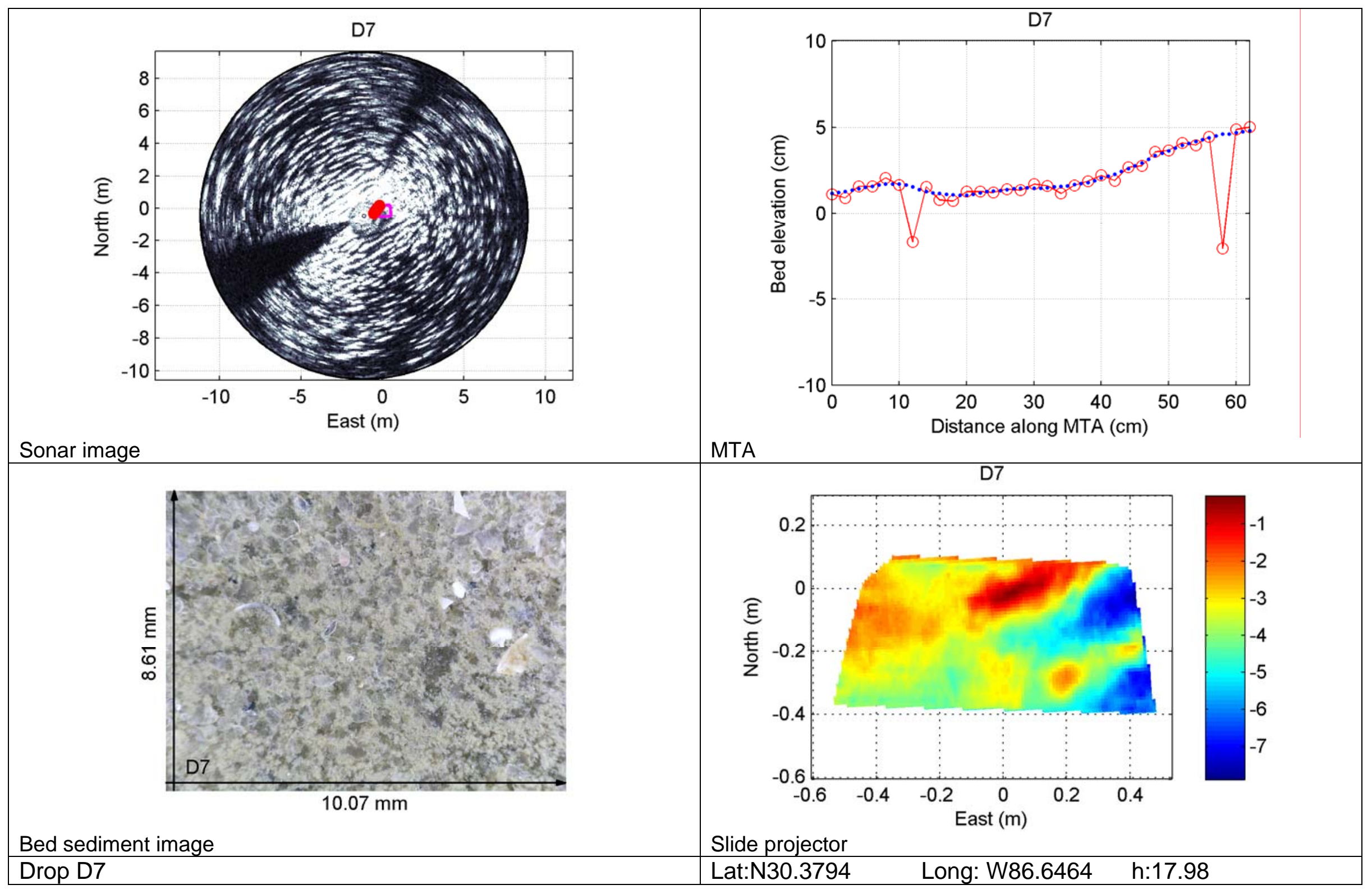




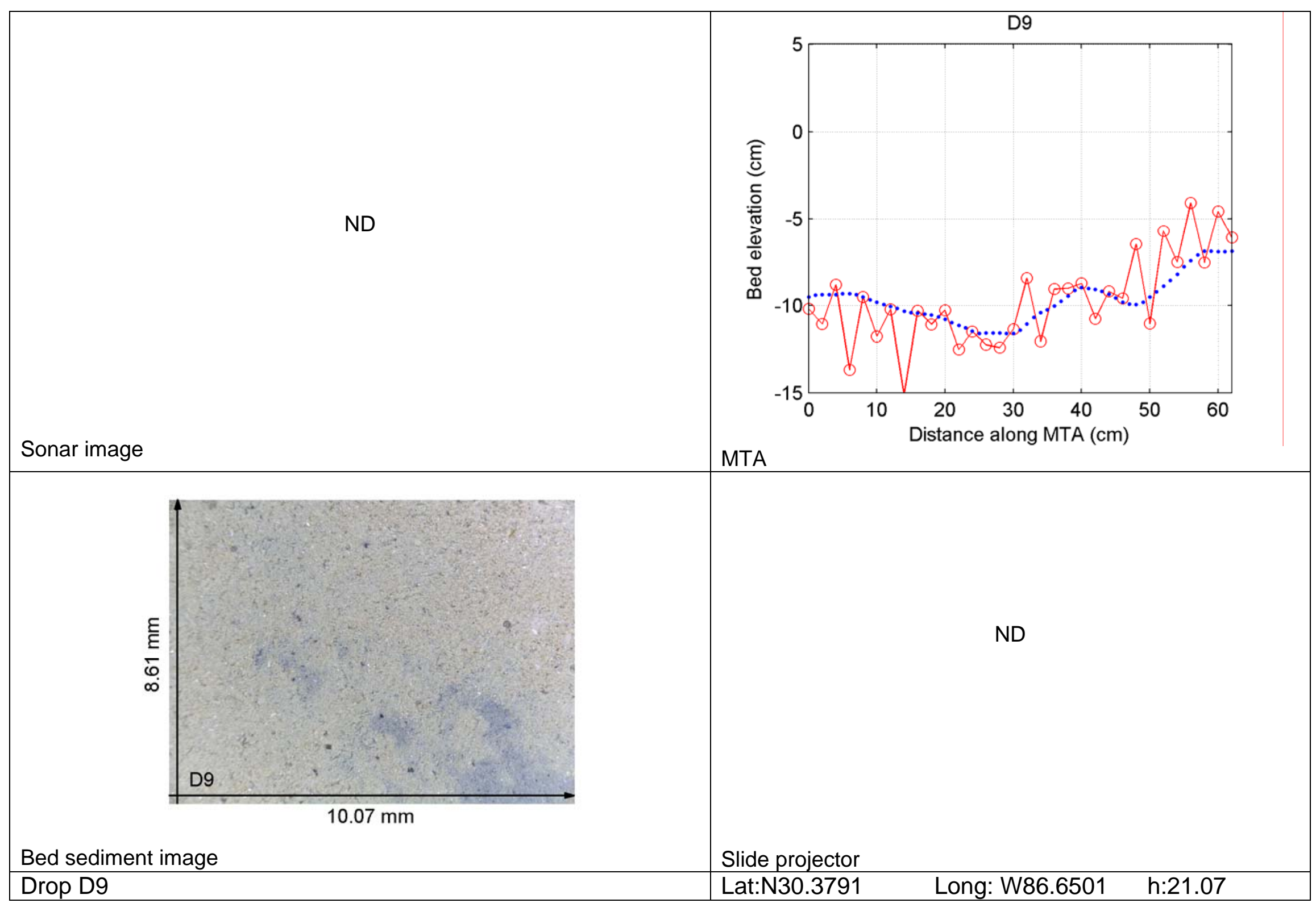




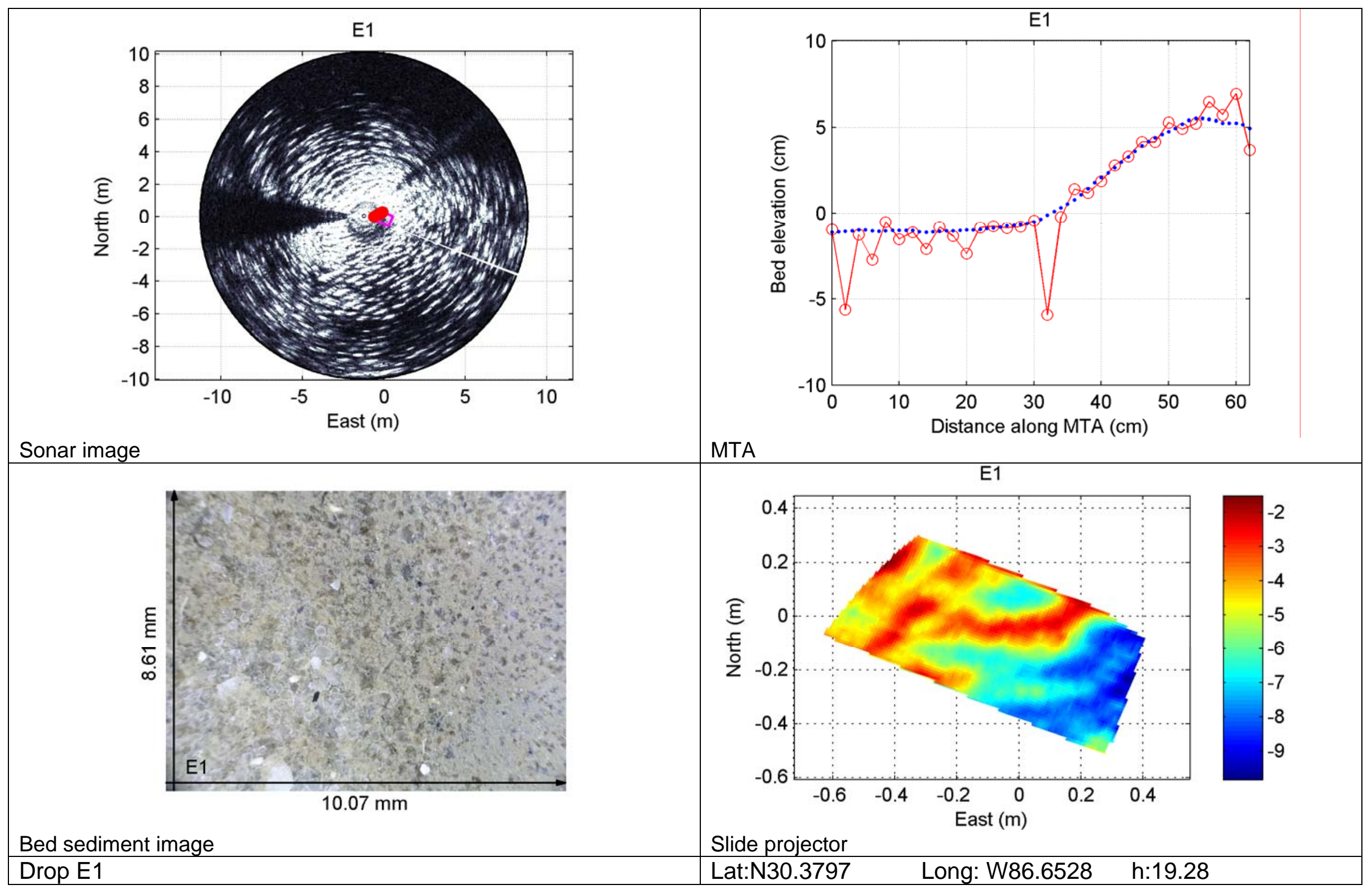




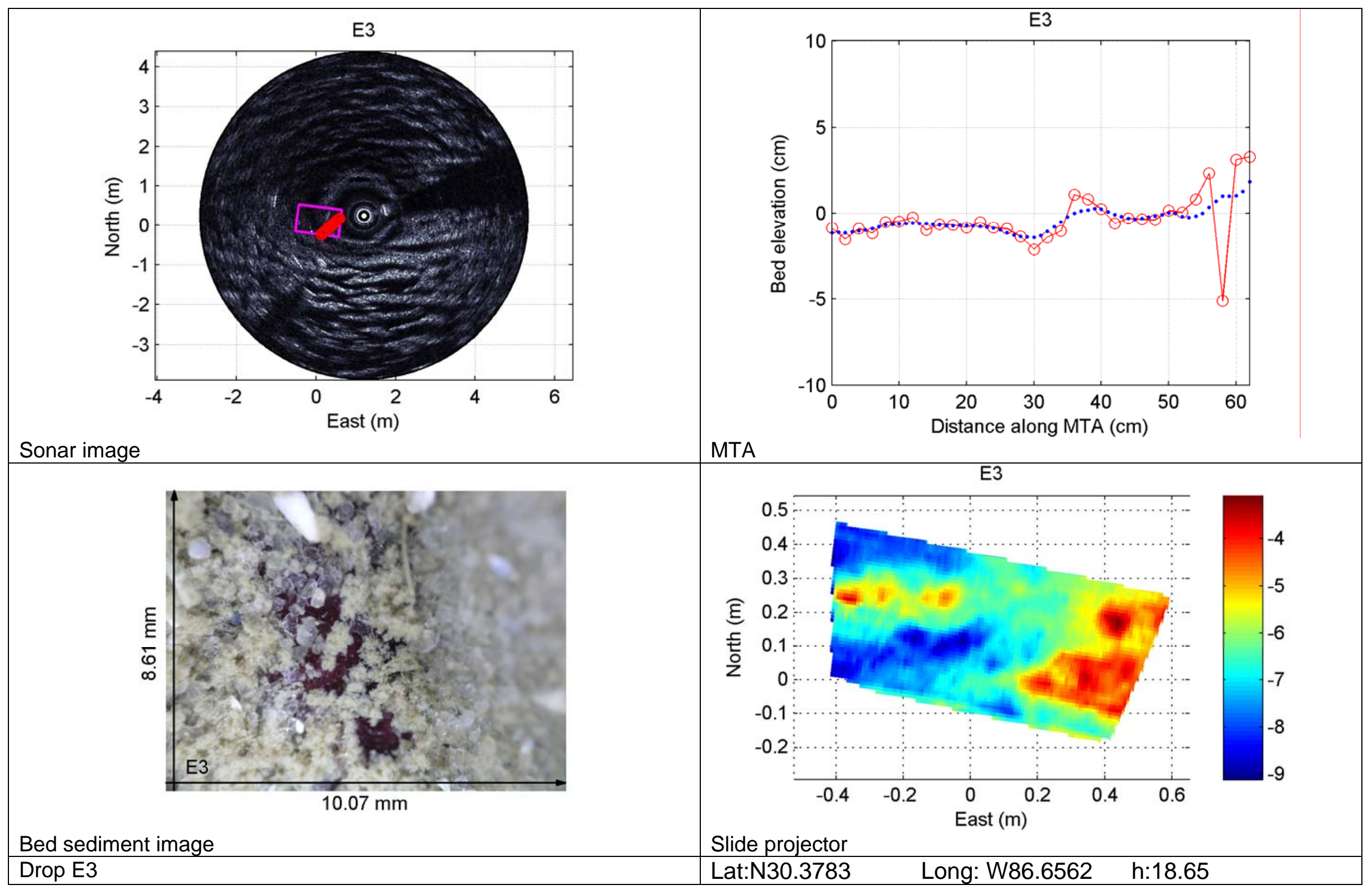




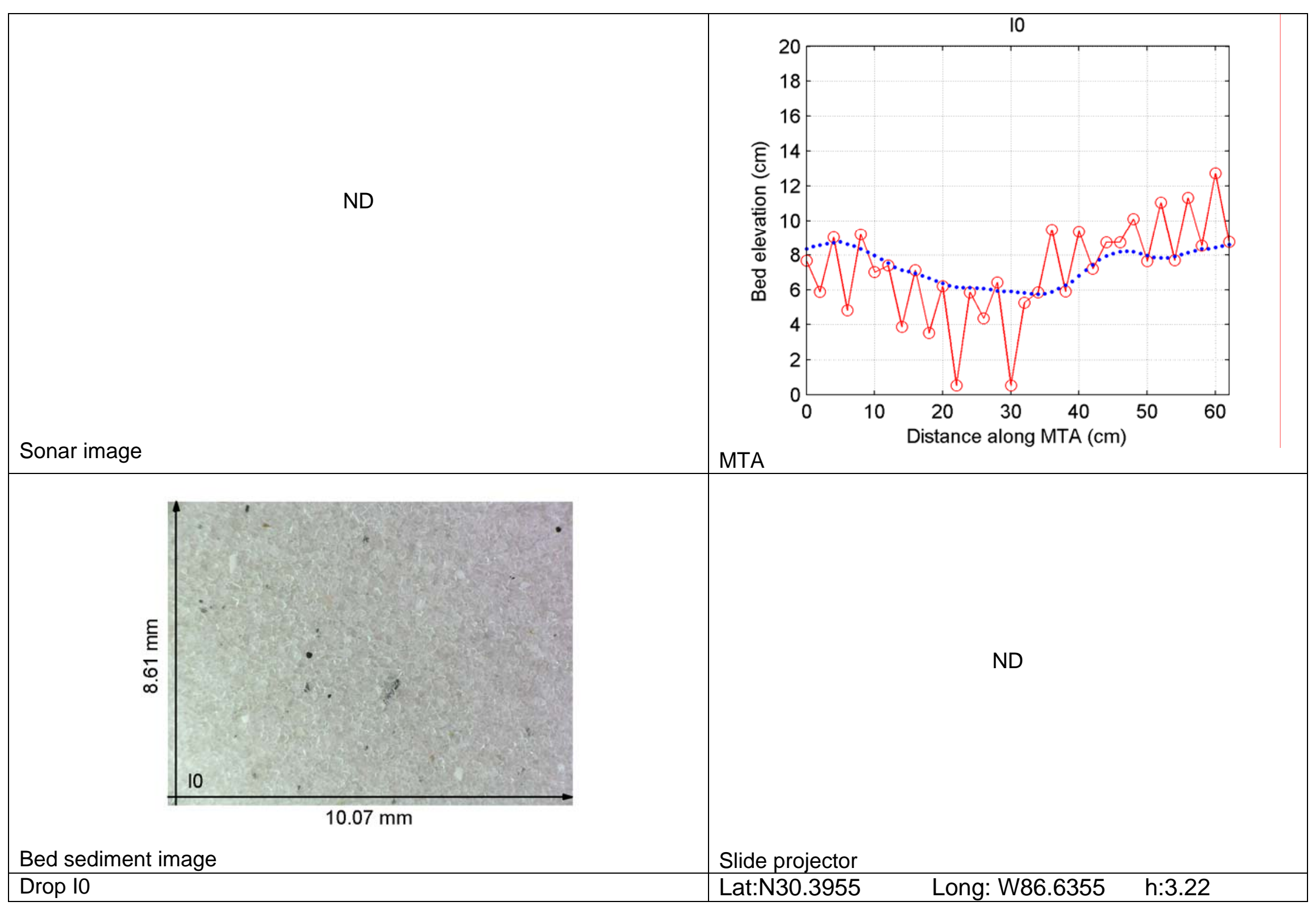




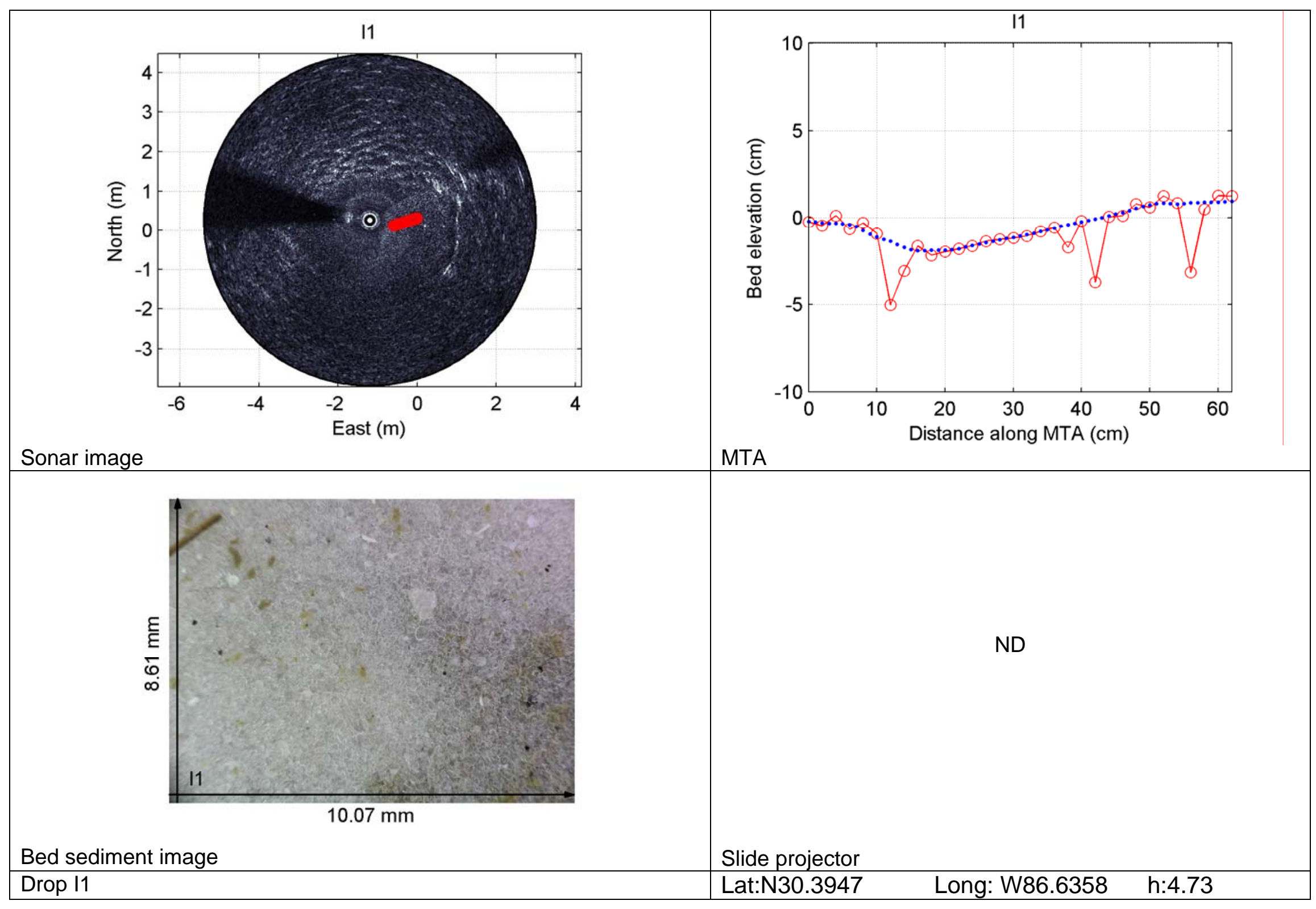




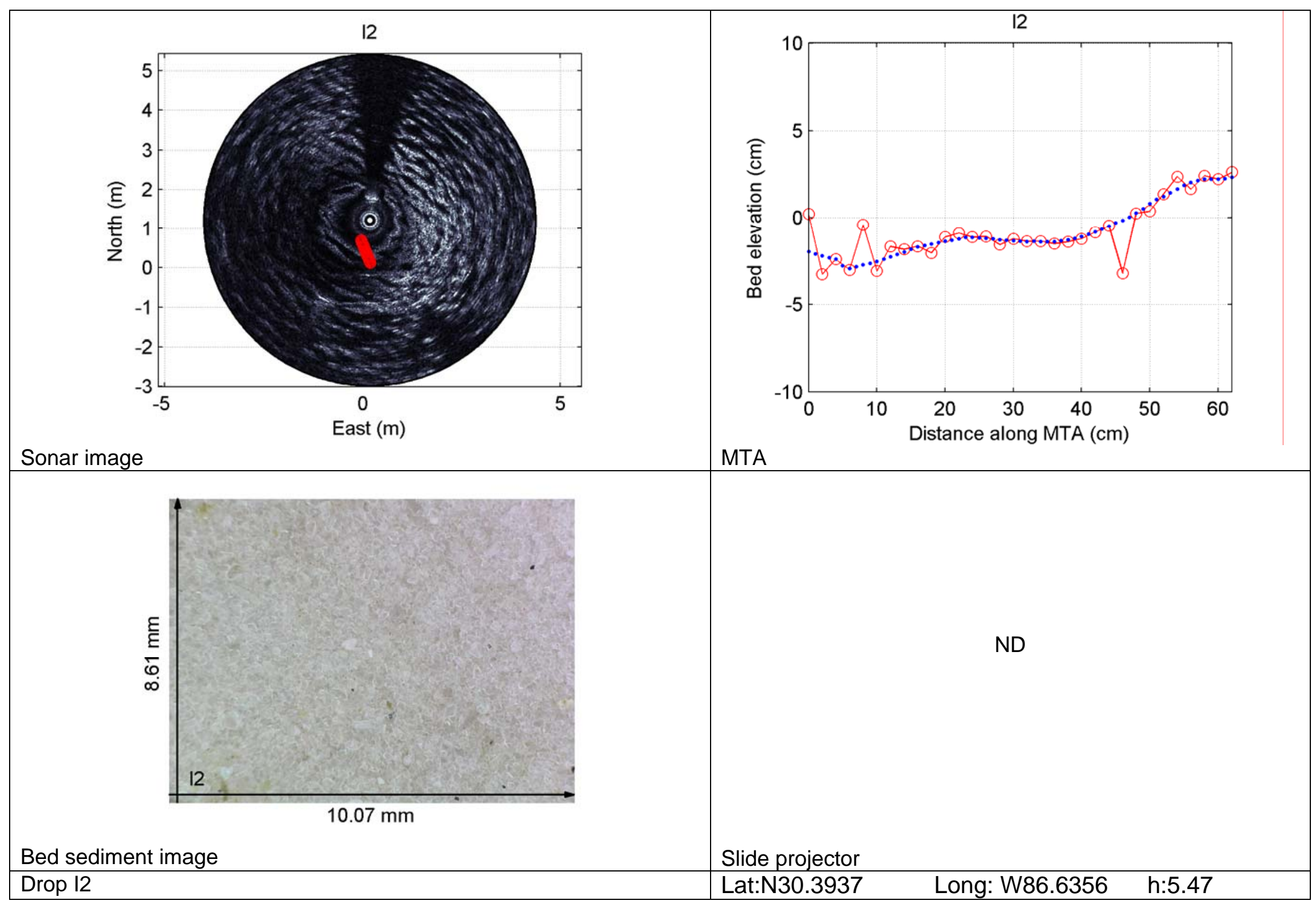




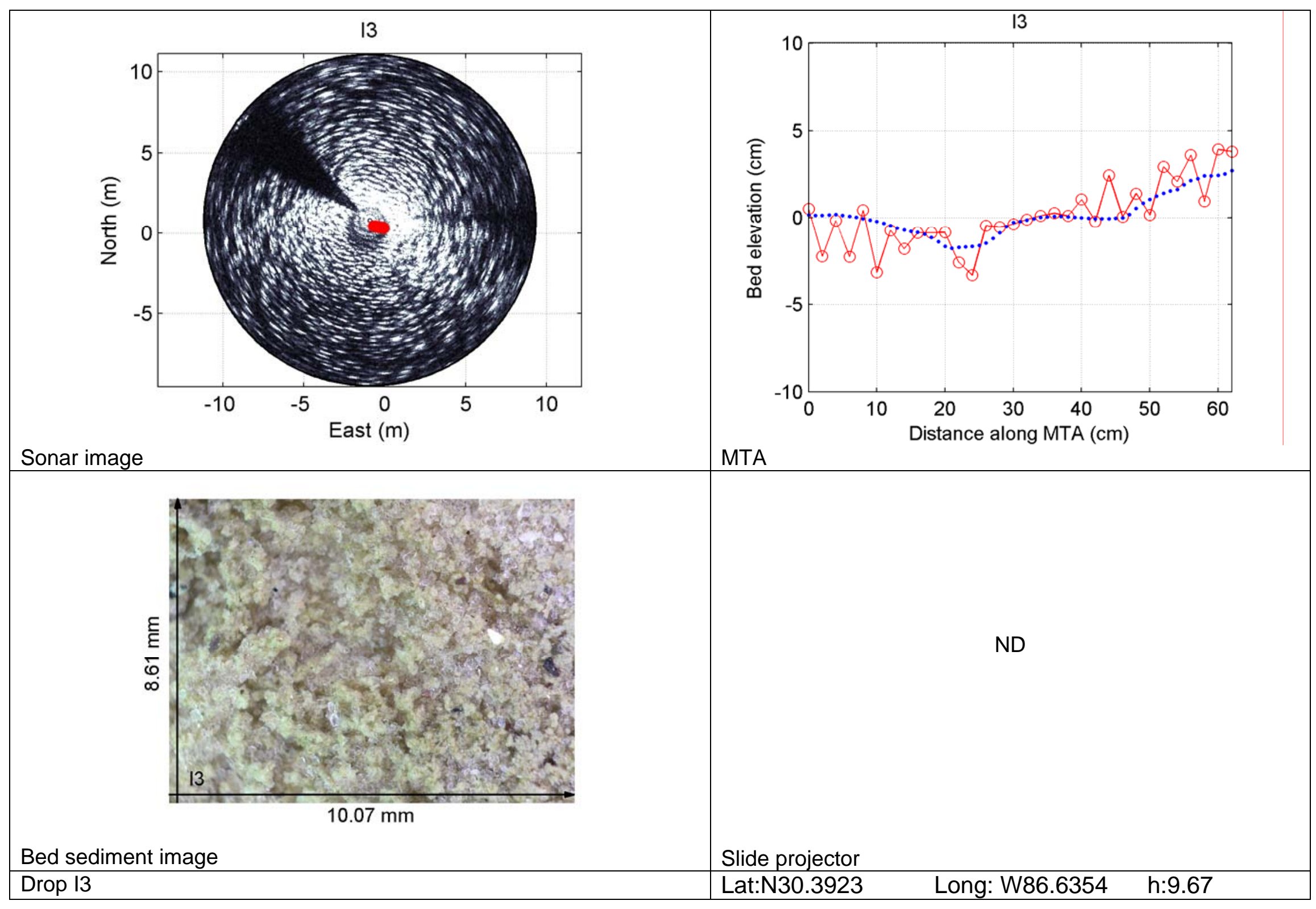




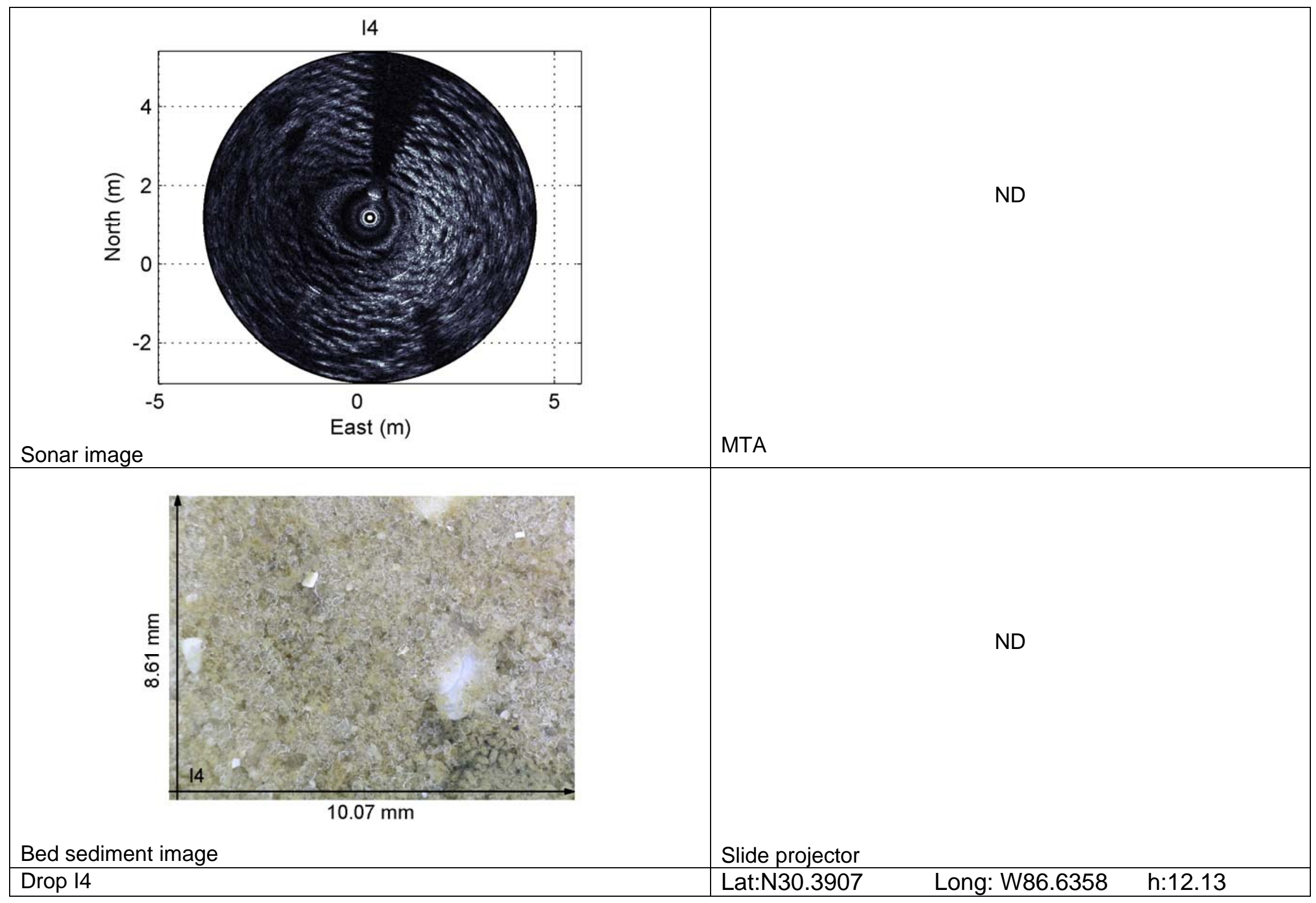




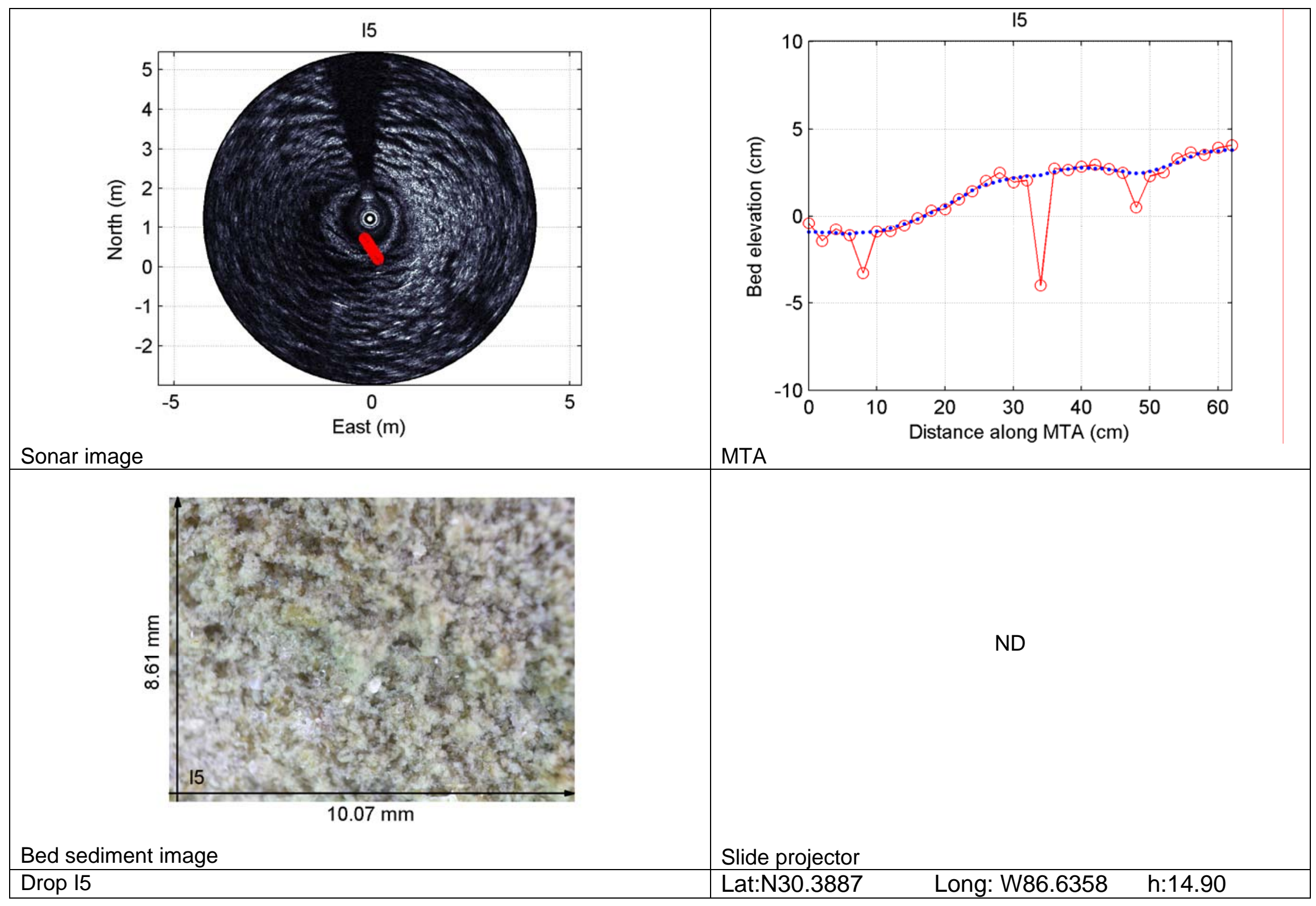




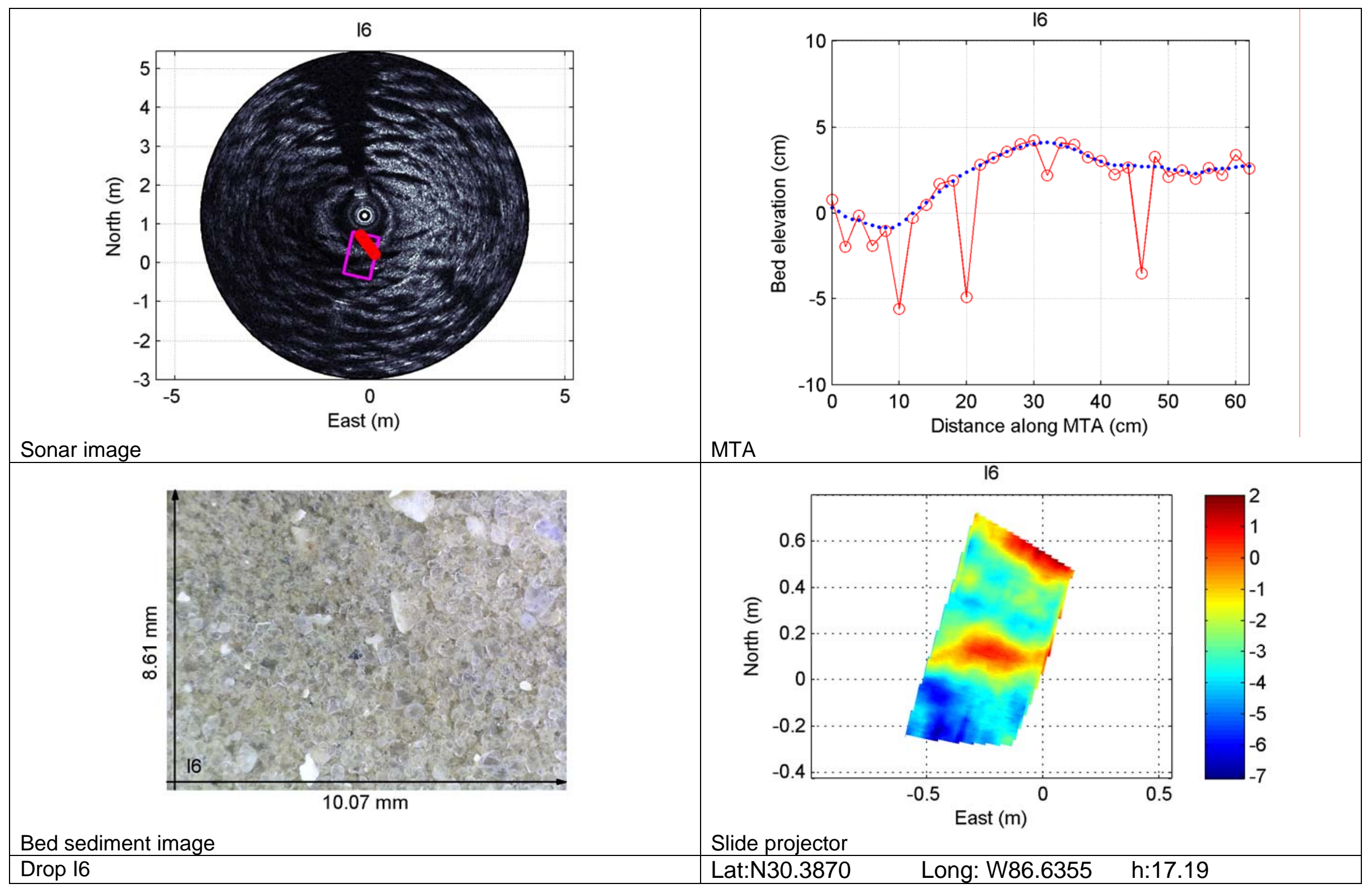




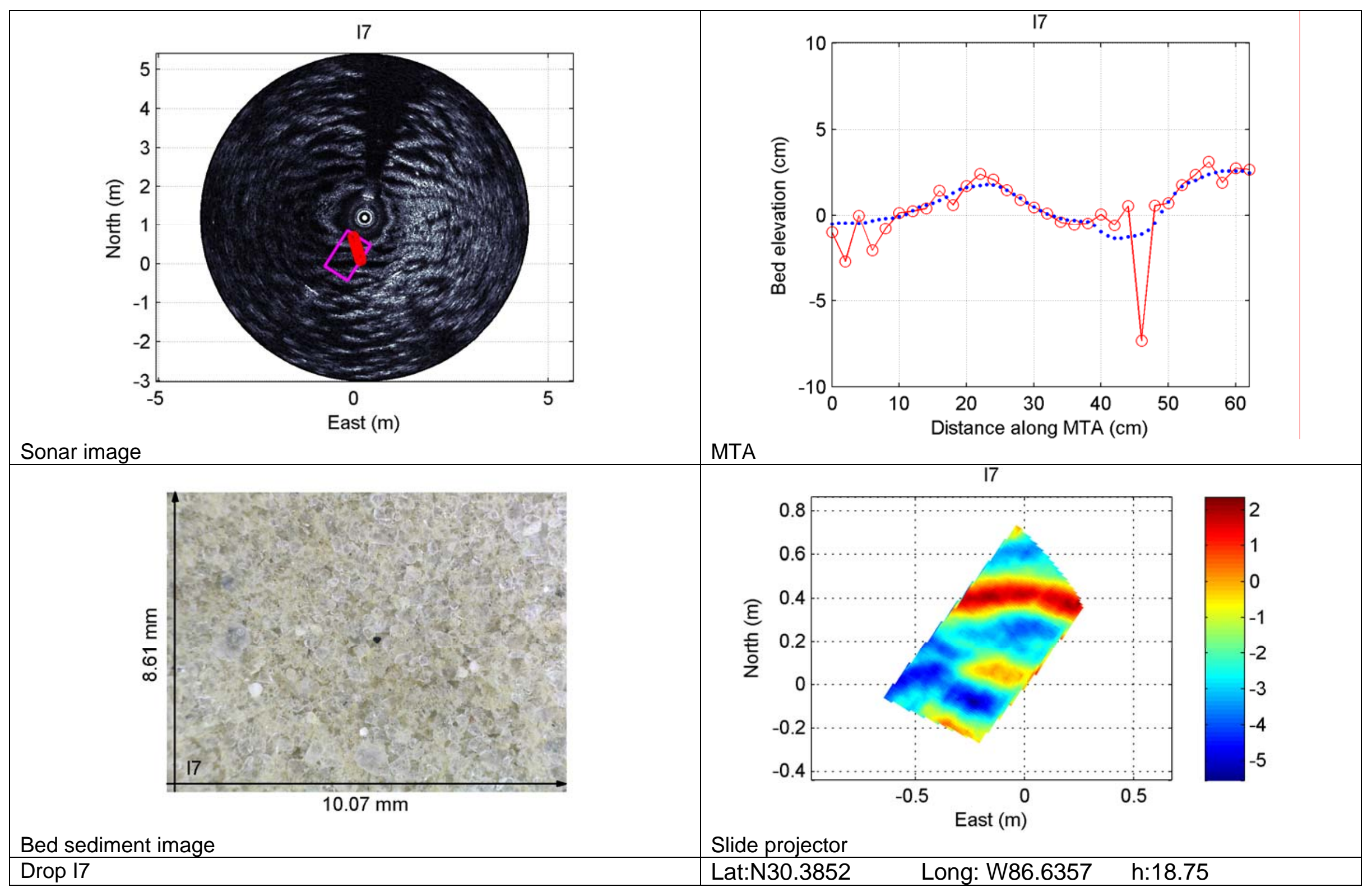




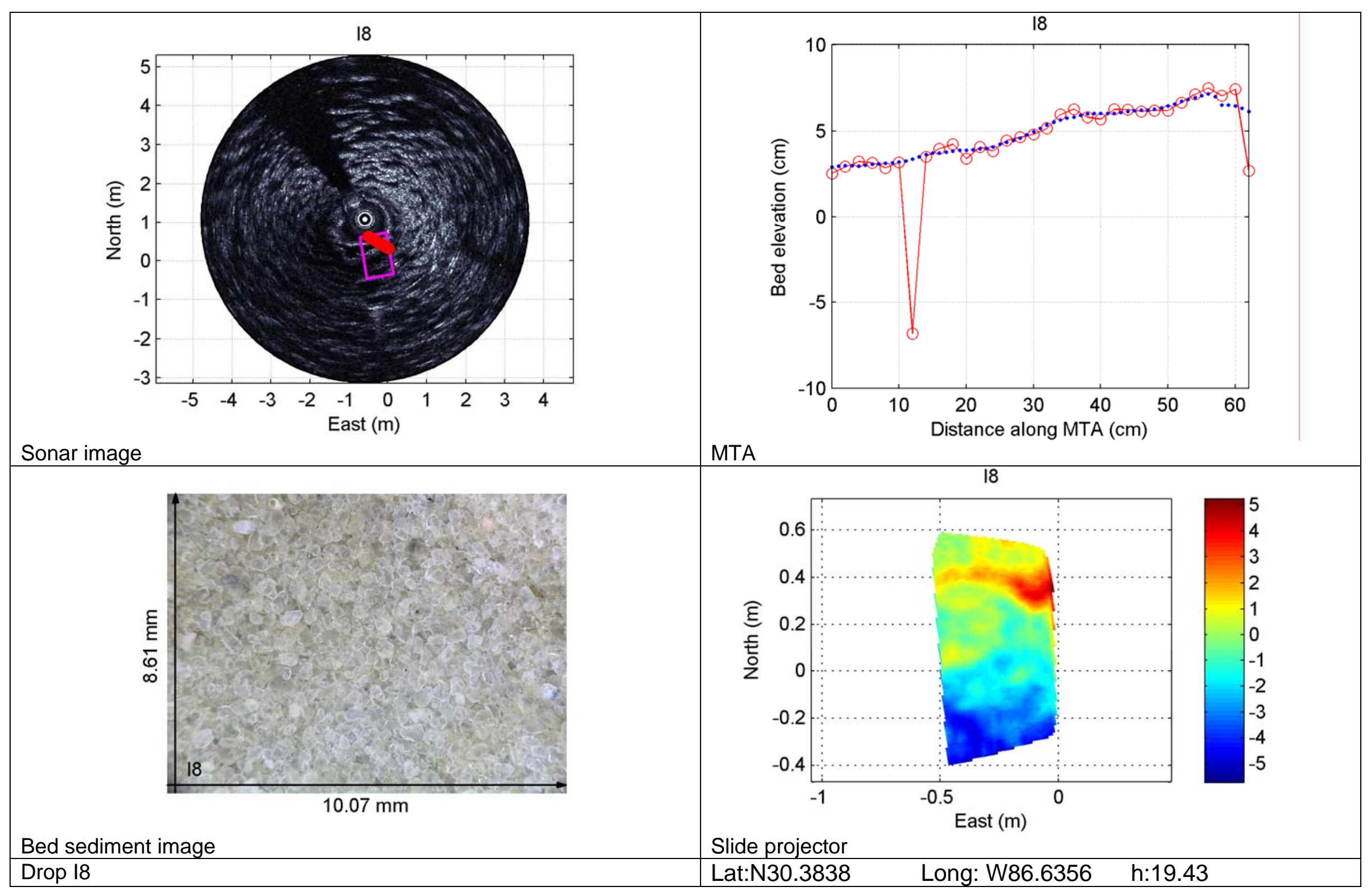




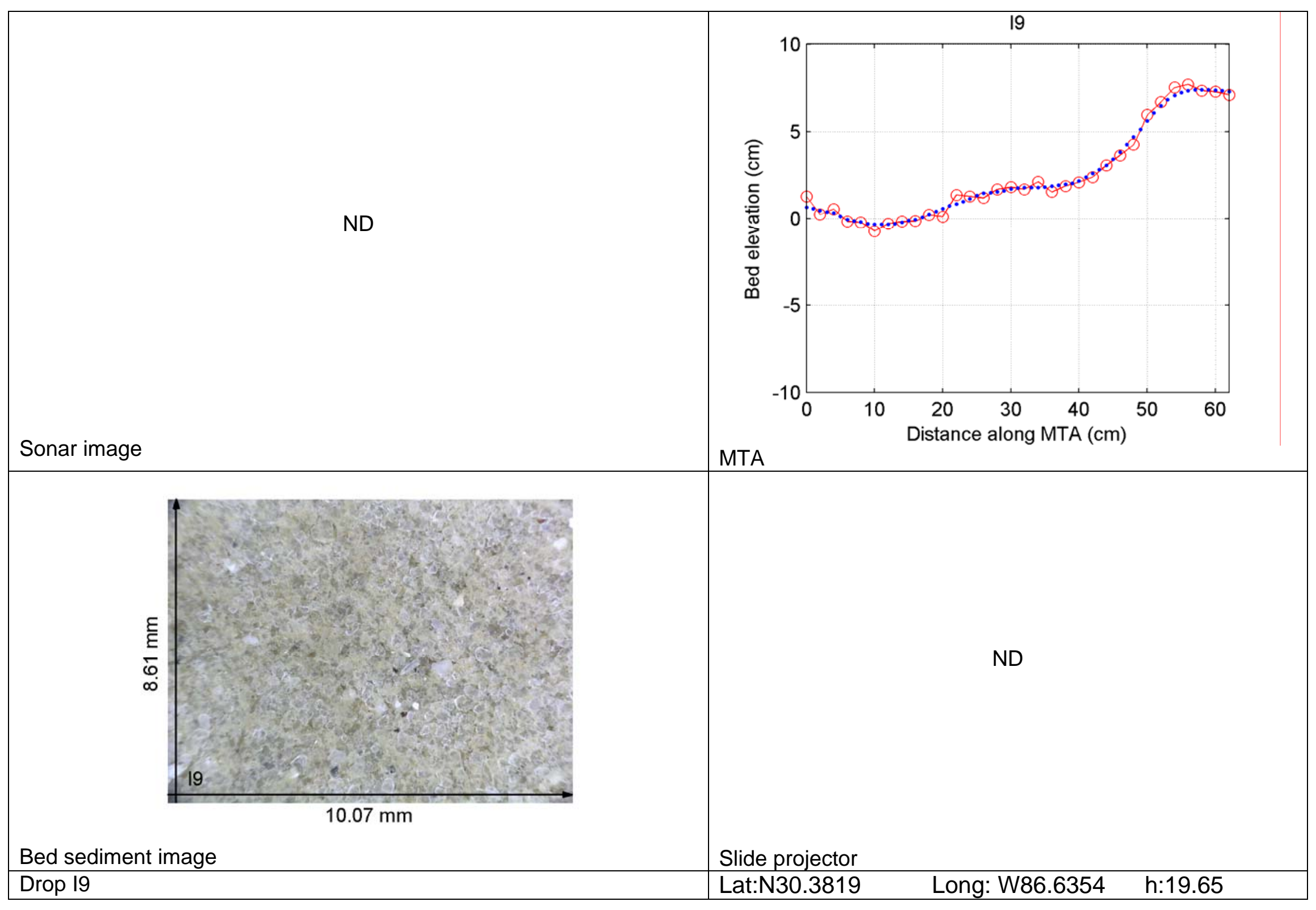




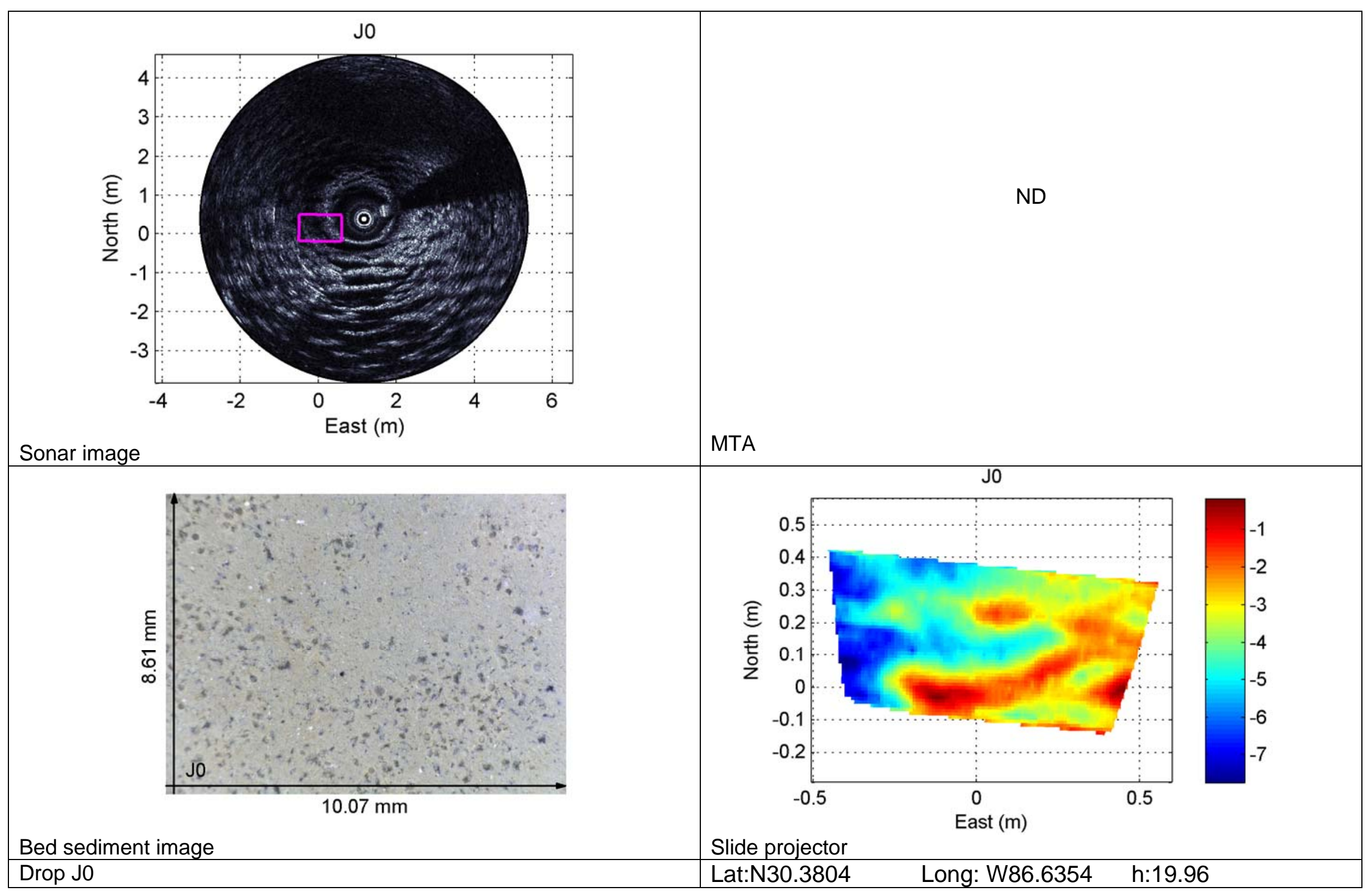




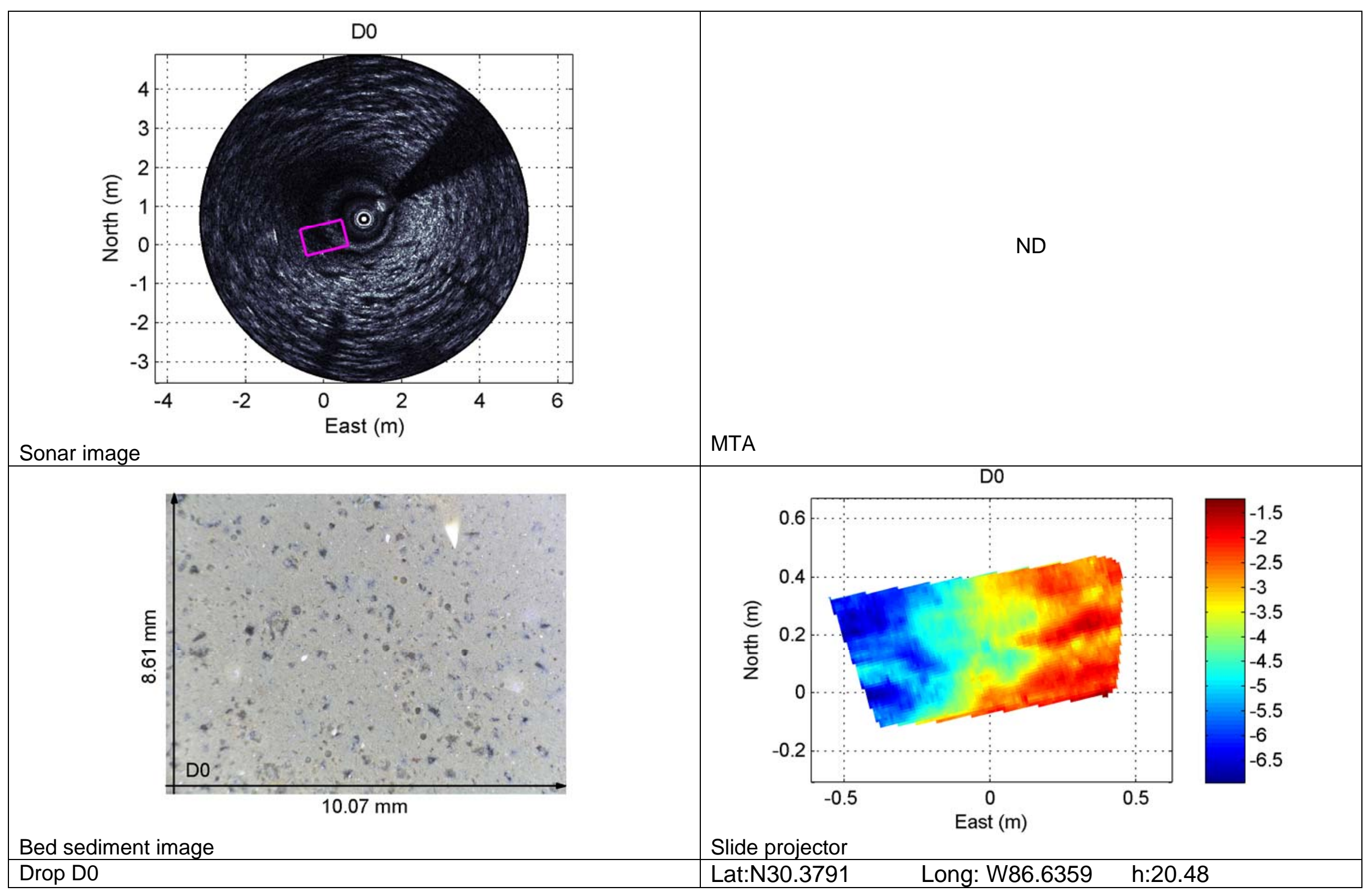




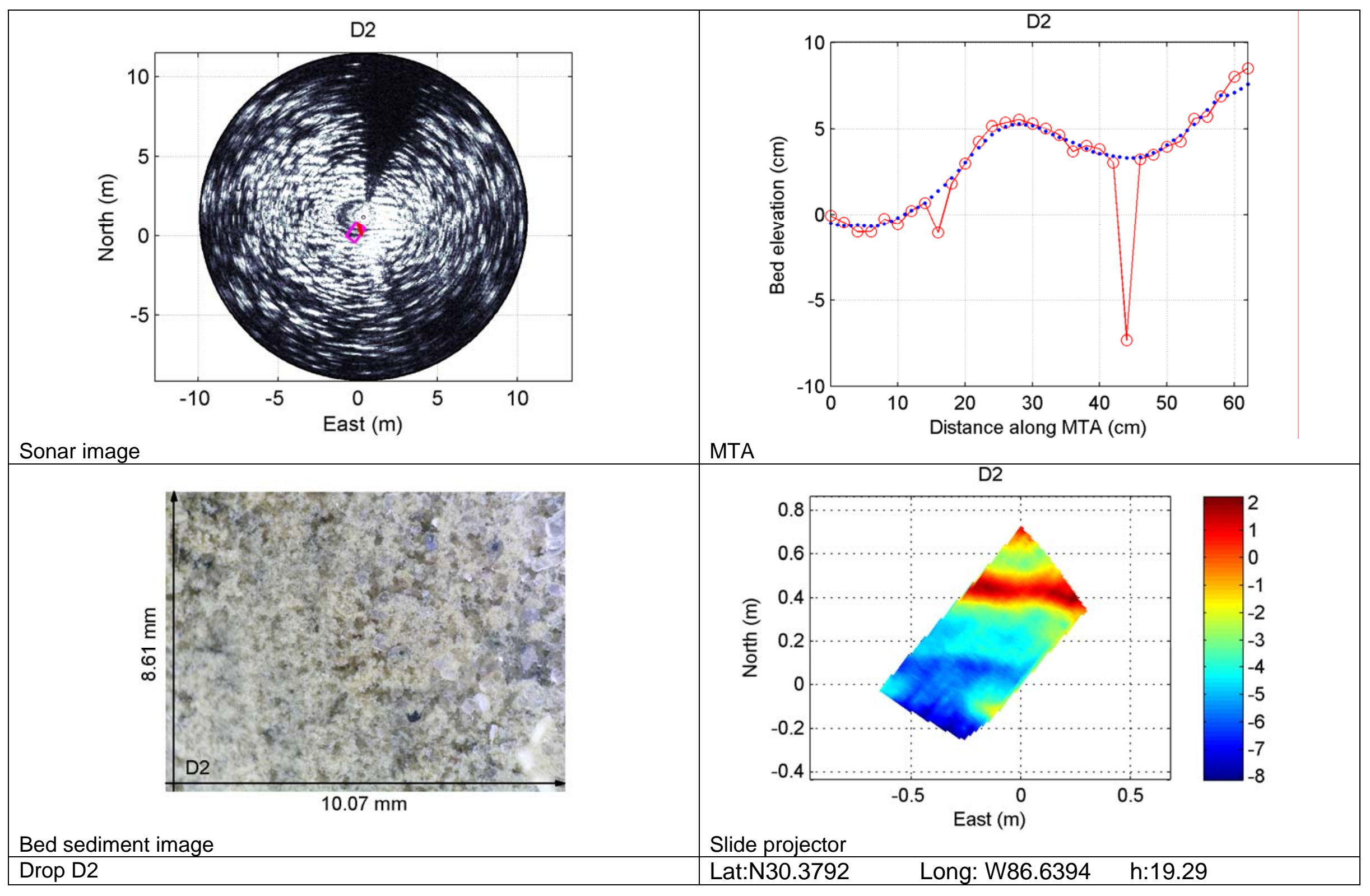




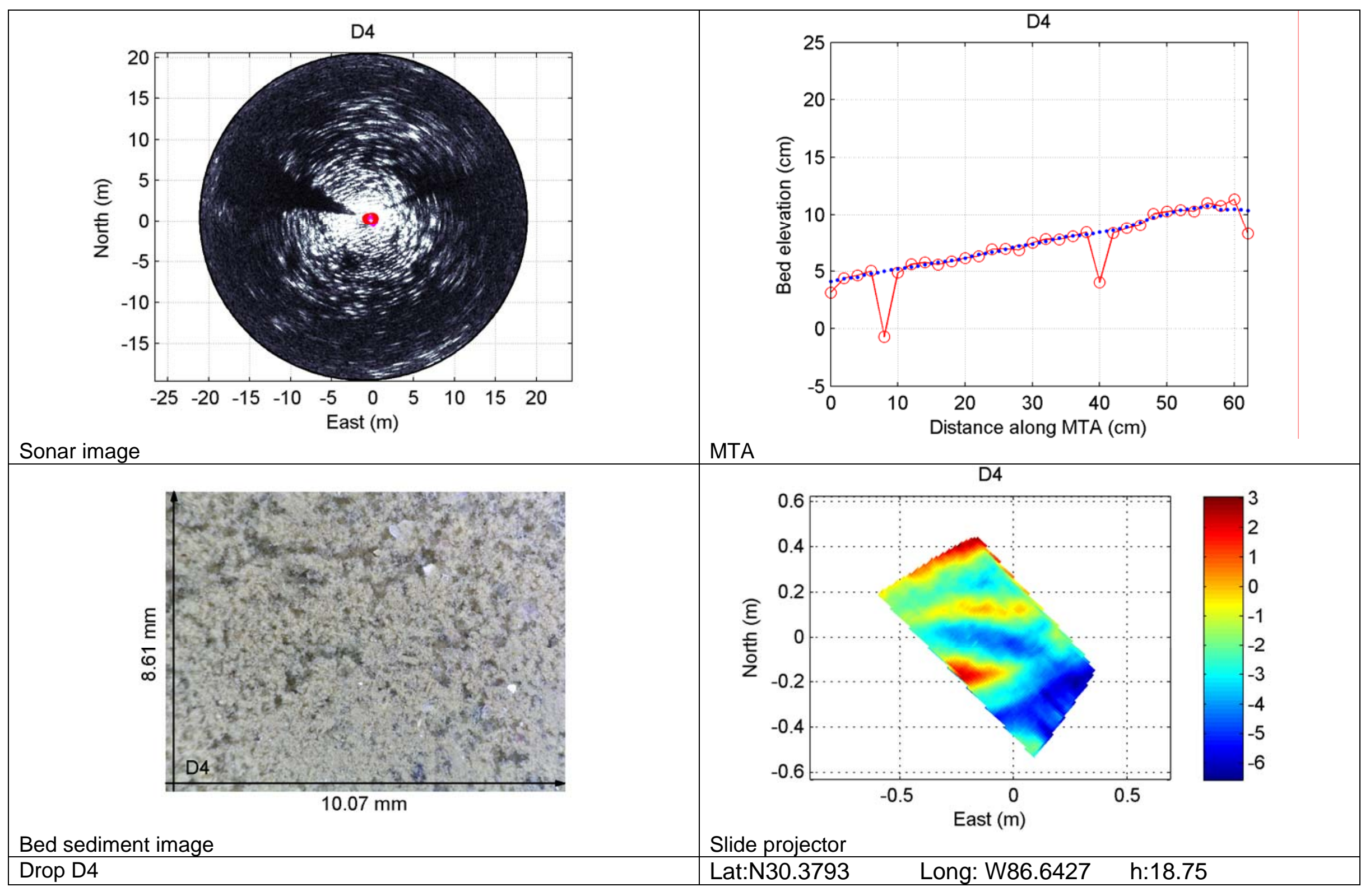




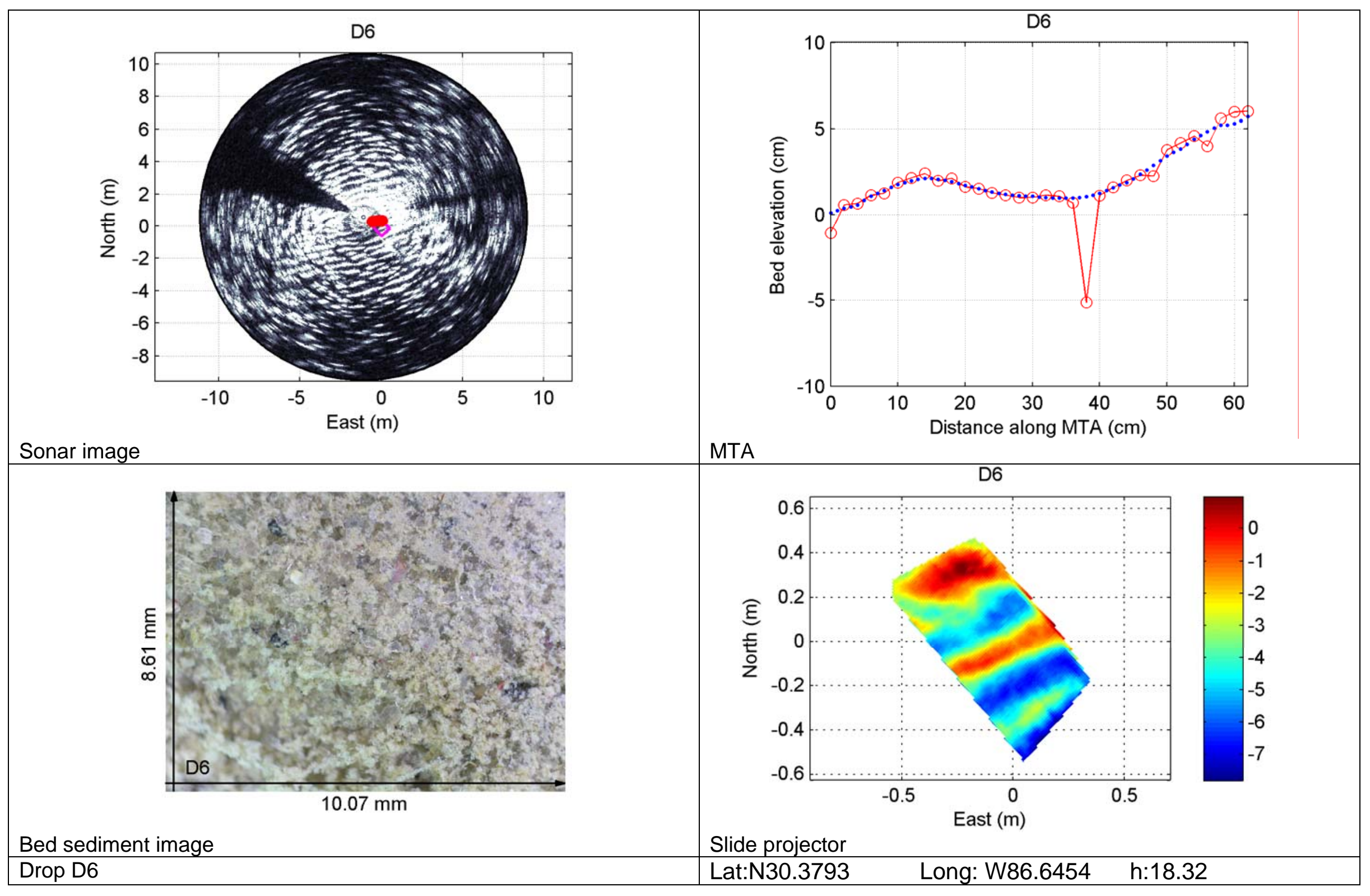




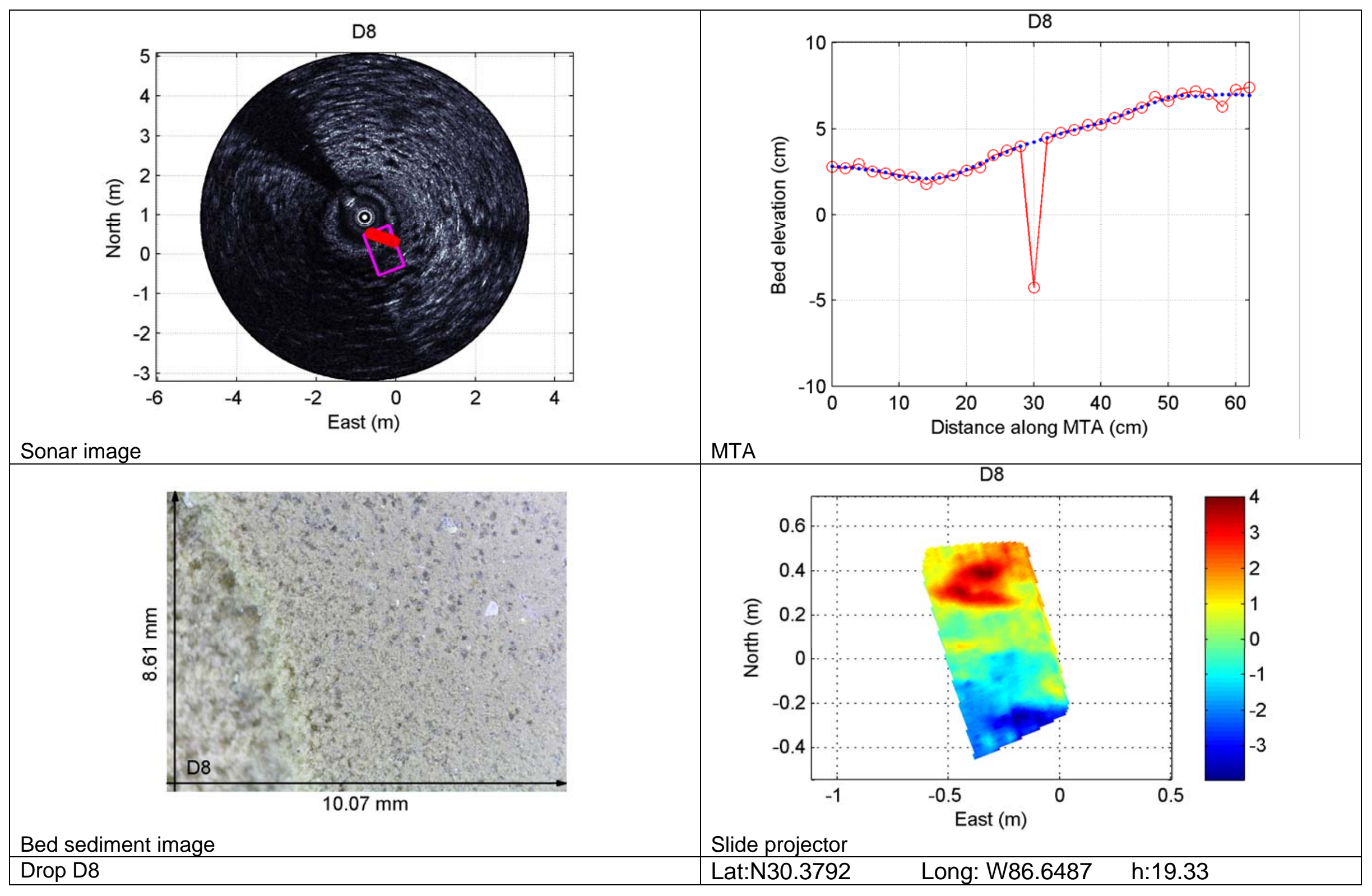




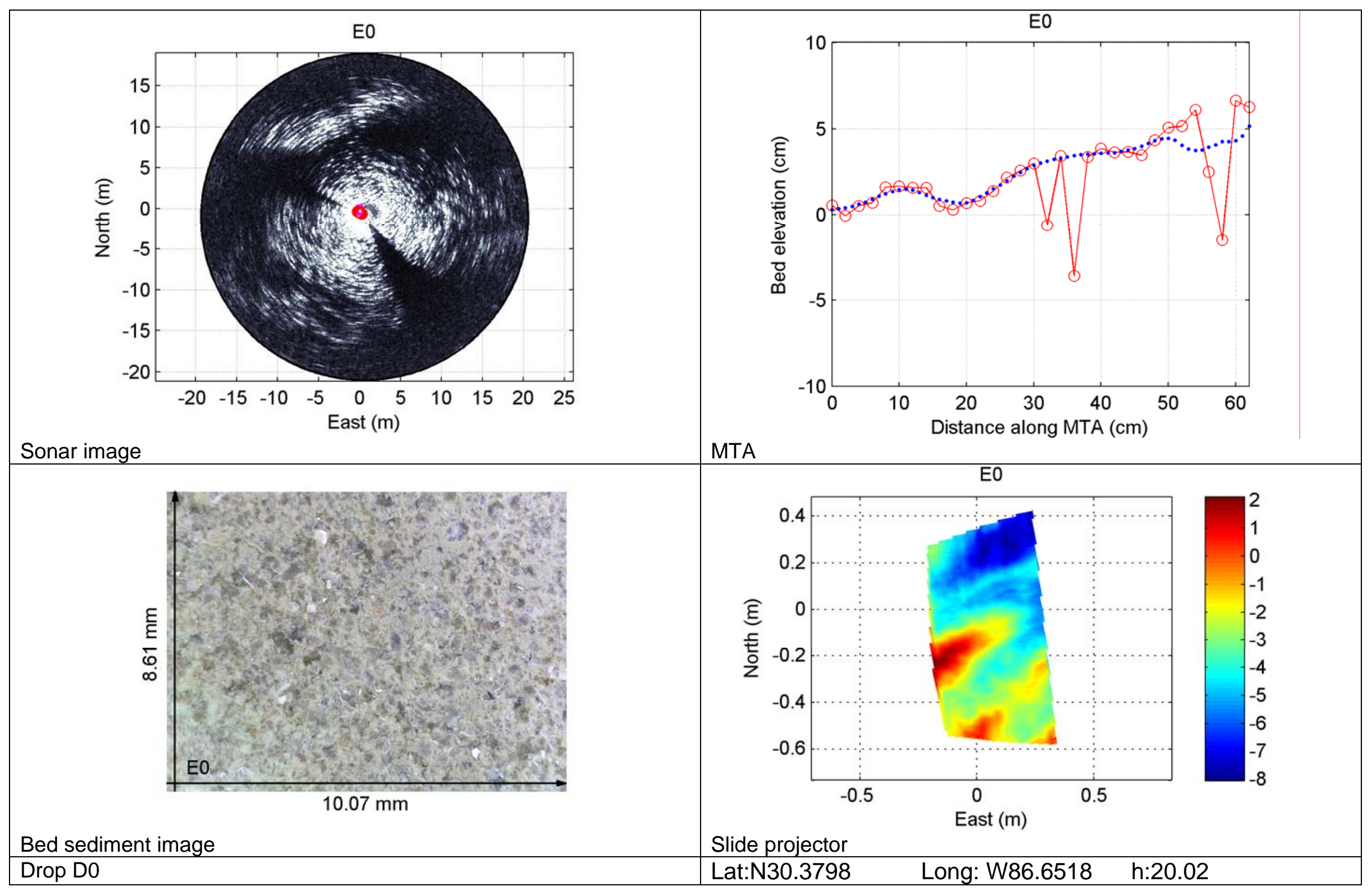




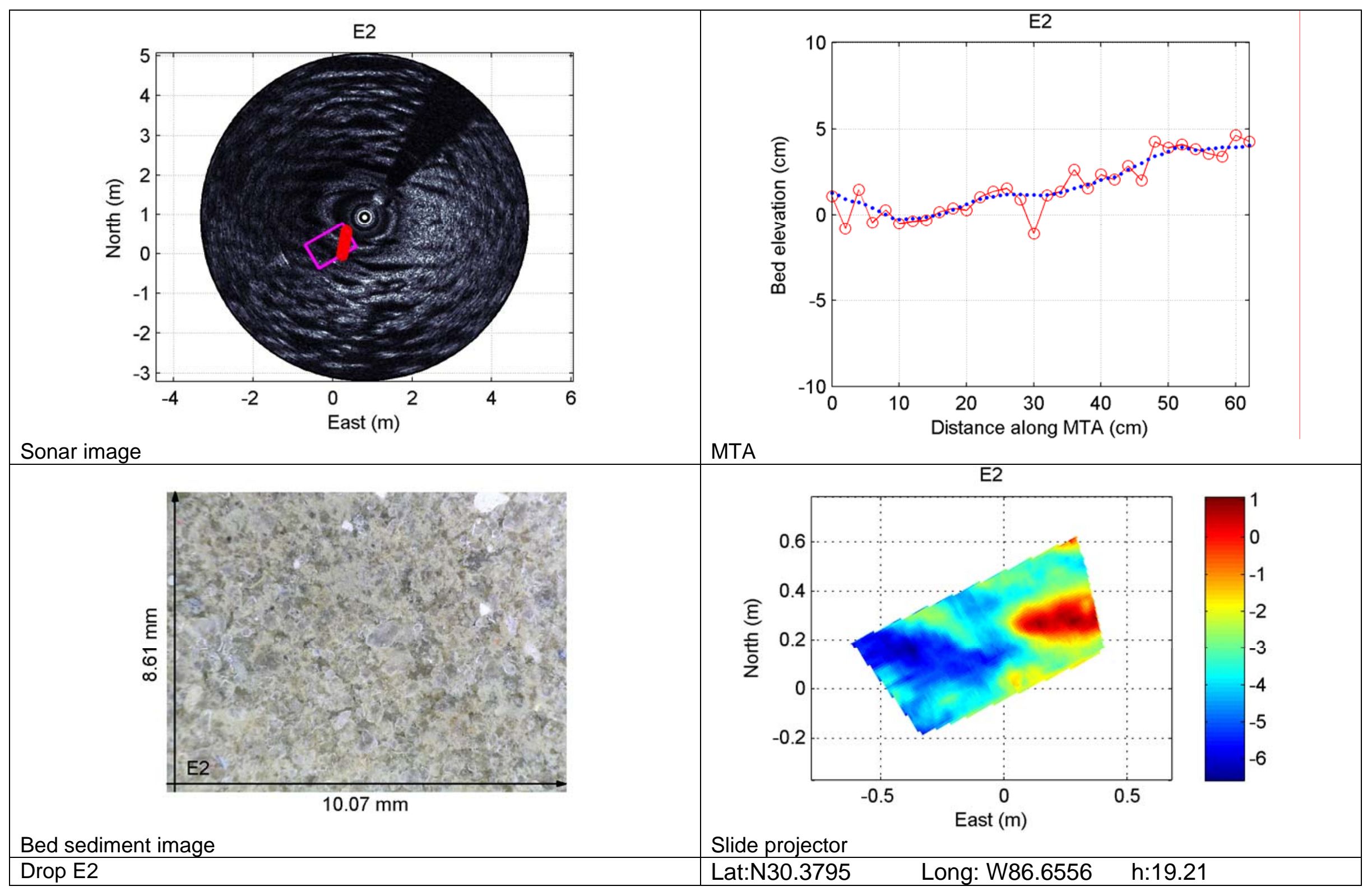




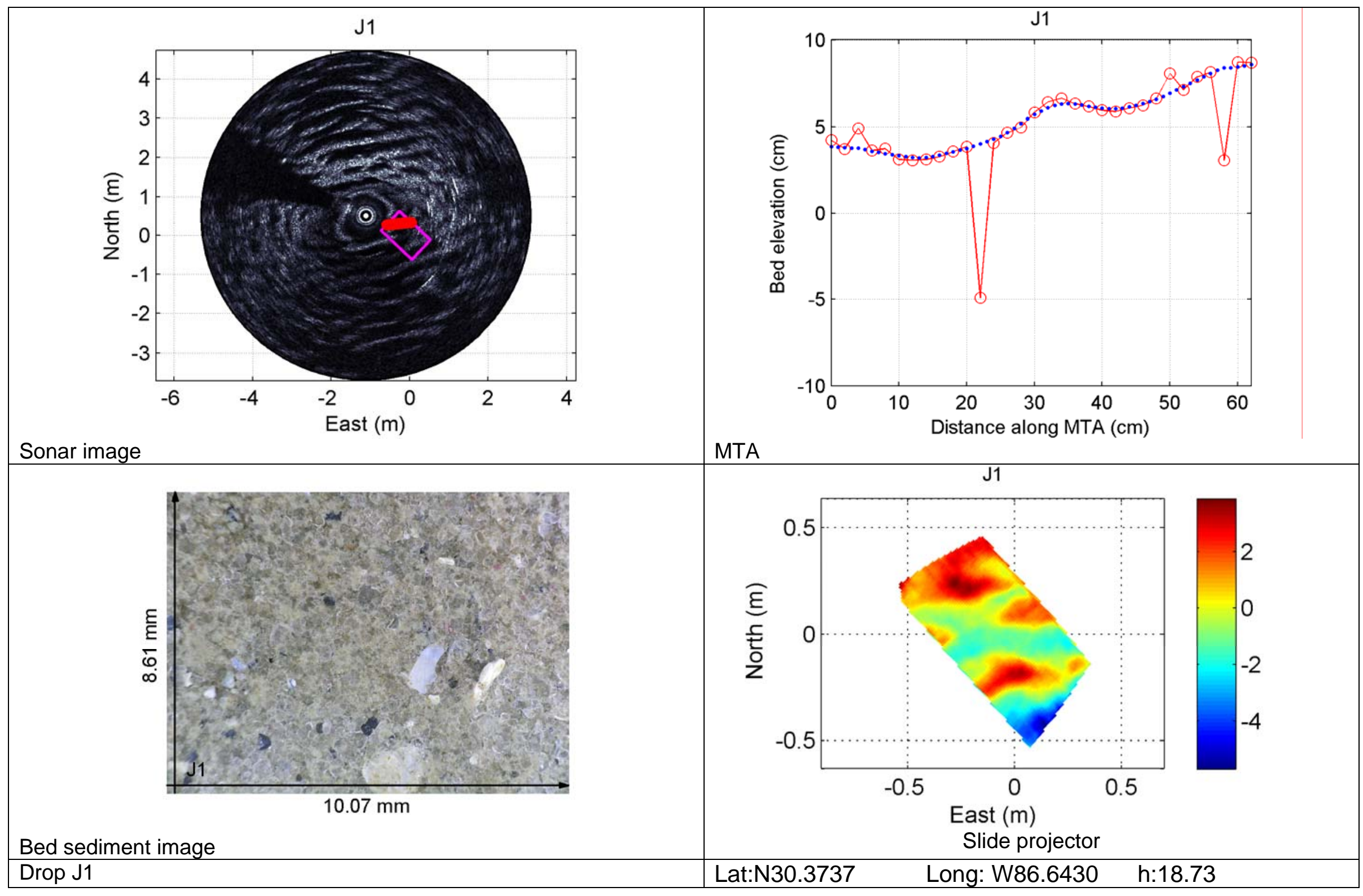




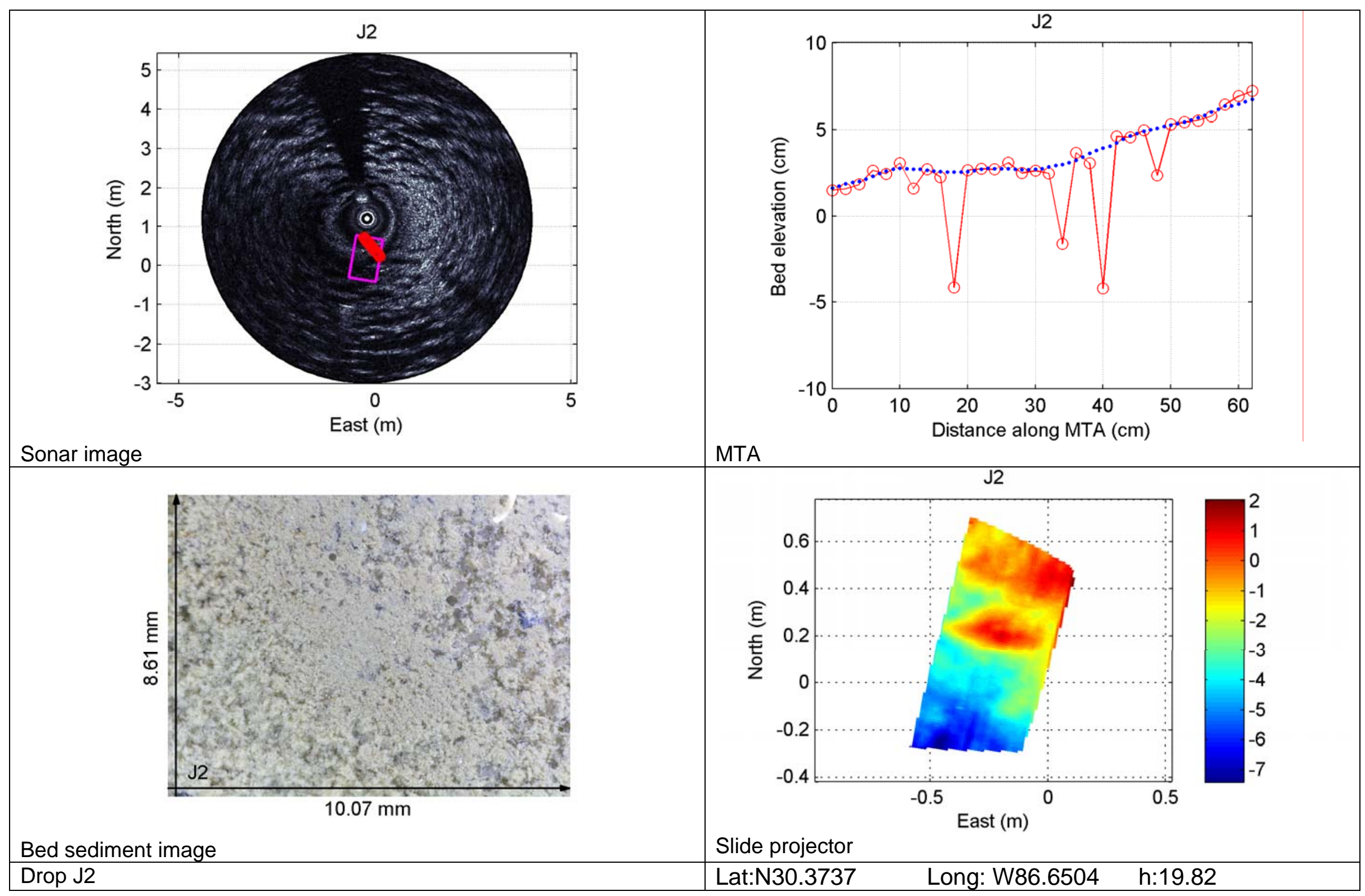




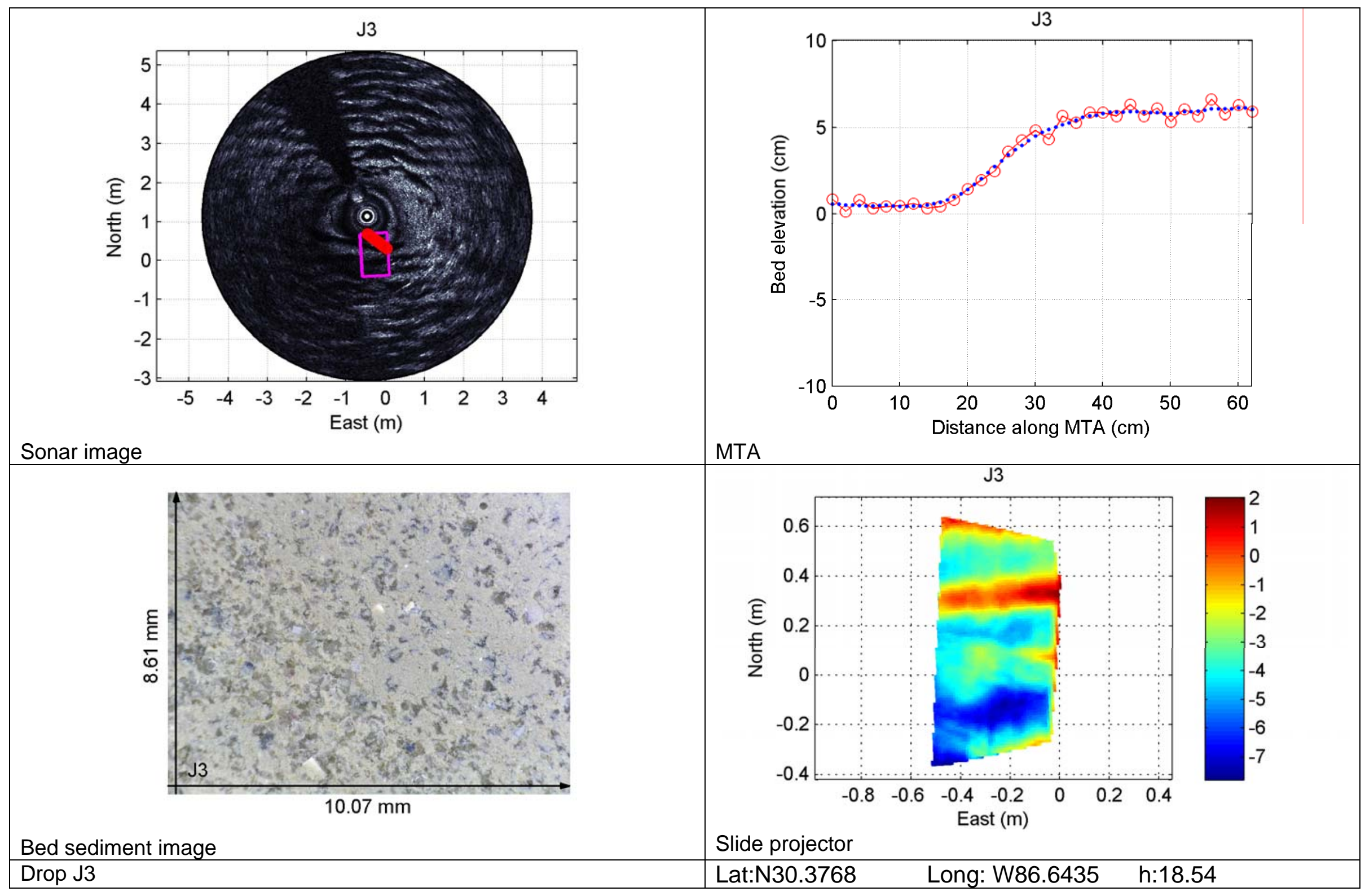




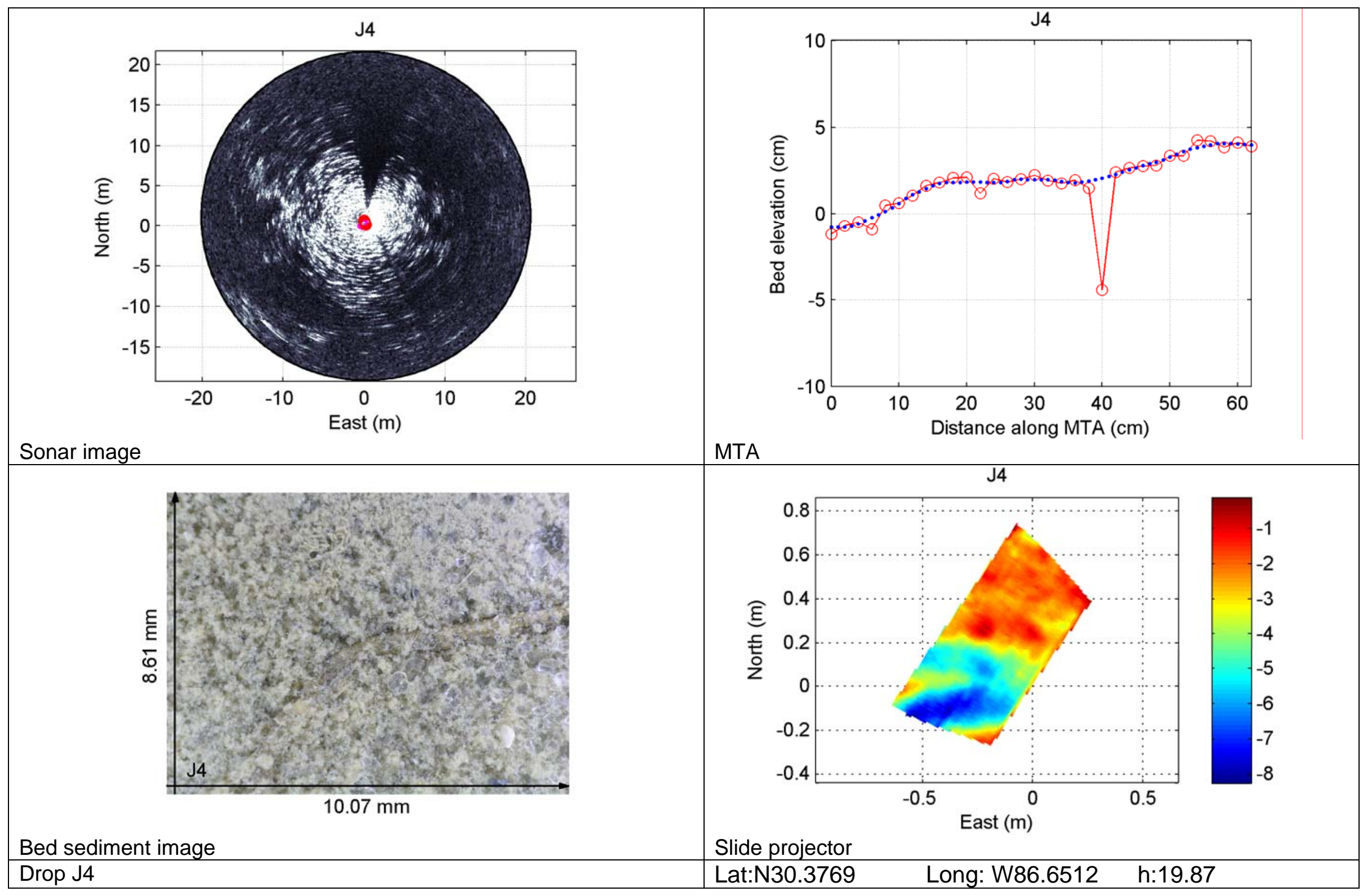




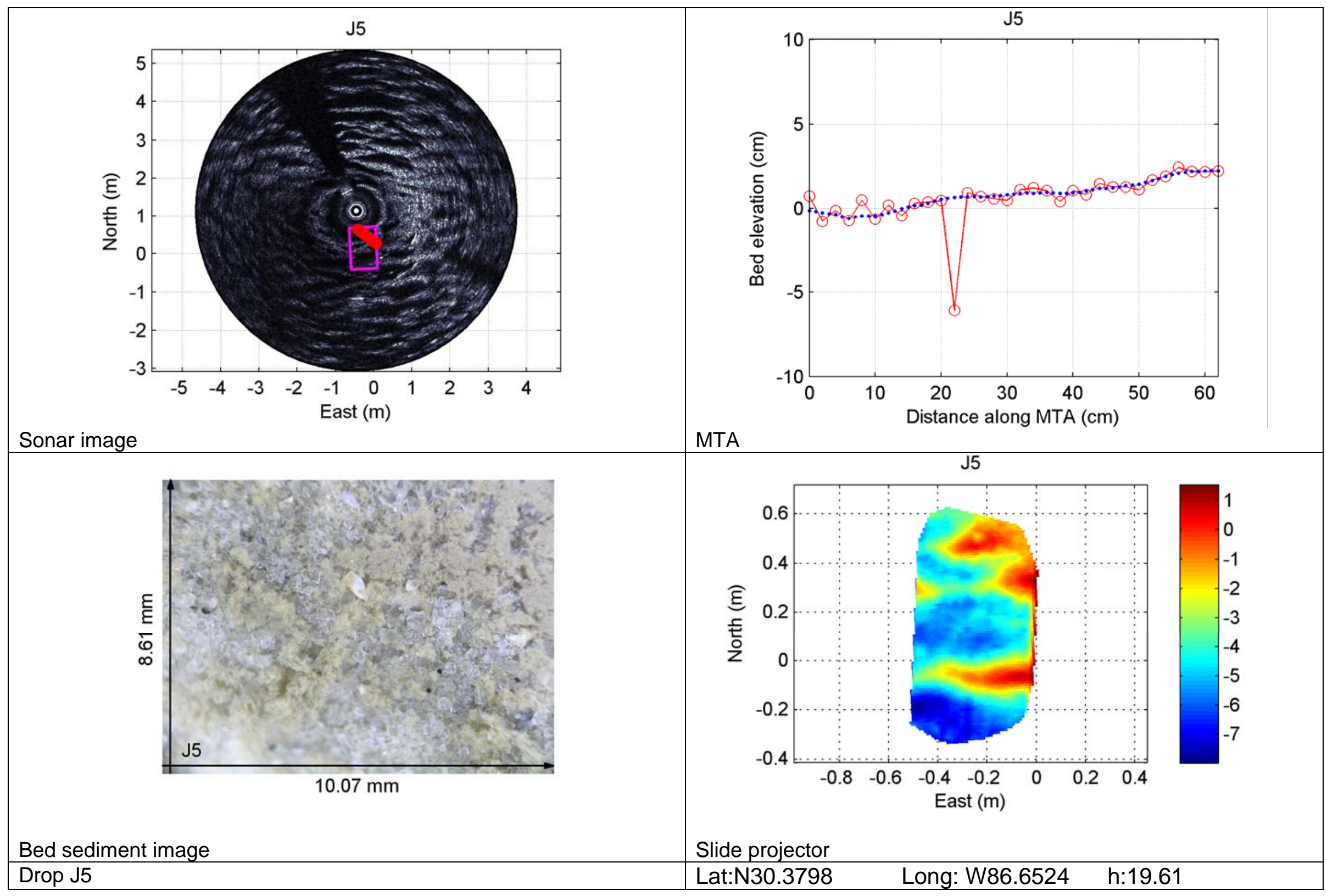




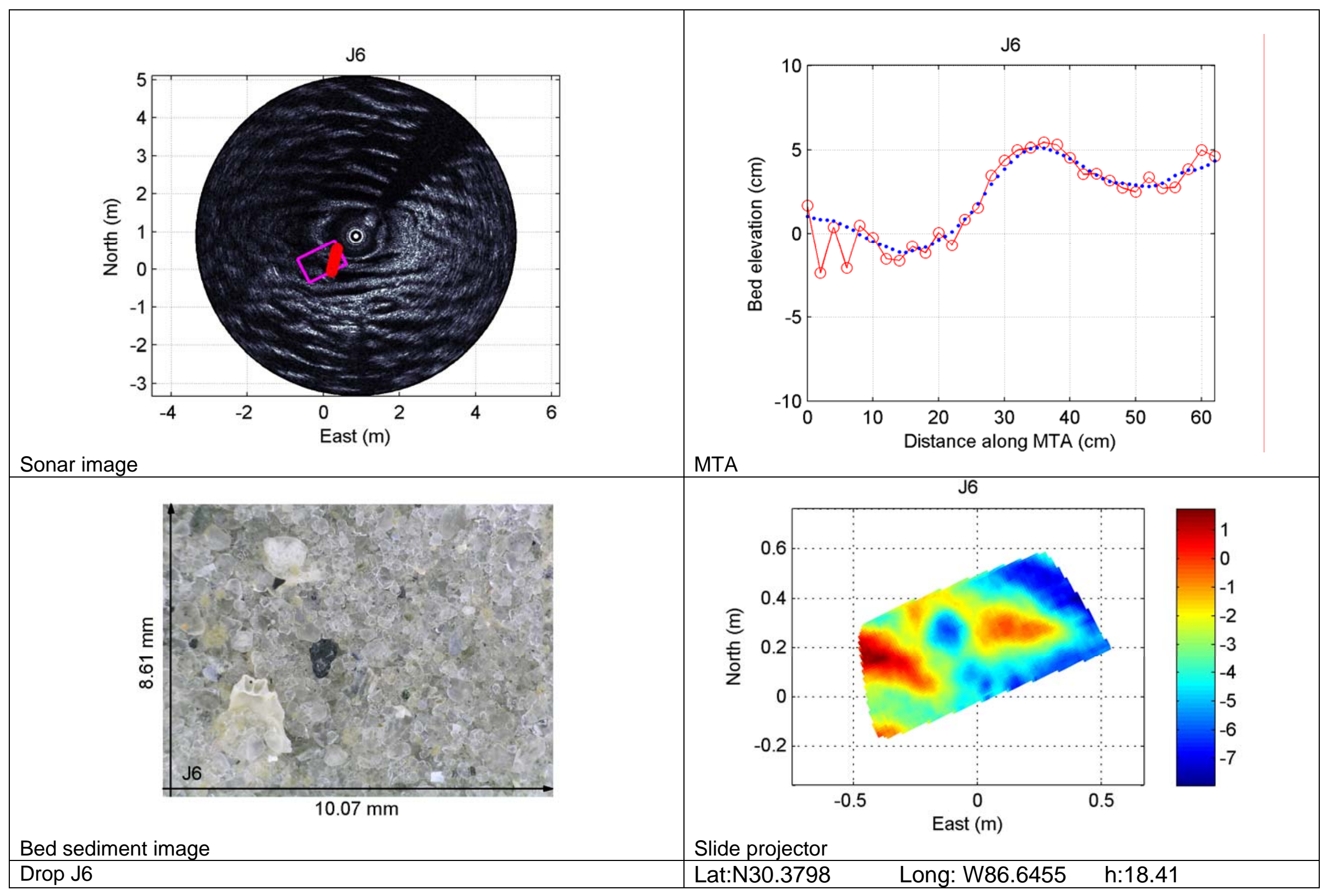




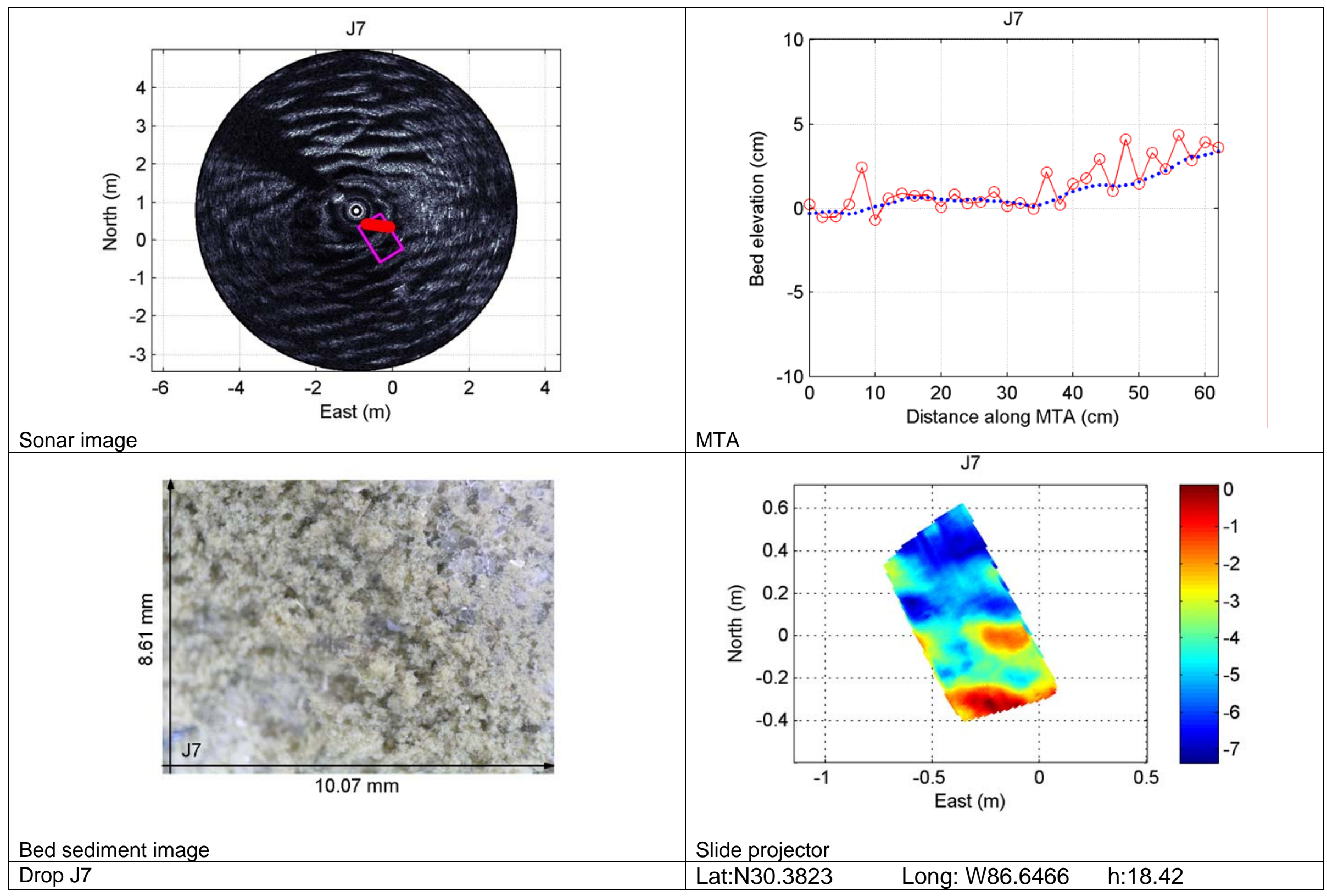




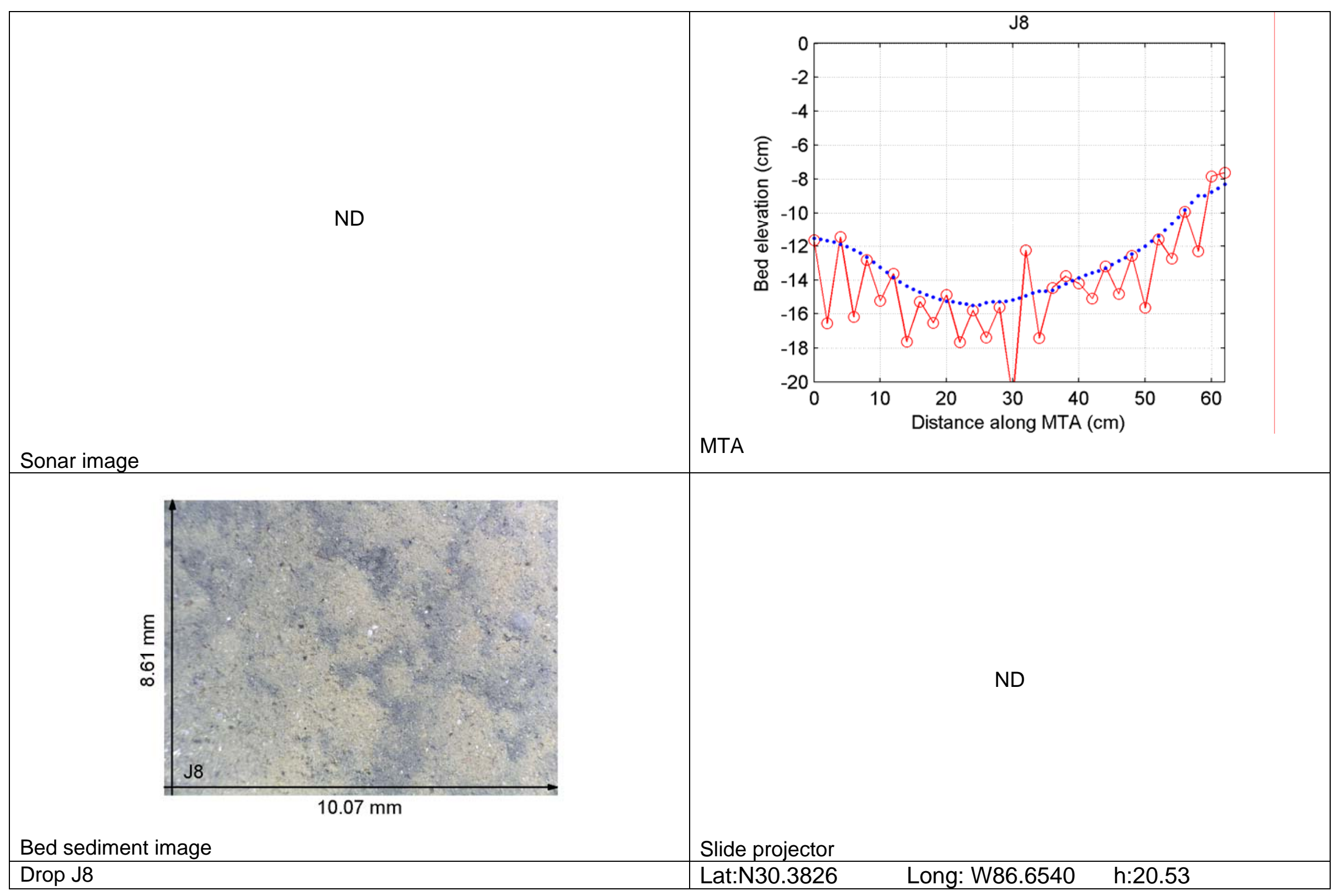




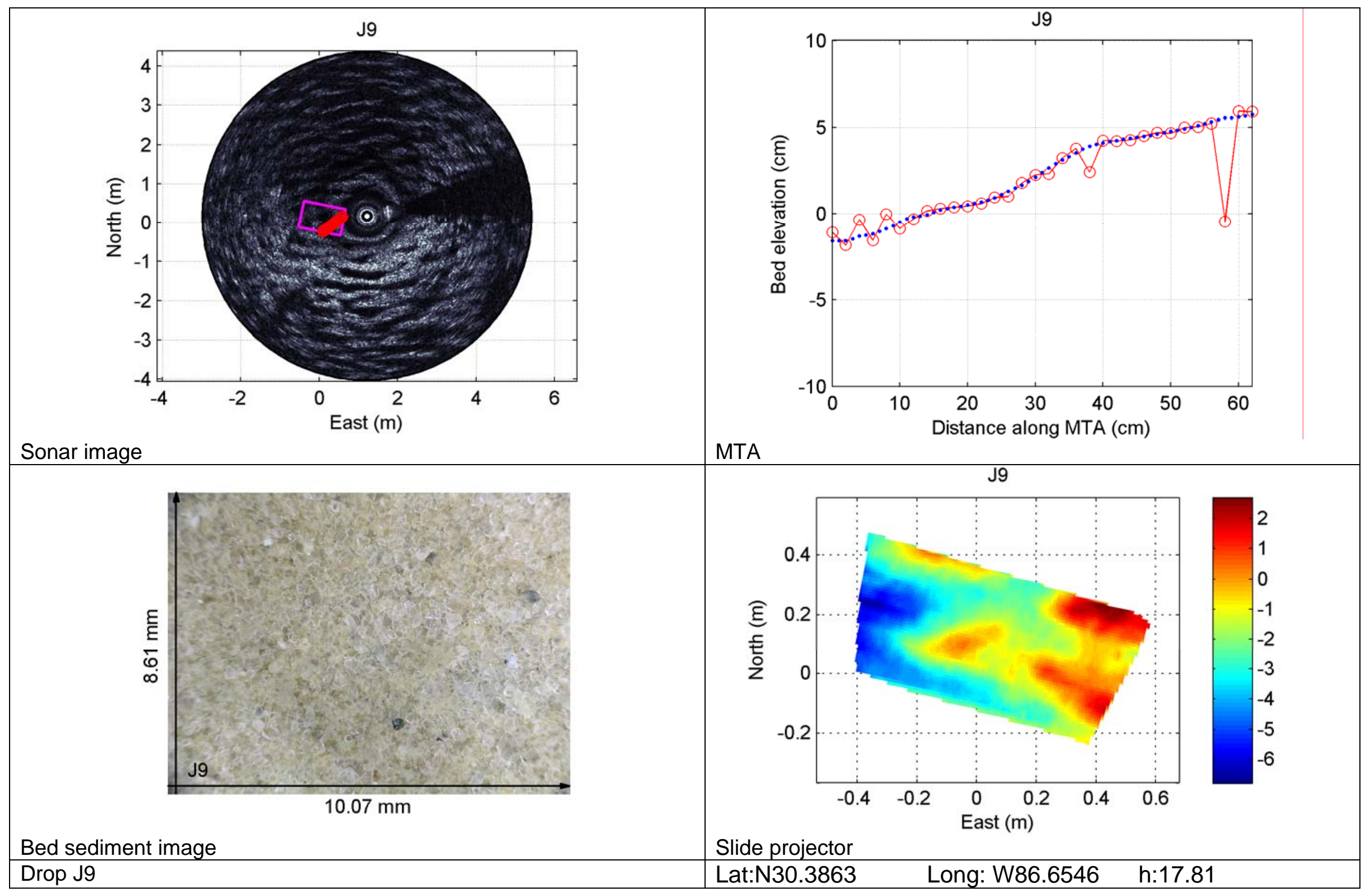




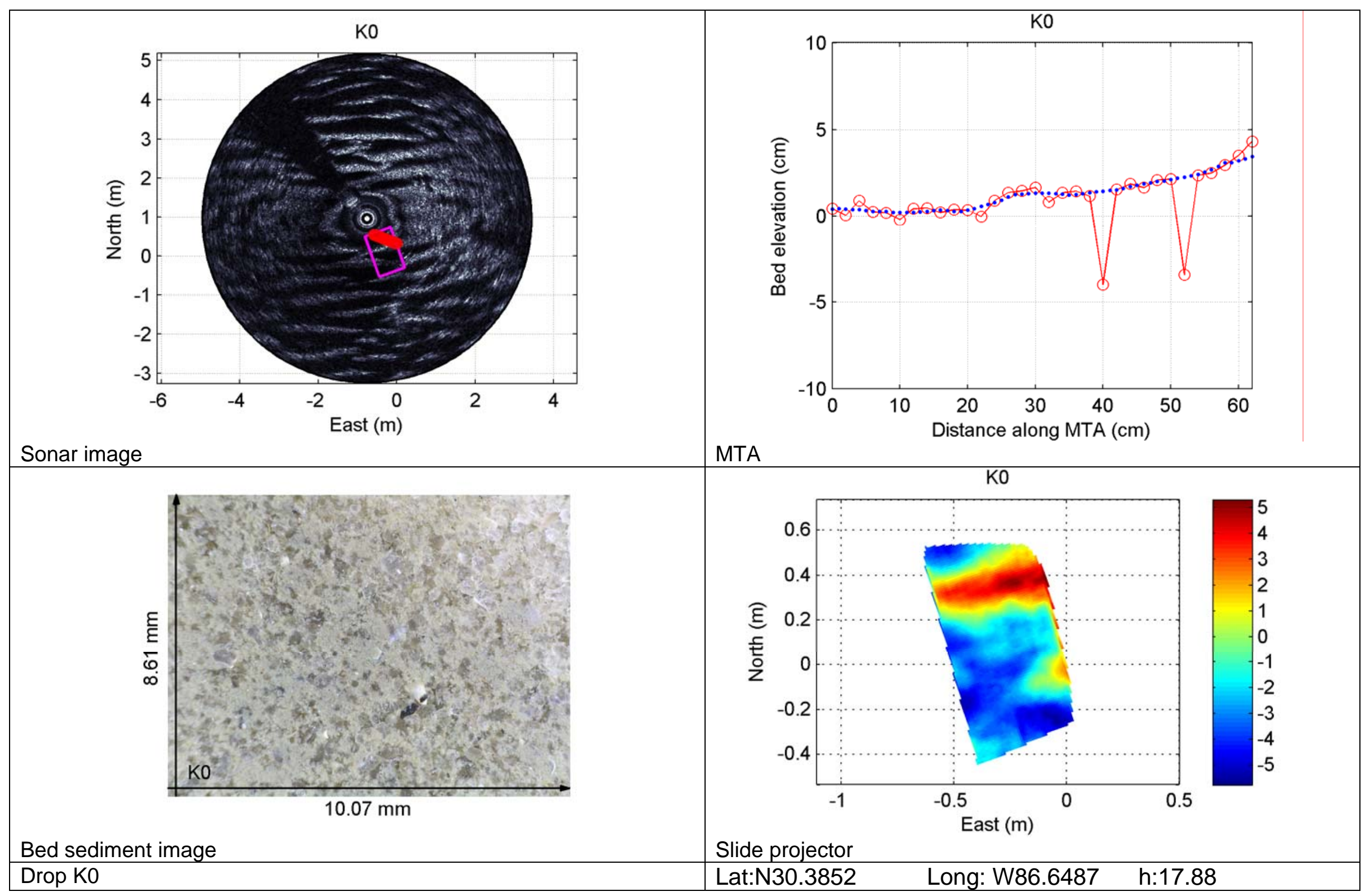




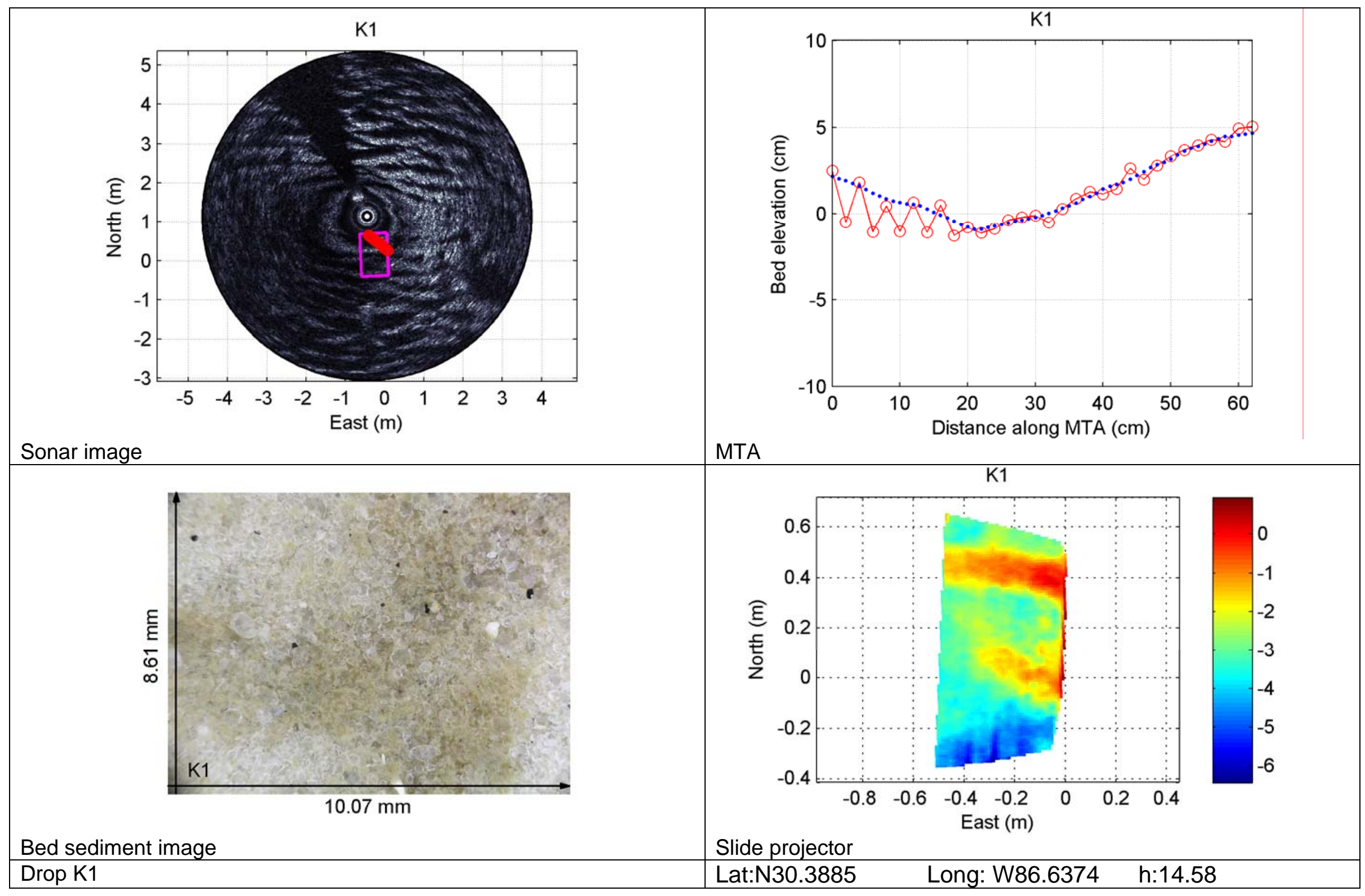




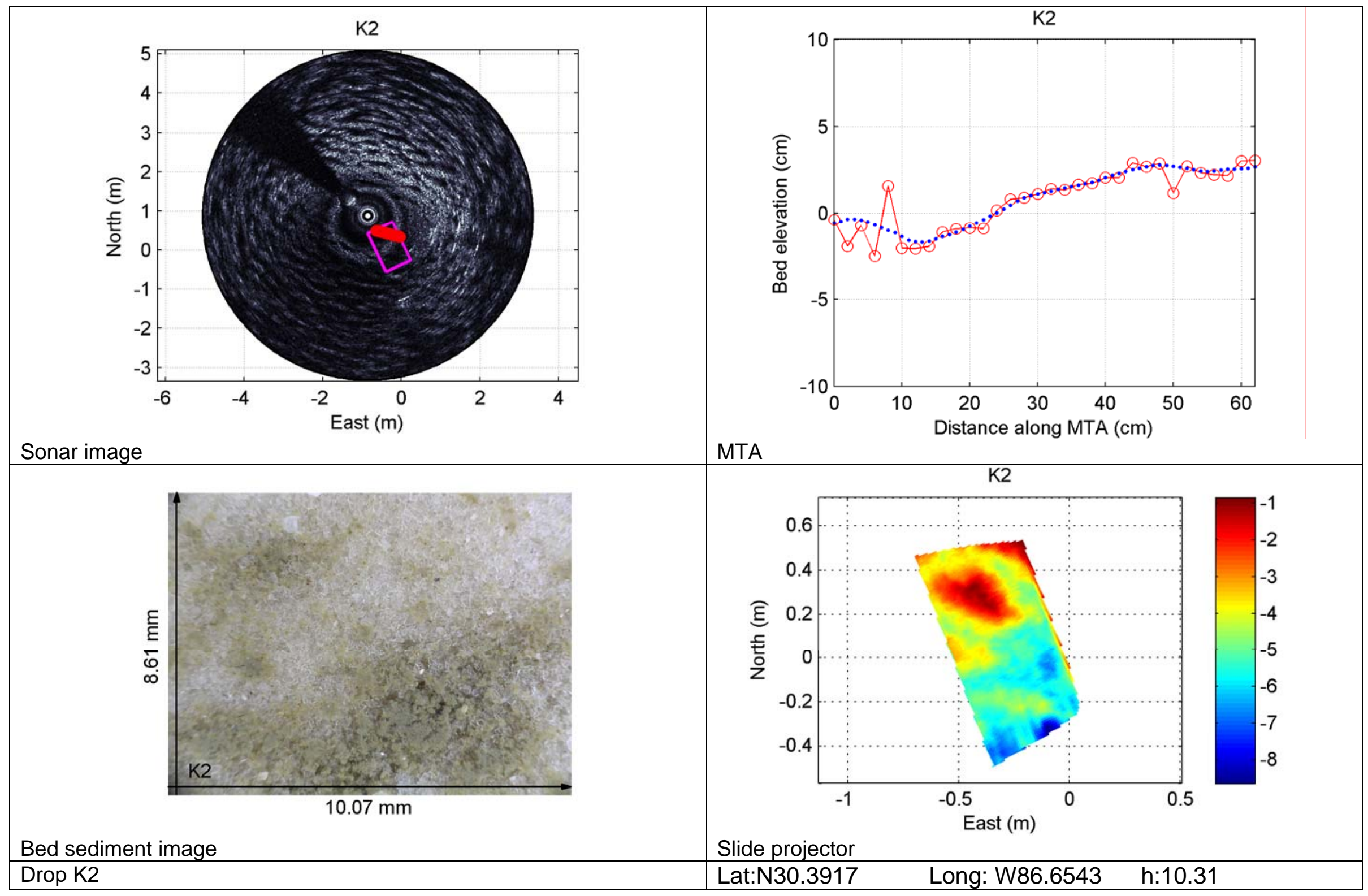




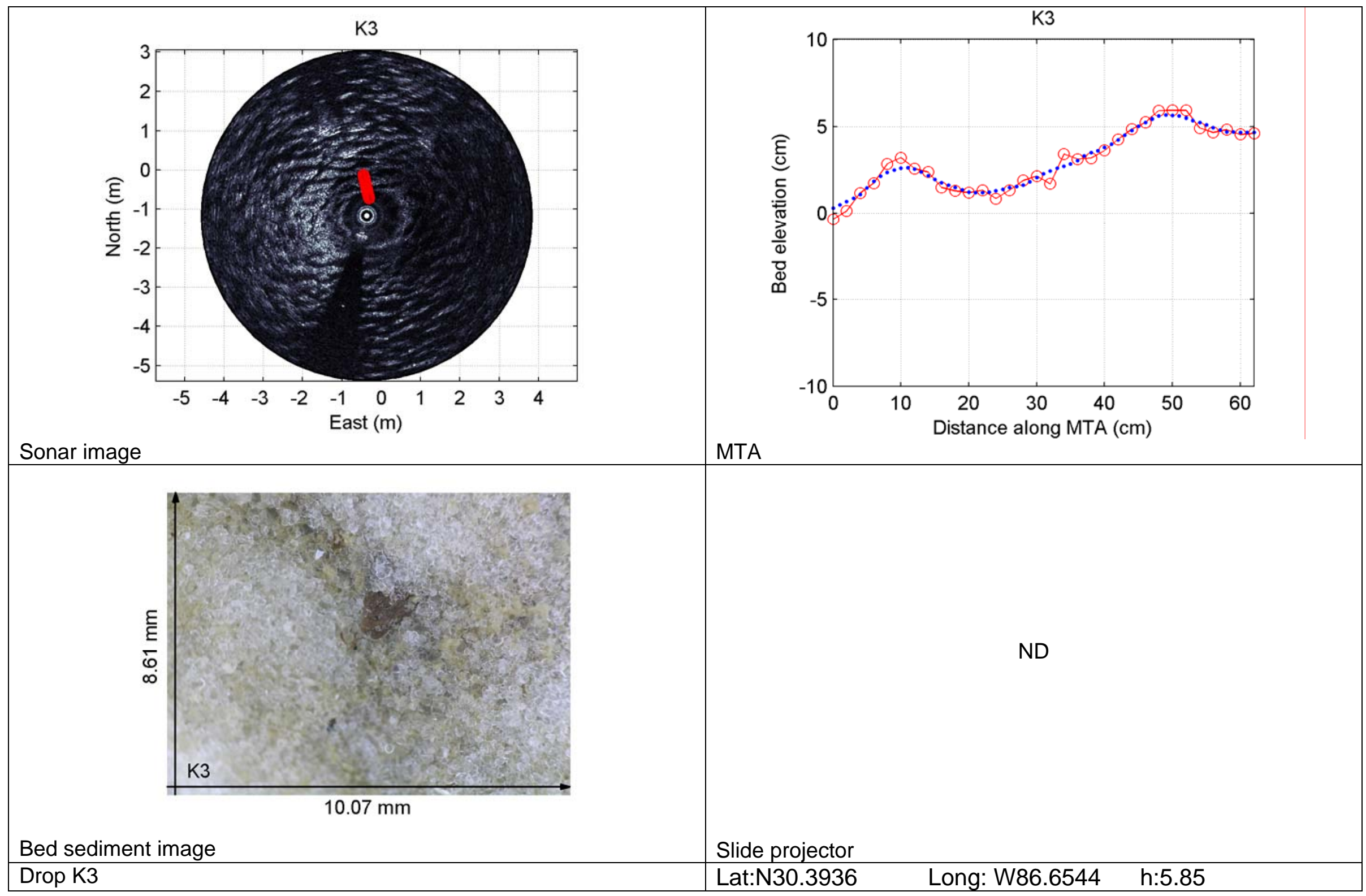

